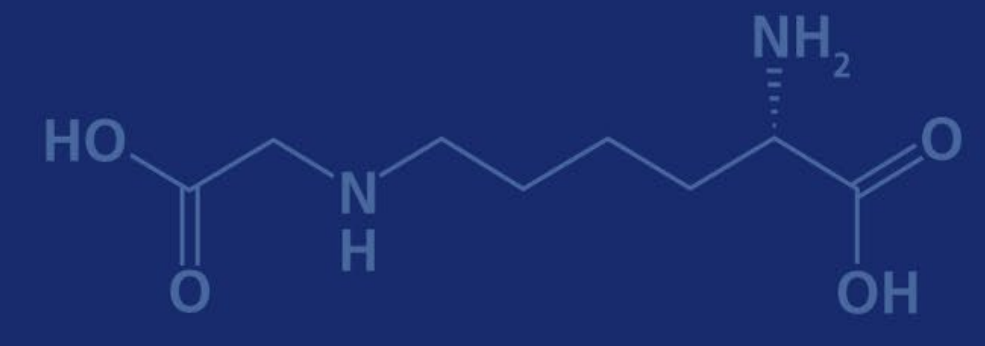

Towards understanding the role of heat-induced structural changes on immunoreactivity and digestibility of cow's milk protein

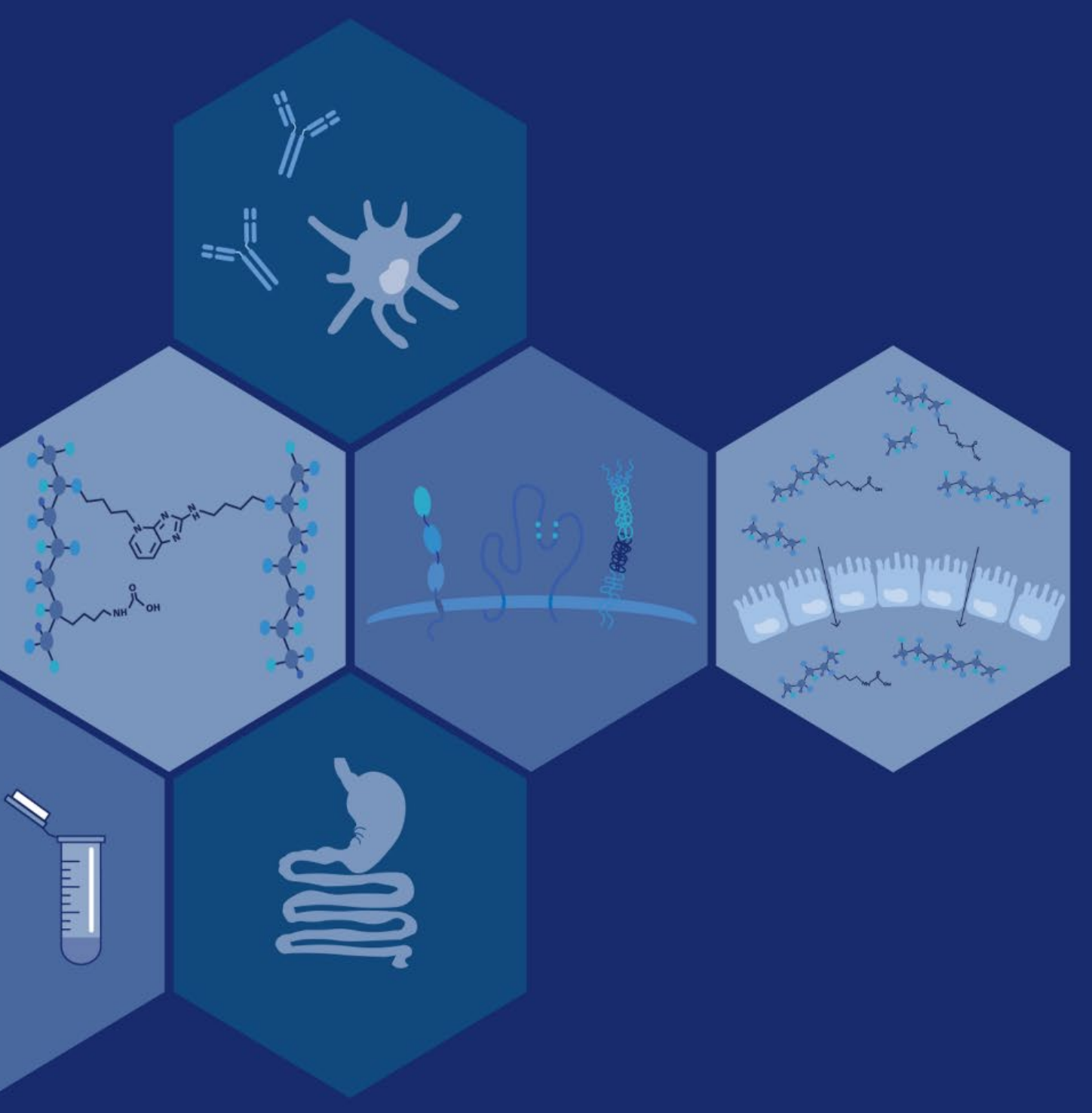

Hannah E. Zenker 


\section{Propositions:}

1. The sum of structural modifications, occurring upon heating, affects the immunoreactivity of cow's milk protein and not a single modification by itself. (This thesis)

2. Immunoreactivity and digestibility are linked by the digestion resistance of immunoreactive structures (This thesis).

3. Being a multidisciplinary researcher is another form of being an expert.

4. The biggest challenge of doing a $\mathrm{PhD}$ is telling your friends about your work.

5. Increasing availability of information alone does not make us more educated.

6. Commercialism of news is the biggest threat to fact-based reports.

7. Justice in a society is better served by the consensus to act as a community than by its laws.

Propositions belonging to the thesis, entitled

Towards understanding the role of heat-induced structural changes on immunoreactivity and digestibility of cow's milk protein

Hannah E. Zenker

Wageningen, $23^{\text {rd }}$ of October 2020 
Towards understanding the role of heat-induced structural changes on immunoreactivity and digestibility of cow's milk protein 


\section{Thesis Committee}

\section{Promotor}

Prof. dr H.J. Wichers

Professor of Immunomodulation by Food

Wageningen University \& Research

Dr K.A. Hettinga

Associate Professor, Food Quality and Design

Wageningen University \& Research

\section{Co-Promotors}

Dr N.W. De Jong

Associate Professor, Dept. of Allergology

Erasmus Medical Centre Rotterdam

Dr M. Teodorowicz

Researcher, Cell Biology and Immunology

Wageningen University \& Research

\section{Other members}

Prof. Dr W. H. Hendriks, Wageningen University \& Research

Dr D. Dupont, INRAe, Rennes, France

Dr K.C.M. Verhoeckx, University Medical Centre Utrecht

Prof. Dr E.N.C. Mills, University of Manchester, Manchester, UK

This research was conducted under the auspice of the Graduate school VLAG (Advanced studies in Food Technology, Agrobiotechnology, Nutrition and Health Sciences) 


\title{
Towards understanding the role of heat-induced structural changes on immunoreactivity and digestibility of cow's milk protein
}

\author{
Hannah E. Zenker
}

\section{Thesis}

Submitted in the fulfilment of the requirements for the degree of doctor at Wageningen University

by the authority of the Rector Magnificus,

Prof. Dr A.P.J. Mol,

in the presence of the

Thesis Committee appointed by the Academic Board

to be defended in public

on Friday 23 October 2020

at 11 a.m. in the Aula 
Hannah E. Zenker

Towards understanding the role of heat-induced structural changes on immunoreactivity and digestibility of cow's milk protein, 202 pages

$\mathrm{PhD}$ thesis Wageningen University, Wageningen, the Netherlands (2020).

With references, with summary in English.

ISBN: 978-94-6395-522-5

DOI: https://doi.org/10.18174/530195 


\section{List of contents}

Chapter 1

General Introduction

Chapter 2

The effect of low vs. high temperature dry heating on solubility and digestibility of cow's milk protein

Chapter 3

Differential effects of dry vs. wet heating on the formation of SRAGE binding ligands and IgE epitope recognition

\section{Chapter 4}

Binding of CML-modified as well as heat-glycated $\beta$-lactoglobulin to receptors for AGEs is determined by charge and hydrophobicity

\section{Chapter 5}

Enhanced uptake of processed bovine $\beta$-lactoglobulin by antigen presenting cells:

Identification of receptors and implications for immunogenicity

\section{Chapter 6}

Peptide release after simulated infant in vitro digestion of dry-heated cow's milk protein and transport of potentially immunoreactive peptides across the Caco-2 cell monolayer

\section{Chapter 7}

General Discussion

Summary

List of abbreviations

Acknowledgments 

Chapter 1

General Introduction 


\subsection{Project overview}

This thesis investigated the physical-chemical changes that occur during heating of cow's milk protein and the potential effects on digestibility and immunogenicity. It was part of a larger NWO-TTW project (Immunogenic Properties of Heated and Glycated Cow's Milk Protein - Effect on Initiation and Resolution of Cow's Milk Allergy) and was carried out in collaboration with the Allergology \& Clinical Immunology group at Erasmus Medical Centre in Rotterdam and the Cell Biology and Immunology group at Wageningen University. This larger project consisted of 4 work packages:

- Work package 1 is described in this thesis and focused on the physicochemical modifications of heated and glycated cow's milk protein.

- Work package 2 investigated the immunogenicity and allergenicity of heated and glycated (MP) in vitro.

- Work package 3 developed a product of heated and glycated MP that can be added to the daily diet of cow's milk (CM) allergic children.

- Work package 4 studied the induction of tolerance by the in work package 3 developed product in a clinical trial.

Combining data from different disciplines (physicochemical analysis and molecular data) leads to new insights in the possible causes for heating induced changes in cow's milk immunoreactivity and the role of the Maillard reaction (MR).

\subsection{CM protein and application in infant nutrition}

CM protein is a commonly used basis of infant formula that is used as a substitute for human milk when breastfeeding is not possible or commonly introduced between the age of 6-12 months [1]. CM can roughly be divided in two main protein fractions: $80 \%$ caseins and $20 \%$ whey proteins (WPs). WPs are globular proteins and in contrast to caseins soluble at $\mathrm{pH}$ 4.6. The major WP in CM is $\beta$-lactoglobulin (BLG) $(\sim 50 \%(\mathrm{w} / \mathrm{w})$ of all WPs), followed by $\alpha$-lactalbumin (ALA) $\sim 20 \%(\mathrm{w} / \mathrm{w})$, immunoglobulins $\sim 10 \%(\mathrm{w} / \mathrm{w})$, and bovine serum albumin (BSA) $\sim 6 \%$ (w/w) [2]. The globular structure of both BLG and ALA is stabilised via disulphide bonds. While ALA exists as monomer, BLG exists in a monomer-dimer equilibrium in solution and is predominantly dimeric under physiological conditions. Moreover, it contains the free cystein-121 that is buried in the interior of the protein, however upon denaturation becomes exposed and plays an important role in the aggregation of BLG [3]. The casein fraction covers four proteins, $\alpha_{\mathrm{s} 1}$-casein, $\alpha_{\mathrm{s} 2}$-casein, $\beta$-casein, and $\kappa$-casein in the ratio of $4 / 1 / 3.5 / 1.5$ [4]. Caseins are unstructured proteins with little secondary and tertiary structure. All caseins contain clustered phosphorylated serine residues, except $\kappa$-casein that only contains one phosphoserine in its sequence [5]. Most of the $\kappa$-casein is located on the surface of the casein micelle. The $\mathrm{C}$-terminal $\kappa$-casein macropeptide, which has a variable degree of glycosylation, extends on the 
outside of the casein micelle to form a hairy layer that, via steric repulsion, inhibits self-association of casein micelles. The size of the casein micelles depends on the milk composition as well as the glycosylation degree of the $\kappa$-casein and usually ranges between $100 \mathrm{~nm}$ and $300 \mathrm{~nm}$ [4]. Both $\alpha_{\mathrm{s} 2}$-casein and $\kappa$-casein contain free cysteine residues that enable them to form intermolecular disulphide bonds. These disulphide bonds occur naturally but can also be redistributed during thermal processing of MP, for instance the heat induced interaction of BLG with $\kappa$-casein via S-S/thiol disulphide interchange [6,7]. Three caseins, $\alpha_{s 1}$-casein, $\beta$-casein, $\kappa$-casein, and ALA in CM are structurally similar to their counterparts in human milk, while BLG and $\alpha_{\mathrm{s} 2}$-casein are not part of the natural components of human milk $[8,9]$. Moreover, protein composition of human milk and the contribution of the individual proteins differ compared to CM. For example, while $\alpha_{\mathrm{s} 1}$-casein is highly abundant in CM it is only a minor component in human milk. The ratio of casein to WPs in human milk is estimated to 40:60 compared to 80:20 in CM, however also shows large variation during lactation [9]. In early infant nutrition the ratio of casein to WP in CM based infant formula is adjusted closer to the composition of human milk, while at a later stage a higher ratio of casein to whey is chosen. Next to compositional adjustment of MP based infant formulas, heat treatment is applied to ensure product safety. This is of great importance in infant nutrition as their immune system still develops. However, the thermal processes also change protein structure which affects its digestibility and immunoreactivity.

\subsection{Heat induced modifications of MP}

Thermal processing of $\mathrm{CM}$ is often applied in industry to obtain powdered products and ensure product safety. Upon heating, protein structure may change and chemical modifications occur. The type and relative abundance of these modifications, as well as the extent to which these modifications occur, depends on the applied conditions during heating, such as $\mathrm{pH}$, salt concentrations, $\mathrm{a}_{\mathrm{w}}$-level, temperature, and time as well as on the native structure of the protein. The threshold temperature for irreversible structural changes (aggregation) in isolated BLG and $\alpha$-lactalbumin, in solution is between $65-70{ }^{\circ} \mathrm{C}[10,11]$, however heat induced changes to BLG are strongly affected by $\mathrm{pH}$ and ionic strength [12]. Caseins, in contrast, are more heat-stable due to their minimal secondary and tertiary structure. Their arrangement in the casein micelle stabilises them against precipitation and makes the casein molecules more resistant towards changes of environmental conditions. In the presence of both micellar casein and WPs, a complex between WPs and the casein micelle is formed resulting in the coverage of the casein micelle surface with aggregated WP upon heating in solution. This complex formation is triggered via disulphide bond formation and predominantly occurs between $\kappa$-casein and $\beta$-lactoglobulin. Although ALA is also involved in the formation of this complex on the casein micelle surface, it does not interact with the casein micelle in the absence of BLG [13].

While heat induced modifications in solution have been object of many studies in the past, only a few studies investigated dry heating of WPs [14-21]. Dry heating of WPs, induces relatively 
more glycation and less denaturation than wet heating. For WPs it is suggested that dry heating temperatures $<55{ }^{\circ} \mathrm{C}$ do not result in significant changes of the protein structure while temperatures $>55{ }^{\circ} \mathrm{C}$ may lead to structural modifications [22]. Significantly increased aggregation was reported at temperatures above $80^{\circ} \mathrm{C}$, however this is also strongly depending on the presence of reducing sugars [23]. For example, Deng et al. [21] showed that dry-heated BLG at $130{ }^{\circ} \mathrm{C}$ in the presence of lactose is composed of $\sim 60 \%$ oligomers and polymers, while heating in the absence of a reducing sugar lead to only $\sim 10 \%$ polymerisation. Moreover, they observed the formation of insoluble material for high temperature dry-heated BLG in the presence of reducing sugars which was also supported by previous findings [20]. For casein micelles, only few studies can be found that report dry heating conditions for milk protein concentrates (micellar casein together with WPs) at temperatures below $50{ }^{\circ} \mathrm{C}$ [24-35] and micellar casein in the presence or absence of lactose at $60{ }^{\circ} \mathrm{C}$ [36,37]. Dry heating of milk protein concentrates at elevated temperatures results in loss of solubility of caseins while WPs are less affected. Next to hydrophobic interactions, hydrogen bonds, disulphide bonds [34], and high calcium ion activity [31], many studies attributed the loss of solubility to glycation via the MR [27,30].

During thermal processing of food products, side chain modifications on the amino acids will occur, of which MR, oxidation, isopeptide bond formation, and crosslinking following a $\beta$-elimination of cysteines or serine residues are most commonly described [38]. For milk and dairy products, the MR is considered as the predominant reaction. The MR is the reaction between the reactive carbonyl group of a reducing sugar with the primary or secondary amino group of proteins, peptides and free amino acids to form the Amadori product. Due to the high levels of the reducing milk sugar lactose, and the high availability of lysine, milk is particularly prone to this reaction. The MR is often divided into three stages: the early MR, the advanced MR, and the late MR [39]. For each stage, representative marker molecules are defined (Figure 1.1). Especially the products of the advanced stage, the so called advanced glycation end products (AGEs) that can be categorised in linear and crosslinking AGEs. An example for a crosslinking AGE is pentosidine, while examples for linear AGEs are $\mathrm{N}^{\varepsilon}$-carboxymethyllysine (CML) and pyrraline that have also previously been studied in relation to their immunomodulatory properties and metabolic transit [41-44]. However, due to the temperature dependence of the MR, it is often not possible to separate the effects of heat and glycation on modifications of the protein structure. Moreover, the occurrence of the MR has been described to have a promoting effect on disulphide bond formation and protein aggregation $[45,46]$ and has been shown to significantly affect the morphology of the formed aggregates [47]. Next to the MR, dephosphorylation reactions of caseins can also occur resulting in the formation of serine and threonine adducts. However, significant changes are only observed after prolonged heat at temperatures $>100{ }^{\circ} \mathrm{C}[48]$ and therefore uncommon in most dairy products. 


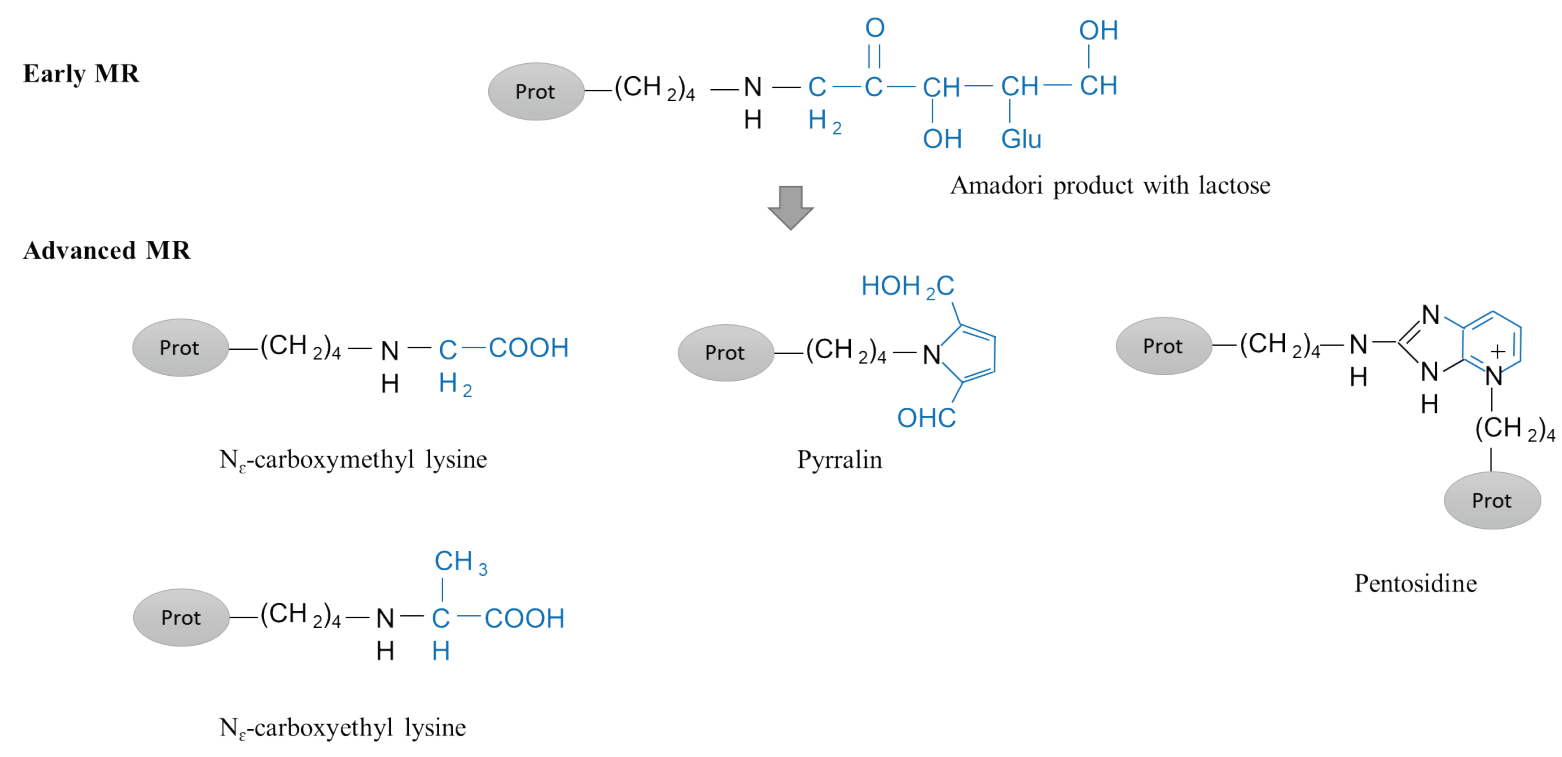

Late MR

Figure 1.1: Selected protein bound (Prot) Maillard reaction (MR) products representative for each state of the MR. Adapted from Arena et al. [40].

These structural modifications of milk proteins during heat treatment either in solution or under dry conditions can affect the immunoreactivity of the protein and may alter the immunological response of CM allergic children [49].

\subsection{CM allergy}

$\mathrm{CM}$ allergy (CMA) is an adverse reaction of the immune system towards one or more $\mathrm{CM}$ derived proteins. CMA occurs as immunoglobulin E (IgE) mediated, non-IgE mediated, or mixed forms of CMA. Symptoms of CMA usually affect one or more organs, especially the skin, the respiratory tract, and the gastrointestinal tract. In IgE mediated CMA, symptoms usually occur within 30 min of ingestion, while in non-IgE mediated CMA symptoms are delayed beyond $2 \mathrm{~h}$ of ingestion. While IgE mediated CMA can be indicated by the presence of specific $\operatorname{IgE}(\mathrm{s} \operatorname{IgE})$ in the serum together with a positive skin prick test, the diagnosis of non-IgE mediated CMA can only be confirmed via oral challenge [50]. Clinical manifestation of CMA symptoms usually occurs, within 2- 3 days after the first introduction of MP based infant formula. Prognosis for natural resolution of $\mathrm{CM}$ allergic symptoms is estimated to be at the age of 1 year for non-IgE mediated CMA, while it is likely to be of longer persistence in IgE mediated CMA [50]. For IgE mediated CMA, the natural resolution rate of symptoms has been estimated to be $70 \%$ by the age of 3 years $[51,52]$.

\subsection{Management of CMA}

Despite the natural resolution of CMA symptoms in the majority of $\mathrm{CM}$ allergic children, a careful management of CMA is required for the period in which symptoms frequently occur. 
The most common approach is the strict avoidance of MP and the replacement of MP based infant formula with other products, such as extensively hydrolysed MP based formulas and amino acid formulas as well as plant based infant formulas such as soy or rice-based products. On the other hand, the introduction of dry-heated MP, often referred to as "baked milk", to the diet of allergic children was positively correlated with the resolution of CMA symptoms in $70 \%$ of the tested children. These studies often use milk powder which was baked into a food matrix (waffle or muffin) [53-55], however, also other matrices (cheese on pizza) [54,55], fermented products [56], and liquid baked milk with and without wheat matrix (30 min at $180{ }^{\circ} \mathrm{C}$ ) have been used [57]. These studies showed that the heat treatment of MP under dry or semi-dry conditions can, in a certain subgroup of MP allergic children, result in the development of a tolerogenic immune response to MP. The choice of the most suitable diet depends on, amongst others, the severity of the symptoms of the child; it is for instance recommended to only use amino acid formulas for patients with a high risk for anaphylaxis. Moreover, dietary requirements of the infant, for instance the availability of essential amino acids as well as potential cross-reactivity to soy-based formulas, need to be carefully evaluated [50].

\subsection{Cow's milk allergens}

BLG was often described as the major MP allergen due to the high frequency $\mathrm{CM}$ allergic children to $\beta$-lactoglobulin, as well as its high quantity in $\mathrm{CM}$ but its absence in human milk. Nevertheless, Wal et al. [58] pointed out that the majority of MP allergic children also shows reactivity to caseins. Moreover, in a later study it was shown that sensitisation to $\alpha$-caseins and $\kappa$-casein is equally frequent in $20 \mathrm{MP}$ allergic children as to BLG [59]. Next to this, Docena et al. [60] reported a higher prevalence of sensitisation towards caseins than WPs by monitoring IgE and immunoglobulin $\mathrm{G}$ (IgG) in $80 \mathrm{CM}$ allergic children. Table 1.1 shows an overview over common CM protein allergens. 
Table 1.1: Properties of cow's milk allergens, adapted from Hochwallner et al. [61]. Relative amount of the milk proteins was calculated from another source [2] and for caseins was estimated based on $80 \%$ of total cow's milk proteins and their relative ratio [4]. Post translational modifications (PTMs) and disulphide bonds were based upon the Uniprot database (https://www.uniprot.org/ January 2020)

\begin{tabular}{|c|c|c|c|c|c|c|}
\hline $\begin{array}{l}\text { Milk } \\
\text { protein } \\
\text { fraction }\end{array}$ & $\begin{array}{l}\text { Allergen } \\
\text { name }\end{array}$ & Protein name & $\begin{array}{l}\text { Amount of } \\
\text { total } \\
\text { protein }[\%]\end{array}$ & $\begin{array}{l}\text { Size } \\
{[\mathrm{kDa}]}\end{array}$ & $\begin{array}{l}\text { Prevalence [\% } \\
\text { of patients] }\end{array}$ & PTMs \\
\hline \multirow{9}{*}{$\begin{array}{l}\text { Whey } \\
\text { proteins } \\
(20 \% \text {, } \\
\sim 5 \mathrm{~g} / \mathrm{L})\end{array}$} & Bos d 4 & $\alpha$-Lactalbumin & $\sim 3 \%$ & 16.247 & $0-67$ & \\
\hline & Bos d 5 & $\beta$-Lactoglobulin & $\sim 7 \%$ & 19.883 & $13-62$ & \\
\hline & Bos d 6 & Bovine serum & $\sim 0.9 \%$ & & $0-76$ & Phosphoserine \\
\hline & & albumin & & & & $29,82,89,296,442,512$ \\
\hline & & & & & & Phosphothreonine \\
\hline & & & & & & $107,443,445,569$ \\
\hline & & & & & & Glycosylation \\
\hline & & & & & & \\
\hline & Bos d 7 & Ig & $\sim 1.4 \%$ & & $12-36$ & \\
\hline \multirow[t]{9}{*}{$\begin{array}{l}\text { Caseins } \\
(80 \%, \\
\sim 30 \mathrm{~g} / \mathrm{L})\end{array}$} & Bos d 9 & $\alpha_{\text {s1-casein }}$ & $\sim 32 \%$ & 24.529 & $65-100$ & $\begin{array}{l}\text { Phosphoserine } \\
56,61,63,79,81,82,83 \text {, } \\
90,130\end{array}$ \\
\hline & Bos d 10 & $\alpha_{\mathrm{s} 2 \text {-casein }}$ & $\sim 8 \%$ & 26.019 & N/A & $\begin{array}{l}\text { Phosphoserine } \\
23,24,25,28,46,71,72, \\
73,76,144,146,150,158\end{array}$ \\
\hline & Bos d 11 & $\beta$-casein & $\sim 28 \%$ & 25.107 & $35-44$ & $30,32,33,34,50$ \\
\hline & Bos d 12 & $\kappa$-casein & $\sim 12 \%$ & & $35-41$ & Phosphoserine \\
\hline & & & & & & $148,170,187$ \\
\hline & & & & & & Phosphothreonine \\
\hline & & & & & & 166 \\
\hline & & & & & & Glycosylation \\
\hline & & & & & & $\begin{array}{l}152,153,154,157,163, \\
170,186\end{array}$ \\
\hline
\end{tabular}

To summarise, literature repeatedly reported that not only BLG but also other MP and especially caseins are important allergens in CM. This highlights the importance to not only study the immunogenicity and allergenicity of BLG but to also include caseins and other WPs in the studies of CMA induction and prevention.

\subsection{Mechanism of food allergy}

Food allergy is an adverse reaction of the immune system towards a food derived antigen. The overall self-reported prevalence of food allergy in Europe is estimated to be $5.9 \%$ and is higher in children than in adults [62]. Food antigens can lead to sensitisation via the cutaneous route, the gastrointestinal tract, oral cavity, and the respiratory tract [63]. After oral intake the first contact with antigen presenting cells already starts in membrane of the mouth which can cause mild oral allergic symptoms. Subsequently, the antigens are hydrolysed by digestive enzymes in the gastrointestinal tract. Once they reach the small intestine, they can cross the intestinal barrier where they are exposed to the gastrointestinal immune system. The molecular mechanism from the first contact with the antigen to the allergic reaction can roughly be divided in two phases, the sensitisation phase and the effector phase (Figure 1.2) [64]. In the sensitisation phase, the antigen is recognised and taken up by antigen presenting cells (APCs), such as dendritic cells (DCs), macrophages, and activated B-cells [65]. Amongst these APCs, DCs display a unique role due to their ability to migrate to the mesenteric lymph nodes to present the antigen to naive T-cells [66]. To make the antigen accessible for naive T-cells, DCs 
present it on their surface via the major histocompatibility complex class II molecule (MHC-II). Naive T-cells recognise the antigen via the T-cell receptor and present it to naive B-cells. These subsequently undergo a class switch from immunoglobulin $\mathrm{M}(\operatorname{IgM})$ to $\operatorname{IgE}$ and differentiate to effector B-cells. Finally, IgE released by effector B-cells binds to the FceRl receptor on the surface of mast cells and basophils [64,67].

a

Sensitisation phase

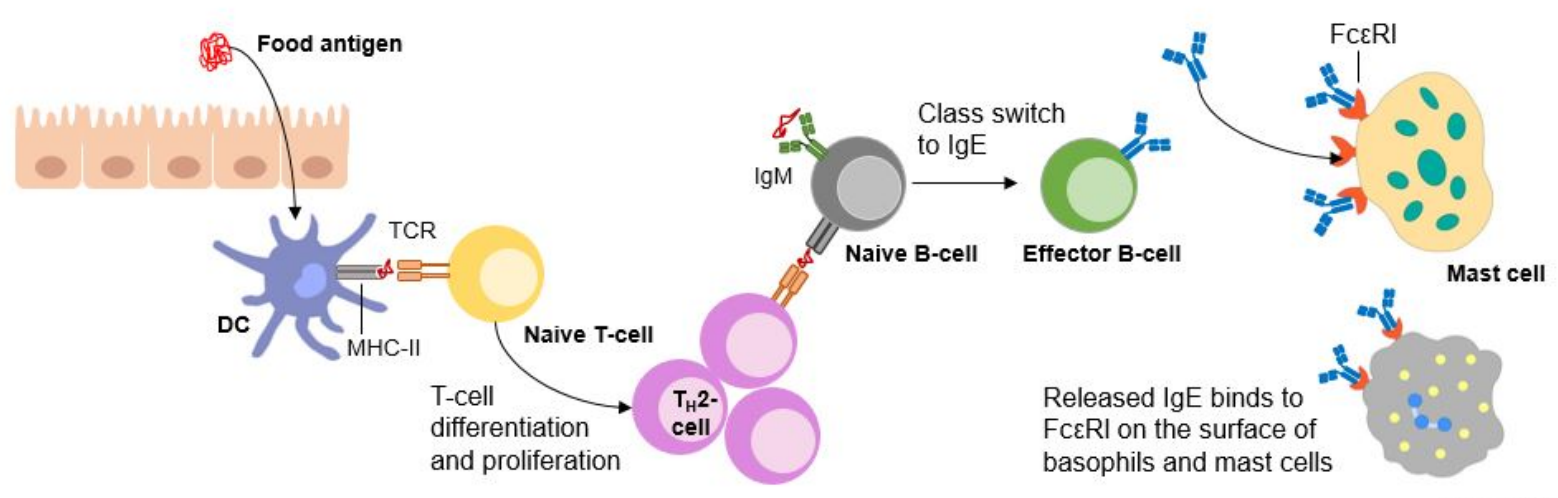

b

Effector phase

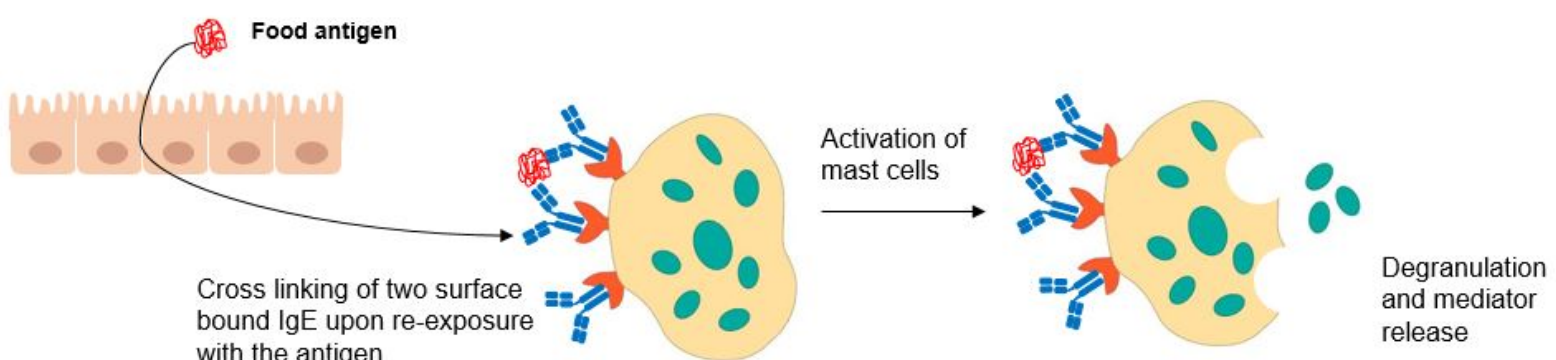

Figure 1.2: Simplified molecular mechanism showing the sensitisation phase (a) and the effector phase (b) of food allergy, modified from Ontiveros et al. [64] and Larché et al. [67]. DC: dendritic cell, MHC-II: major histocompatibility complex class II molecule, TCR: T-cell receptor, $\mathrm{T}_{\mathrm{H}}$ : T helper cell, IgE: Immunoglobulin E, IgM: Immunoglobulin M.

Upon re-exposure (Figure 1.2b), two mast cell surface-bound IgE molecules crosslink due to the binding to the antigen. This results in the activation of the mast or basophilic cell and their subsequent degranulation, which ultimately leads to the release of pro-inflammatory mediators such as histamine [68].

\subsection{Induction either pro-inflammatory or tolerogenic responses}

The interaction of activated DCs with naive T-cells and the resulting T-cell proliferation and differentiation determines whether a pro-inflammatory or tolerogenic immune response is induced. The T-cell recognises the antigen that is presented on the MHC-II complex of the DC via the T-cell receptor, however also other costimulatory and adhesion molecules, as well as mediator release are important determinants in DC-T-cell interaction. The dynamics and duration of this interaction as well as the activation state of the DC has been described as crucial 
factor for the subsequent T-cell maturation [69]. During this step different subsets of T-helper cells (Th)-1, Th2, Th17 as well as regulatory T-cells $\left(\mathrm{T}_{\text {reg }}\right)$ are produced. The balance between these subsets determines the elicitation of a pro-inflammatory or tolerogenic immune response [70]. While differentiation and proliferation towards Th2 and Th17 subsets results in a pro-inflammatory response, differentiation towards $\mathrm{Th} 1$ and $\mathrm{T}_{\text {reg }}$ subsets redirects to a tolerogenic innate immune response [71]. The receptor mediated recognition and uptake of antigens by APCs is a crucial step in T-cell immunogenicity. The potential role of glycated food proteins in T-cell immunogenicity has previously been demonstrated in a study by Heilmann et al. [42] where uptake of pyrraline-modified ovalbumin by murine DCs was mediated via scavenger receptor class $A$ and resulted in an enhanced Th2 polarisation. However, little is known about the modulatory role of other heat induced modifications as well as other receptors in T-cell activation.

\subsection{Antigen sampling in the small intestine}

The intestinal epithelium is the physicochemical barrier between the lumen of the small intestine and the underlying lamina propria, hence the mucosal immune system. Most of the intestinal epithelial cells are adsorptive enterocytes that are organised in crypts and microvilli that facilitate the sampling of nutrients from the lumen due to its largely extended surface. Next to the epithelial cells, microfold cells (M-cells), which are located in the follicle associated epithelium of Peyer's Patches are also present in the intestinal barrier. Their morphology differs in three main characteristics from intestinal enterocytes: a rather unorganised brush border with short microvilli, a lower enzymatic activity, and an M-cell underlying pocket enriched with B- and T-cells, macrophages and DCs. They are thus considered a key player in antigen sampling from the intestinal lumen [72]. This morphological variability of the intestinal epithelium already indicates that proteins and their digestive breakdown products, can pass the intestinal epithelial tissue via different pathways (Figure 1.3) which can also affect the form in which they are presented to the immunes system. The transport pathway of ingested proteins can roughly be divided into paracellular (between the tight junctions) and transcellular routes. Moreover, specialised DCs and macrophages can actively sample antigens from the lumen by reaching in between the tight junctions of the epithelial cells, while follicle associated epithelium transport routes occur mainly via M-cells [74,75]. The transport pathway, determines whether the antigen reaches the lamina propria intact or hydrolysed to smaller fragments and can also predispose the immunological response. 


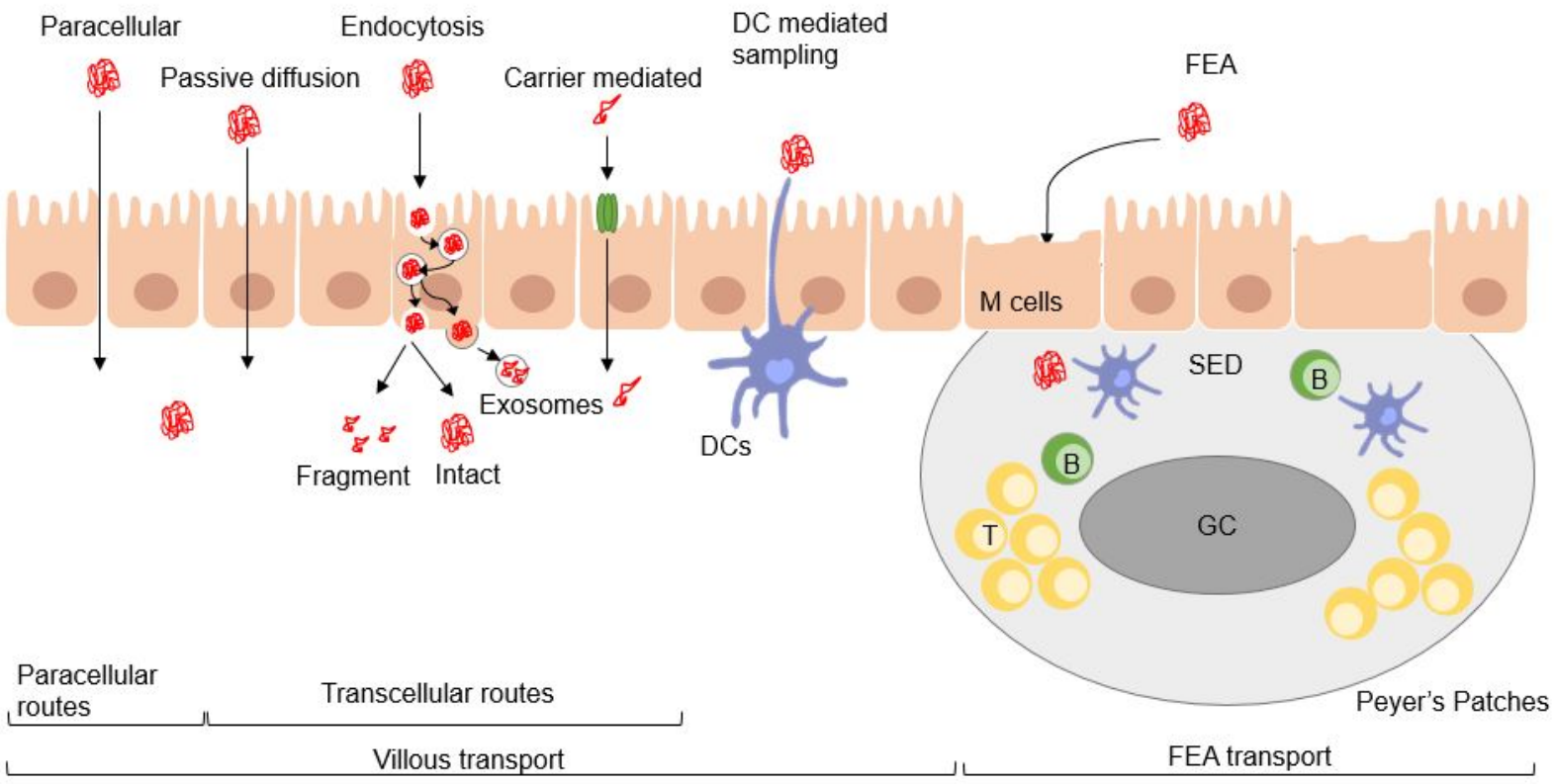

\section{Lamina propria}

Figure 1.3: Epithelial transport routes of food proteins and antigens in the small intestine adapted from Corr et al. [72] and Reitsma et al.[73]. DC: dendritic cell, FEA: follicle-associated epithelium, microfold cells (M)-cells, B: B-cells, T: T-cells, SED: subepithelial dome, GC: germinal centre.

\subsection{Effect of thermal processing on cow's MP immunogenicity and allergenicity}

Immunogenicity describes the potential of a material to initiate a cellular immune response [76]. Heating of food protein results in several structural changes that can affect immunogenicity. The presence of AGEs on glycated food proteins can affect the immunogenicity via binding to the receptors for AGEs [41,42]. Moreover, their presence in heated food proteins has been linked to the induction of inflammatory responses in APCs [77-79]. Next to the presence of AGEs, heating-induced aggregation has been shown to modulate immunogenicity. For example, pasteurisation $\left(30 \mathrm{~min}\right.$ at $63{ }^{\circ} \mathrm{C}$ ) of BLG has been shown to skew the uptake towards Peyer's Patches, indicating a higher immunogenicity [80]. Moreover, binding to receptors of AGEs can also be initiated by the formation of aggregates [20] and can occur independent from the presence of a reducing sugars, as shown on BLG heated in solution [81]. Moreover, aggregation as well as increasing hydrophobicity and the formation of amyloid-like structures during heating in solution has been shown to enhance the receptor-mediated uptake of BLG by THP-1 macrophages [21]. Next to immunogenicity, thermal processing of food allergens can also modify their allergenicity [49]. Industrial heat treatments of liquid dairy products have been shown to both decreased and increased IgE and IgG binding to WPs. At the same time, casein allergenicity is mostly unaffected by these heat treatments due to their relative heat stability [76]. As discussed before, the structural modifications strongly depend on the applied 
heating conditions and thus also determine whether epitopes are exposed, hidden in the interior, or if neo-epitopes are formed. Bu et al. [82] showed that heating of WPs resulted in an initial increase of IgE binding and subsequent decrease if heated $>90{ }^{\circ} \mathrm{C}$ which was related to the unfolding and subsequent aggregation. Next to this, the MR showed a masking effect on $\operatorname{IgE}$ binding at a high degree of glycation [83].

The accelerated resolution of $\mathrm{CM}$ allergy symptoms in allergic children after ingestion of "baked milk" has been shown repeatedly in the past [53-55]. The applied heating conditions (low $a_{w}-l e v e l$, high temperatures, and presence of reducing sugars) during the preparation process, indicate a potential role of the MR as well as aggregation in these products. However, the changes that occur to the protein during these processes and the underlying immunological mechanisms are not well established. Especially regarding the role of AGEs, disentangling the effect of structural modifications and the MR on immunogenicity is often difficult as the conditions used to glycate the protein as well as MR itself promote protein aggregation [45] and thus requires further investigation.

\subsection{The MR and immunity - the role of cell surface receptors of APCs}

Several AGE binding cell surface receptors have been described in previous studies, such as the receptor for AGEs (RAGE), CD36, galectin-3 (Gal-3) as part of the AGE-R-complex, and scavenger receptor class A type I and type II [84-88]. Next to endogenously formed AGEs, also food derived AGEs have been described as ligands for AGE receptors, indicating the role of exogenous AGEs in inflammatory responses [41,42,81]. RAGE is involved in endocytosis of antigens as well as in cellular signalling pathways that determine the maturation and differentiation of macrophages and DCs and therefore plays a key role in the innate immune system [89]. The CD36 pattern recognition receptor belongs to the scavenger receptor class B family, and is predominantly found on macrophages, endothelial cells, and smooth muscle cells. In contrast to RAGE it has a key role in endocytosis and cell adhesion, rather than cellular signalling [90]. Gal-3 is highly expressed on cells of the innate immune system, such as neutrophils, macrophages, and DCs [91]. Its role in the differentiation and proliferation mechanisms of antigen presenting cells has been demonstrated by a number of studies and indicates the importance of Gal-3/ligand interactions in the immunological response to an antigen [92-95]. The binding of food derived AGEs to these receptors is hence a crucial step in the initiation of an immune response.

\subsection{Cow's MP digestion}

Most studies showed the binding of AGE receptor to glycated food proteins prior to digestion. However, Liu et al. [20] also observed binding of glycated WPs after simulated infant in vitro digestion. Upon digestion, MP is hydrolysed into peptides and amino acids by the digestive enzymes. The digestive system of an infant still develops and enzyme activity as well as bile acid concentrations are lower, while the $\mathrm{pH}$ of the stomach and the intestine is higher compared 
to adult digestion [96]. While the WPs are relative resistant to gastric digestion, caseins rapidly disappear from the soluble fraction of the digestive juice. This is partly related the clotting of caseins upon acidic precipitation in the stomach ( $\mathrm{pH} \sim 5.5$ in infants) but also to the rapid hydrolysis of caseins as pepsin cleavage sites in caseins are easy accessible for the enzyme due to their open structure. In the intestine, the $\mathrm{pH}$ slightly increases ( $\sim 6.5$ in infants) and both caseins and WPs are hydrolysed by the two main proteolytic enzymes trypsin and chymotrypsin. Moreover, other carboxypeptidases and brush border enzymes located on the luminal side of the intestinal epithelial cells further hydrolyse the proteins and digestion-derived peptides [97]. Thermal processing of MP can have both a negative or positive effect on its digestibility depending on the heating conditions and the heat-induced modifications on the protein structure. Denaturation may facilitate digestibility as unfolding makes the protein's cleavage sites more accessible to the enzymes, while aggregation rather shows a negative effect on protein digestion by reducing its accessibility. Moreover, glycation impairs digestibility possibly by blocking cleavage sites of trypsin which specifically cleaves after lysine residues [98]. Next to the overall digestibility, also the peptides that are released upon digestion differ depending on the heat treatment of the digested product. Both, decreasing and increasing numbers of peptides have been described [99,100], as well as an increased average peptide length at $20.5 \%$ blocked lysine in infant formula [101]. The presence of relatively larger fragments may increase the risk of CM allergy symptoms. This has been demonstrated with a screening ELISA measuring residual immunoreactivity with specific monoclonal antibodies $[100,102]$ but has also been shown using IgE and IgG ELISA on in vitro digests of CM with various thermal treatments [103]. However, there is no direct link between the released peptide patterns upon digestion and an increasing or decreasing immunoreactivity, as this strongly depends on the bioavailability of the peptides and the immunological mechanism under investigation.

\subsection{Research objectives and outline of the thesis}

The consumption of "baked" milk products has raised increasing attention as a possible alternative to strict avoidance diets for $\mathrm{CM}$ allergic children. However, the underlying (molecular) mechanisms that result in the enhanced resolution of allergic symptoms upon ingestion of baked milk compared to raw milk are yet unclear. As reviewed in the previous paragraphs heat treatment causes several structural modifications of milk proteins which may alter immunoreactivity of the protein. To describe the molecular consequences of the particular heat treatment, the detailed structural analysis of the protein needs to be combined with functional read-outs assessing immunoreactivity of modified protein. Such a multidisciplinary approach is so far rare and therefore more studies involving physicochemical analysis together with molecular immunological assays are needed to understand the baked milk-induced tolerance. The hypothesis of this thesis is that heat-induced molecular alterations in the proteins that are contained in CM, notably MR products (MRPs), are responsible for the accelerated resolution of CMA in CMA-children that are exposed to baked milk. This thesis aims to acquire 
knowledge about the occurring structural changes, and how they may affect the immune response. This is crucial for predicting the outcome of food challenges with baked milk, and to better understand the potential mechanism of oral tolerance induction. The objective of this work was thus to gain more insights in the structural modifications of dry-heated MP, to understand how these may affect digestibility and immunoreactivity, and to determine the role of the MR within the observations made.

In chapter 2, the composition of the buffer soluble and insoluble fraction of MP, heated under controlled humidity conditions in the presence of lactose, is studied. Furthermore, it aims to gain better understanding which molecular interactions are involved in the formation of insoluble protein upon dry heating at low and high temperatures and the resulting effects on infant in vitro digestion.

In chapter 3, the role of aggregation and glycation on antigenicity and immunogenicity of BLG is investigated. As protein aggregation and the extent of glycation is determined by the applied heating conditions, different heat treatments at low and high temperatures, as well as in solution and under dry conditions, are applied. The treatment-dependent effects on allergenicity and immunogenicity are examined by means of IgE binding and sRAGE binding capacity.

In chapter 4, the chemical modification of BLG with CML is conducted to better understand the role of this specific AGE in immunogenicity, independent from changes in the secondary and tertiary protein structure. Therefore, the modified BLG is exposed to the receptors for AGEs, CD36, Gal-3, and sRAGE using ELISA and possible structural changes are closely monitored and related to the receptor binding.

In chapter 5, the receptor binding and internalisation by APCs of wet heated and glycated BLG to CD36, Gal-3, scavenger receptor class A type I, and sRAGE are investigated. Additionally, the solutions of heated BLG are fractionated into two size ranges (above and below $100 \mathrm{kDa}$ ) to evaluate the relevance of large aggregates in binding and internalisation. After initial screening with receptor binding ELISAs, binding to the cell surface bound receptors is tested in THP-1 cells. Internalisation experiments are conducted on THP-1 cells and DCs which are isolated and differentiated from human peripheral blood mononuclear cell. To indicate the physiological relevance of the aggregates in vivo, experiments are also conducted on in vitro digests of heated and glycated BLG.

In chapter 6, the peptides released upon simulated infant in vitro digestion of MP heated under dry conditions at low and high temperature are monitored. sIgE binding epitopes are identified based on literature, while T-cell epitopes are identified using a prediction software. Moreover, the transport across a Caco-2 cell monolayer is investigated. Both non-modified and glycated peptides are monitored before and after Caco- 2 cell transport. This study gives and overview over potential immunoreactive peptides and glycated peptides generate upon simulated infant in vitro digestion of differentially heated MP and their transport across the Caco-2 cell monolayer. 
Finally, in the General Discussion presented in chapter 7, the results are summarised as well as interpreted in coherence and against the background of existing literature. An interpretation for the relevance of MR based on the presented findings is given. The main conclusion and further perspectives are given in this chapter. 


\section{Reference}

1. Martin, C.R.; Ling, P.R.; Blackburn, G.L. Review of infant feeding: Key features of breast milk and infant formula. Nutrients 2016, 8, doi:10.3390/nu8050279.

2. Ng-Kwai-Hang, K.F.; Kroeker, E.M. Rapid Separation and Quantification of Major Caseins and Whey Proteins of Bovine Milk by Polyacrylamide Gel Electrophoresis. Journal of Dairy Science 1984, 67, 30523056, doi:10.3168/jds.S0022-0302(84)81671-9.

3. Madureira, A.R.; Pereira, C.I.; Gomes, A.M.P.; Pintado, M.E.; Xavier Malcata, F. Bovine whey proteins Overview on their main biological properties. Food Research International 2007, 40, 1197-1211, doi:10.1016/j.foodres.2007.07.005.

4. Dalgleish, D.G.; Corredig, M. The structure of the casein micelle of milk and its changes during processing. Annu. Rev. Food Sci. Technol. 2012, 3, 449-467, doi:10.1146/annurev-food-022811-101214.

5. Gaucheron, F. The minerals of milk. Reprod. Nutr. Dev. 2005, 45, 473-483, doi:10.1051/rnd:2005030.

6. Rasmussen, L.K. Purification of Disulphide-Linked as2-and k-casein from Bovine Milk. Journal of Dairy Research 1991, 58, 187-193, doi:10.1017/S0022029900029733.

7. Lowe, E.K.; Anema, S.G.; Bienvenue, A.; Roland, M.J.; Creamer, L.K.; Jiménez-Flores, R. Heat-induced redistribution of disultide bonds in milk proteins. 2. Disulfide bonding patterns between bovine $\beta$-lactoglobulin and $\kappa$-casein. Journal of Agricultural and Food Chemistry 2004, 52, 7669-7680, doi:10.1021/jf0491254.

8. Lönnerdal, B. Infant formula and infant nutrition: Bioactive proteins of human milk and implications for composition of infant formulas. Am. J. Clin. Nutr. 2014, 99, 712S-717S, doi:10.3945/ajcn.113.071993.

9. Liao, Y.; Weber, D.; Xu, W.; Durbin-Johnson, B.P.; Phinney, B.S.; Lönnerdal, B. Absolute Quantification of Human Milk Caseins and the Whey/Casein Ratio during the First Year of Lactation. J. Proteome Res. 2017, 16, 4113-4121, doi:10.1021/acs.jproteome.7b00486.

10. Iametti, S.; De Gregori, B.; Vecchio, G.; Bonomi, F. Modifications occur at different structural levels during the heat denaturation of $\beta$-lactoglobulin. European Journal of Biochemistry 1996, 237, 106-112, doi:10.1111/j.1432-1033.1996.0106n.x.

11. Boye, J.I.; Alli, I.; Ismail, A.A. Use of Differential Scanning Calorimetry and Infrared Spectroscopy in the Study of Thermal and Structural Stability of $\alpha$-Lactalbumin. Journal of Agricultural and Food Chemistry 1997, 45, 1116-1125, doi:10.1021/jf960360z.

12. Verheul, M.; Roefs, S.P.F.M.; De Kruif, K.G. Kinetics of Heat-Induced Aggregation of $\beta$ Lactoglobulin. Journal of Agricultural and Food Chemistry 1998, 46, 896-903, doi:10.1021/jf970751t.

13. Elfagm, A.A.; Wheelock, J.V. Heat Interaction Between $\alpha$-Lactalbumin, $\beta$-Lactoglobulin and Casein in Bovine Milk. Journal of Dairy Science 1978, 61, 159-163, doi:10.3168/jds.S0022-0302(78)83572-3.

14. Enomoto, H.; Hayashi, Y.; Li, C.P.; Ohki, S.; Ohtomo, H.; Shiokawa, M.; Aoki, T. Glycation and phosphorylation of $\alpha$-lactalbumin by dry heating: Effect on protein structure and physiological functions. Journal of Dairy Science 2009, 92, 3057-3068, doi:10.3168/jds.2009-2014.

15. Enomoto, H.; Li, C.P.; Morizane, K.; Ibrahim, H.R.; Sugimoto, Y.; Ohki, S.; Ohtomo, H.; Aoki, T. Glycation and phosphorylation of $\beta$-lactoglobulin by dry-heating: Effect on protein structure and some properties. Journal of Agricultural and Food Chemistry 2007, 55, 2392-2398, doi:10.1021/jf062830n.

16. Morgan, F.; Mollé, D.; Henry, G.; Vénien, A.; Léonil, J.; Peltre, G.; Levieux, D.; Maubois, J.L.; Bouhallab, S. Glycation of bovine $\beta$-lactoglobulin: Effect on the protein structure. International Journal of Food Science and Technology 1999, 34, 429-435, doi:10.1046/j.1365-2621.1999.00318.x.

17. Morgan, F.; Léonil, J.; Mollé, D.; Bouhallab, S. Modification of bovine $\beta$-lactoglobulin by glycation in a powdered state or in an aqueous solution: Effect on association behavior and protein conformation. Journal of Agricultural and Food Chemistry 1999, 47, 83-91, doi:10.1021/jf9804387.

18. Gulzar, M.; Bouhallab, S.; Jeantet, R.; Schuck, P.; Croguennec, T. Influence of pH on the dry heat-induced denaturation/aggregation of whey proteins. Food Chemistry 2011, 129, 110-116, doi:10.1016/j.foodchem.2011.04.037.

19. Gulzar, M.; Bouhallab, S.; Jardin, J.; Briard-Bion, V.; Croguennec, T. Structural consequences of dry heating on alpha-lactalbumin and beta-lactoglobulin at pH 6.5. Food Research International 2013, 51, 899906, doi:10.1016/j.foodres.2013.02.025.

20. Liu, F.; Teodorowicz, M.; Wichers, H.J.; Van Boekel, M.A.J.S.; Hettinga, K.A. Generation of Soluble Advanced Glycation End Products Receptor (sRAGE)-Binding Ligands during Extensive Heat Treatment of Whey Protein/Lactose Mixtures Is Dependent on Glycation and Aggregation. Journal of Agricultural and Food Chemistry 2016, 64, 6477-6486, doi:10.1021/acs.jafc.6b02674.

21. Deng, Y.; Govers, C.; Bastiaan-Net, S.; van der Hulst, N.; Hettinga, K.; Wichers, H.J. Hydrophobicity and aggregation, but not glycation, are key determinants for uptake of thermally processed $\beta$-lactoglobulin by THP-1 macrophages. Food Research International 2019, 120, 102-113, doi:10.1016/j.foodres.2019.01.038. 
22. Schong, E.; Famelart, M.H. Dry heating of whey proteins. Food Research International 2017, 100, 31-44, doi:10.1016/j.foodres.2017.08.057.

23. Mulsow, B.B.; Jacob, M.; Henle, T. Studies on the impact of glycation on the denaturation of whey proteins. Eur. Food Res. Technol. 2009, 228, 643-649, doi:10.1007/s00217-008-0973-0.

24. Anema, S.G.; Pinder, D.N.; Hunter, R.J.; Hemar, Y. Effects of storage temperature on the solubility of milk protein concentrate (MPC85). Food Hydrocolloids 2006, 20, 386-393, doi:10.1016/j.foodhyd.2005.03.015.

25. Havea, P. Protein interactions in milk protein concentrate powders. International Dairy Journal 2006, 16 , 415-422, doi:10.1016/j.idairyj.2005.06.005.

26. Mimouni, A.; Deeth, H.C.; Whittaker, A.K.; Gidley, M.J.; Bhandari, B.R. Investigation of the microstructure of milk protein concentrate powders during rehydration: Alterations during storage. Journal of Dairy Science 2010, 93, 463-472, doi:10.3168/jds.2009-2369.

27. Le, T.T.; Bhandari, B.; Holland, J.W.; Deeth, H.C. Maillard reaction and protein cross-linking in relation to the solubility of milk powders. Journal of Agricultural and Food Chemistry 2011, 59, 12473-12479, doi:10.1021/jf203460z.

28. Le, T.T.; Deeth, H.C.; Bhandari, B.; Alewood, P.F.; Holland, J.W. Quantification of lactosylation of whey proteins in stored milk powder using multiple reaction monitoring. Food Chemistry 2013, 141, 1203-1210, doi:10.1016/j.foodchem.2013.03.073.

29. Le, T.T.; Deeth, H.C.; Bhandari, B.; Alewood, P.F.; Holland, J.W. A proteomic approach to detect lactosylation and other chemical changes in stored milk protein concentrate. Food Chemistry 2012, 132, 655-662, doi:10.1016/j.foodchem.2011.11.012.

30. Le, T.T.; Holland, J.W.; Bhandari, B.; Alewood, P.F.; Deeth, H.C. Direct evidence for the role of Maillard reaction products in protein cross-linking in milk powder during storage. International Dairy Journal 2013, 31, 83-91, doi:10.1016/j.idairyj.2013.02.013.

31. Gazi, I.; Huppertz, T. Influence of protein content and storage conditions on the solubility of caseins and whey proteins in milk protein concentrates. International Dairy Journal 2015, 46, 22-30, doi:10.1016/j.idairyj.2014.09.009.

32. Haque, E.; Bhandari, B.R.; Gidley, M.J.; Deeth, H.C.; Whittaker, A.K. Ageing-induced solubility loss in milk protein concentrate powder: Effect of protein conformational modifications and interactions with water. Journal of the Science of Food and Agriculture 2011, 91, 2576-2581, doi:10.1002/jsfa.4478.

33. Haque, E.; Whittaker, A.K.; Gidley, M.J.; Deeth, H.C.; Fibrianto, K.; Bhandari, B.R. Kinetics of enthalpy relaxation of milk protein concentrate powder upon ageing and its effect on solubility. Food Chemistry 2012, 134, 1368-1373, doi:10.1016/j.foodchem.2012.03.034.

34. Fan, F.; Liu, M.; Shi, P.; Xu, X.; Lu, W.; Wang, Z.; Du, M. Protein cross-linking and the Maillard reaction decrease the solubility of milk protein concentrates. Food Science and Nutrition 2018, 6, 1196-1203, doi:10.1002/fsn3.657.

35. Fyfe, K.N.; Kravchuk, O.; Le, T.; Deeth, H.C.; Nguyen, A.V.; Bhandari, B. Storage induced changes to high protein powders: Influence on surface properties and solubility. Journal of the Science of Food and Agriculture 2011, 91, 2566-2575, doi:10.1002/jsfa.4461.

36. Nasser, S.; De Sa Peixoto, P.; Moreau, A.; Croguennec, T.; Bray, F.; Rolando, C.; Tessier, F.J.; Hédoux, A.; Delaplace, G. Storage of Micellar Casein Powders with and without Lactose: Consequences on Color, Solubility, and Chemical Modifications. Journal of Agricultural and Food Chemistry 2018, 66, 1027410282, doi:10.1021/acs.jafc.7b06147.

37. Nasser, S.; Moreau, A.; Jeantet, R.; Hédoux, A.; Delaplace, G. Influence of storage conditions on the functional properties of micellar casein powder. Food Bioprod. Process. 2017, 106, 181-192, doi:10.1016/j.fbp.2017.09.004.

38. Gerrard, J.A. Protein-protein crosslinking in food: Methods, consequences, applications. Trends in Food Science and Technology 2002, 13, 391-399, doi:10.1016/S0924-2244(02)00257-1.

39. Van Boekel, M.A.J.S. Effect of heating on Maillard reactions in milk. Food Chemistry 1998, 62, 403-414, doi:10.1016/s0308-8146(98)00075-2.

40. Arena, S.; Renzone, G.; D'Ambrosio, C.; Salzano, A.M.; Scaloni, A. Dairy products and the Maillard reaction: A promising future for extensive food characterization by integrated proteomics studies. Food Chemistry 2017, 219, 477-489, doi:10.1016/j.foodchem.2016.09.165.

41. Xue, J.; Rai, V.; Singer, D.; Chabierski, S.; Xie, J.; Reverdatto, S.; Burz, D.S.; Schmidt, A.M.; Hoffmann, R.; Shekhtman, A. Advanced glycation end product recognition by the receptor for AGEs. Structure 2011, 19, 722-732, doi:10.1016/j.str.2011.02.013.

42. Heilmann, M.; Wellner, A.; Gadermaier, G.; Ilchmann, A.; Briza, P.; Krause, M.; Nagai, R.; Burgdorf, S.; Scheurer, S.; Vieths, S., et al. Ovalbumin modified with pyrraline, a maillard reaction product, shows enhanced T-cell immunogenicity. Journal of Biological Chemistry 2014, 289, 7919-7928, doi:10.1074/jbc.M113.523621. 
43. Foerster, A.; Henle, T. Glycation in food and metabolic transit of dietary AGEs (advanced glycation endproducts): Studies on the urinary excretion of pyrraline. Biochem. Soc. Trans. 2003, 31, 1383-1385, doi:10.1042/bst0311383.

44. Roncero-Ramos, I.; Delgado-Andrade, C.; Tessier, F.J.; Niquet-Léridon, C.; Strauch, C.; Monnier, V.M.; Navarro, M.P. Metabolic transit of Ne-carboxymethyl-lysine after consumption of AGEs from bread crust. Food and Function 2013, 4, 1032-1039, doi:10.1039/c3fo30351a.

45. Cardoso, H.B.; Wierenga, P.A.; Gruppen, H.; Schols, H.A. Maillard induced aggregation of individual milk proteins and interactions involved. Food Chemistry 2019, 276, 652-661, doi:10.1016/j.foodchem.2018.10.061.

46. Chevalier, F.; Chobert, J.M.; Dalgalarrondo, M.; Choiset, Y.; Haertlé, T. Maillard glycation of $\beta$ lactoglobulin induces conformation changes. Nahrung - Food 2002, 46, 58-63, doi:10.1002/15213803(20020301)46:2<58::AID-FOOD58>3.0.CO;2-Y.

47. Pinto, M.S.; Léonil, J.; Henry, G.; Cauty, C.; Carvalho, A.F.; Bouhallab, S. Heating and glycation of $\beta$ lactoglobulin and $\beta$-casein: Aggregation and in vitro digestion. Food Research International 2014, 55, 7076, doi:10.1016/j.foodres.2013.10.030.

48. Wada, Y.; Lönnerdal, B. Effects of different industrial heating processes of milk on site-specific protein modifications and their relationship to in vitro and in vivo digestibility. Journal of Agricultural and Food Chemistry 2014, 62, 4175-4185, doi:10.1021/jf501617s.

49. Nowak-Wegrzyn, A.; Fiocchi, A. Rare, medium, or well done? The effect of heating and food matrix on food protein allergenicity. Current Opinion in Allergy and Clinical Immunology 2009, 9, 234-237, doi:10.1097/ACI.0b013e32832b88e7.

50. Lifschitz, C.; Szajewska, H. Cow's milk allergy: evidence-based diagnosis and management for the practitioner. Eur. J. Pediatr. 2015, 174, 141-150, doi:10.1007/s00431-014-2422-3.

51. Host, A.; Jacobsen, H.P.; Halken, S.; Holmenlund, D. The natural history of cow's milk protein allergy/intolerance. EUR. J. CLIN. NUTR. 1995, 49, S13-S18.

52. Høst, A.; Halken, S. A prospective study of cow milk allergy in Danish infants during the first 3 years of life: Clinical course in relation to clinical and immunological type of hypersensitivity reaction. Allergy Eur. J. Allergy Clin. Immunol. 1990, 45, 587-596, doi:10.1111/j.1398-9995.1990.tb00944.x.

53. Nowak-Wegrzyn, A.; Bloom, K.A.; Sicherer, S.H.; Shreffler, W.G.; Noone, S.; Wanich, N.; Sampson, H.A. Tolerance to extensively heated milk in children with cow's milk allergy. Journal of Allergy and Clinical Immunology 2008, 122, 342-347.e342, doi:10.1016/j.jaci.2008.05.043.

54. Andrews, T.; Banks, J.R. Dietary baked milk accelerates the resolution of cow's milk allergy in children. Pediatrics 2012, 130, doi:10.1542/peds.2012-2183R.

55. Kim, J.S.; Nowak-Wgrzyn, A.; Sicherer, S.H.; Noone, S.; Moshier, E.L.; Sampson, H.A. Dietary baked milk accelerates the resolution of cow's milk allergy in children. Journal of Allergy and Clinical Immunology 2011, 128, 125-131.e122, doi:10.1016/j.jaci.2011.04.036.

56. Uncuoglu, A.; Yologlu, N.; Simsek, I.E.; Uyan, Z.S.; Aydogan, M. Tolerance to baked and fermented cow's milk in children with IgE-mediated and non-IgE-mediated cow's milk allergy in patients under two years of age. Allergologia et Immunopathologia 2017, 45, 560-566, doi:10.1016/j.aller.2017.02.008.

57. Miceli Sopo, S.; Greco, M.; Monaco, S.; Bianchi, A.; Cuomo, B.; Liotti, L.; Iacono, I.D. Matrix effect on baked milk tolerance in children with IgE cow milk allergy. Allergologia et Immunopathologia 2016, 44, 517-523, doi:10.1016/j.aller.2016.03.005.

58. Wal, J.M. Allergy review series II: An update on allergens. Cow's milk allergens. Allergy: European Journal of Allergy and Clinical Immunology 1998, 53, 1013-1022.

59. Natale, M.; Bisson, C.; Monti, G.; Peltran, A.; Garoffo, L.P.; Valentini, S.; Fabris, C.; Bertino, E.; Coscia, A.; Conti, A. Cow's milk allergens identification by two-dimensional immunoblotting and mass spectrometry. Molecular Nutrition and Food Research 2004, 48, 363-369, doi:10.1002/mnfr.200400011.

60. Docena, G.H.; Fernandez, R.; Chirdo, F.G.; Fossati, C.A. Identification of casein as the major allergenic and antigenic protein of cow's milk. Allergy: European Journal of Allergy and Clinical Immunology 1996, 51, 412-416, doi:10.1111/j.1398-9995.1996.tb04639.x.

61. Hochwallner, H.; Schulmeister, U.; Swoboda, I.; Spitzauer, S.; Valenta, R. Cow's milk allergy: From allergens to new forms of diagnosis, therapy and prevention. Methods 2014, 66, 22-33, doi:10.1016/j.ymeth.2013.08.005.

62. Nwaru, B.I.; Hickstein, L.; Panesar, S.S.; Roberts, G.; Muraro, A.; Sheikh, A. Prevalence of common food allergies in Europe: A systematic review and meta-analysis. Allergy: European Journal of Allergy and Clinical Immunology 2014, 69, 992-1007, doi:10.1111/all.12423.

63. Sampson, H.A.; O'Mahony, L.; Burks, A.W.; Plaut, M.; Lack, G.; Akdis, C.A. Mechanisms of food allergy. Journal of Allergy and Clinical Immunology 2018, 141, 11-19, doi:10.1016/j.jaci.2017.11.005. 
64. Ontiveros, N.F.-M., L., K.; Canizalez-Román, V., A.; Cabrera-Chavez, F. Food Allergy: Prevalence and Food Technology Approaches for the Control of IgE-mediated Food Allergy. Austin J Nutri Food Science 2014, $2,7$.

65. Hughes, C.E.; Benson, R.A.; Bedaj, M.; Maffia, P. Antigen-presenting cells and antigen presentation in tertiary lymphoid organs. Frontiers in Immunology 2016, 7, doi:10.3389/fimmu.2016.00481.

66. Cerovic, V.; Bain, C.C.; Mowat, A.M.; Milling, S.W.F. Intestinal macrophages and dendritic cells: What's the difference? Trends Immunol. 2014, 35, 270-277, doi:10.1016/j.it.2014.04.003.

67. Larché, M.; Akdis, C.A.; Valenta, R. Immunological mechanisms of allergen-specific immunotherapy. Nat. Rev. Immunol. 2006, 6, 761-771, doi:10.1038/nri1934.

68. Krystel-Whittemore, M.; Dileepan, K.N.; Wood, J.G. Mast cell: A multi-functional master cell. Frontiers in Immunology 2016, 6, doi:10.3389/fimmu.2015.00620.

69. Hugues, S. Dynamics of dendritic cell-T cell interactions: A role in T cell outcome. Semin.Immunopathol. 2010, 32, 227-238, doi:10.1007/s00281-010-0211-2.

70. Akdis, M.; Verhagen, J.; Taylor, A.; Karamloo, F.; Karagiannidis, C.; Crameri, R.; Thunberg, S.; Deniz, G.; Valenta, R.; Fiebig, H., et al. Immune responses in healthy and allergic individuals are characterized by a fine balance between allergen-specific T regulatory 1 and T helper 2 cells. J. Exp. Med. 2004, 199, 15671575, doi:10.1084/jem.20032058.

71. Teodorowicz, M.; Van Neerven, J.; Savelkoul, H. Food processing: The influence of the maillard reaction on immunogenicity and allergenicity of food proteins. Nutrients 2017, 9, doi:10.3390/nu9080835.

72. Corr, S.C.; Gahan, C.C.G.M.; Hill, C. M-cells: Origin, morphology and role in mucosal immunity and microbial pathogenesis. FEMS Immunol. Med. Microbiol. 2008, 52, 2-12, doi:10.1111/j.1574695X.2007.00359.x.

73. Reitsma, M.; Westerhout, J.; Wichers, H.J.; Wortelboer, H.M.; Verhoeckx, K.C.M. Protein transport across the small intestine in food allergy. Molecular Nutrition and Food Research 2014, 58, 194-205, doi:10.1002/mnfr.201300204.

74. Schulz, O.; Pabst, O. Antigen sampling in the small intestine. Trends Immunol. 2013, 34, 155-161, doi:10.1016/j.it.2012.09.006.

75. Yu, W.; Freeland, D.M.H.; Nadeau, K.C. Food allergy: Immune mechanisms, diagnosis and immunotherapy. Nat. Rev. Immunol. 2016, 16, 751-765, doi:10.1038/nri.2016.111.

76. Verhoeckx, K.C.M.; Vissers, Y.M.; Baumert, J.L.; Faludi, R.; Feys, M.; Flanagan, S.; Herouet-Guicheney, C.; Holzhauser, T.; Shimojo, R.; van der Bolt, N., et al. Food processing and allergenicity. Food and Chemical Toxicology 2015, 80, 223-240, doi:10.1016/j.fct.2015.03.005.

77. Hilmenyuk, T.; Bellinghausen, I.; Heydenreich, B.; Ilchmann, A.; Toda, M.; Grabbe, S.; Saloga, J. Effects of glycation of the model food allergen ovalbumin on antigen uptake and presentation by human dendritic cells. Immunology 2010, 129, 437-445, doi:10.1111/j.1365-2567.2009.03199.x.

78. Ilchmann, A.; Burgdorf, S.; Scheurer, S.; Waibler, Z.; Nagai, R.; Wellner, A.; Yamamoto, Y.; Yamamoto, H.; Henle, T.; Kurts, C., et al. Glycation of a food allergen by the Maillard reaction enhances its T-cell immunogenicity: Role of macrophage scavenger receptor class A type I and II. Journal of Allergy and Clinical Immunology 2010, 125, 175-183.e111, doi:10.1016/j.jaci.2009.08.013.

79. Van Der Lugt, T.; Weseler, A.R.; Gebbink, W.A.; Vrolijk, M.F.; Opperhuizen, A.; Bast, A. Dietary advanced glycation endproducts induce an inflammatory response in human macrophages in vitro. Nutrients 2018, 10, doi:10.3390/nu10121868.

80. Roth-Walter, F.; Berin, M.C.; Arnaboldi, P.; Escalante, C.R.; Dahan, S.; Rauch, J.; Jensen-Jarolim, E.; Mayer, L. Pasteurization of milk proteins promotes allergic sensitization by enhancing uptake through Peyer's patches. Allergy: European Journal of Allergy and Clinical Immunology 2008, 63, 882-890, doi:10.1111/j.1398-9995.2008.01673.x.

81. Zenker, H.E.; Ewaz, A.; Deng, Y.; Savelkoul, H.F.J.; Van Neerven, R.J.J.; De Jong, N.; Wichers, H.J.; Hettinga, K.A.; Teodorowicz, M. Differential effects of dry vs. Wet heating of $\beta$-lactoglobulin on formation of sRAGE binding ligands and sIgE epitope recognition. Nutrients 2019, 11, doi:10.3390/nu11061432.

82. Bu, G.; Luo, Y.; Zheng, Z.; Zheng, H. Effect of heat treatment on the antigenicity of bovine $\alpha$-lactalbumin and $\beta$-lactoglobulin in whey protein isolate. Food and Agricultural Immunology 2009, 20, 195-206, doi:10.1080/09540100903026116.

83. Taheri-Kafrani, A.; Gaudin, J.C.; Rabesona, H.; Nioi, C.; Agarwal, D.; Drouet, M.; Chobert, J.M.; Bordbar, A.K.; Haertle, T. Effects of heating and glycation of $\beta$-lactoglobulin on its recognition by ige of sera from cow milk allergy patients. Journal of Agricultural and Food Chemistry 2009, 57, 4974-4982, doi:10.1021/jf804038t.

84. Ott, C.; Jacobs, K.; Haucke, E.; Navarrete Santos, A.; Grune, T.; Simm, A. Role of advanced glycation end products in cellular signaling. Redox Biology 2014, 2, 411-429, doi:10.1016/j.redox.2013.12.016. 
85. Ohgami, N.; Nagai, R.; Ikemoto, M.; Arai, H.; Kuniyasu, A.; Horiuchi, S.; Nakayama, H. CD36, a Member of the Class B Scavenger Receptor Family, as a Receptor for Advanced Glycation End Products. Journal of Biological Chemistry 2001, 276, 3195-3202, doi:10.1074/jbc.M006545200.

86. Ohgami, N.; Nagai, R.; Miyazaki, A.; Ikemoto, M.; Arai, H.; Horiuchi, S.; Nakayama, H. Scavenger Receptor Class B Type I-mediated Reverse Cholesterol Transport Is Inhibited by Advanced Glycation End Products. Journal of Biological Chemistry 2001, 276, 13348-13355, doi:10.1074/jbc.M011613200.

87. Araki, N.; Higashi, T.; Mori, T.; Shibayama, R.; Kawabe, Y.; Kodama, T.; Takahashi, K.; Shichiri, M.; Horiuchi, S. Macrophage Scavenger Receptor Mediates the Endocytic Uptake and Degradation of Advanced Glycation End Products of the Maillard Reaction. European Journal of Biochemistry 1995, 230, 408-415, doi:10.1111/j.1432-1033.1995.0408h.x.

88. Vlassara, H.; Li, Y.M.; Imani, F.; Wojciechowicz, D.; Yang, Z.; Liu, F.T.; Cerami, A. Identification of galectin-3 as a high-affinity binding protein for advanced glycation end products (AGE): a new member of the AGE-receptor complex. Mol Med 1995, 1, 634-646.

89. Kierdorf, K.; Fritz, G. RAGE regulation and signaling in inflammation and beyond. Journal of Leukocyte Biology 2013, 94, 55-68, doi:10.1189/jlb.1012519.

90. Gough, P.J.; Gordon, S. The role of scavenger receptors in the innate immune system. Microbes Infect. 2000, 2, 305-311, doi:10.1016/S1286-4579(00)00297-5.

91. Díaz-Alvarez, L.; Ortega, E. The Many Roles of Galectin-3, a Multifaceted Molecule, in Innate Immune Responses against Pathogens. Mediators Inflamm. 2017, 2017, doi:10.1155/2017/9247574.

92. Henderson, N.C.; Mackinnon, A.C.; Farnworth, S.L.; Poirier, F.; Russo, F.P.; Iredale, J.P.; Haslett, C.; Simpson, K.J.; Sethi, T. Galectin-3 regulates myofibroblast activation and hepatic fibrosis. Proc. Natl. Acad. Sci. U. S. A. 2006, 103, 5060-5065, doi:10.1073/pnas.0511167103.

93. MacKinnon, A.C.; Farnworth, S.L.; Hodkinson, P.S.; Henderson, N.C.; Atkinson, K.M.; Leffler, H.; Nilsson, U.J.; Haslett, C.; Forbes, S.J.; Sethi, T. Regulation of alternative macrophage activation by galectin-3. Journal of Immunology 2008, 180, 2650-2658, doi:10.4049/jimmunol.180.4.2650.

94. MacKinnon, A.C.; Gibbons, M.A.; Farnworth, S.L.; Leffler, H.; Nilsson, U.J.; Delaine, T.; Simpson, A.J.; Forbes, S.J.; Hirani, N.; Gauldie, J., et al. Regulation of transforming growth factor- $\beta 1$-driven lung fibrosis by galectin-3. Am. J. Respir. Crit. Care Med. 2012, 185, 537-546, doi:10.1164/rccm.201106-0965OC.

95. Vray, B.; Camby, I.; Vercruysse, V.; Mijatovic, T.; Bovin, N.V.; Ricciardi-Castagnoli, P.; Kaltner, H.; Salmon, I.; Gabius, H.J.; Kiss, R. Up-regulation of galectin-3 and its ligands by Trypanosoma cruzi infection with modulation of adhesion and migration of murine dendritic cells. Glycobiology 2004, 14, 647657, doi:10.1093/glycob/cwh068.

96. Bourlieu, C.; Ménard, O.; Bouzerzour, K.; Mandalari, G.; Macierzanka, A.; Mackie, A.R.; Dupont, D. Specificity of Infant Digestive Conditions: Some Clues for Developing Relevant In Vitro Models. Critical reviews in food science and nutrition 2014, 54, 1427-1457, doi:10.1080/10408398.2011.640757.

97. Dallas, D.C.; Underwood, M.A.; Zivkovic, A.M.; German, J.B. Digestion of Protein in Premature and Term Infants. J Nutr Disord Ther 2012, 2, 112-112, doi:10.4172/2161-0509.1000112.

98. van Lieshout, G.A.A.; Lambers, T.T.; Bragt, M.C.E.; Hettinga, K.A. How processing may affect milk protein digestion and overall physiological outcomes: A systematic review. Critical reviews in food science and nutrition 2019, 10.1080/10408398.2019.1646703, doi:10.1080/10408398.2019.1646703.

99. Kopf-Bolanz, K.A.; Schwander, F.; Gijs, M.; Vergères, G.; Portmann, R.; Egger, L. Impact of milk processing on the generation of peptides during digestion. International Dairy Journal 2014, 35, 130-138, doi:10.1016/j.idairyj.2013.10.012.

100. Dupont, D.; Mandalari, G.; Mollé, D.; Jardin, J.; Rolet-Répécaud, O.; Duboz, G.; Léonil, J.; Mills, C.E.N.; Mackie, A.R. Food processing increases casein resistance to simulated infant digestion. Molecular Nutrition and Food Research 2010, 54, 1677-1689, doi:10.1002/mnfr.200900582.

101. Zenker, H.E.; Van Lieshout, G.A.A.; Van Gool, M.P.; Bragt, M.C.E.; Hettinga, K.A. Lysine blockage of milk proteins in infant formula impairs overall protein digestibility and peptide release. Food and Function 2020, 11, 358-369, doi:10.1039/c9fo02097g.

102. Dupont, D.; Boutrou, R.; Menard, O.; Jardin, J.; Tanguy, G.; Schuck, P.; Haab, B.B.; Leonil, J. Heat treatment of milk during powder manufacture increases casein resistance to simulated infant digestion. Food Digestion 2010, 1, 28-39, doi:10.1007/s13228-010-0003-0.

103. Sletten, G.B.G.; Holden, L.; Egaas, E.; Faeste, C.K. Differential influence of the degree of processing on immunogenicity following proteolysis of casein and $\beta$-lactoglobulin. Food and Agricultural Immunology 2008, 19, 213-228, doi:10.1080/09540100802350963. 



\section{Chapter 2}

The effect of low vs. high temperature dry heating on solubility and digestibility of cow's milk protein

This chapter has been published as:

Hannah E. Zenker, Jana Raupbach, Sjef Boeren, Harry J. Wichers, Kasper A. Hettinga (2020). The effect of low vs. high temperature dry heating on solubility and digestibility of cow's milk protein. Food Hydrocolloids. (in press) 


\begin{abstract}
:
Dry heating of cow's milk protein in the presence of the milk sugar lactose leads to a loss of solubility and digestibility. Most studies that investigated the loss of solubility in milk protein powders suggested that, besides structural changes, hydrophobic interaction, hydrogen bonds, disulphide bonds, and Maillard reaction-induced crosslinking are responsible for this. However, little is known about the direct contribution of these inter- and intramolecular interactions on loss of solubility and protein digestibility. Low temperature $\left(60^{\circ} \mathrm{C}\right)$ and high temperature $\left(130^{\circ} \mathrm{C}\right)$ dry heating of cow's milk protein in the presence of lactose was applied after which both the soluble and insoluble fractions were analysed with SDS-PAGE and LC-MS/MS. The Maillard reaction was monitored by quantification of $\mathrm{N}^{\varepsilon}$-carboxymethyllysine, $\mathrm{N}^{\varepsilon}$-carboxyethyllysine, and pentosidine with LC-MS/MS. Loss of solubility was analysed with solvent solubility tests. Protein hydrolysis after simulated infant in vitro digestion, and after hydrolysis with single enzymes, was monitored using SDS-PAGE and the o-phthaldialdehyde assay. The results indicated that caseins are the main proteins that become insoluble upon dry heating, independent of the heating temperature. The decreased solubility of low temperature dry-heated cow's milk protein is induced by hydrogen bonds and hydrophobic interactions and did not impair protein hydrolysis. At the same time, covalent protein crosslinking is an important determinant in protein solubility and digestibility of high temperature dry-heated cow's milk protein.
\end{abstract}




\subsection{Introduction}

Cow's milk protein (MP) consists of two main protein fractions: casein and whey protein (WP). These two protein fractions show different susceptibility to heat induced denaturation and aggregation on their structure. Caseins have little secondary and tertiary structure and are organised in a micellar structure that makes them more resistant to heat induced aggregation than the globular WPs [1,2]. Besides protein unfolding and aggregation as a result of hydrophobic interactions and aggregation via disulphide interactions, the Maillard reaction (MR) also occurs in both casein and WPs. Disulphide bond induced protein interaction is a key reaction in protein aggregation of MP in solution. The formation of the K-casein/WP complexes on the surface of the casein micelle is the predominant disulphide bond-induced intermolecular reaction in MP. With respect to the WPs, both $\beta$-lactoglobulin (BLG) and $\alpha$-lactalbumin (ALA) are involved in the aggregation and complexation on the casein micelle surface $[3,4]$. However, the complexation of WPs with the casein micelle is mainly driven by the S-S/thiol disulphide interchange between the free cysteine residue of BLG and к-casein [5]. Next to к-casein, also $\alpha_{\mathrm{s} 2}$-casein contains free cysteine residues, which enables it to form disulphide bonds. Despite that $\alpha_{\mathrm{s} 2}$-casein is mainly found in the interior of the casein structure, small amounts can migrate into the serum and form disulphide bonds with к-casein and WPs [6]. Despite hydrophobic interactions and disulphide bond formation, the MR is one of the most abundant reactions occurring during thermal processing of MP. The MR is the reaction between $\alpha$-amino groups of proteins, peptides, and amino acids and the reactive carbonyl group of a reducing sugar. In MP, the MR most often occurs between lysine and arginine residues of milk proteins and lactose, with the initial formation of the Amadori product that in the advanced stage of the MR reacts further to a pool of different advanced glycation end products (AGEs) [7]. Depending on the reaction conditions (reactants, $\mathrm{pH}$, water activity $\left(\mathrm{a}_{\mathrm{w}}\right)$, temperature, and time), different AGEs are formed, which can be both linear or crosslinked. Examples of linear AGEs are $\mathrm{N}^{\varepsilon}$-carboxymethyllysine $(\mathrm{CML})$ and $\mathrm{N}^{\varepsilon}$-carboxyethyllysine (CEL), while pentosidine is a representative of a crosslinked AGE between lysine and arginine residues [8]. Moreover, low $\mathrm{a}_{\mathrm{w}}$ levels $(<0.9)$ increase the reaction rate which leads to relatively more MR if heated under dry conditions compared to heating in a liquid system [9]. Recent studies showed that both the MR and MR-induced protein crosslinking can lead to loss of solubility of MP concentrates during storage $[10,11]$. However, it was also indicated that protein interactions via hydrophobic forces, hydrogen bonds and disulphide bonds play a role in MP interactions, potentially resulting in a loss of solubility [12-14]. Loss of solubility and structural changes of MP during thermal processing may also affect its digestibility and thereby the nutritional value of the proteins [15]. While heat-induced protein unfolding may facilitate protein hydrolysis, it has been suggested that heat induced MP aggregation and high levels of glycation negatively affect digestibility [16-18]. Dry heating was applied in this study to create a model system that results in similar protein modifications as during the production of "baked milk", which refers to MP powder that was baked into a muffin or waffle and was previously shown to be involved in the 
accelerated resolution of cow's milk allergy symptoms in allergic children [19]. Due to the low $\mathrm{a}_{\mathrm{w}}$, the high temperatures, and the high level of reducing sugars in these systems, it is hypothesised that protein aggregation and glycation via the MR plays an important role in modulating the immunoreactivity. These two factors have also previously been reported to affect both digestibility and immunoreactivity of MP [20-22]. Therefore, MP was heated at low temperature (LT) in the presence of lactose to induce glycation with minimal aggregation as well as at high temperature (HT) to induce glycation and aggregation, to investigate the contribution of different molecular interaction on solubility and aggregation. This was done by using similar parameters as reported in previous studies that investigated the effects of dry heating on immunoreactivity and digestibility [23,24]. Moreover, protein hydrolysis after infant in vitro digestion was monitored to assess the effect of these parameters on protein digestibility. The possible consequences on immunoreactivity were discussed against the background of existing literature.

\subsection{Material and Methods}

\subsubsection{Chemicals}

NuPAGE ${ }^{\circledR}$ LDS sample buffer (4× concentrated), NuPAGETM 12\% Bis-Tris Protein Gel, $1.0 \mathrm{~mm}, \mathrm{NuPAGE}{ }^{\mathrm{TM}}$ 10x MOPS running buffer, NuPAGE ${ }^{\circledR}$ reducing agent, NuPAGE ${ }^{\circledR}$ 4-12\% Bis-Tris gel, NuPAGE® $20 \times$ MES running buffer were obtained from Thermo Fisher Scientific (Waltham, Massachusetts, USA). CML, CEL, d4-CML, and d4-CEL were purchased from Iris Biotech (Marktredwitz, Germany). EMSURE® Anhydrous di-sodium hydrogen phosphate was purchased from Merck Millipore (Burlington, Massachusetts, USA). Glutaraldehyde and osmium tetroxide were purchased from Electron Microscopy Science (Hatfield, England). Sequencing grade trypsin used for protein identification was obtained from Roche (Mannheim, Germany). Corning ${ }^{\circledR}$ BioCoat ${ }^{\mathrm{TM}}$ poly-L-lysine coated plates were purchased from Corning (New York, USA). Coomassie brilliant blue R-250 was obtained from Biorad (Hercules, California, USA). All other chemicals were obtained from Sigma Aldrich (St. Louise, Missouri, USA)

\subsubsection{Preparation of milk powder and heat treatment}

Liquid concentrated raw MP, composed of a mixture of micellar casein fraction (MCI88 liquid) and a WP fraction (acid WPC80 liquid), was received from FrieslandCampina (Wageningen, Netherlands). The protein composition and $\mathrm{pH}$ of the two main milk protein fractions was comparable to skim milk, while lactose had been reduced by membrane filtration processes at FrieslandCampina to $0.6 \%$. Lactose monohydrate was added to the MP to achieve a lactose/protein ratio of 1.5/1.0 (w/w), as it is found in milk. The solution was stirred at room temperature until complete dissolution of the lactose and then lyophilised. The obtained powder was ground and sieved through a $425 \mu \mathrm{m}$ round sieve (Retsch, Haan, Germany). The resulting powder was heated and glycated using two different procedures. To obtain LT heated MP 
(LT-MP), the powder was incubated for 3 weeks at $60{ }^{\circ} \mathrm{C}$, over a saturated potassium fluoride solution to keep the $a_{w}$-level at 0.23 . To produce HT heat MP (HT-MP), the powder was incubated over a saturated potassium acetate solution at $10{ }^{\circ} \mathrm{C}$ until an $\mathrm{a}_{\mathrm{w}}$-level of 0.23 was reached. This powder was then heated for $10 \mathrm{~min}$ at $130{ }^{\circ} \mathrm{C}$ in a screw cap heating tube and immediately transferred to an ice bath to stop the heating. One part of the powder was non-treated (NT-MP) to serve as an unheated control. All samples were kept at $-20{ }^{\circ} \mathrm{C}$ until analyses were done. An overview of the sample preparation and analysis is shown in the supplementary material (Figure 2-S1).

\subsubsection{Dissolving of powdered MP and protein quantification}

All powders were dissolved in simulated milk ultra-filtrate (SMUF). SMUF ( $\mathrm{pH}$ 6.7) was prepared according to the protocol of Jenness \& Koops [25]. Samples were dissolved at a protein/SMUF ratio of $1 / 12(\mathrm{w} / \mathrm{v})$ and left shaking for $1 \mathrm{~h}$ at room temperature. Subsequently, samples were centrifuged using an Eppendorf centrifuge 5430R (Eppendorf, Hamburg, Germany) for $15 \mathrm{~min}, 14000 \times \mathrm{g}, 20^{\circ} \mathrm{C}$ and supernatants were filtered through a $0.45 \mu \mathrm{m}$ cellulose acetate syringe filter (Phenomenex, Torrance, California, USA). The remaining pellet was washed 5 times with SMUF buffer. All compounds which were not dissolved after this procedure were considered as insoluble material. The insoluble material was lyophilised and grinded, while the soluble fraction was analysed for its protein content by DUMAS Flash EA 1112 Protein analyser (Thermo Fisher Scientific, Waltham, Massachusetts, USA) in technical duplicates. The procedure was repeated twice on different days.

\subsubsection{Acidic hydrolysis}

To release (modified) amino acids from their protein structure, acid hydrolysis was performed according to Kehm et al. [26]. Milk powder samples and the SMUF soluble protein fractions in an amount which equals $1 \mathrm{mg}$ of protein were mixed with $100 \mu \mathrm{L}$ ultrapure water and were directly incubated with $250 \mu \mathrm{L}$ borate buffer $(0.4 \mathrm{~N}, \mathrm{pH} 10.2)$ and $250 \mu \mathrm{L}$ sodium borohydride ( $1 \mathrm{M}$ in $0.1 \mathrm{M}$ sodium hydroxide) for $2 \mathrm{~h}$ at room temperature. The incubation was performed to reduce early glycation products such as fructosyllysine to avoid neo-formation of CML during heating in hydrochloric acid. Protein precipitation was achieved by adding $1 \mathrm{~mL}$ of trichloroacetic acid $(20 \%, \mathrm{w} / \mathrm{v})$ and centrifugation $\left(4{ }^{\circ} \mathrm{C}, 10000 \times \mathrm{g}, 10 \mathrm{~min}\right)$. The supernatant was discarded, and the precipitate was washed with trichloroacetic acid $(5 \%, \mathrm{w} / \mathrm{v})$ and centrifugation was repeated. After removal of the supernatant, $1 \mathrm{~mL}$ of hydrochloric acid $(6 \mathrm{M})$ and $10 \mu \mathrm{L}$ internal standard mix containing $30 \mu \mathrm{M}$ d4-CML and d4-CEL was added to the protein pellet after which the sample was heated at $110{ }^{\circ} \mathrm{C}$ for $23 \mathrm{~h}$. The hydrolysed samples were evaporated to dryness with a vacuum concentrator (SpeedVac, Thermo Fisher Scientific, Waltham, Massachusetts, USA). The residue was dissolved in $100 \mu \mathrm{L}$ ultrapure water and after centrifugation $\left(4{ }^{\circ} \mathrm{C}, 10000 \times \mathrm{g}, 10 \mathrm{~min}\right)$ an aliquot was used for MRM analysis of glycation end products by LC-MS/MS. 


\subsubsection{Analysis of advanced glycation end (AGE) products}

AGE analysis was performed in acid hydrolysed samples. External calibration with the respective deuterated internal standards for CML and CEL was used for quantification, whereas d4-CML was used as an internal standard for pentosidine. UPLC analysis was performed with an Acquity Ultra Performance LC system coupled to a Waters Quattro Premier XE mass spectrometer (both Waters Corporation, Milford, Massachusetts, USA). For chromatographic separation, a Waters Cortecs C18 column $(2.1 \times 50 \mathrm{~mm}, 1.6 \mu \mathrm{m})$ at a column temperature of $30{ }^{\circ} \mathrm{C}$ was used. Solvent A was $10 \mathrm{mM}$ nonafluoropentanoic acid in LC-MS grade water and solvent $\mathrm{B}$ was $10 \mathrm{mM}$ nonafluoropentanoic acid in acetonitrile (ACN). The solvents were pumped at a flow rate of $0.4 \mathrm{~mL} / \mathrm{min}$ in gradient mode $(0 \mathrm{~min}, 1 \% \mathrm{~B} ; 1 \mathrm{~min}, 1 \% \mathrm{~B} ; 6 \mathrm{~min}$, $50 \% \mathrm{~B} ; 6.1 \mathrm{~min}, 1 \% \mathrm{~B} ; 8 \mathrm{~min}, 1 \% \mathrm{~B})$. The injection volume was $10 \mu \mathrm{L}$. The ESI source was operated in positive mode and nitrogen was utilized as the nebulizing gas with a gas flow of $650 \mathrm{~L} / \mathrm{h}$ and a gas temperature of $450^{\circ} \mathrm{C}$. The capillary voltage was set to $2.6 \mathrm{kV}$ and the source temperature was $150^{\circ} \mathrm{C}$. Analytes were measured in MRM mode with the following transitions and optimized collision energy (CE) as well as cone voltage (CV). CML: 204.9 $\rightarrow 84.2$ (q, CV: 24, CE: 18 V), 204.9 $\rightarrow 130.2$ (Q, CV: 24, CE: 12 V), d4-CML: 209.2 $\rightarrow 88.1$ (q, CE: $20 \mathrm{~V}), 209.2 \rightarrow 134.1$ (Q, CE: $12 \mathrm{~V}$ ); CEL: 219.1 $\rightarrow 84.1$ (q, CV: 24, CE: $18 \mathrm{~V}$ ), $219.1 \rightarrow 130.1(\mathrm{Q}, \mathrm{CV}: 24, \mathrm{CE}: 12 \mathrm{~V})$, d4-CEL: $223.2 \rightarrow 88.1$ (q, CE: $20 \mathrm{~V}), 223.2 \rightarrow 134.1$ (Q, CE: 12 V). pentosidine: $379.2 \rightarrow 187.2$ (q, CV: 42, CE: 36 V), 379.2 $\rightarrow 135.1$ (Q, CV: 42, $\mathrm{CE}: 44 \mathrm{~V})$. Transitions used for quantification are labelled with $\mathrm{q}$ and transitions used for the confirmation of the presence of the analyte are labelled with Q. Data were acquired and evaluated with the MassLynx Software (Waters, version 4.1).

\subsubsection{Solvent dependent solubility test}

The insoluble material from LT-MP and HT-MP was added to 4 different solvents, to determine the amount of material that could be solubilised under different conditions. Solvent 1 (S1) was composed of $10 \mathrm{mM}$ phosphate buffer saline (PBS) at pH 7.4, solvent 2 (S2) was composed of $10 \mathrm{mM}$ PBS and 1\% sodium dodecyl sulphate (SDS), solvent 3 (S3) was composed of $10 \mathrm{mM}$ PBS, $1 \%$ SDS, and $6 \mathrm{M}$ urea, while solvent 4 (S4) was composed of $10 \mathrm{mM}$ PBS, $1 \%$ SDS, and $6 \mathrm{M}$ urea, and $1 \%$ dithiothreitol (DTT). Ten milligrams of lyophilised insoluble material were accurately weighed in separate Eppendorf tubes using a micro balance XA105 (Mettler Toledo, Columbus, Ohio, USA) and $300 \mu \mathrm{L}$ of S1, S2, S3, and S4 were added, respectively. Samples were vortexed thoroughly and left at $70{ }^{\circ} \mathrm{C}$ for $10 \mathrm{~min}$. To discriminate the effect of heating, which was used for all four solvents, $10 \mathrm{mM}$ PBS ( $\mathrm{pH}$ 7.4) without heating was used as a control. All solutions were centrifuged using an Eppendorf centrifuge 5430R (Eppendorf, Hamburg, Germany) and supernatants were collected. The procedure was repeated once, and the supernatants were combined. Protein content of the supernatants was quantified using Pierce bicinchoninic acid (BCA) protein assay kit (Thermo Fisher Scientific, Waltham, Massachusetts, USA) after precipitation of the protein with $20 \%$ trichloroacetic acid and solubilisation of the 
pellet with $0.1 \mathrm{M}$ sodium hydroxide. The procedure was repeated twice on the pellets obtained from the procedure described under 2.2.3.

\subsubsection{Sodium dodecyl sulphate gel electrophoresis (SDS-PAGE) of undigested samples}

To monitor the protein composition, formation of aggregates, and protein glycation, SDS-PAGE was conducted under both reducing and non-reducing conditions. Analyses were conducted on both the soluble and insoluble fraction of the unheated control, and heated samples. Samples were diluted with $5 \mu \mathrm{L}$ NuPAGE® LDS sample buffer $(4 \times$ concentrated), and ultrapure water. After centrifugation $\left(1 \mathrm{~min}, 500 \times \mathrm{g}, 20^{\circ} \mathrm{C}\right)$, the solutions were heated for $10 \mathrm{~min}$ at $70{ }^{\circ} \mathrm{C}$ and centrifuged again $\left(1 \mathrm{~min}, 500 \times \mathrm{g}, 20^{\circ} \mathrm{C}\right)$. From each sample, $12.5 \mu \mathrm{g}$ protein were loaded on a NuPAGETM $12 \%$ Bis-Tris Protein Gel, $1.0 \mathrm{~mm}$, and run at $120 \mathrm{~V}$ (constant) with NuPAGETM $1 x$ MOPS SDS running buffer. Gels were stained with Coomassie brilliant blue R-250 and unstained in 7.5\% acetic acid, 10\% ethanol. Images of each gel were obtained using a Universal Hood III (Biorad, Hercules, California, USA) and Image Lab 4.1 software (Biorad, Hercules, California, USA).

\subsubsection{Protein identification}

To identify specific bands on the SDS-PAGE of LT-MP, in-gel based proteomics was applied. Briefly, gels were prepared as described previously and stained with Coomassie blue R-250. After destaining, gels were reduced in $50 \mathrm{mM}$ ammonium bicarbonate solution and $100 \mathrm{mM}$ DTT for $1 \mathrm{~h}$ at $60{ }^{\circ} \mathrm{C}$. Subsequently, gels were alkylated in the dark for $30 \mathrm{~min}$ at $60{ }^{\circ} \mathrm{C}$ using $50 \mathrm{mM}$ ammonium bicarbonate, $1 \mathrm{M}$ Tris $(\mathrm{pH} 8)$, and acrylamide (9/1/0.014) (v/v/w). Bands were cut from the gel and digested with $5 \mathrm{ng} / \mu \mathrm{L}$ trypsin in $50 \mathrm{mM}$ ammonium bicarbonate solution at room temperature for $14 \mathrm{~h}$. All samples were adjusted to $\mathrm{pH} 2-4$ with $10 \%$ trifluoroacetic acid and diluted with $150 \mu \mathrm{L} 25 \mathrm{mM}$ formic acid. Samples were desalted using in-house made stage tip C18 $\mu$ columns and eluted with $50 \mu \mathrm{L}$ ACN/25 mM formic acid (1/1) $(\mathrm{v} / \mathrm{v})$. ACN was removed using an Eppendorf concentrator plus (Eppendorf, Hamburg, Germany) and sample volumes were adjusted to $50 \mu \mathrm{L}$ final volume with $25 \mathrm{mM}$ formic acid.

Peptides were analysed on a Thermo nLC 1000 system (Thermo Fisher Scientific, Waltham, Massachusetts, USA) coupled to a LTQ orbitrap XL (Thermo Fisher Scientific, Waltham, Massachusetts, USA). Chromatographic separation was conducted over a $0.10 * 250 \mathrm{~mm}$ ReproSil-Pur $120 \mathrm{C} 18$-AQ $1.9 \mu \mathrm{m}$ beads analytical column with pre-concentration column prepared in house. Flow rate was set to $0.5 \mu \mathrm{L} / \mathrm{min}$ and ran with an $\mathrm{ACN}$ in water gradient spiked with $0.1 \%$ formic acid. ACN increased from $9 \%$ to $34 \%$ ACN within 50 min. Full scan positive mode spectra were measured between $\mathrm{m} / \mathrm{z} 380$ and 1400 in the Orbitrap at high resolution (60000). Collision-induced dissociation fragmented (isolation width $2 \mathrm{~m} / \mathrm{z}, 30 \%$ normalised collision energy, activation Q 0.25 and activation time $15 \mathrm{~ms}$ ) MSMS scans of the four most abundant $2+$ and $3+$ charged peaks in the full scan positive mode spectra were recorded in data dependent mode in the linear trap (MSMS threshold $=5.000,45 \mathrm{~s}$ exclusion 
duration for the selected $\mathrm{m} / \mathrm{z}+/-25 \mathrm{ppm})$. LC-MS/MS runs were processed with MaxQuant 1.6.1.0 with the Andromeda search engine [27]. using the "Specific Trypsin/P" digestion mode. Propionamide formation on cysteines was set as a fixed modification while variable modifications were set for acetylation of the N-terminus, deamidation of asparagine and glutamine, and oxidation of methionine.

To identify the proteins and peptides, a bovine database from Uniprot (downloaded in March 2016 from https:/www.uniprot.org) was used together with a database for common contaminants. Trypsin/P was used as the specific digestion mode. The false discovery rate was set to $1 \%$ on both protein and peptide level. Reversed hits and proteins only identified by site were deleted from the protein group's results table. Non-bovine derived contaminants, e.g. human keratins, were manually removed. Filtered MaxQuant data were analysed with Perseus 1.5.5.3 using the normalised label free quantification (LFQ) intensities. Proteins with a minimum number of 2 distinct peptides and at least one unique peptide were displayed. Additionally, LFQ intensities of each protein were converted to a percentage of the total LFQ intensity of the sample, to identify the most abundant proteins. Only proteins with a relative LFQ intensity higher than $2.0 \%$ were shown.

\subsubsection{Infant in vitro digestion}

MP powders heated at LT and HT, as well as an unheated control (NT-MP), were applied to simulated infant in vitro digestion according to the method by Ménard et al. [28]. The protein concentration was adjusted to $1.2 \%(\mathrm{w} / \mathrm{v})$ with ultra-pure water. The meals were preheated for 10 min at $37^{\circ} \mathrm{C}$ and applied to simulated gastric and intestinal digestion. Briefly, in the gastric phase (GP), $\mathrm{pH}$ was adjusted to 5.3 while the pepsin activity was set to $268 \mathrm{U} / \mathrm{mL}$ digest. The meals were incubated for $60 \mathrm{~min}$ at $37{ }^{\circ} \mathrm{C}$ under continuous shaking $(25 \mathrm{rpm})$ in an incubator (Venti-Line, VWR, Radnor, Pennsylvania, USA). In the intestinal phase (IP) the $\mathrm{pH}$ was adjusted to 6.6 and trypsin activity in the final digest was adjusted to $16 \mathrm{U} / \mathrm{mL}$. The meals were incubated for 60 min under the same conditions as in the GP. Samples were taken after $60 \mathrm{~min}$ in the GP, $10 \mathrm{~min}$ in the IP, and $60 \mathrm{~min}$ in the IP. In addition to the simulation of infant in vitro gastrointestinal digestion, hydrolysis with different combinations of the single enzymes trypsin, chymotrypsin, and pepsin were conducted in the same manner as for the simulated infant in vitro digestion, with slight modifications. For tryptic digestion, pepsin stock solution was replaced by gastric fluid and trypsin TPCK treated (T1426) was added instead of pancreatin, keeping the same enzyme activity in the final digest. For chymotryptic digestion, digestion was conducted as for tryptic digestion but trypsin TPCK was replaced by chymotrypsin TLCK treated $(\mathrm{C} 3142)$ to the same enzyme activity as was reached in the digest by the addition of pancreatin. Chymotrypsin activity in pancreatin was measured according to the protocol of Brodkorb et al. [29]. A combination of pepsin in the GP and trypsin in the IP was used with the same enzyme activities as described before. A combination of chymotrypsin and trypsin without pepsin was used with the same enzyme activities for each enzyme as used for the 
respective single enzyme digestion. Enzyme activity was stopped after the GP by increasing the $\mathrm{pH}$ to 6.6 and after the IP by the addition of $0.5 \mathrm{mM}$ Pefabloc to the digest in the ratio Pefabloc/digest of $1 / 20(\mathrm{v} / \mathrm{v})$. Each digestion experiment was performed in duplicate. For determining the level of nitrogen transfer, an aliquot was taken directly after digestion, centrifuged and the supernatant was collected. For the o-phthaldialdehyde assay (OPA-assay), $0.5 \mathrm{~mL}$ digest was added to $0.4 \mathrm{~mL}$ cooled $10 \%$ trichloroacetic acid $(\mathrm{w} / \mathrm{v})$, vortexed and centrifuged. For the OPA-assay and nitrogen transfer, enzyme activity of the aliquots was not additionally stopped with Pefabloc to avoid interference of the enzyme blocker. An enzyme control was taken containing all substrates of the IP, but sample was replaced by an equal amount of water.

\subsubsection{Determination of degree of hydrolysis}

To monitor the degree of protein hydrolysis (DH) after digestion, the OPA-assay was conducted according to the method of Mulet-Cabero et al. [30]. Briefly, supernatants of trichloroacetic acid precipitated undigested meals as well as meals after $60 \mathrm{~min}$ in the GP, 10 $\mathrm{min}$ in the IP, and $60 \mathrm{~min}$ in the IP were diluted in $10 \mathrm{mM}$ PBS (pH 7.4) and mixed with OPA reagent in a ratio of $1 / 20(\mathrm{v} / \mathrm{v})$ to a final volume of $200 \mu \mathrm{L}$. The mixture was incubated in a transparent 96-well polystyrene plate (Greiner, Kremsmuenster, Austria) for $15 \mathrm{~min}$ in the dark. Absorbance was measured at $340 \mathrm{~nm}$ using Infinite ${ }^{\circledR} 200$ PRO NanoQuant with i-control software (Tecan, Meannedorf, Switzerland). DH was calculated according to the following formula:

$$
\mathrm{DH}[\%]=\left(\left[\mathrm{NH}_{2}(\text { final })-\mathrm{NH}_{2}(\text { initial })\right] /\left[\mathrm{NH}_{2}(\text { acid })-\mathrm{NH}_{2}(\text { initial })\right]\right) \times 100
$$

where $\mathrm{NH}_{2}$ (final) is the concentration of free amino groups in the digested sample, $\mathrm{NH}_{2}$ (initial) is the concentration of free amino groups in the undigested sample (at time 0 of digestion), and $\mathrm{NH}_{2}$ (acid) is the total content of free amino groups in the sample after acid hydrolysis. Different concentrations of D-Leucine were used to obtain a calibration curve in the concentration range between 0.4 and $4 \mathrm{mM}$. Each sample of the in duplicate conducted digestion experiment was measured in technical triplicates with the OPA-assay.

\subsubsection{SDS-PAGE of digested samples}

Gel electrophoresis was conducted to monitor the remaining intact protein at each sampling point of digestion. Prior to analysis, meals were centrifuged to remove insoluble material. The supernatant was mixed with sample NuPAGE® LDS sample buffer $(4 \times$ concentrated $)$ and NuPAGE® reducing agent. After heating for $10 \mathrm{~min}$ at $70{ }^{\circ} \mathrm{C}, 12.5 \mu \mathrm{g}$ protein (based on nitrogen content measured with DUMAS) were loaded on a NuPAGE® 4-12\% Bis-Tris gel. Gels were run at $140 \mathrm{~V}$ with NuPAGE® $2 \times$ MES running buffer. Gels were stained and images were developed as described before. 


\subsubsection{Quantification of nitrogen transfer after in vitro digestion}

Nitrogen transfer, as a measure for the total soluble protein, after $60 \mathrm{~min}$ in the GP, $10 \mathrm{~min}$ in the IP, and $60 \mathrm{~min}$ in the IP was quantified using DUMAS Flash EA 1112 Protein analyser (Thermo Fisher Scientific, Massachusetts, USA). Meals were centrifuged (10 $000 \times \mathrm{g}, 10 \mathrm{~min}$, $4{ }^{\circ} \mathrm{C}$ ) and $300 \mu \mathrm{L}$ was dried at $60{ }^{\circ} \mathrm{C}$ before analysis. L-methionine was used as a standard and cellulose was used as a blank. The conversion factor was 6.38 , as generally used for milk protein. Nitrogen transfer was calculated by the following formula and corrected for the enzyme control:

$$
\mathrm{N}_{\text {transfer }}[\%]=\mathrm{N}_{\text {measured }}[\mathrm{mg} / \mathrm{mL}] / \mathrm{N}_{\text {theoretical }}[\mathrm{mg} / \mathrm{mL}] * 100
$$

Where $\mathrm{N}_{\text {measured }}$ is the nitrogen concentration in the soluble fraction as obtained by DUMAS and $\mathrm{N}_{\text {theoretical }}$ is the maximum possible concentration of nitrogen that can go into solution. Each sample of the in duplicate conducted digestions was measured in technical duplicates with DUMAS.

\subsubsection{Scanning electron microscopy (SEM) images}

SEM images of representative samples for each time point of digestion and each treatment were taken on the Magellan 400 XHR SEM (FEI, Lausanne, Switzerland). Samples were centrifuged (30 seconds, $13720 \times \mathrm{g}, 20{ }^{\circ} \mathrm{C}$ ) and diluted to a protein concentration between 0.1 and $0.25 \mathrm{mg} / \mathrm{mL}$. Samples were fixed for $1 \mathrm{~h}$ on a poly lysine plate using $2.5 \%$ glutaraldehyde. A second fixation was done for $1 \mathrm{~h}$ using $1 \%$ osmium tetroxide followed by a stepwise dehydration with ethanol $(10 \%, 30 \%, 50 \%, 70 \%, 80 \%, 90 \%, 100 \%)$. Finally, the samples were dried using critical point drying. Between steps samples were washed with $0.1 \mathrm{M}$ phosphate/citrate buffer ( $\mathrm{pH} 7.2)$.

\subsubsection{Statistical analyses}

Statistical analyses were conducted with IBM SPSS version 25 using one-way ANOVA, with the Tukey post hoc test. Differences were considered as statistically significant at $\mathrm{p}<0.05$.

\subsection{Results}

\subsubsection{Recovery of SMUF soluble protein}

Dry heating of the MP mixture used in this study caused the formation of SMUF insoluble material (Figure 2.1a). The remaining soluble protein was quantified using DUMAS (Figure 2.1b). 
a

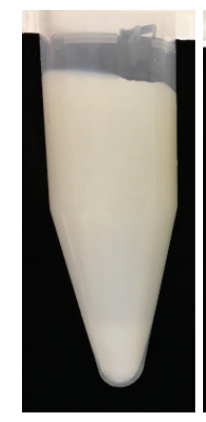

NT

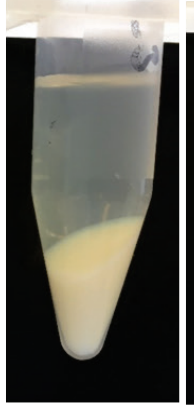

LT

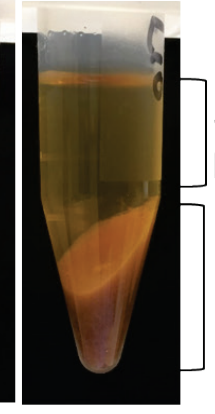

HT

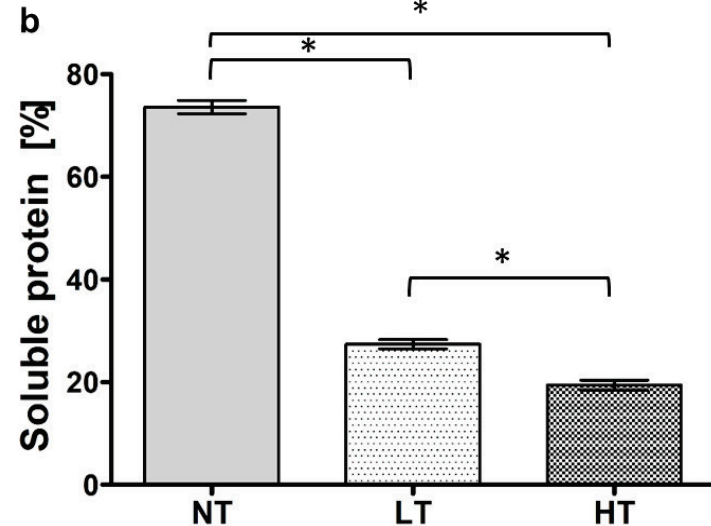

Figure 2.1: (a) Images of cow's milk protein powders dissolved in simulated milk ultrafiltrate (SMUF), when non-treated (NT), heated at low temperature (LT), and heated at high temperature (HT). (b) Percentage of MP soluble in SMUF. Error bars represent standard deviation of technical duplicates. Statistical differences were analysed using one-way ANOVA and Tukey post hoc test, with $* \mathrm{p}<0.05$.

The soluble fraction of LT-MP turned translucent, while the soluble fraction of HT-MP turned dark brown. Protein solubility decreased by $67 \%$ in LT heated MP compared to NT-MP reaching only $27.4 \pm 0.9 \%$ soluble protein recovery. In HT-MP, the protein solubility was 8.0 percent-point lower compared to LT-MP, resulting in $19.4 \pm 1.0 \%$ soluble protein recovery.

\subsubsection{Quantification of AGEs}

AGEs were quantified in both the MP powder and the SMUF soluble fraction. For CML and CEL absolute concentrations were obtained whereas for pentosidine relative concentrations based were obtained based on $\mathrm{d} 4-\mathrm{CML}$ as internal standard. The recovery of each AGE in the SMUF soluble fraction was calculated based on the total amount in the powder (Figure 2.2).

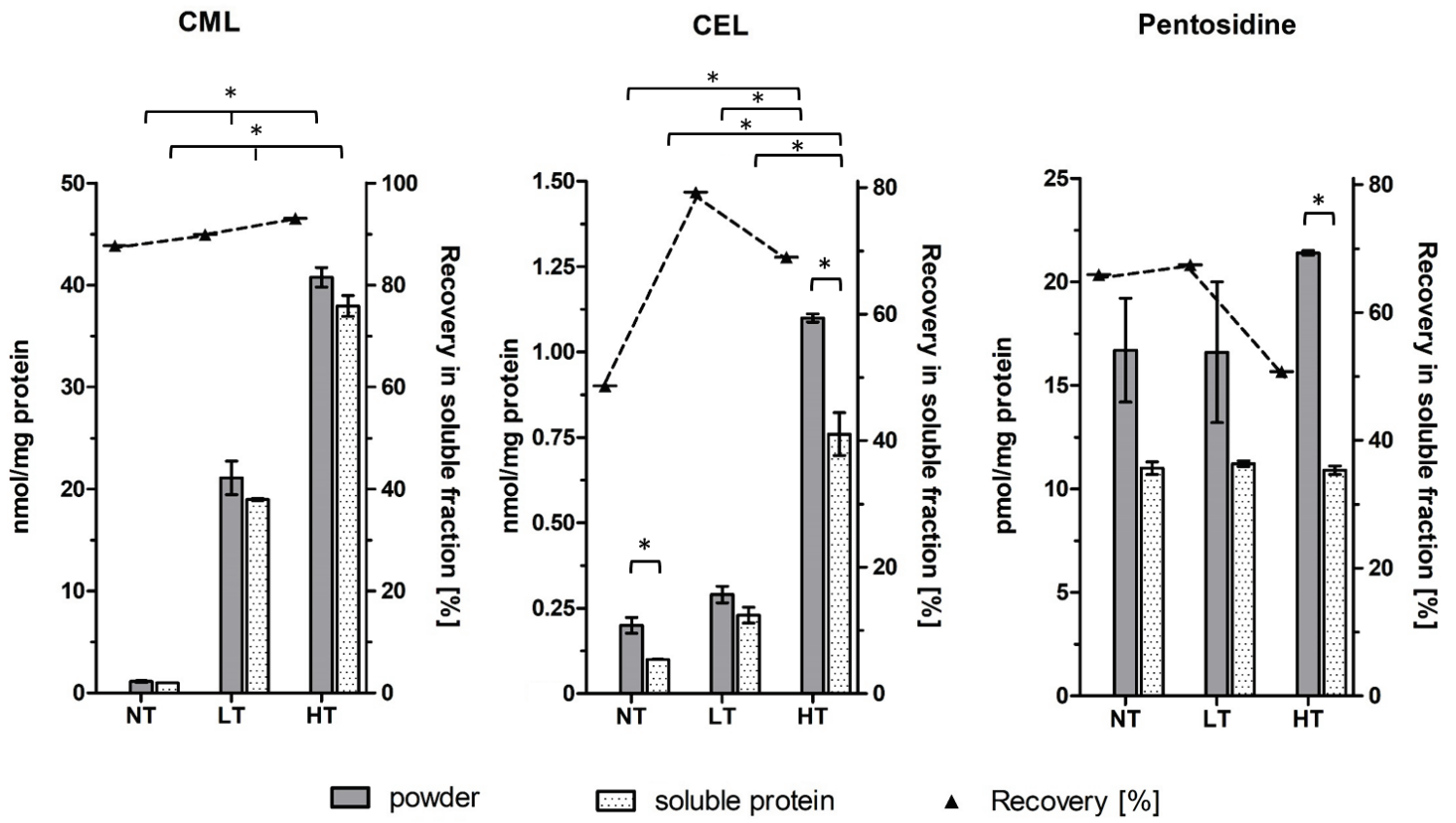

Figure 2.2: $\mathrm{N}^{\varepsilon}$-Carboxymethyllysine (CML), $\mathrm{N}^{\varepsilon}$-carboxyethyllysine (CEL), and pentosidine quantities in cow's milk protein powder in non-treated (NT) sample, after glycation with lactose at low temperature (LT), high temperature (HT) with - $\mathbf{\Delta}$ - showing the recovery in SMUF soluble protein fraction. Error bars represent standard deviations of measurements of duplicate acidic hydrolysis. Statistical differences were analysed using one-way ANOVA and Tukey post hoc test, with *p $<0.05$. 
The levels of CML and CEL increased with increasing heating temperature. Levels of pentosidine were $\sim 28 \%$ higher in the HT heated MP powder compared to the other samples without significant difference between NT-MP and LT-MP. Levels of CML in the powder ranged between $1.13 \pm 0.01$ and $40.8 \pm 0.96 \mathrm{nmol} / \mathrm{mg}$ protein, while CEL levels ranged from $0.20 \pm 0.02$ to $1.10 \pm 0.01 \mathrm{nmol} / \mathrm{mg}$ protein. Pentosidine levels were observed between $16.6 \pm 3.40$ and $21.4 \pm 0.01 \mathrm{pmol} / \mathrm{mg}$ protein in the powder and soluble fraction, respectively. For HT-MP, but not LT-MP, significantly lower levels of CEL and pentosidine were recovered in the soluble fraction. Interestingly, especially the recovery of pentosidine shows a drop in HT-MP (51\%) compared to NT-MP and LT-MP, where it showed a similar recovery of $66 \%$ and $67 \%$, respectively. This was not observed for CML, which showed comparable levels between the powder and the soluble fraction in all samples.

\subsubsection{Protein composition of SMUF soluble and insoluble fraction}

The protein composition of soluble and insoluble material was analysed using SDS-PAGE (Figure 2.3). To analyse the insoluble fraction, the pellet was dissolved in S3 $(10 \mathrm{mM}$ PBS $+1 \% \mathrm{SDS}+6 \mathrm{M}$ urea). S3 was chosen to also identify the proteins that are part of the aggregates visible in the top of the gel (see also paragraph 2.3.4).

a

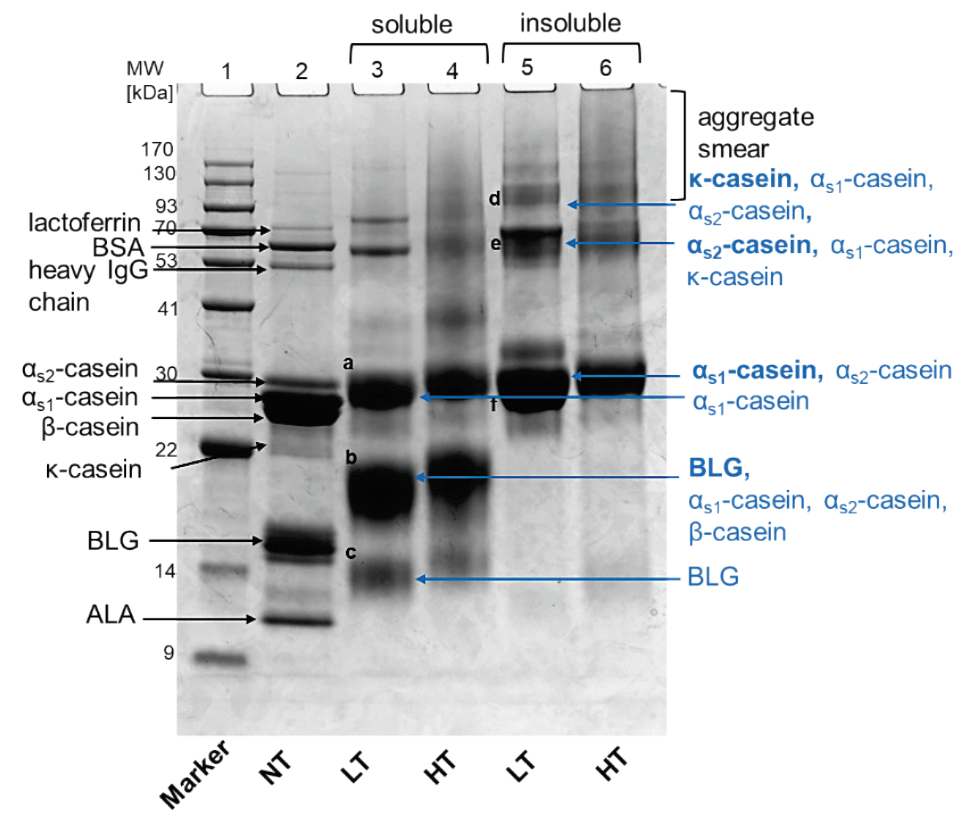

b

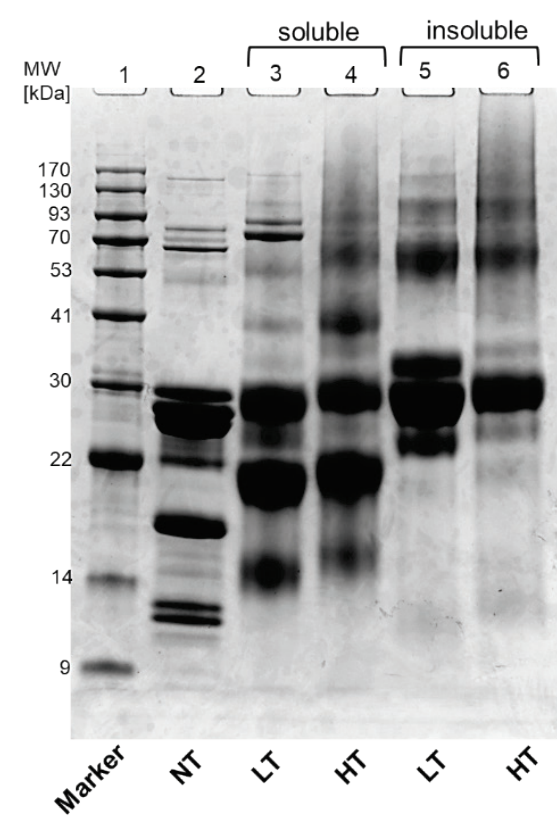

Figure 2.3: (a) SDS-PAGE image of heated and glycated cow's milk protein (MP) under non-reducing conditions. Bands are indicated as $\alpha$-lactalbumin (ALA), $\beta$-lactoglobulin (BLG), bovine serum albumin (BSA), and immunoglobulin G (IgG). (b) SDS-PAGE image of heated and glycated MP under reducing conditions. Lane 2-4: SMUF soluble fraction of MP not-treated (NT), glycated at low temperature (LT), and glycated at high temperature (HT). Lane 5 and 6: SMUF insoluble fraction of HT heated MP and LT heated MP, dissolved in solvent 3 (10 mM PBS $+1 \%$ SDS $+6 \mathrm{M}$ Urea). Letters indicate the bands that have been analysed using LC-MS/MS. Identified proteins in blue with bold words indicating the main component of the band based on the LFQ intensity. Identification of bands in NT-MP was done in comparison with Uniprot database (https://www.uniprot.org) as well as literature [31,32] and represents the true mobility of the native proteins.

NT-MP (lane 2) showed four dominant bands on the SDS-PAGE image under non-reducing conditions corresponding to five of the major milk proteins ALA (10 kDa), BLG (15 kDa), 
$\alpha_{\mathrm{s} 1}$-casein and $\beta$-casein $(26 \mathrm{kDa})$, and $\alpha_{\mathrm{s} 2}$-casein $(29 \mathrm{kDa})$. A faint band at $22 \mathrm{kDa}$ indicated the presence of $\kappa$-casein. The three bands on top correspond to other serum proteins, heavy IgG chain, bovine serum albumin (BSA), and lactoferrin, all of lower abundance. Once heating was applied, two intense bands at $20 \mathrm{kDa}$ and $30 \mathrm{kDa}$ (indicated in lane 3 as a and b) and a faint band at $15 \mathrm{kDa}$ (indicated as c) were visible in the soluble fraction of both LT-MP and HT-MP. Moreover, HT-MP showed a slightly larger shift to a higher molecular weight (MW) than LT-MP and a smear at higher MW ( $>53 \mathrm{kDa}$ ). In the insoluble fraction (lane 5 and lane 6 ), one dominant band was observed at $\sim 30 \mathrm{kDa}$ (indicated as f). Additionally, both samples showed two more bands at $33 \mathrm{kDa}$ and $60 \mathrm{kDa}$ which were more intense in LT-MP than in HT-MP. Moreover, two additional bands at $34 \mathrm{kDa}$ and $68 \mathrm{kDa}$ (indicated as e) were observed as well as a smear at $>53 \mathrm{kDa}$, indicating the presence of aggregates. Under reducing conditions, the soluble fraction of all samples showed the same dominant bands as under non-reducing conditions. In the insoluble fraction of LT-MP, the band at $33 \mathrm{kDa}$ became more intense and an additional band at $25 \mathrm{kDa}$ corresponding to $\kappa$-casein appeared, while the aggregate smear became less intense. This effect was also observed in the insoluble fraction of HT-MP but to a much lesser extent.

Bands indicated with a letter in Figure 2.3 have been analysed using LC-MS/MS to determine which proteins are present in which band. Broad bands were cut into smaller pieces to have multiple segments representing different MW for better identification. The pieces were labelled according to their MW. Results are shown in Figure 2.4.

a

b

$k D a$

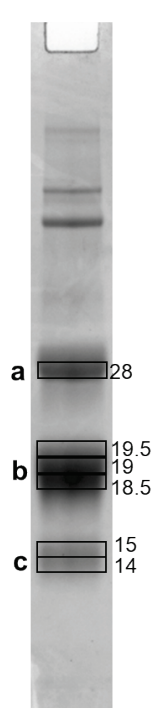

$14 \mathrm{kDa}$

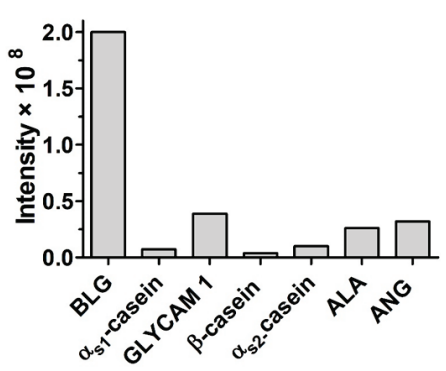

$19 \mathrm{kDa}$

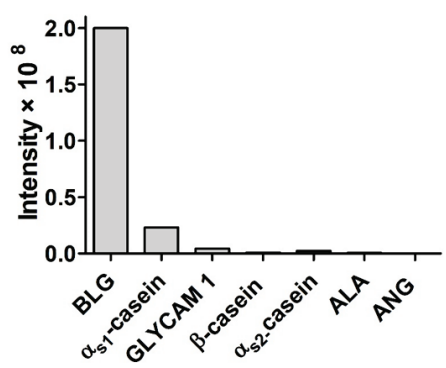

$15 \mathrm{kDa}$

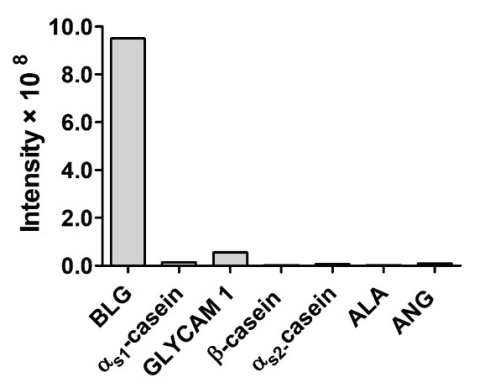

$19.5 \mathrm{kDa}$

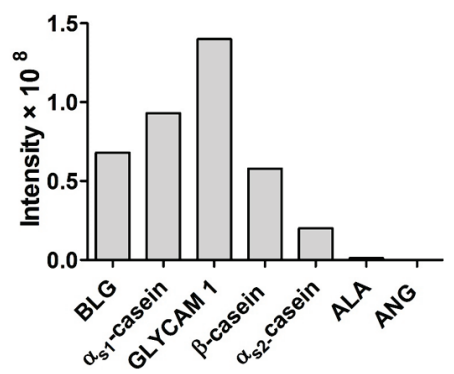

$18.5 \mathrm{kDa}$

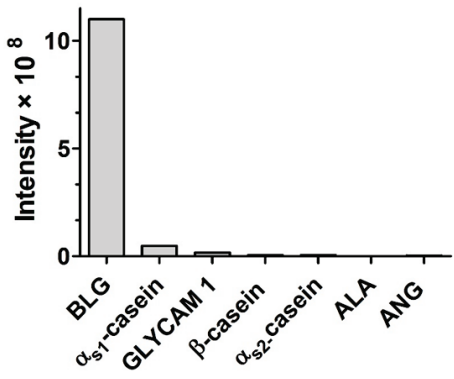

$28 \mathrm{kDa}$

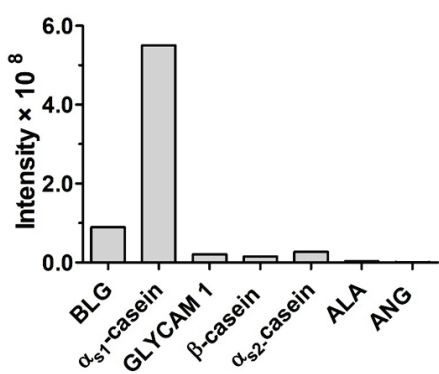


c
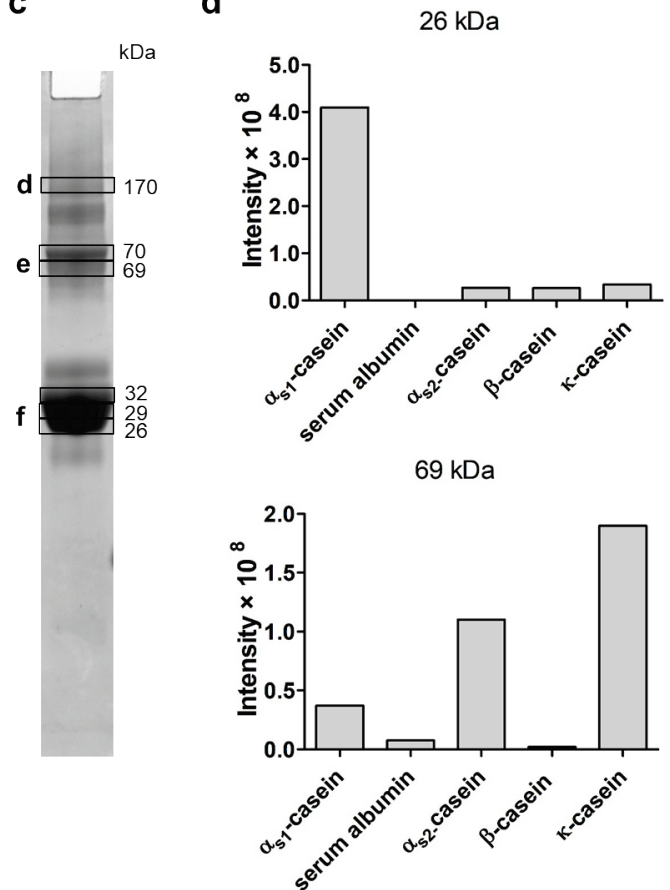

$29 \mathrm{kDa}$
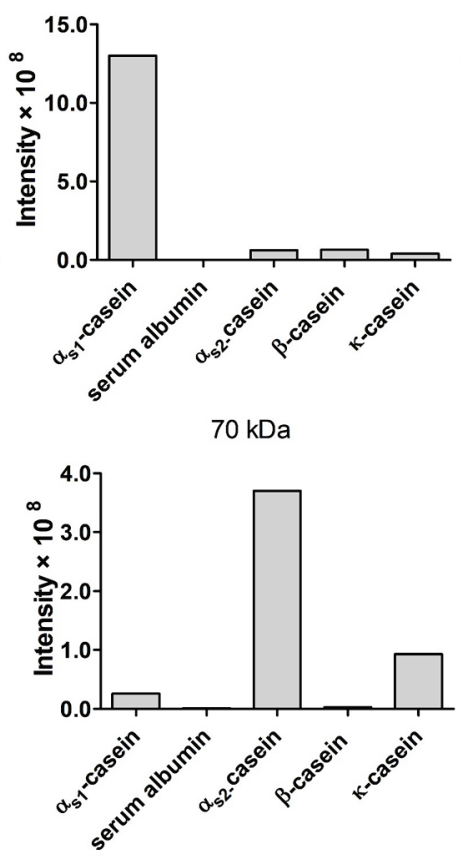

$32 \mathrm{kDa}$
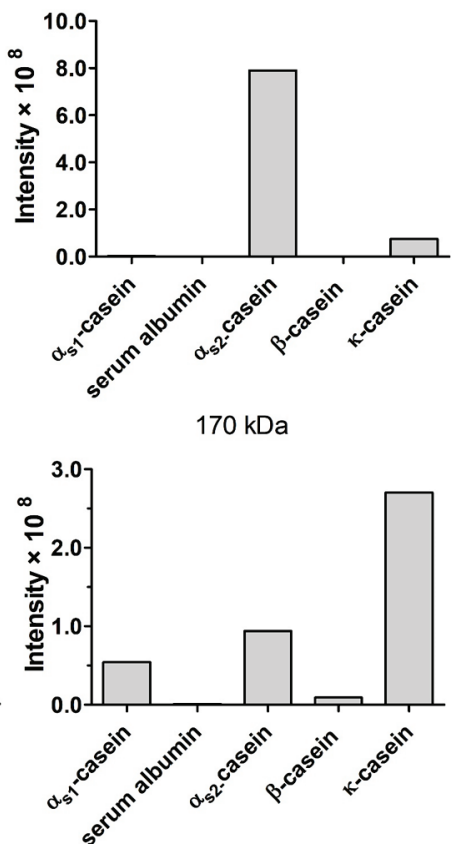

Figure 2.4: (a) SDS-PAGE image of the SMUF soluble fraction of low temperature (LT) glycated cow's milk protein (MP) Letters indicate the bands that have been cut for protein identification. Squares indicate the cutting pattern. (b) LFQ intensities of the proteins identified in each band from the SMUF soluble fraction of LT-MP. (c) SDS-PAGE image of SMUF insoluble fraction of LT-MP dissolved in solvent 3. (d) LFQ intensities of the proteins identified in each band from the SMUF insoluble fraction of LT-MP dissolved in solvent 3. All proteins that showed $<2.0 \%$ LFQ intensity in all samples were not displayed. Proteins are indicated as $\alpha$-lactalbumin (ALA), $\beta$-lactoglobulin (BLG), 1 Glycosylation-dependent cell adhesion molecule 1 (GLYCAM), Angiogenin ribonuclease (ANG).

In the soluble fraction, BLG was the most abundant protein. Figure 2.4a, band a, showed $\alpha_{\mathrm{s} 1}$-casein as the main protein but also traces of BLG were found. Band $\mathrm{b}$ was divided in three parts. In the lower parts $(18.5 \mathrm{kDa}$ and $19 \mathrm{kDa}) \mathrm{BLG}$ was the major protein with traces of $\alpha_{\mathrm{s} 1}$-casein in the $19 \mathrm{kDa}$ part. In the top part $(19.5 \mathrm{kDa})$ the highest abundant protein was the glycosylation-dependent cell adhesion molecule 1. Interestingly, the three major caseins and BLG were also found in the top part of band $b$ with the following order of relative abundance: $\alpha_{\mathrm{s} 1}$-casein $>$ BLG $>\beta$-casein $>\alpha_{\mathrm{s} 2}$-casein. Band $\mathrm{c}(14 \mathrm{kDa}$ and $15 \mathrm{kDa})$ showed BLG as the most abundant protein as well as traces of ALA at the lower part of the band. In the insoluble fraction, mainly caseins were found. In the aggregates on top of the gel (Figure 2.4c, band d), $\kappa$-casein and $\alpha_{\mathrm{s} 2}$-casein were the most abundant proteins but also $\alpha_{\mathrm{s} 1}$-casein and traces of $\beta$-casein were found.

\subsubsection{Dissolution of SMUF insoluble material in different solvents}

To investigate the molecular interactions that lead to decreased solubility of heated and glycated MP, the solubility of the SMUF insoluble fraction in HT-MP and LT-MP in 4 different solvents was monitored. Solubility differences represent hydrophobic interactions (addition of SDS, S1 vs. S2), hydrogen bonds (extra addition of urea S2 vs. S3), and disulphide bonds (extra addition of DTT S3 vs. S4). The recovery of soluble protein in the solvents is shown in Figure 2.5. 


\section{a}

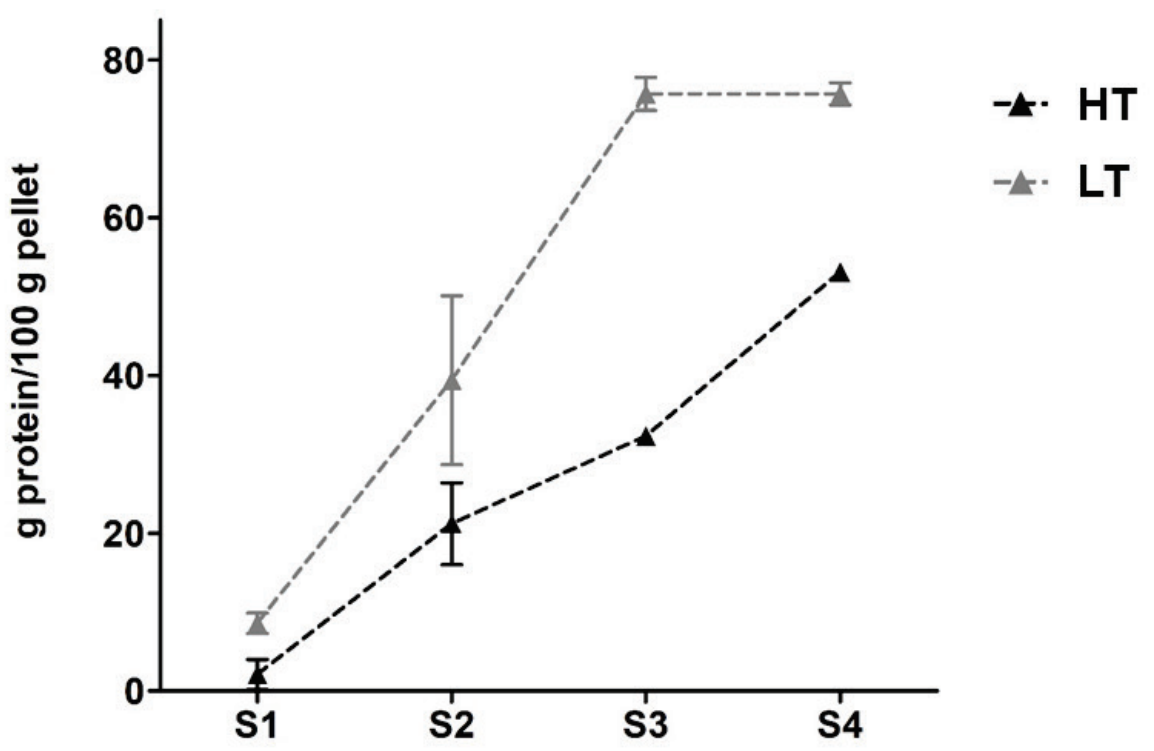

b
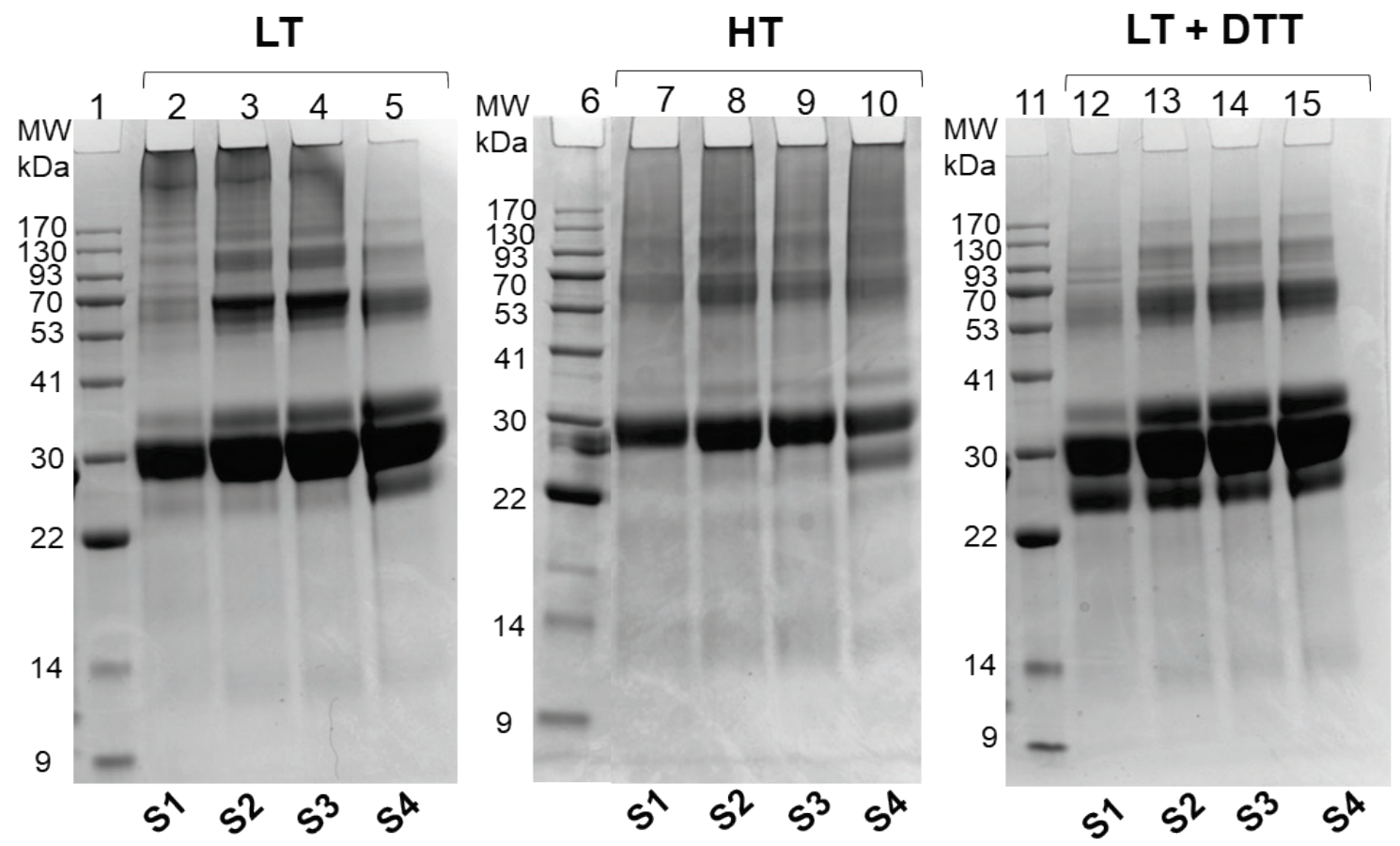

Figure 2.5: (a) Soluble protein recovery from SMUF insoluble cow's milk protein formed after heating with lactose at low temperatures (LT) and at high temperature (HT) in 4 different solvents. S1: $10 \mathrm{mM}$ PBS (pH 7.4), $\mathrm{S} 2: \mathrm{S} 1+1 \%$ SDS (pH 7.4), S3: S2 + $6 \mathrm{M}$ urea (pH 7.4), S4: S3 + 1\% dithiothreitol (pH 7.4). Error bars represent standard deviation of technical duplicates. (b) SDS-PAGE image of soluble proteins after dissolving in S1 to S4, under non-reducing and reducing conditions (+DTT).

In LT-MP, protein solubility continuously increased from S1 to S3, reaching $75 \%$ soluble protein, but did not further increase by the addition of DTT (S4). In HT-MP, protein solubility increased 10 -fold by the addition of SDS but showed only 1.5 -fold additional protein solubility after the addition of urea. After the addition of DTT, the recovery of soluble protein further increased 1.6-fold to 53\%. The protein composition of LT-MP was similar in S1 to S3, as shown in Figure 2.5b. Mainly caseins were observed in the insoluble fraction indicated by a dominant 
band at $30 \mathrm{kDa}$. Additionally, a smear from $>53 \mathrm{kDa}$ was observed, indicating the presence of soluble protein aggregates. A faint band at $35 \mathrm{kDa}$ corresponding to $\alpha_{\mathrm{s} 2}$-casein was observed in $\mathrm{S} 2$ as well as in S3 and became more intense in S4. In S4 also one additional band at $25 \mathrm{kDa}$ corresponding to к-casein appeared. Moreover, no bands corresponding to the MW of WPs were detected in S1 to S4. For S1 to S3, the protein composition of the insoluble fraction of LT-MP and HT-MP were comparable. Interestingly, the smear at $>53 \mathrm{kDa}$ was not visible in S4 for LT-MP. SDS-PAGE was also conducted under reducing conditions which allowed differentiating of the effect of S4 vs. S1-S3 (Figure 2.5b, lanes 11-15). Under reducing conditions, the smears of LT-MP in S1 to S3 vanished from the SDS-PAGE image while the band at $25 \mathrm{kDa}$, corresponding to к-casein, became more intense.

\subsubsection{Nitrogen transfer after simulated infant in vitro digestion}

Nitrogen transfer from the powder into the digestive fluid was determined after simulated infant in vitro digestion at different time points during digestion as a measure for the solubilisation of the heated and glycated MP (Figure 2.6).

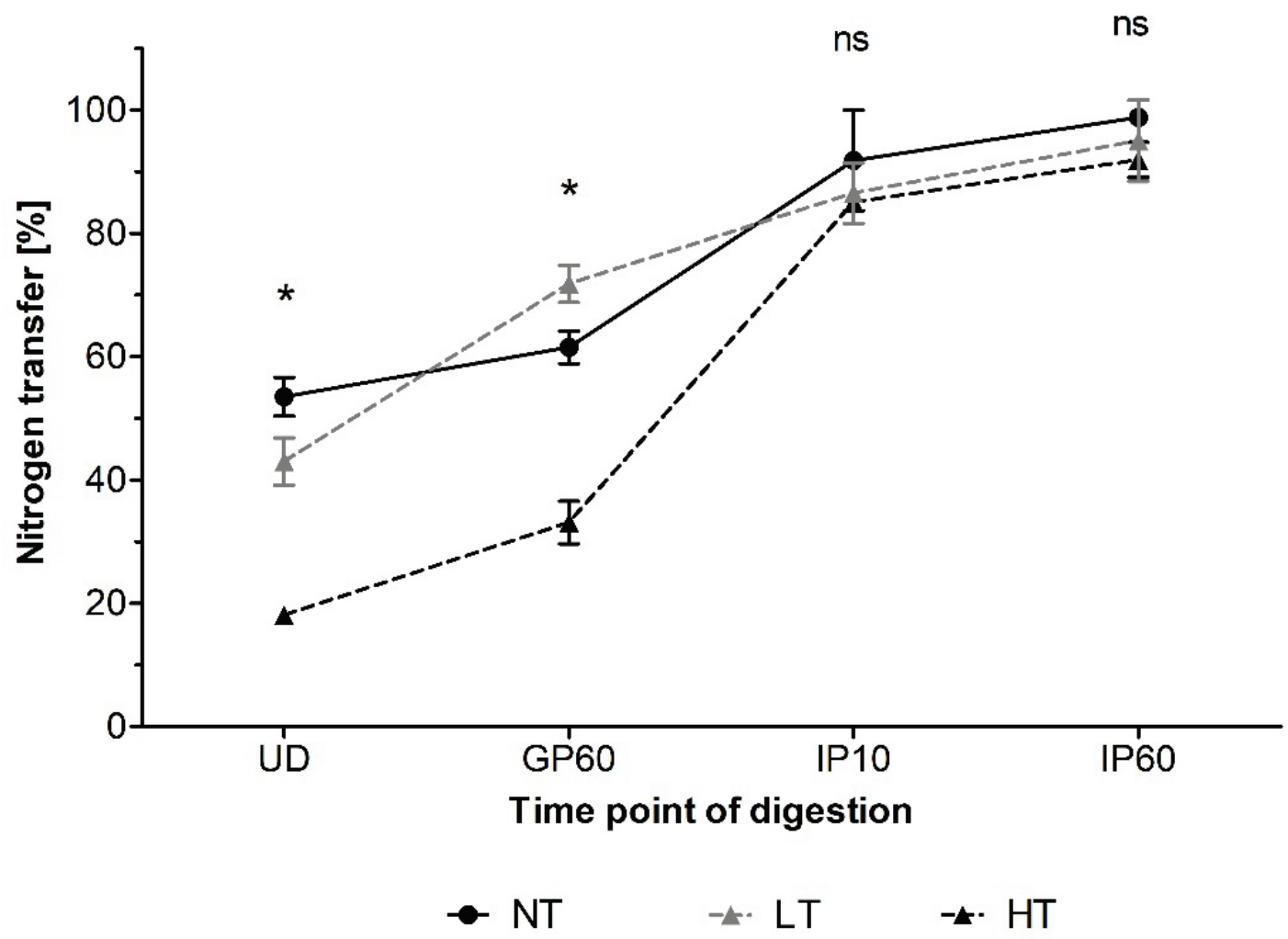

Figure 2.6: Nitrogen transfer of cow's milk protein, non-treated (NT), glycated at low temperature (LT), and high temperature (HT) after simulated gastro intestinal infant in vitro digestion. UD: undigested (UD) meal, GP60: after hydrolysis in the gastric phase for $60 \mathrm{~min}$, IP10 and IP60: after hydrolysis in the intestinal phase for $10 \mathrm{~min}$ (IP10) and $60 \mathrm{~min}$ (IP60), respectively. Error bars represent standard deviation of duplicate digestions. Statistical differences were tested using one-way ANOVA and Tukey post hoc test. Differences were considered statistically significant at $* p<0.05$ with ns: not significant.

Gastric digestion led to an increase of total nitrogen in the soluble phase of the digested MP powders, where heated samples showed stronger increases than the unheated powder due to the 
initial lower solubility. Throughout the GP, HT-MP showed lower solubility compared to the other samples. After $60 \mathrm{~min}$ in the IP, all samples reached between $91.9 \pm 2.8 \%$ (HT-MP) and $98.9 \pm 1.1 \%(\mathrm{NT}-\mathrm{MP})$ nitrogen transfer, with no significant $(\mathrm{p}<0.05)$ differences among samples.

\subsubsection{Protein hydrolysis during simulated infant in vitro digestion}

The extent of protein hydrolysis was monitored by measuring the DH with the OPA-assay (Figure 2.7).

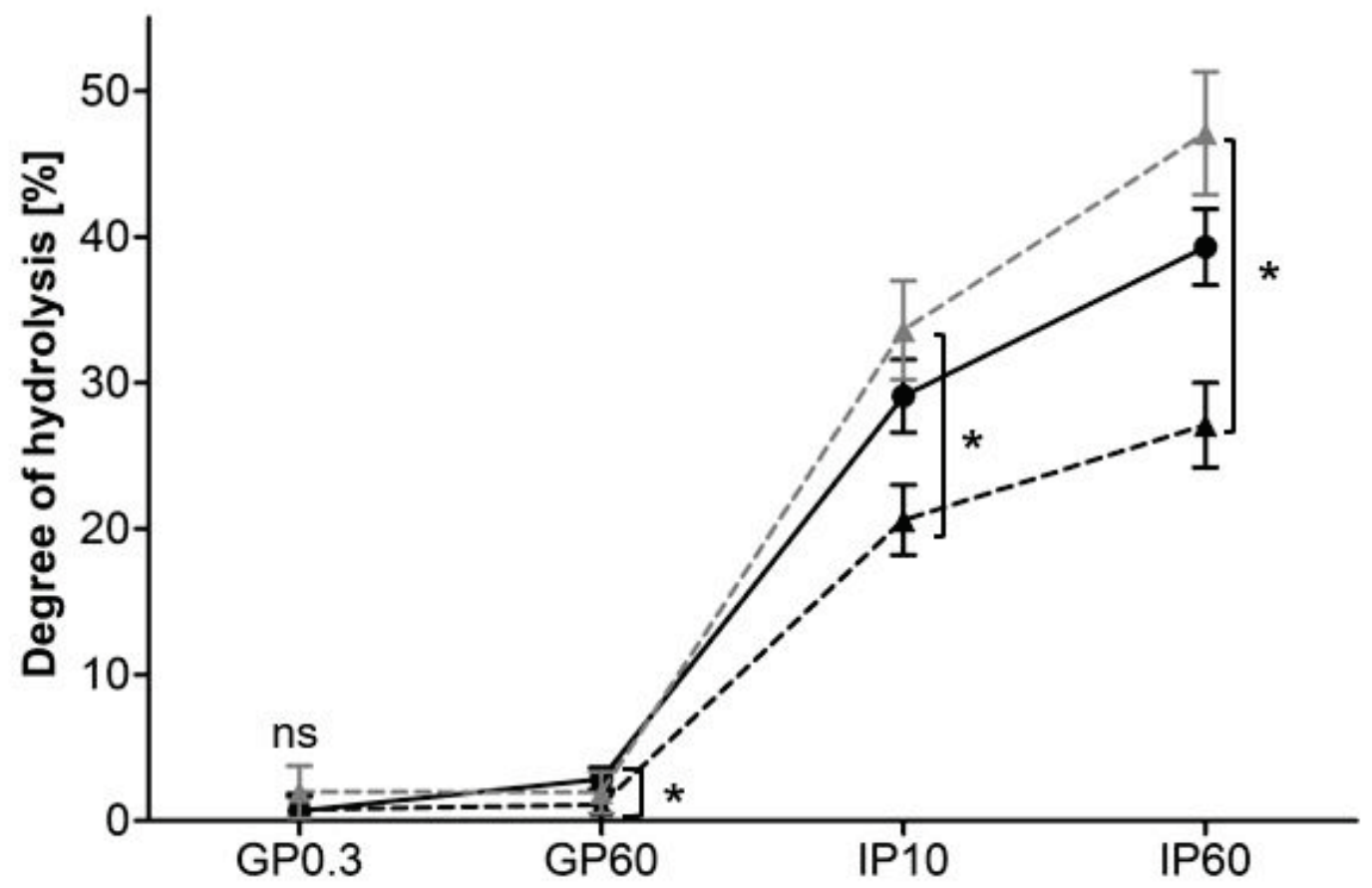

Time point of digestion

\section{NT}

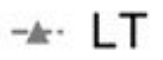

-^. HT

Figure 2.7: Degree of hydrolysis of cow's milk protein, non-treated (NT), glycated at low temperature (LT), and high temperature (HT), after simulated gastro intestinal infant in vitro digestion. GP0.3: after hydrolysis in the gastric phase for $0.3 \mathrm{~min}, \mathrm{GP} 60$ : after hydrolysis in the gastric phase for $60 \mathrm{~min}$, IP10 and IP60: after hydrolysis in the intestinal phase for $10 \mathrm{~min}$ (IP10) and $60 \mathrm{~min}$ (IP60), respectively. Error bars represent standard deviation between digestion duplicates. Statistical differences were tested using one-way ANOVA and Tukey post hoc test. Differences were considered statistical significant at * $p<0.05$ with ns: not significant.

The highest DH after $60 \mathrm{~min}$ in the GP was observed for NT-MP with $2.9 \pm 0.8 \%$. While the DH of HT-MP was significantly lower compared to NT-MP, no differences were observed compared to LT-MP. After $10 \mathrm{~min}$ in the IP, the highest DH was observed for LT-MP followed by NT-MP and HT-MP but was only significantly different between LT-MP and HT-MP. At the end of intestinal digestion, DH reached $39.3 \pm 2.6 \%$ for NT-MP, $47.1 \pm 4.2 \%$ for LT heating, and $27.1 \pm 2.9 \%$ for HT heating, with significant differences between samples remaining the same as after $10 \mathrm{~min}$ in the IP. 
Remaining intact proteins at different time points of gastrointestinal infant in vitro digestion were visualized using SDS-PAGE (Figure 2.8).

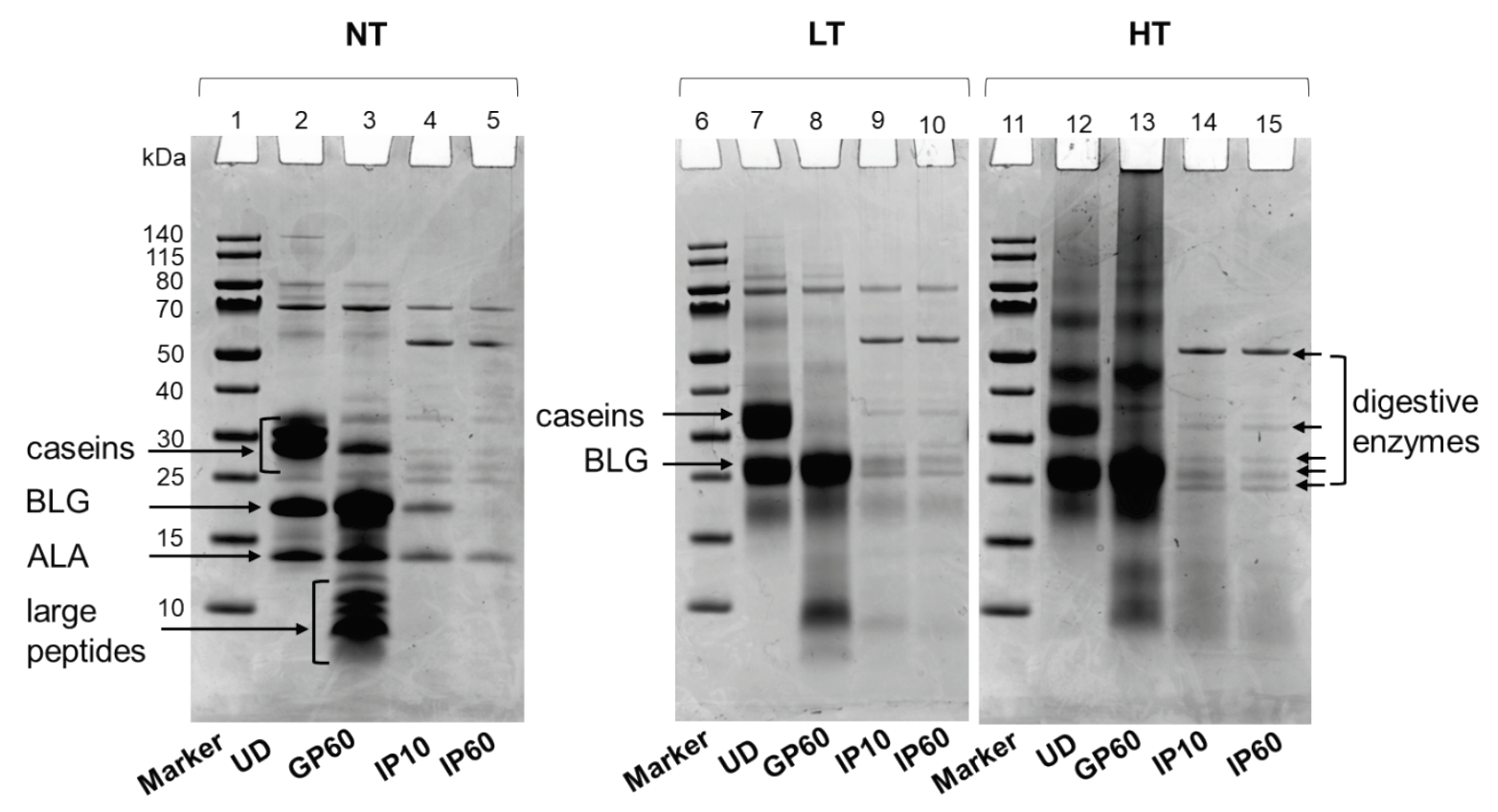

Figure 2.8: SDS-PAGE image of cow's milk protein, non-treated (NT), glycated at low temperature (LT), and high temperature (HT)), after simulated gastro intestinal infant in vitro digestion. In comparison to the undigested (UD) meal, samples were taken after hydrolysis in the gastric phase for 60 min (GP60), after hydrolysis in the intestinal phase for $10 \mathrm{~min}$ (IP10) and $60 \mathrm{~min}$ (IP60), respectively. Bands are indicated as $\beta$-lactoglobulin (BLG) and $\alpha$-lactalbumin (ALA).

The casein bands disappeared in all samples after $60 \mathrm{~min}$ in the GP. Only one band from the caseins remained visible in NT-MP at $28 \mathrm{kDa}$. However, this band was not observed in the glycated MP powders. The disappearance of the casein bands was accompanied by the appearance of large peptides at $\sim 10 \mathrm{kDa}$ indicating the formation of large peptides during the gastric hydrolysis of the caseins. In HT-MP, a smear of aggregated protein over the whole lane appeared on the gel after $60 \mathrm{~min}$ in the GP. WPs did not appear to be hydrolysed in the GP independent of the heat treatment. In NT-MP, intact BLG remained until $10 \mathrm{~min}$ in the IP, while intact ALA was still visible after $60 \mathrm{~min}$ in the IP. In HT-MP, the bands of ALA and BLG were not observed after intestinal digestion. At the same time, the bands between 10 and $15 \mathrm{kDa}$, indicating the presence of large casein-derived peptides, remained visible until the end of intestinal digestion. In LT-MP, the band of BLG at $19 \mathrm{kDa}$ and larger peptides at $15 \mathrm{kDa}$ remained present until the end of intestinal digestion.

\subsubsection{Protein hydrolysis after simulated in vitro digestion with chymotrypsin and trypsin}

To disentangle the effect of heat induced protein modifications on the major enzymes in the applied in vitro digestion model, in vitro digestion with individual enzymes and with specific combinations of individual enzymes was conducted. Remaining intact proteins after hydrolysis with single enzymes were monitored using SDS-PAGE (Figure 2.9). 
a

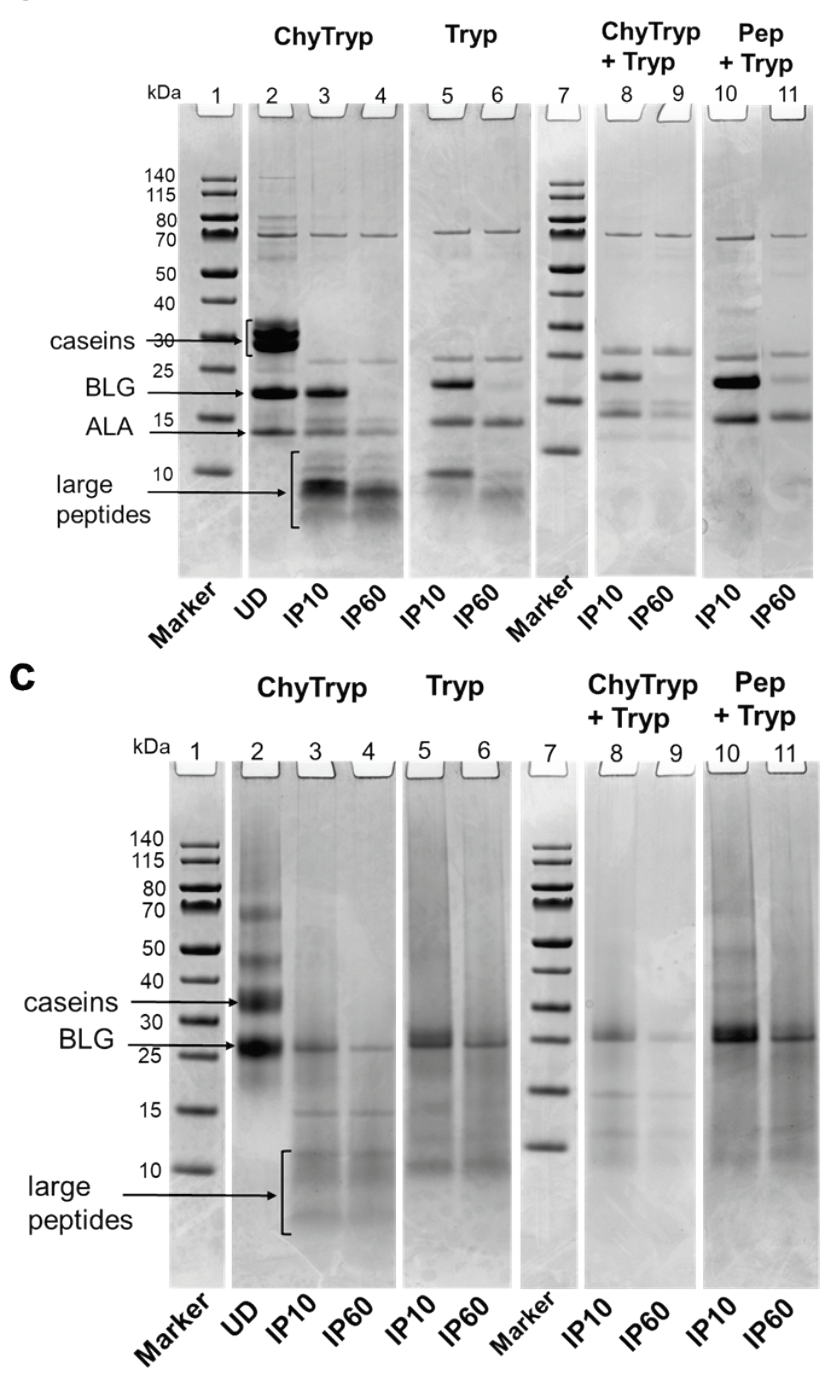

b

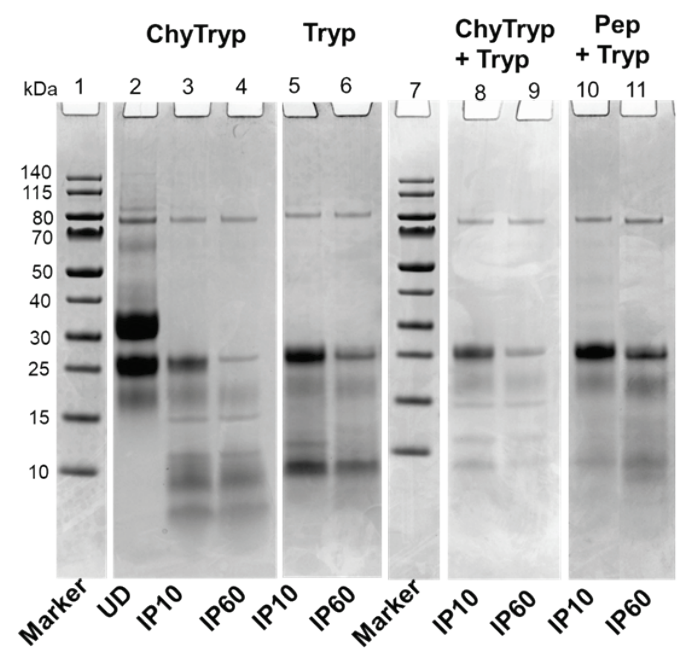

Figure 2.9: (a) SDS-PAGE image after 0,10 and $60 \mathrm{~min}$ in the intestinal phase (IP) of non-treated (NT) cow's milk protein (MP) with chymotrypsin (ChyTryp), trypsin (Tryp), respectively, as well as combinations of chymotrypsin and trypsin (ChyTryp+Tryp), and pepsin and trypsin (Pep+Tryp), respectively. (b) SDS-PAGE image of MP heated at low temperatures (LT) after simulated gastro intestinal digestion with various enzymes at different time points. (c) SDS-PAGE image of MP heated at high temperatures (HT) after simulated gastro intestinal digestion with various enzymes at different time points. Bands are indicated as $\beta$-lactoglobulin (BLG) and $\alpha$-lactalbumin (ALA).

After chymotryptic hydrolysis of NT-MP (Figure 2.9a, lane 3-4), the band of BLG remained until $10 \mathrm{~min}$ in the IP, while ALA and the bands corresponding to large peptides remained until the end of the IP. This was similar for all other used enzymes. However, when a combination of two enzymes was used, larger peptides were not observed. Additionally, the combination or pepsin and trypsin showed even higher density of the BLG band and it was still visible until the end of the IP. Once heating was applied to the MP (Figure 2.9b and c), BLG remained until the end of the IP and larger peptides were observed regardless of the used enzyme combination. Additionally, a smear from $30 \mathrm{kDa}$ to $>140 \mathrm{kDa}$ was observed for HT-MP hydrolysed with trypsin as well as trypsin and pepsin, but not for other enzyme combinations. 
Combinations of enzymes showed higher DH compared to single enzyme hydrolysis, but only in three cases they showed a potentially synergistic effect, defined as larger DH by the combination of enzymes compared to the sum of the DH values of the individual enzymes (supplementary material: Figure 2-S2). Especially in HT-MP, the combination of pepsin with trypsin seemed to have a synergistic effect on the DH at both sampling points (supplementary material: Figure 2-S2b and Figure 2.7 for DH after hydrolysis with pepsin). For the combination of chymotrypsin and trypsin, this promoting effect was only seen for LT heating after $10 \mathrm{~min}$ in the IP but not after $60 \mathrm{~min}$ in the IP.

\subsubsection{SEM images}

SEM images were taken from all samples before and after infant in vitro digestion from all sampling time points (Figure 2.10). Undigested NT-MP showed several round particles (Figure 2.10a), which appeared as white dots in the image. These particles were of various size in an estimated range between $50 \mathrm{~nm}$ and $200 \mathrm{~nm}$ (Figure 2.10b) and showed a smooth surface indicating that these particles are casein micelles. In the background of the images, smaller particles with a less defined contrast were visible. After gastric digestion (Figure 2.10c) no larger particles were visible while in both IP10 (Figure 2.10d) and IP60 (Figure 2.10e) the majority of the particles was smaller than $50 \mathrm{~nm}$ with a tendency to become smaller in IP60. Nevertheless, some particles with a size around $100 \mathrm{~nm}$ were still detectable. In undigested LT-MP (Figure 2.10f), no particles large enough to be detected with SEM were visible. At the same time, GP60 samples of LT-MP showed both, network-like structures (Figure 2.10g) and spherical particles with a broad size range between 20 to $100 \mathrm{~nm}$ (Figure 2.10h). The network-like structures were not detected at any time in the IP and only some spherical particles around $100 \mathrm{~nm}$ remained in the IP. In the undigested HT-MP (Figure 2.10m), larger particles were observed with a size around $300 \mathrm{~nm}$. These particles showed a variable shape, either round or as unordered particle that seem to be composed of smaller protein aggregates. After gastric digestion of this sample (Figure 2.10n and o), network-like structures were observed that partly incorporated round particles with a size around $300 \mathrm{~nm}$, as well as particles smaller than $50 \mathrm{~nm}$ (left top corner Figure 2.10n). Additionally, larger unstructured particles around $5 \mu \mathrm{m}$ that seemed to partly incorporate the round particles within other structures were found (Figure 2.10o). After $10 \mathrm{~min}$ in the IP, the network-like structures and particles above $500 \mathrm{~nm}$ disappeared. Many linear shaped particles of around $100 \mathrm{~nm}$ size were observed as well as some larger spherical particles around $250 \mathrm{~nm}$ size (Figure 2.10p). After $60 \mathrm{~min}$ in the IP (Figure 2.10q), the linear shaped particles seemed to be further broken down and only sometimes some larger particles were still observed. However, those were more frequently observed after $60 \mathrm{~min}$ in the IP in HT-MP than in LT-MP. 

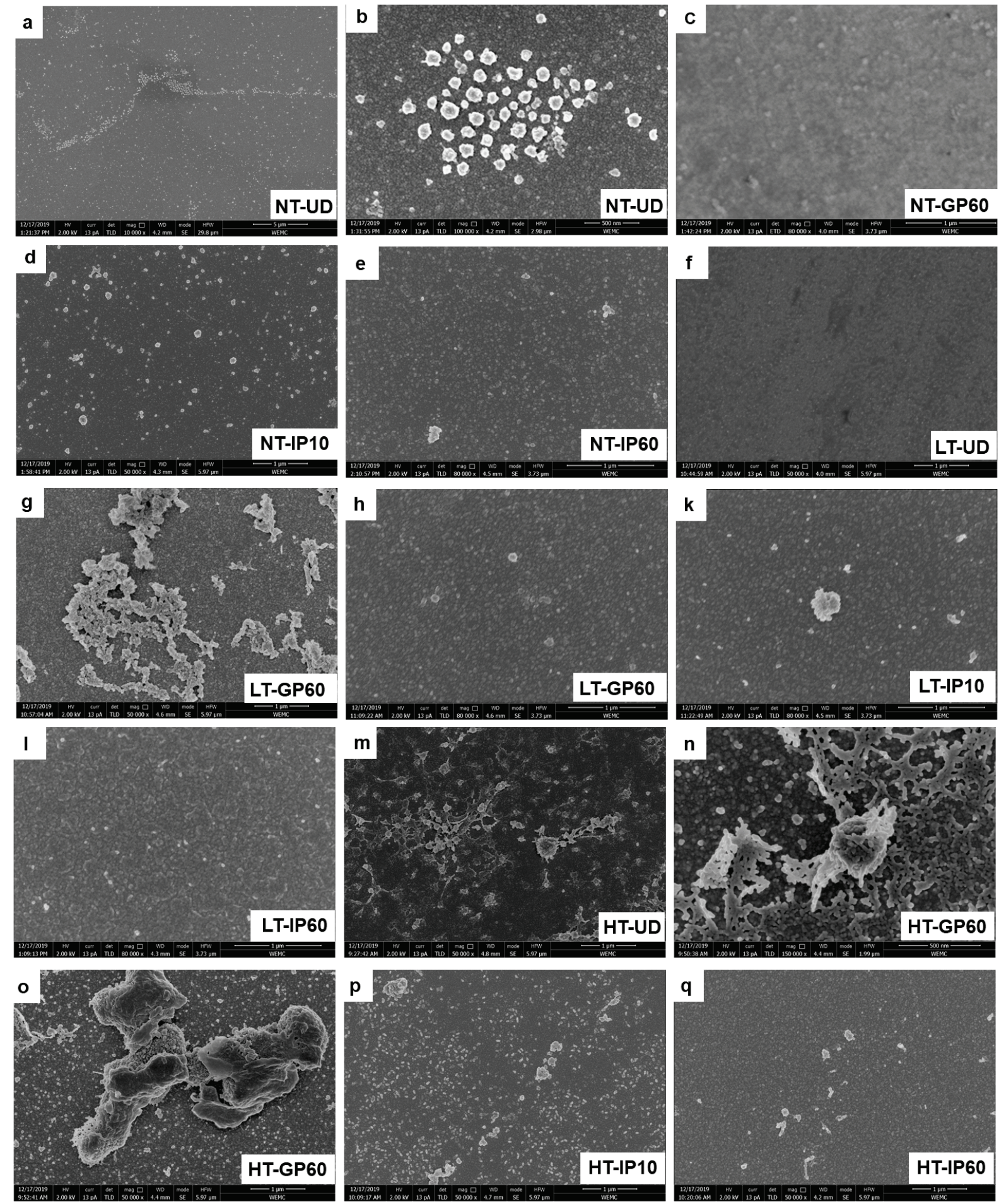

Figure 2.10: Scanning electron microscopy images of non-treated (NT) cow's milk protein (MP), dry heated at low temperature (LT), and dry heated at high temperature (HT) in the presence of lactose, after 60 min in the gastric phase (GP), $10 \mathrm{~min}$ in the intestinal phase (IP), and $60 \mathrm{~min}$ in the IP of an infant in vitro digestion model. (a and b) NT-MP undigested (NT-UD), (c) NT-MP after 60 min in the GP (NT-GP60), (d) NT-MP after 10 min in the IP (NT-IP10), (e) NT-MP after $60 \mathrm{~min}$ in the IP (NT-IP60), (f) LT heated MP undigested (LT-UD), ( $g$ and $\mathrm{h}$ ) LT heated MP after $60 \mathrm{~min}$ in the GP (LT-GP60), (k) LT heated MP after 10 min in the IP (LT-IP10), (1) LT heated MP after 60 min in the IP (LT-IP60), (m) HT heated MP undigested (HT-UD), (n and o) HT heated MP after $60 \mathrm{~min}$ in the GP (HT-GP60), (p) HT heated MP after $10 \mathrm{~min}$ in the IP (HT-IP10), (q) HT heated MP after $60 \mathrm{~min}$ in the IP (HT-IP60). 


\subsection{Discussion}

Cow's milk contains two major protein fractions, casein and WP, that show different susceptibility to enzymatic hydrolysis as well as sensitivity to heat induced structural modifications. Both HT and LT heating led to decreased solubility of MP. In line with previous findings $[13,14]$, caseins were the main proteins that remained in the insoluble fraction under both heating conditions (Figure 2.3). This is also in line with SEM images which showed no larger particles or casein micelles in the undigested LT-MP (Figure 2.10f). At the same time, undigested HT-MP showed larger particles around $200 \mathrm{~nm}$ size (Figure 2.10m), which could be either aggregated WP or WP-coated casein micelles. Higher levels of glycation led to a significant decrease in protein solubility (Figure 2.1), however also disulphide bond formation as well as non-covalent interactions such as hydrophobic interactions and hydrogen bonds contributed to the loss of solubility (Figure 2.5). This is in line with previous findings suggesting that the MR, and especially MR-induced crosslinking, but also disulphide bond formation, hydrogen bonds and hydrophobic interactions can all contribute to loss of solubility in MP concentrates [10,11,13,33,34]. The contribution of these molecular interactions appeared to be heat treatment dependent (Figure 2.5a). In LT-MP, loss of solubility is mainly driven by hydrophobic interactions and hydrogen bonds, but not via MR or disulphide bond formation. However, disulphide bonds are the main interaction driving the formation of the high MW aggregates in LT-MP that are released by the use of urea and SDS, as is shown by the disappearance of these aggregates under reducing conditions and in S4 (Figure 2.5). This is also supported by the relative abundance of $\alpha_{\mathrm{s} 2}$-caseins and $\kappa$-caseins in the larger MW aggregates of the insoluble fraction (Figure 2.4d). These two caseins have a free cysteine residue which allows them to form disulphide bonds amongst each other and with WPs [35]. The absence of BLG in the $170 \mathrm{kDa}$ band of the insoluble fraction (Figure 2.4d) does, not support the involvement of the $\kappa$-casein/BLG complex in dry-heated samples. Overall, the low abundance of WPs in the insoluble fraction (Figure 2.5b), indicates that they play a minor role in the loss of solubility. This is in agreement with previous findings showing that casein solubility in MP powders is more affected by heating and long term storage than WP solubility [14]. In HT-MP, not only disulphide bonds but also the formation of other covalent bonds contributed to the decrease in solubility. The $47 \%$ of protein remaining insoluble after dissolving in S4 (Figure $2.5 \mathrm{a}$ ) and the low recovery of especially pentosidine of $51 \%$ in the soluble fraction (Figure 2.2) indicates that MR-induced crosslinking contributed to the observed loss of solubility of especially caseins (Figure $2.1 \mathrm{~b}$ and Figure 2.4). The large aggregates shown on the SDS-PAGE after tryptic hydrolysis of HT-MP, but not after chymotryptic hydrolysis, (Figure 2.9c) also indicate the role of MR-induced crosslinking in aggregate formation, as trypsin specifically cleaves at the lysine and arginine residues which makes its hydrolysis prone to lysine blockage via the MR [36]. While tryptic hydrolysis of LT-MP is impaired (supplementary material: Figure 2-S2), it does not show hydrolysis-resistant aggregates on the SDS-PAGE (Figure 2.9b), suggesting that MR-induced crosslinking is less involved in the 
formation of these aggregates. This is also supported by the results of the pentosidine analysis of the heat-treated MP: LT-MP contained less pentosidine than HT-MP (Figure 2.2), which may ultimately have influenced its degradability. Our findings showed that indeed several intramolecular interactions were involved in the loss of solubility upon dry heating, however their contribution strongly depends on the applied heating conditions. The combination of single enzyme digestions and solubility tests on heated and glycated MP allow two conclusions about the nature of the covalent interactions that result in insolubility and formation of large aggregates in MP heated in the presence of lactose (Figure 2.3). First, covalent crosslinking, other than disulphide bond formation, seems to promote casein insolubility at HT dry heating but not at LT dry heating. Secondly, aggregates that are formed during heating are released from the insoluble material but the further hydrolysis/breakdown of these aggregates by trypsin is strongly impaired, especially when they are formed via covalent crosslinking, implying a role for the MR.

Aggregation and MR in this model system may not only have negative technological consequences, but also affect the overall digestibility of MP. After simulated infant in vitro digestion, the aggregates of HT-MP were still visible at the end of the GP but not after 10 min in the IP (Figure 2.8). This is in line with the results from the combined hydrolysis by chymotrypsin and trypsin, which showed that chymotrypsin hydrolysed these aggregates and thereby partly compensated for the impaired trypsin hydrolysis (Figure 2.9 and supplementary material: Figure 2-S2). In contrast to the single enzyme hydrolysis experiments, the degree of hydrolysis in infant in vitro digestion was impaired for HT heating, but not for LT heating (Figure 2.7). This may be due to the use of pancreatin, which besides chymotrypsin and trypsin also contains other enzymes that can contribute to the protein hydrolysis. The experiments with specific enzymes suggest that adding another protease to trypsin can compensate for the impaired hydrolysis of trypsin in LT-MP but not in HT-MP (supplementary material: Figure 2-S2). Therefore, it is possible that all pancreatic enzymes together are also less affected by LT heating than HT heating of MP. The higher protein digestibility of LT-MP compared to HT-MP can be explained by the differences in the applied heating conditions and the resulting protein modifications. In general, thermal processing under either dry or wet conditions, of MP can both increase or decrease protein digestibility which is strongly dependent on the applied heating conditions that determine the structural protein modifications. Most in vitro studies reported an increase in protein digestibility after thermal processing of MP, possibly as a result of heat induced unfolding of the globular WP [20]. However, when heating is conducted at low temperatures $\left(<70^{\circ} \mathrm{C}\right)$ and at low $\mathrm{a}_{\mathrm{w}}$-levels, that favour MR over protein unfolding, most studies report decreased in vitro protein digestibility [15,37-40]. In our study, we observed that LT dry heating, accompanied with an increase of MR, does not directly result in decreased protein digestibility. However, HT dry heating decreased protein digestibility, probably due to the higher levels of advanced glycation and MR-induced crosslinking (Figure 2.2). Additionally, SEM images showed relatively larger particles in undigested HT-MP (Figure $2.10 \mathrm{~m}$ ) than in LT-MP (Figure 2.10f) as well as a slower hydrolysis of these particles during the intestinal 
digestion of HT-MP (Figure 2.10p and q). This is in line with other findings showing that more severe heating in solution, resulting in relatively more aggregation and formation of e.g. lactosyllysine, leads to decreased protein digestibility in vitro [16,17]. Interestingly, it seems that insolubility does not directly affect digestibility in the IP, as no significant differences were observed in nitrogen transfer (Figure 2.6). The rapid disappearance of caseins on the SDS-PAGE, independent from the applied heating conditions and the network-like structures observed in the SEM images (Figure 2.10), is in line with previous findings and a result of acidic depletion and rapid hydrolysis in the GP [39,41]. The observation of these network-like structures in the GP of the heated MP but not in NT-MP is in line with previous findings that showed that unheated milk forms more firm clots than homogenised and heated milk [42]. Moreover, the observation of larger spherical particles within these networks in the GP of HT-MP (Figure 2.10n) and the longer persistence of larger particles in the IP (Figure 2.10p and q) indicate a higher resistance of caseins towards digestion in HT-MP, which is also supported by the partly hydrolysed casein fragments on the SDS-PAGE (Figure 2.8). This is in line with the findings by Dupont et al. [38], who reported that extensive heat treatment of milk powder results in a higher resistance of caseins to infant in vitro digestion. In contrast to this, WPs showed enhanced hydrolysis in both LT-MP and HT-MP compared to NT-MP (Figure 2.8). This is in agreement with previous findings, which reported that glycated ALA $[43,44]$ and WPs in spray dried skim milk powders [38] showed enhanced protein hydrolysis in infant in vitro digestion. Heating and glycation of MP can both increase and decrease allergenicity [22]. Pinto et al. [18] showed that the aggregates of glycated BLG survive until $60 \mathrm{~min}$ in the IP of adult gastrointestinal in vitro digestion. Moreover, another study reported that aggregation of BLG when glycated at HT and low $\mathrm{a}_{\mathrm{w}}$-levels resulted in the formation of binding ligands for the receptor of AGEs and immunoglobulin E [45]. This suggests that impaired MP digestibility, as well as the survival of aggregates in the gastrointestinal tract, can affect the allergenicity and immunogenicity of MP. Treating MP under such harsh conditions as in this study is not practiced in food industry. However, the ingestion of MP baked into a wheat matrix, such as a muffin or waffle, has been shown to positively correlate with the resolution of cow's milk allergy symptoms in allergic children [19]. In these products, protein aggregation and MR are promoted due to the HT, low $\mathrm{a}_{\mathrm{w}}$-levels, and high sugar content. Our findings show that dry heating of MP in the presence of reducing sugars can affect protein digestibility and suggest that this could have an effect on the immunogenicity of the MP, although further studies would be needed to directly show the link between the digestibility and immunogenicity of dry-heated MP.

\subsection{Conclusion}

Dry heating of a powdered mixture of casein and WP in the presence of lactose led to changes in the protein structure that affected both solubility and digestibility. Different inter- and intramolecular interactions lead to a decreased solubility of mainly caseins. Despite the high level of MR in both LT-MP and HT-MP, impaired protein digestibility after simulated 
infant in vitro digestion was only observed for HT heating, which is possibly related to the higher level of MR-induced covalent crosslinking. Moreover, large particles were present at the end of the GP and were slower hydrolysed in dry-heated MP compared to NT-MP. This will not only negatively affect the nutritional value of the MP but also determine in which form the protein will be presented to the mucosal immune system in the gastrointestinal tract, which may affect the immunological response towards ingested MP. 


\section{Supplementary material}

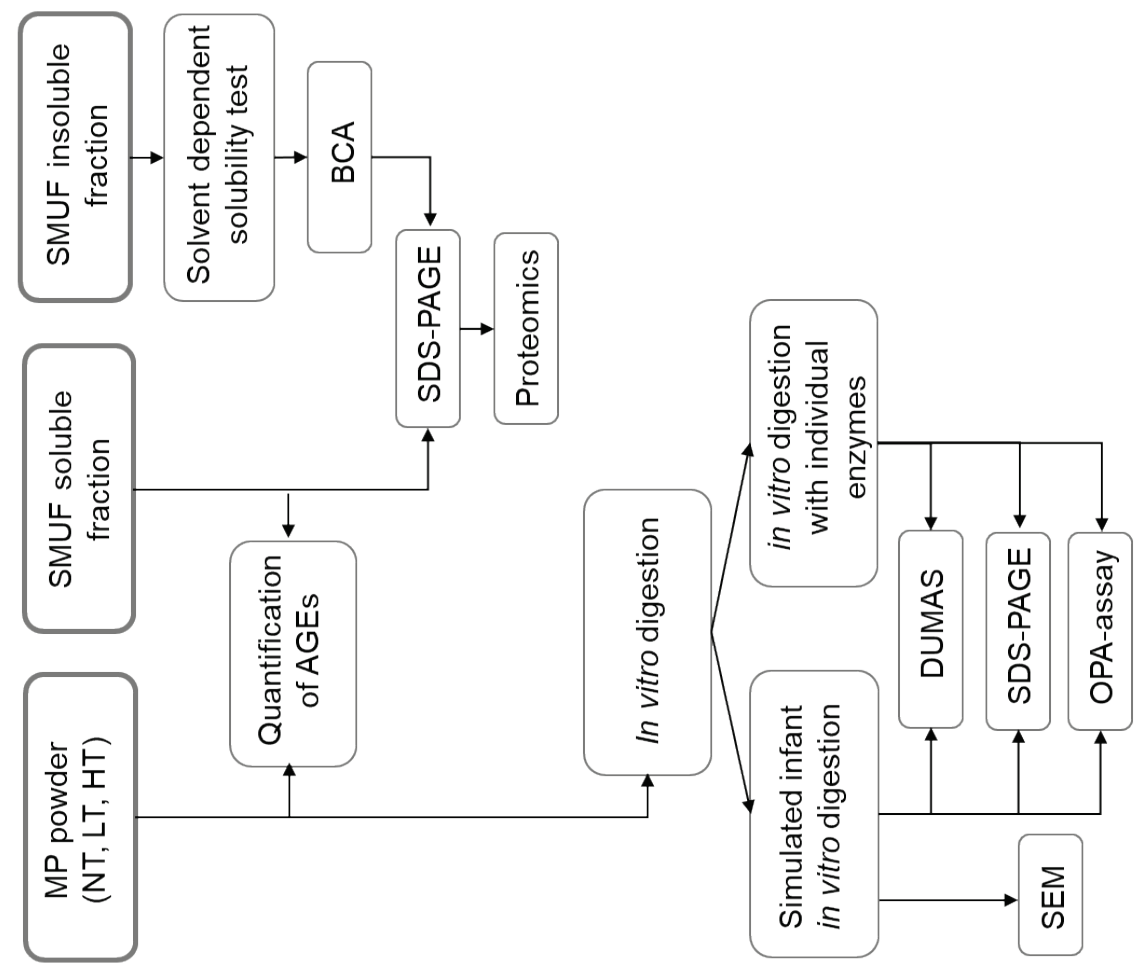

오

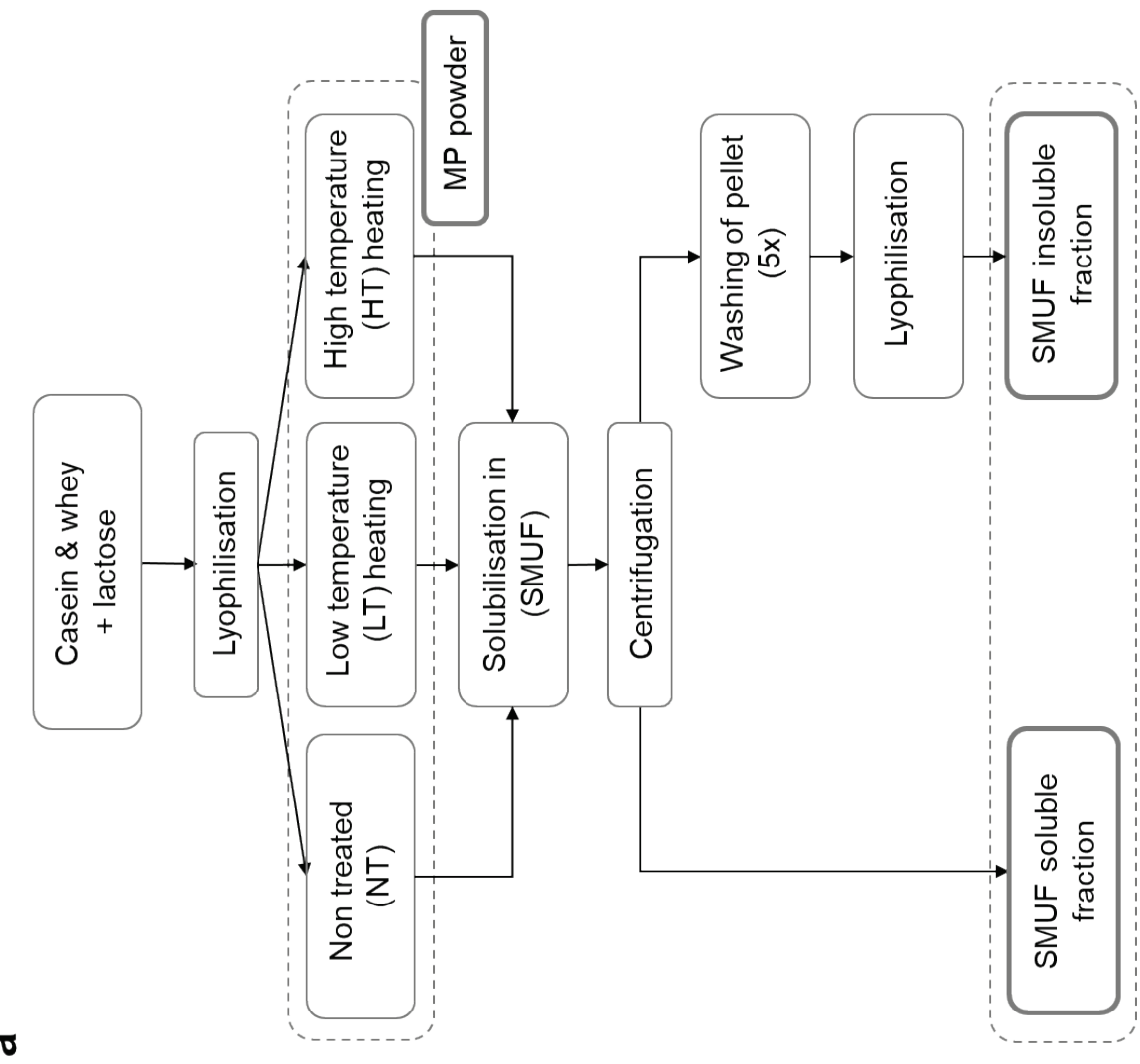

Figure 2-S1: (a) flow chart for the preparation of heated and glycated milk protein (MP) powder and the simulated milk ultrafiltrate (SMUF) soluble and SMUF insoluble fraction. (b) flow chart for sample analysis and in vitro digestion experiments. 
a

IP10

IP60
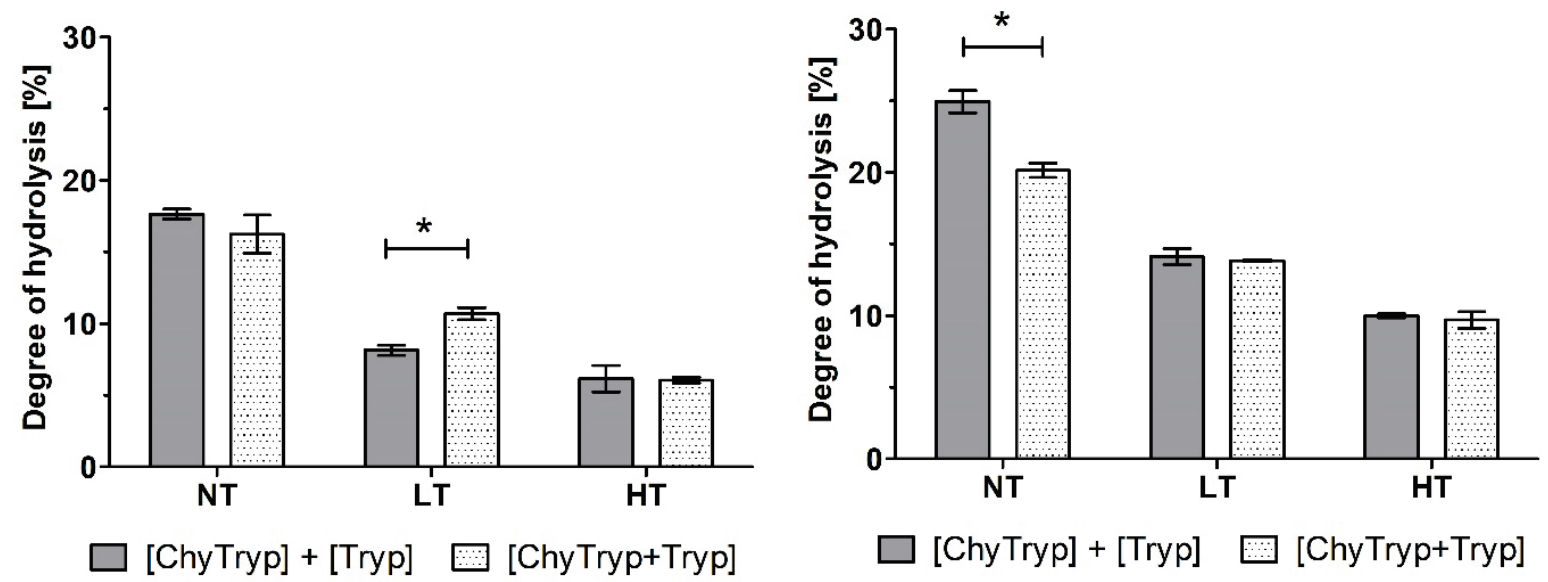

b

IP10

IP60
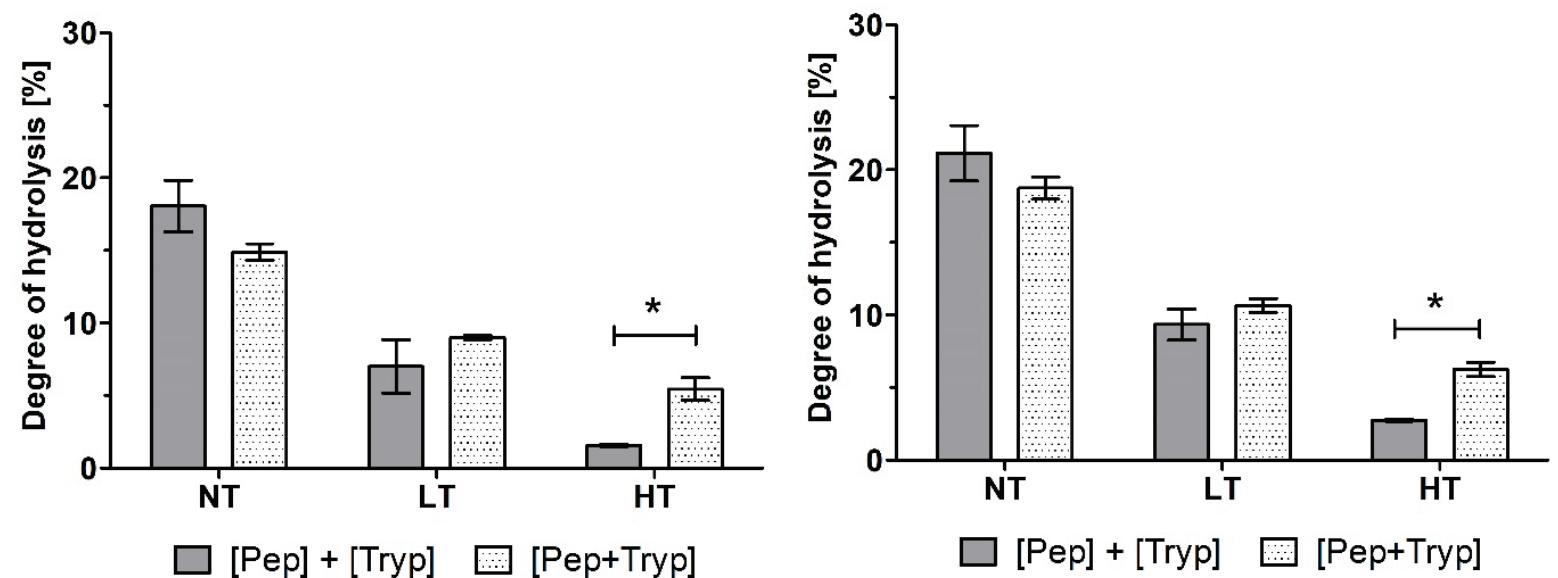

Figure 2-S2: (a) Comparison of sum of DH from chymotryptic and tryptic hydrolysis ([ChyTryp] + [Tryp]) to combined hydrolysis of both enzymes ([ChyTryp + Tryp]) after $10 \mathrm{~min}$ and $60 \mathrm{~min}$ in the intestinal phase (IP). (b) Comparison of sum of DH from pepsin and trypsin hydrolysis ([Pep] + [Tryp]) to combined hydrolysis of both enzymes ([Pep+ Tryp]) after $10 \mathrm{~min}$ and $60 \mathrm{~min}$ in the IP. Error bars represent standard deviation of technical duplicates. Statistical differences were analysed using one-way ANOVA with *p $<0.05$. 


\section{References}

1. Walstra, P. On the Stability of Casein Micelles. Journal of Dairy Science 1990, 73, 1965-1979, doi:10.3168/jds.S0022-0302(90)78875-3.

2. De Wit, J.N. Thermal Stability and Functionality of Whey Proteins. Journal of Dairy Science 1990, 73, 3602-3612, doi:10.3168/jds.S0022-0302(90)79063-7.

3. Dalgleish, D.G.; Van Mourik, L.; Corredig, M. Heat-Induced Interactions of Whey Proteins and Casein Micelles with Different Concentrations of $\alpha$-Lactalbumin and $\beta$-Lactoglobulin. Journal of Agricultural and Food Chemistry 1997, 45, 4806-4813.

4. Dalgleish, D.G.; Senaratne, V.; Francois, S. Interactions between $\alpha$-Lactalbumin and $\beta$-Lactoglobulin in the Early Stages of Heat Denaturation. Journal of Agricultural and Food Chemistry 1997, 45, 3459-3464, doi:10.1021/jf970113a.

5. Corredig, M.; Dalgleish, D.G. The mechanisms of the heat-induced interaction of whey proteins with casein micelles in milk. International Dairy Journal 1999, 9, 233-236, doi:10.1016/S0958-6946(99)000667.

6. Donato, L.; Guyomarc'h, F. Formation and properties of the whey protein/א-casein complexes in heated skim milk - A review. Dairy Science and Technology 2009, 89, 3-29, doi:10.1051/dst:2008033.

7. Van Boekel, M.A.J.S. Effect of heating on Maillard reactions in milk. Food Chemistry 1998, 62, 403-414, doi:10.1016/s0308-8146(98)00075-2.

8. Arena, S.; Renzone, G.; D'Ambrosio, C.; Salzano, A.M.; Scaloni, A. Dairy products and the Maillard reaction: A promising future for extensive food characterization by integrated proteomics studies. Food Chemistry 2017, 219, 477-489, doi:10.1016/j.foodchem.2016.09.165.

9. Schong, E.; Famelart, M.H. Dry heating of whey proteins. Food Research International 2017, 100, 31-44, doi:10.1016/j.foodres.2017.08.057.

10. Fan, F.; Liu, M.; Shi, P.; Xu, X.; Lu, W.; Wang, Z.; Du, M. Protein cross-linking and the Maillard reaction decrease the solubility of milk protein concentrates. Food Science and Nutrition 2018, 6, 1196-1203, doi: $10.1002 /$ fsn3.657.

11. Le, T.T.; Holland, J.W.; Bhandari, B.; Alewood, P.F.; Deeth, H.C. Direct evidence for the role of Maillard reaction products in protein cross-linking in milk powder during storage. International Dairy Journal 2013, 31, 83-91, doi:10.1016/j.idairyj.2013.02.013.

12. Yüksel, Z.; Erdem, Y.K. The influence of main milk components on the hydrophobic interactions of milk protein system in the course of heat treatment. Journal of Food Engineering 2005, 67, 301-308, doi:10.1016/j.jfoodeng.2004.04.032.

13. Anema, S.G.; Pinder, D.N.; Hunter, R.J.; Hemar, Y. Effects of storage temperature on the solubility of milk protein concentrate (MPC85). Food Hydrocolloids 2006, 20, 386-393, doi:10.1016/j.foodhyd.2005.03.015.

14. Gazi, I.; Huppertz, T. Influence of protein content and storage conditions on the solubility of caseins and whey proteins in milk protein concentrates. International Dairy Journal 2015, 46, 22-30, doi:10.1016/j.idairyj.2014.09.009.

15. Rudloff, S.; Lönnerdal, B. Solubility and digestibility of milk proteins in infant formulas exposed to different heat treatments. Journal of Pediatric Gastroenterology and Nutrition 1992, 15, 25-33, doi:10.1097/00005176-199207000-00005.

16. Wada, Y.; Lönnerdal, B. Effects of different industrial heating processes of milk on site-specific protein modifications and their relationship to in vitro and in vivo digestibility. Journal of Agricultural and Food Chemistry 2014, 62, 4175-4185, doi:10.1021/jf501617s.

17. Wada, Y.; Lönnerdal, B. Effects of Industrial Heating Processes of Milk-Based Enteral Formulas on SiteSpecific Protein Modifications and Their Relationship to in Vitro and in Vivo Protein Digestibility. Journal of Agricultural and Food Chemistry 2015, 63, 6787-6798, doi:10.1021/acs.jafc.5b02189.

18. Pinto, M.S.; Léonil, J.; Henry, G.; Cauty, C.; Carvalho, A.F.; Bouhallab, S. Heating and glycation of $\beta-$ lactoglobulin and $\beta$-casein: Aggregation and in vitro digestion. Food Research International 2014, 55, 7076, doi:10.1016/j.foodres.2013.10.030.

19. Kim, J.S.; Nowak-Wgrzyn, A.; Sicherer, S.H.; Noone, S.; Moshier, E.L.; Sampson, H.A. Dietary baked milk accelerates the resolution of cow's milk allergy in children. Journal of Allergy and Clinical Immunology 2011, 128, 125-131.e122, doi:10.1016/j.jaci.2011.04.036.

20. van Lieshout, G.A.A.; Lambers, T.T.; Bragt, M.C.E.; Hettinga, K.A. How processing may affect milk protein digestion and overall physiological outcomes: A systematic review. Critical reviews in food science and nutrition 2019, 10.1080/10408398.2019.1646703, doi:10.1080/10408398.2019.1646703.

21. Deng, Y.; Govers, C.; Bastiaan-Net, S.; van der Hulst, N.; Hettinga, K.; Wichers, H.J. Hydrophobicity and aggregation, but not glycation, are key determinants for uptake of thermally processed $\beta$-lactoglobulin by THP-1 macrophages. Food Research International 2019, 120, 102-113, doi:10.1016/j.foodres.2019.01.038. 
22. Nowak-Wegrzyn, A.; Fiocchi, A. Rare, medium, or well done? The effect of heating and food matrix on food protein allergenicity. Current Opinion in Allergy and Clinical Immunology 2009, 9, 234-237, doi:10.1097/ACI.0b013e32832b88e7.

23. Zenker, H.E.; Van Lieshout, G.A.A.; Van Gool, M.P.; Bragt, M.C.E.; Hettinga, K.A. Lysine blockage of milk proteins in infant formula impairs overall protein digestibility and peptide release. Food and Function 2020, 11, 358-369, doi:10.1039/c9fo02097g.

24. Liu, F.; Teodorowicz, M.; Wichers, H.J.; Van Boekel, M.A.J.S.; Hettinga, K.A. Generation of Soluble Advanced Glycation End Products Receptor (sRAGE)-Binding Ligands during Extensive Heat Treatment of Whey Protein/Lactose Mixtures Is Dependent on Glycation and Aggregation. Journal of Agricultural and Food Chemistry 2016, 64, 6477-6486, doi:10.1021/acs.jafc.6b02674.

25. Jennes, R.K., J. Preparation and properties of a salt solution which simulates milk ultrafiltrate. Neth. Milk Dairy J. 1983, 16, 153-164.

26. Kehm, R.; Rückriemen, J.; Weber, D.; Deubel, S.; Grune, T.; Höhn, A. Endogenous advanced glycation end products in pancreatic islets after short-term carbohydrate intervention in obese, diabetes-prone mice. Nutr. Diabetes 2019, 9, doi:10.1038/s41387-019-0077-x.

27. Cox, J.; Mann, M. MaxQuant enables high peptide identification rates, individualized p.p.b.-range mass accuracies and proteome-wide protein quantification. Nature Biotechnology 2008, 26, 1367-1372, doi:10.1038/nbt.1511.

28. Ménard, O.; Bourlieu, C.; De Oliveira, S.C.; Dellarosa, N.; Laghi, L.; Carrière, F.; Capozzi, F.; Dupont, D.; Deglaire, A. A first step towards a consensus static in vitro model for simulating full-term infant digestion. Food Chemistry 2018, 240, 338-345, doi:10.1016/j.foodchem.2017.07.145.

29. Brodkorb, A.; Egger, L.; Alminger, M.; Alvito, P.; Assunção, R.; Ballance, S.; Bohn, T.; Bourlieu-Lacanal, C.; Boutrou, R.; Carrière, F., et al. INFOGEST static in vitro simulation of gastrointestinal food digestion. Nat. Protoc. 2019, 14, 991-1014, doi:10.1038/s41596-018-0119-1.

30. Mulet-Cabero, A.I.; Rigby, N.M.; Brodkorb, A.; Mackie, A.R. Dairy food structures influence the rates of nutrient digestion through different in vitro gastric behaviour. Food Hydrocolloids 2017, 67, 63-73, doi:10.1016/j.foodhyd.2016.12.039.

31. Hinz, K.; O'Connor, P.M.; Huppertz, T.; Ross, R.P.; Kelly, A.L. Comparison of the principal proteins in bovine, caprine, buffalo, equine and camel milk. Journal of Dairy Research 2012, 79, 185-191, doi:10.1017/s0022029912000015.

32. Costa, F.F.; Vasconcelos Paiva Brito, M.A.; Moreira Furtado, M.A.; Martins, M.F.; Leal De Oliveira, M.A.; Mendonça De Castro Barra, P.; Amigo Garrido, L.; De Oliveira Dos Santos, A.S. Microfluidic chip electrophoresis investigation of major milk proteins: Study of buffer effects and quantitative approaching. Anal. Methods 2014, 6, 1666-1673, doi:10.1039/c3ay41706a.

33. Le, T.T.; Bhandari, B.; Holland, J.W.; Deeth, H.C. Maillard reaction and protein cross-linking in relation to the solubility of milk powders. Journal of Agricultural and Food Chemistry 2011, 59, 12473-12479, doi: $10.1021 / \mathrm{jf} 203460 \mathrm{z}$

34. Morgan, F.; Appolonia Nouzille, C.; Baechler, R.; Vuataz, G.; Raemy, A. Lactose crystallisation and early Maillard reaction in skim milk powder and whey protein concentrates. Lait 2005, 85, 315-323, doi:10.1051/lait:2005017.

35. Broyard, C.; Gaucheron, F. Modifications of structures and functions of caseins: a scientific and technological challenge. Dairy Science and Technology 2015, 95, 831-862, doi:10.1007/s13594-015-0220y.

36. Olsen, J.V.; Ong, S.E.; Mann, M. Trypsin cleaves exclusively C-terminal to arginine and lysine residues. Molecular and Cellular Proteomics 2004, 3, 608-614, doi:10.1074/mcp.T400003-MCP200.

37. Culver, C.A.; Swaisgood, H.E. Changes in the Digestibility of Dried Casein and Glucose Mixtures Occurring During Storage at Different Temperatures and Water Activities. Journal of Dairy Science 1989, 72, 2916-2920, doi:10.3168/jds.S0022-0302(89)79442-X.

38. Dupont, D.; Boutrou, R.; Menard, O.; Jardin, J.; Tanguy, G.; Schuck, P.; Haab, B.B.; Leonil, J. Heat treatment of milk during powder manufacture increases casein resistance to simulated infant digestion. Food Digestion 2010, 1, 28-39, doi:10.1007/s13228-010-0003-0.

39. Dupont, D.; Mandalari, G.; Mollé, D.; Jardin, J.; Rolet-Répécaud, O.; Duboz, G.; Léonil, J.; Mills, C.E.N.; Mackie, A.R. Food processing increases casein resistance to simulated infant digestion. Molecular Nutrition and Food Research 2010, 54, 1677-1689, doi:10.1002/mnfr.200900582.

40. Sanz, M.L.; Corzo-Martínez, M.; Rastall, R.A.; Olano, A.; Moreno, F.J. Characterization and in vitro digestibility of bovine $\beta$-lactoglobulin glycated with galactooligosaccharides. Journal of Agricultural and Food Chemistry 2007, 55, 7916-7925, doi:10.1021/jf0711111.

41. Picariello, G.; Ferranti, P.; Fierro, O.; Mamone, G.; Caira, S.; Di Luccia, A.; Monica, S.; Addeo, F. Peptides surviving the simulated gastrointestinal digestion of milk proteins: Biological and toxicological 
implications. Journal of Chromatography B: Analytical Technologies in the Biomedical and Life Sciences 2010, 878, 295-308, doi:10.1016/j.jchromb.2009.11.033.

42. Ye, A.; Cui, J.; Dalgleish, D.; Singh, H. Effect of homogenization and heat treatment on the behavior of protein and fat globules during gastric digestion of milk. Journal of Dairy Science 2017, 100, 36-47, doi:10.3168/jds.2016-11764.

43. Joubran, Y.; Moscovici, A.; Lesmes, U. Antioxidant activity of bovine alpha lactalbumin Maillard products and evaluation of their in vitro gastro-duodenal digestive proteolysis. Food and Function 2015, 6, 12291240, doi:10.1039/c4fo01165a.

44. Joubran, Y.; Moscovici, A.; Portmann, R.; Lesmes, U. Implications of the Maillard reaction on bovine alpha-lactalbumin and its proteolysis during in vitro infant digestion. Food and Function 2017, 8, 2295 2308, doi:10.1039/c7fo00588a.

45. Zenker, H.E.; Ewaz, A.; Deng, Y.; Savelkoul, H.F.J.; Van Neerven, R.J.J.; De Jong, N.; Wichers, H.J.; Hettinga, K.A.; Teodorowicz, M. Differential effects of dry vs. Wet heating of $\beta$-lactoglobulin on formation of sRAGE binding ligands and sIgE epitope recognition. Nutrients 2019, 11, doi:10.3390/nu11061432. 


\section{Chapter 3}

Differential effects of dry vs. wet heating on the formation of sRAGE binding ligands and IgE epitope recognition

This chapter has been published as:

Hannah E. Zenker, Arifa Ewaz, Ying Deng, Huub F. J. Savelkoul, R. J. Joost van Neerven, Nicolette W. De Jong, Harry J. Wichers, Kasper A. Hettinga, Malgorzata Teodorowicz. (2019). Differential effects of dry vs. wet heating of $\beta$-lactoglobulin on formation of sRAGE binding ligands and sIgE epitope recognition. Nutrients, 11(6):1432. 


\begin{abstract}
:
The effect of glycation and aggregation of thermally processed $\beta$-lactoglobulin (BLG) on binding to sRAGE and immunoglobulin $\mathrm{E}$ (IgE) from cow milk allergic patients were investigated. BLG was heated under dry conditions (water activity $<0.7$ ) and wet conditions (in phosphate buffer at $\mathrm{pH} 7.4)$ at low temperature $\left(<73{ }^{\circ} \mathrm{C}\right)$ and high temperatures $\left(>90{ }^{\circ} \mathrm{C}\right)$ in the presence or absence of the milk sugar lactose. $\mathrm{N}^{\varepsilon}$-Carboxymethyllysine (CML) western blot and glycation staining were used to directly identify glycation structures on the protein fractions on SDS-PAGE. Western blot was used to specify sRAGE and SIgE binding fractions. sRAGE binding was highest under wet-heated BLG independent of the presence of the milk sugar lactose. Under wet heating, high-molecular-weight aggregates were most potent and did not require the presence of CML to generate sRAGE binding ligands. In the dry system, sRAGE binding was observed only in the presence of lactose. IgE binding affinity showed large individual differences and revealed four binding profiles. Dependent on the individual, IgE binding decreased or increased by wet heating independent of the presence of lactose. Dry heating required the presence of lactose to show increased binding to aggregates in most individuals. This study highlights an important role of heating condition-dependent protein aggregation and glycation in changing the immunogenicity and antigenicity of cow's milk BLG.
\end{abstract}




\subsection{Introduction}

The manufacturing of many dairy products implies heating at moderate $\left(<73{ }^{\circ} \mathrm{C}\right)$ or high temperatures $\left(>90^{\circ} \mathrm{C}\right)$ to ensure product safety or to produce powdered products such as infant formula. Maillard reaction (MR)-induced glycation, as well as protein aggregation, are the most abundant protein modifications during milk processing. The formation of aggregates and the degree of glycation strongly depends on the applied processing conditions and may strongly differ between wet and dry heating conditions as they are applied in industrial processing of milk or dried dairy products. Wet heating of $\beta$-lactoglobulin (BLG) results in relatively more aggregation and the formation of polymers with a $\mathrm{MW}>10 \mathrm{kDa}$ compared to dry heating [1]. At the same time, dry heating induces more glycation as low moisture content (water activity $\left(a_{w}\right)$ between 0.2 and 0.8 ) enhances protein glycation via the MR [2]. These protein modifications are known to change reactivity of food allergens to innate cell surface receptors and immunoglobulin $\mathrm{E}$ ( $\mathrm{IgE}$ ) binding affinity by either destruction and masking of epitopes or formation of neo-epitopes via exposure of interior structures and amino acid side chain modifications [3]. The applied processing conditions, such as $\mathrm{pH}$, humidity, and temperature are crucial determinants for epitope destruction/formation. For example, pasteurization of cow's milk (CM) BLG enhances its allergenicity by redirecting its epithelial uptake towards Peyer's patches [4]. At the same time, clinical studies report that "baked milk products" can be tolerated by $\sim 70 \%$ of children with IgE-mediated CM allergy and that consumption of these products potentially facilitates the development of oral tolerance towards raw milk [5-7]. Both glycation and aggregation result in decreased binding of IgE from CM allergic children if heated above $90{ }^{\circ} \mathrm{C}$ in a wet system [8,9]. At the same time, cellular signalling can be promoted by the formation of glycation structures on the food allergen [10].

The receptor for advanced glycation end products (RAGE) is one of the most studied cell surface receptors in relation to protein glycation. It is known to bind to advanced glycation end products (AGEs) that are formed via the MR. RAGE is expressed by vascular endothelial cells and cells of the innate and adaptive immune system [10]. RAGE-ligand interaction activates an intracellular signalling cascade, resulting in the release of pro-inflammatory cytokines via NF- $\kappa B$ activation. Its soluble isoform (sRAGE) binds to the same ligands; however, it is considered to be a decoy for RAGE in the peripheral system [11]. Besides AGEs, sRAGE binds to several other ligands, such as lipopolysaccharide, amyloid- $\beta$, and S100 protein. Those ligands have the common property to act as oligomers [12]. Liu et al. [13] indicated that not only the level of glycation but also the aggregation occurring during dry heating of BLG can promote sRAGE binding affinity. Perkins et al. [14] recently reported the involvement of RAGE in type 2 cytokine signal transduction in the lungs of mice. Type 2 cytokines, e.g. interleukin (IL)-4 are involved in B-cell class switch and IgE production [15]. These findings indicate the direct involvement of RAGE with the clinical manifestation of the allergic reaction towards the allergen. MR not only leads to the formation of AGEs, as commonly described RAGE ligands, but also promotes protein aggregation [16]. By using controlled processing 
conditions, protein modification can be directed towards either the formation of AGEs or the formation of aggregates enabling a distinction between the functional effects of these two distinct protein modifications. This study aimed to investigate the effect of protein aggregation and glycation on sRAGE binding affinity and the potential allergenic impact. Therefore, BLG was heated under controlled wet and dry conditions to investigate whether AGE formation or rather aggregation (glycation or non-glycation-induced) contributes to changes in sRAGE and IgE binding affinity to BLG.

\subsection{Materials and Methods}

\subsubsection{Chemicals}

Acetonitrile uHPLC-MS grade was purchased from VWR chemicals (Radnor, Pennsylvania, USA). $\mathrm{N}^{\varepsilon}$-(carboxymethyl)-1-lysine (CML) and $\mathrm{N}^{\varepsilon}$-(carboxy [2H2]methyl)-1-lysine (d2-CML) were purchased from Polypeptide laboratories (Strasbourg, France). NuPAGE ${ }^{\circledR}$ LDS sample buffer (4X conc.), and NuPAGETM MOPS SDS running buffer (20X), NuPAGETM 12\% Bis-Tris protein gel, $1.0 \mathrm{~mm}$. gels. Soluble AGE Product-Specific Receptor Human E. coli (RD172116100) was obtained from Biovendor (Brno, Czech Republic). Anti-RAGE antibody (monoclonal mouse $\operatorname{IgG}_{2} \mathrm{~B}$ clone, MAB11451) purchased from R\&D systems (Minneapolis, Minnesota, USA). HRP conjugated anti-mouse polyclonal goat (P0447) was purchased from

Dako (Glostrup, Denmark). TMB substrate (3,3',5,5'-tetramethylbenzidine) for high sensitivity ELISA was purchased from sdt-reagents (Baesweiler, Germany). WesternBright ${ }^{\mathrm{TM}}$ Enhanced chemiluminescence (ECL) western blotting detection kit was obtained from Advansta (San Jose, California, USA). Ovalbumin was purchased from InvivoGen (San Diego, California, USA). Bovine Serum Albumin Fraction V was obtained from Roche (Basel, Switzerland). Amyloid- $\beta$ (1-42) ultrapure HFIP was purchased from Westburg (Leusden, The Netherlands). (N-Epsilon)-Carboxymethyl-Lysine primary antibody was purchased from Nordic-MUbio (Susteren, The Netherlands). Pro-Q ${ }^{\circledR}$ Emerald 300 Glycoprotein Gel and Blot Stain Kit (Thermo Fisher Scientific, Waltham, Massachusetts, USA).

BlueRay prestained protein marker was obtained from Jena Bioscience GmbH (Jena, Germany). Coomassie brilliant blue R-250 was purchased from Bio-Rad (Hercules, California, USA). Ultrapure water was prepared by an Purelab ${ }^{\circledR}$ Ultra water system from ELGA LabWaters (Celle, Germany).Three Plasma were purchased from PlasmaLab International (Everett, Washington, USA). Two sera were provided by the Queen Beatrix Hospital (Winters Wijk, The Netherlands), all other sera were provided by the archival serumbank of the Erasmus Medical Centre (Rotterdam, The Netherlands). All other chemicals were purchased from Sigma Aldrich (St Louise, Minnesota, USA) unless mentioned otherwise.

\subsubsection{BLG isolation and purification}

Raw bulk milk obtained from the Department of Animal Sciences, Wageningen University \& Research (Wageningen, The Netherlands). BLG was purified and isolated as described by 
De Jongh et al. [17] using anion exchange chromatography DEAE Sepharose C-6B (GE healthcare, Chicago, Illinois, USA). Isolated BLG was lyophilised and a purity $>94 \%$ was measured as described by Deng et al. [1].

\subsubsection{Heat treatment of $B L G$}

BLG was heated in a wet system above the denaturation temperature by heating it in phosphate buffer saline (PBS) at pH 7.4 applying $100^{\circ} \mathrm{C}$ for $90 \mathrm{~min}$ in the presence of lactose (W-HT-Lac) and in the absence of lactose (W-HT). Three additional treatments were conducted as described by Deng et al. [1]. Briefly, a low temperature (LT) wet heating was conducted by heating BLG below its denaturation temperature in $10 \mathrm{mM}$ PBS ( $\mathrm{pH} 7.4$ ) at $60^{\circ} \mathrm{C}$ for $72 \mathrm{~h}$ in the presence of lactose (W-LT-Lac) and in the absence of lactose (W-LT). High temperature (HT) dry heating of BLG was conducted at $130{ }^{\circ} \mathrm{C}$ for $10 \mathrm{~min}$ in the presence of lactose (D-HT-Lac) and in the absence of lactose (D-HT). Prior to heat treatment, the BLG solution was lyophilised and $\mathrm{a}_{\mathrm{w}}$-level was adjusted to 0.53 over saturated sodium bromide solution. For low temperature dry heating, BLG was heated at $50{ }^{\circ} \mathrm{C}$ for $9 \mathrm{~h}$ at $\mathrm{a}_{\mathrm{w}} 0.65$ in the absence of lactose (D-LT) and the presence of lactose (D-LT-Lac). Humidity was monitored with a humidity control chamber (HCP108, Memmert, Schwabach, Germany). After heat processing, dry-heated samples were dissolved in water to starting protein concentration. All samples were centrifuged at $2900 \times g$ for $30 \mathrm{~min}$ to remove insoluble material and unreacted lactose was removed by dialysis. Protein concentration of samples showing the formation of insoluble material was determined with DUMAS as described by Deng et al. [1].

\subsubsection{Quantification of $N^{\varepsilon}$-carboxymethyllysine (CML) using uHPLC-MS/MS}

CML was quantified using uHPLC-ESI-MS/MS according to a method described by Troise et al. [18]. Samples were diluted to $2.5 \mathrm{mg} / \mathrm{mL}$ in ultrapure water and mixed with hydrochloric acid to a final ratio of $0.63 \mathrm{mg}$ protein/ $1 \mathrm{~mL} 6 \mathrm{M}$ hydrochloric acid. Solutions were saturated with nitrogen and heated for $22 \mathrm{~h}$ at $110{ }^{\circ} \mathrm{C}$. Hydrolysates were centrifuged (4500 $\times \mathrm{g}, 10 \mathrm{~min}, 20^{\circ} \mathrm{C}$ ) using a Heraeus multifuge X3R (Thermo Fisher Scientific, Waltham, Massachusetts, USA) and filtered through a $0.2 \mu \mathrm{m}$ Polytetrafluoroethylene syringe filter (Phenomenex, Torrance, California, USA). An aliquot was dried under nitrogen and dissolved to the same volume in ultrapure water. Samples were centrifuge $\left(10,000 \times g, 20 \mathrm{~min}, 20{ }^{\circ} \mathrm{C}\right)$ using an Eppendorf multifuge 5430R (Eppendorf, Hamburg, Germany). Subsequently, they were diluted with acetonitrile to reach $50 \%$ acetonitrile and spiked with internal standard CML-d2.

Standard solutions were prepared in a concentration range between $25 \mathrm{ng} / \mathrm{mL}$ and $750 \mathrm{ng} / \mathrm{mL}$ and spiked with CML-d2. Final concentration of CML-d2 in all sample and standard solutions was $250 \mathrm{ng} / \mathrm{mL}$. CML was separated on a Kinetex $2.6 \mu \mathrm{m}$ HILIC $100 \mathrm{~A}, 100 \times 2.1 \mathrm{~mm}$ (Phenomenex, Torrance, California, USA) at $35{ }^{\circ} \mathrm{C}$ column temperature. Eluent A was ultrapure water with $0.1 \%$ formic acid, eluent $\mathrm{B}$ was acetonitrile with $0.1 \%$, and eluent $\mathrm{C}$ was 
$50 \mathrm{mM}$ ammonium formate. Flow rate was set to $0.4 \mathrm{~mL} / \mathrm{min}$ using the following gradient (time [min]/eluent B [\%]/eluent C [\%]): (0/80/10), (0.8/80/10), (3.5/40/10), (6.5/80/10), $(8.0 / 80 / 10),(11 / 80 / 10)$. Electron ionisation was conducted in positive mode. Spray voltage was set to $3500{ }^{\circ} \mathrm{C}$, vaporising temperature was $250{ }^{\circ} \mathrm{C}$, and sheath gas pressure was $60 \mathrm{psig}$. Capillary temperature was set to $290{ }^{\circ} \mathrm{C}$. The parent mass $[\mathrm{M}+\mathrm{H}]^{+} 205.3 \mathrm{~m} / \mathrm{z}$ and $207.3 \mathrm{~m} / \mathrm{z}$ were selected in $\mathrm{Q} 1$ for $\mathrm{CML}$ and CML-d2, respectively The characteristic product ions $130.0 \mathrm{~m} / \mathrm{z}$ (collision energy (CE): $12 \mathrm{~V}$; tube lens: 78) and $84.0 \mathrm{~m} / \mathrm{z}(\mathrm{CE}: 22 \mathrm{~V}$; tube lens: 78 ) were recorded in Q3.

\subsubsection{Sodium dodecyl sulphate gel electrophoresis (SDS-PAGE)}

Gel electrophoresis under non-reducing conditions was performed to monitor protein aggregates formed during heat treatment of BLG. Samples, NuPAGE ${ }^{\circledR}$ LDS sample buffer ( $4 \times$ conc.) and ultrapure water were mixed in a ratio $5 / 5 / 10(v / v / v)$, centrifuged (1 min, $500 \times g, 20^{\circ} \mathrm{C}$ ) on an Eppendorf multifuge 5430R (Eppendorf, Hamburg, Germany) and incubated for $10 \mathrm{~min}$ at $70{ }^{\circ} \mathrm{C}$. BlueRay prestained protein marker was used as MW marker. Six microgram protein of each sample were loaded on NuPAGETM $12 \%$ Bis-Tris protein gel, $1.0 \mathrm{~mm}$. Gels were run at $120 \mathrm{~V}$ for $1.5 \mathrm{~h}$ using NuPAGETM $1 \times$ MOPS SDS running buffer and stained with Coomassie Brilliant Blue R-250 or using Pro- ${ }^{\circledR}$ Emerald 300 Glycoprotein staining kit according to the manufacturer's instructions. Images of the stained gels were obtained using a Universal Hood III (Bio-Rad, Hercules, California, USA) and Image Lab 4.1 software (Bio-Rad, Hercules, California, USA).

\subsubsection{Thioflavin-T (ThT)-assay}

ThT-assay was conducted to monitor the formation of fibril structures during heating. Protein concentration was adjusted to $0.25 \mathrm{mg} / \mathrm{mL}$ and mixed with $3.9 \mathrm{mM}$ aqueous ThT solution in a ratio 5.8/1.0 $(v / v)$. All samples were prepared in duplicate. The solution was transferred in a

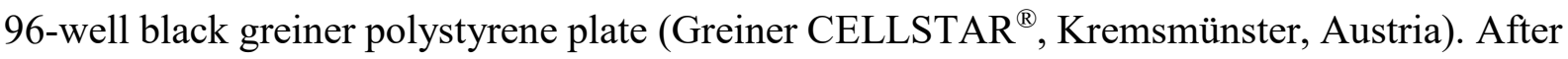
incubated for $10 \mathrm{~min}$ in the dark, fluorescence emission was measured (excitation wavelength $450 \mathrm{~nm}$, emission wavelength $485 \mathrm{~nm}$, gain 100) using Infinite ${ }^{\circledR} 200$ PRO NanoQuant with i-control software (Tecan, Männedorf, Switzerland). The fluorescence intensity of heated and glycated BLG was corrected for the blank (PBS at pH 7.5).

\subsubsection{Inhibition SRAGE ELISA}

Inhibition sRAGE ELISA was conducted to determine sRAGE binding affinity as described by Liu et al. [13] with some modifications. Briefly, soy protein extract glycated with glucose (90 min, $100^{\circ} \mathrm{C}$, wet conditions) was used as coating material. Transparent high binding ELISA plate (Greiner Bio-One, Kremsmuenster, Austria) were coated with G90 for $12 \mathrm{~h}$ at $4{ }^{\circ} \mathrm{C}$. Sample protein concentration was adjusted to $25 \mu \mathrm{g} / \mathrm{mL}$ with $1.5 \%$ bovine serum albumin (BSA) (w/v) in $0.025 \%$ tween in $10 \mathrm{mM}$ PBS (PBST). The optimal protein concentration was chosen based on a dilution curve of BLG-NT obtained from a pre-experiment. The samples 
were pre-incubated with $1 \mu \mathrm{g} / \mathrm{mL}$ sRAGE in a ratio $1: 1(v / v)$ for $45 \mathrm{~min}$ at $37^{\circ} \mathrm{C}$ on a NuncTM polystyrene plate (Thermo Fisher Scientific, Massachusetts, USA) before addition to the ELISA plate. The coated ELISA plate was blocked with PBS with 3\% BSA $(v / w)$ for $1 \mathrm{~h}$ at room temperature and washed with PBST. The washing step was repeated after each step of ELISA. After blocking, the pre-incubated sRAGE/sample mixture was transferred into the ELISA plate and incubation was continued for $1 \mathrm{~h}$ at $37^{\circ} \mathrm{C}$. After washing, anti-sRAGE antibody was added at a concentration of $0.25 \mu \mathrm{g} / \mathrm{mL}$ and the plate was incubated under shaking for $30 \mathrm{~min}$ at room temperature. After washing, anti-mouse polyclonal goat HRP conjugated antibody at a concentration $0.25 \mu \mathrm{g} / \mathrm{mL}$ was added and the incubation was continued for $30 \mathrm{~min}$ at room temperature. The signal was detected with TMB. The colour reaction was measured at $450 \mathrm{~nm}$ vs. $620 \mathrm{~nm}$ reference using a Filter Max F5 multi-mode microplate reader (Molecular Devices, San Jose, California, USA). Each sample was measured in triplicate. Amyloid- $\beta$ was used as a positive control, while ovalbumin was used as a negative control.

Inhibition was calculated using the following formula:

$$
\text { Inhibition }[\%]=\left(\mathrm{Abs}_{\text {Max }}-\left(\mathrm{Abs}_{\text {Sample }}-\mathrm{Abs}_{\mathrm{Min}}\right)\right) / \mathrm{Abs}_{\text {Max }} \times 100
$$

where $\mathrm{Abs}_{\text {Max }}$ is the absorbance obtained from sRAGE without competition agent and AbsMin is the absorbance obtained from blank sample (PBS) without sRAGE, Abs sample is the absorbance obtained from the mixture of sRAGE and each sample. High inhibition indicates high sRAGE binding affinity.

\subsection{8 sRAGE western blot}

SDS-PAGE was conducted as described before. However, protein concentration increased to $20 \mu \mathrm{g}$ protein for wet-heated BLG at HT, $25 \mu \mathrm{g}$ protein for wet-heated BLG at low temperature, $10 \mu \mathrm{g}$ protein for dry-heated BLG in the presence of lactose, and $4 \mu \mathrm{g}$ protein for BLG-NT and BLG heated in a dry system in the absence of lactose, to achieve similar band densities on the gel. Gels were blotted on Amersham ${ }^{\mathrm{TM}} \operatorname{Protran}^{\mathrm{TM}} 0.45 \mu \mathrm{m}$ nitrocellulose membrane (GE Healthcare Life science, Marlborough, Massachusetts, USA). Gels were blotted with semi-dry western blot blotting buffer at $15 \mathrm{~V}$ for $35 \mathrm{~min}$. Membranes were washed for $2 \times 5$ min with $1 \mathrm{x}$ Tris buffer saline (TBS) with $0.2 \%$ tween (TBST) and incubated for $1 \mathrm{~h}$ at room temperature with $3 \%$ BSA in TBST. Subsequently, membranes were washed $2 \times 10$ min with TBST and incubated at $4{ }^{\circ} \mathrm{C}$ for $12 \mathrm{~h}$ with sRAGE diluted to $1 \mu \mathrm{g} / \mathrm{mL}$ with $1.5 \%$ BSA in TBS $(\mathrm{w} / \mathrm{v})$. Membranes were washed $4 \times 7 \mathrm{~min}$ with $1 \times \mathrm{TBST} /$ Triton and $2 \times 5 \mathrm{~min}$ with TBST. Anti-RAGE antibody was diluted to $0.25 \mu \mathrm{g} / \mathrm{mL}$ with $1.5 \%$ BSA in TBS and added to the membrane for $1 \mathrm{~h}$ at room temperature. Subsequently, the membrane was washed as described before and incubated for $1 \mathrm{~h}$ with anti-mouse polyclonal goat HRP conjugated antibody diluted to $0.25 \mu \mathrm{g} / \mathrm{mL}$ with $1.5 \% \mathrm{BSA}$ in TBST. After incubation, membranes were washed $4 \times 7 \mathrm{~min}$ with $1 \times$ TBST/Triton and $2 \times 5$ min with TBS. ECL western blot detection reagent was added for $30 \mathrm{~s}$. Chemiluminescence was visualized in ChemHighsensitivity mode using an Universal 
Hood III (Bio-Rad, Hercules, California, USA) and Image Lab 4.1 software (Bio-Rad, Hercules, California, USA)

\subsubsection{CML western blot}

SDS-PAGE western blotting was performed as described before. Blotted membranes were washed $2 \times 5$ min with TBST and incubated $1 \mathrm{~h}$ in TBST with $3 \%$ BSA. After washing $2 \times 10 \mathrm{~min}$ with TBST, membranes were incubated with $0.25 \mu \mathrm{g} / \mathrm{mL}$ anti-CML-antibody with $1 \%$ BSA and $0.5 \%$ raw whey protein in TBS at $4{ }^{\circ} \mathrm{C}$ for $12 \mathrm{~h}$. Membranes were washed $4 \times 7 \mathrm{~min}$ with TBST/Triton and $2 \times 5 \mathrm{~min}$ with TBST. Anti-mouse polyclonal goat HRP conjugated antibody was diluted to $0.25 \mu \mathrm{g} / \mathrm{mL}$ with $1 \%$ BSA and $1 \%$ raw whey protein in TBST. The membrane was incubated for $30 \mathrm{~min}$ with the antibody. Subsequently, it was washed $4 \times 7 \mathrm{~min}$ with TBST/Triton and $2 \times 5$ min with TBS. ECL chemiluminescence detection was conducted as described before.

\subsubsection{IgE binding dot blot}

IgE dot blot was conducted to screen the available sera and plasma for their binding affinity to BLG heated under dry conditions at HT and BLG heated under wet conditions at HT, each time in the presence of lactose or absence of lactose. Each time, $5 \mu \mathrm{g}$ protein was spotted on the membranes. The membranes were washed 5 min with TBST and incubated for with $3 \%$ BSA in TBST for $1 \mathrm{~h}$ at room temperature. Membranes were washed $2 \times 5 \mathrm{~min}$ in TBST and incubated with sera/plasma diluted in $1 \%$ BSA/TBST for $12 \mathrm{~h}$ at room temperature. Sera dilutions were prepared in the ratios as shown in Table 3.1. Membranes were washed $4 \times 7 \mathrm{~min}$ with TBST/Triton and $2 \times 5$ min with TBST. Mouse anti-human IgE antibody was diluted $0.5 \mu \mathrm{g} / \mathrm{mL}$ with $0.5 \%$ non-fat dry milk in TBST and added to the membranes for $1 \mathrm{~h}$ at room temperature. Subsequently, the membranes were washed $4 \times 7 \mathrm{~min}$ with TBST/Triton and $2 \times 5$ min with TBST. Anti-mouse polyclonal goat HRP conjugated antibody was diluted to $0.25 \mu \mathrm{g} / \mathrm{mL}$ with $0.5 \%$ non-fat dry milk in TBST and added to the membranes for $30 \mathrm{~min}$ at room temperature. Subsequently, they were washed $4 \times 7$ min with TBST/Triton and $2 \times 5$ min with TBS. Chemiluminescence detection was conducted as described before. 
Table 3.1: Levels of specific immunoglobulin E (sIgE) of sera from cow's milk allergic patients. sIgE levels as measured by ImmunoCap.

\begin{tabular}{cccc}
\hline Patient & sIgE-Level Cow's Milk Proteins [kU/L] & Specimen Type & Dilution \\
\hline 1 & 52.2 & Serum & $1: 5$ \\
2 & 0.73 & Serum & $1: 3$ \\
3 & 0.96 & Serum & $1: 3$ \\
4 & 0.53 & Serum & $1: 3$ \\
5 & 0.96 & Serum & $1: 3$ \\
6 & 1.69 & Serum & $1: 3$ \\
7 & 1.55 & Serum & $1: 3$ \\
8 & $>100$ & Plasma & $1: 5$ \\
9 & 91.0 & Plasma & $1: 5$ \\
10 & 94.8 & Plasma & $1: 5$ \\
11 & 28.4 & Serum & $1: 5$ \\
12 & 6.6 & Serum & $1: 5$ \\
\hline
\end{tabular}

\subsubsection{IgE binding western blot}

IgE western blot was conducted to directly identify the bands on the SDS-PAGE that show IgE binding. The specimen was selected depending their activity observed in the IgE dot blot and pooled for similar IgE binding according to the scheme in Table 3.2.

Table 3.2: Pooling of sera and plasma for IgE-western blot and used dilution. Membrane number indicates the membrane that was incubated with the specific pooled specimen.

\begin{tabular}{lll}
\hline Pool/Serum & Patient Serum/Plasma & Dilution \\
\hline Pool 1 & 7,11 , and 12 & $1: 5$ \\
Serum 6 & 6 & $1: 7$ \\
Pool 2 & 8 and 9 & $1: 7$ \\
Pool 3 & 1 and 10 & $1: 5$ \\
\hline
\end{tabular}

SDS-PAGE was prepared and blotted as described for sRAGE western blot (paragraph 3.2.8). All other steps were conducted as described for the IgE dot blot (paragraph 3.2.10).

\subsubsection{Statistical analysis}

Statistical analysis was conducted using IBM SPSS version 23. For multiple sample comparison, one-way ANOVA and Tukey post hoc comparison test was used. Results were considered statistical different at $p<0.05$ if not mentioned otherwise.

\subsection{Results}

To investigate the effect of different heat treatments of BLG on aggregation, formation of MR products, binding to sRAGE, and binding of IgE, BLG was heated in solution (wet conditions) and in powdered form with controlled $\mathrm{a}_{\mathrm{w}}$ (dry conditions). For each humidity condition, BLG was heated in the presence or absence of the milk sugar lactose to distinguish between the effect of glycation and heating. Additionally, each treatment was conducted below the denaturation temperature (LT heating) and above the denaturation temperature (HT heating) of BLG. 


\subsubsection{Solubility of BLG after heat treatments}

Solubility of BLG was impaired after heating in a dry system, but only in the presence of lactose at $130{ }^{\circ} \mathrm{C}$. This was observed by the formation of insoluble material after dissolving BLG in PBS. Therefore, the insoluble aggregates were removed by centrifugation and the soluble fraction of was used for further characterization. Analysis of the total nitrogen content with DUMAS showed a recovery of soluble protein of $76.5 \%$ of the total protein. BLG heated in a wet system and at low temperature in a dry system, did not show the formation of insoluble material, independent of the presence of lactose.

\subsubsection{Quantification of $C M L$}

CML was quantified in all samples to determine the level of the advanced stage of the MR. Table 3.3 compares CML quantities of BLG heated under different conditions in the presence or absence of lactose. No CML was found in the BLG samples that were heated without lactose, because CML formation requires the presence of either a reducing sugar moiety or polyunsaturated fatty acids. CML quantities were on average $\sim 30 \%$ lower when BLG was heated in a wet system than when it was heated in a dry system. The quantities of CML were positively correlated with the temperature of heating in both systems. Additionally, CML levels were relatively higher after dry heating of BLG compared to wet heating.

Table 3.3: CML quantities determined by uHPLC-ESI-MS/MS in the soluble fraction of BLG heated in the presence of lactose (Lac) using wet (W) or dry (D) heat treatment at either low or high temperature (LT/HT), BLG-NT: unheated BLG, ND: quantities below the detection limit. Data are expressed in means of technical duplicates $\pm \mathrm{SD}(n=2)$. Letters indicate significant differences between groups $(p<0.05)$ as analysed by one-way ANOVA and Tukey post hoc comparison test.

\begin{tabular}{cccccccccc}
\hline Sample & $\begin{array}{c}\text { BLG- } \\
\text { NT }\end{array}$ & $\begin{array}{c}\text { W-HT- } \\
\text { Lac }\end{array}$ & W-HT & $\begin{array}{c}\text { W-LT- } \\
\text { Lac }\end{array}$ & W-LT & $\begin{array}{c}\text { D-HT- } \\
\text { Lac }\end{array}$ & D-HT & $\begin{array}{c}\text { D-LT- } \\
\text { Lac }\end{array}$ & D-LT \\
\hline $\begin{array}{c}\text { CML mg/100 g } \\
\text { protein }\end{array}$ & ND & $129 \pm 10 \mathrm{a}$ & ND & $77 \pm 4 \mathrm{~b}$ & ND & $182 \pm 7 \mathrm{c}$ & ND & $158 \pm 9 \mathrm{~d}$ & ND \\
\hline
\end{tabular}

The levels of CML, as a commonly used marker for the "advanced stage" of the MR, indicate that the level of glycation was higher when BLG was heated under dry conditions than under wet conditions. The formation of CML was further facilitated at higher temperature heating within the same humidity conditions.

\subsubsection{SDS-PAGE}

Protein aggregation was monitored using SDS-PAGE under non-reducing conditions, as shown in Figure 3.1. 
a
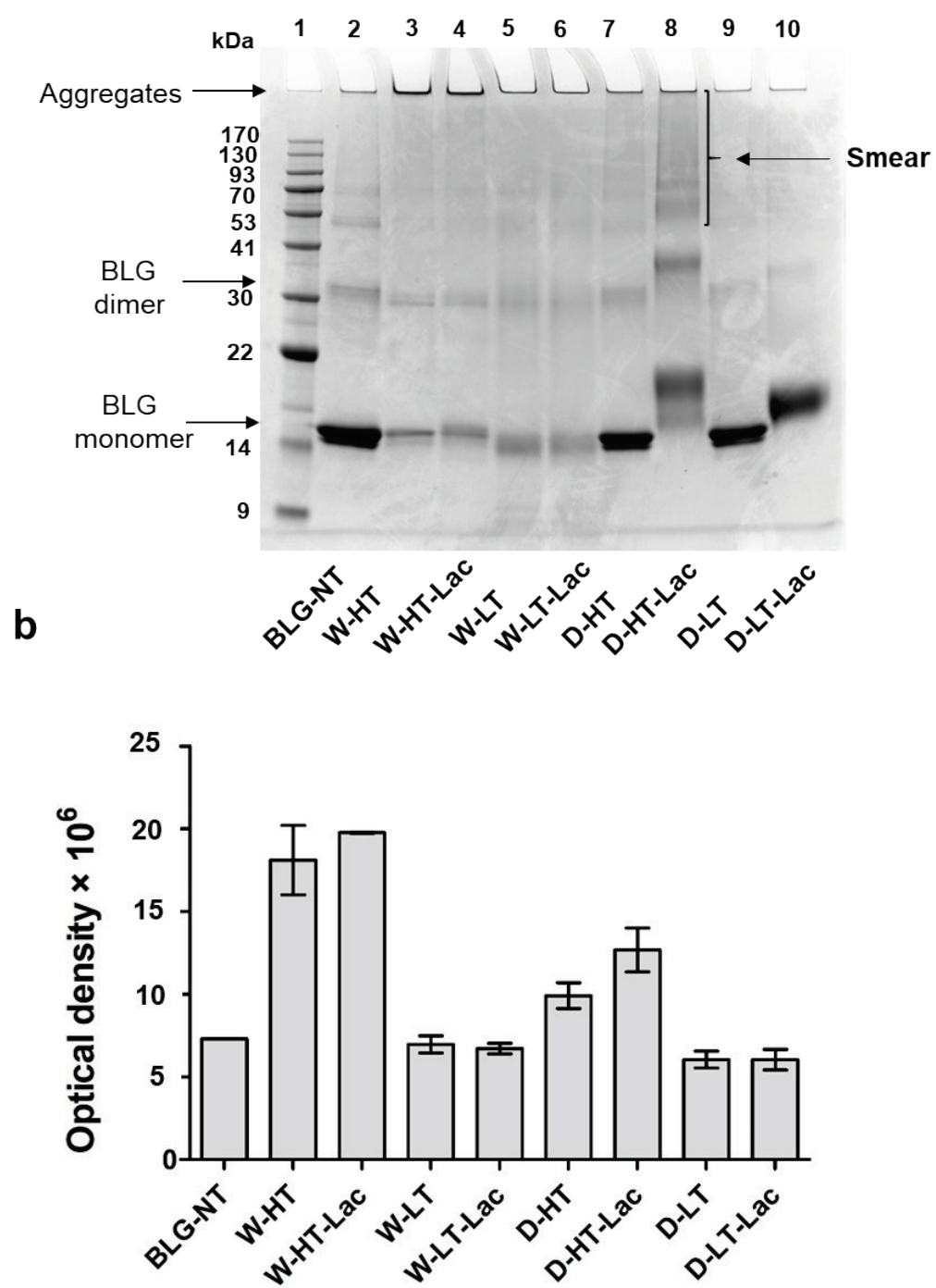

Figure 3.1: (a) Non-reducing SDS-PAGE image of soluble BLG heated and glycated in a wet system (W) and in a dry system (D), respectively in the absence of lactose or in the presence of lactose (Lac) and at either high temperatures (HT) or low temperatures (LT). (b) optical density of the aggregates visible in the top of each lane $(>170 \mathrm{kDa})$. Error bars represent standard deviation of the optical density of two SDS-PAGE gels prepared independently from each other.

When heated in a wet system, BLG formed high-MW aggregates that did not migrate into the gel. Aggregate formation occurred below $\left(60^{\circ} \mathrm{C}\right.$, lanes 5-6) as well as above the denaturation temperature of BLG $\left(100{ }^{\circ} \mathrm{C}\right.$, lanes $\left.3-4\right)$; however, they were more abundant when BLG was heated above its denaturation temperature. The relative aggregate quantities, based on the optical density, showed this effect of heating temperature, but not of lactose presence for the wet-heated samples (lanes 3-4 and lanes 5-6 of Figure 3.1a). Dry-heated BLG aggregates showed 23\% higher optical density in the presence of lactose compared to the heating in the absence of lactose, however only when BLG was heated at HT.

Heating of BLG in a dry system resulted in protein aggregation showing clear differences between the samples with and without lactose. After heating of BLG with lactose at HT (Figure 3.1a, lane 8), the MW of the BLG monomer increased by approx. $4 \mathrm{kDa}$ while the BLG 
dimer showed an increasing MW by approx. $6 \mathrm{kDa}$. The relative intensity of the BLG dimer increased by $55 \%$ compared to the unheated control, indicating a shift of the monomer-dimer equilibrium of BLG. Additionally, D-HT-Lac showed a smear starting from an apparent MW $>53 \mathrm{kDa}$ until the top of the gel (lane 8). D-LT (lane 9) showed monomeric BLG at an apparent MW of $14 \mathrm{kDa}$, which is similar to the non-treated BLG (BLG-NT). However, a faint smear, similar to the one of D-HT-Lac but with much lower intensity, was also observed for this sample. Dry heating at low temperatures did not induce the formation of aggregates, neither in the presence or absence of lactose, in the soluble fraction. However, a shift of apparent MW of the BLG monomer by $2 \mathrm{kDa}$ was observed in D-LT-Lac.

These data indicate that whereas wet heating favours formation of aggregates, dry heating favours MR.

\subsubsection{Detection of glycation structures on SDS-PAGE visible proteins}

To directly identify which of the bands visible on the SDS-PAGE are modified by MR, the Pro-Q ${ }^{\mathrm{TM}}$ Emerald 300 glycoprotein staining kit was used. The staining reacts with structures carrying a reducing carbonyl moiety and can therefore indicate the presence of MR products (MRPs) from all three stages of the MR. Stained glycated protein will appear as white bands on the SDS-PAGE image (Figure 3.2).

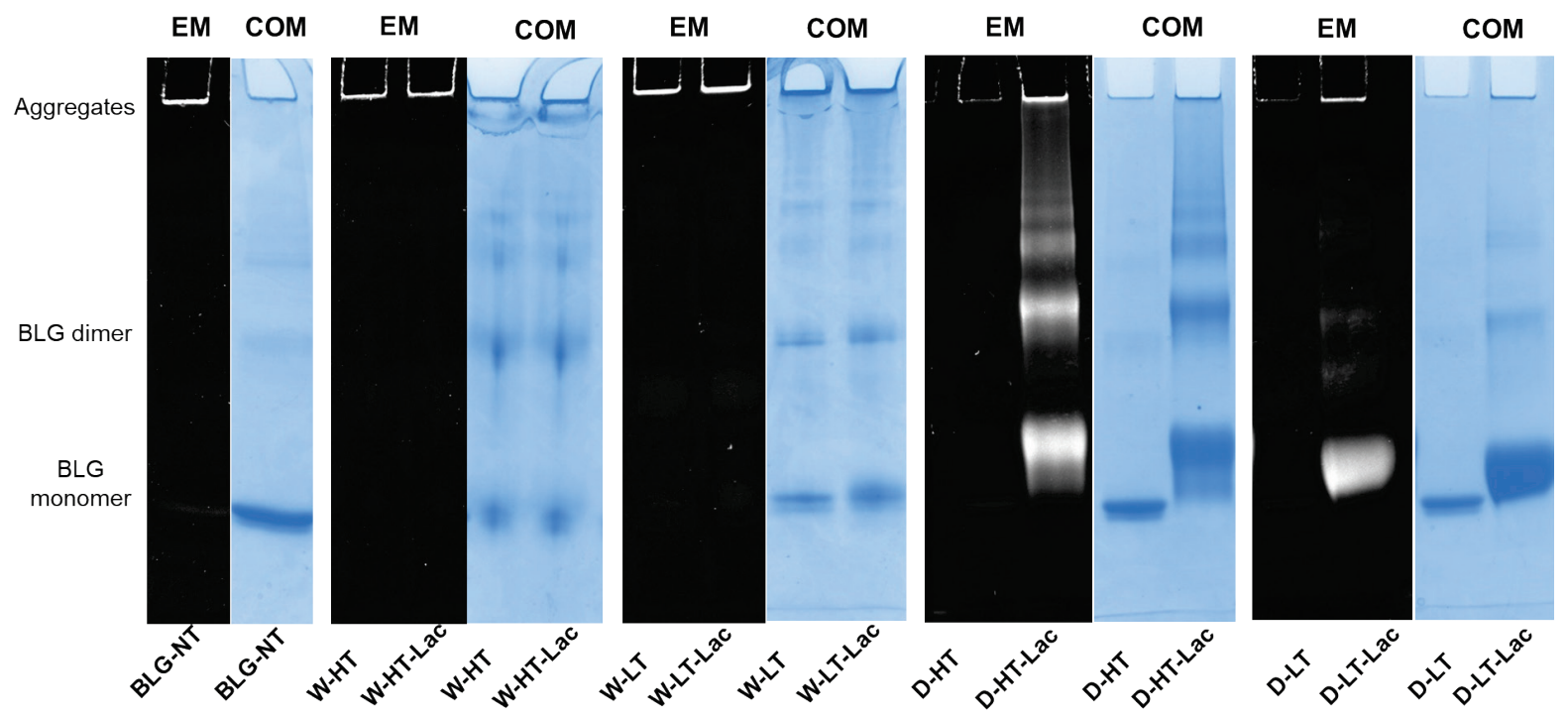

Figure 3.2: Non-reducing SDS-PAGE image of soluble BLG heated and glycated in a wet system (W) and in a dry system (D), respectively in the absence of lactose or in the presence of lactose (Lac) and at either high temperatures (HT) or low temperatures (LT). Gels were stained with $\mathrm{Q}^{\mathrm{TM}}$ Emerald 300 staining for glycoproteins (EM) and Coomassie staining (COM) for total protein staining.

Wet-heated BLG showed a fluorescence signal of the aggregates in the top of the gel, independent of the presence of lactose and the temperature. Based on CML western blot (Figure 3.2) it can be concluded that under wet heating conditions, the glycation structures are mainly present in the high-MW aggregates; however it was not clearly visualized by glycation staining. It may be explained by the fluorescent specking at the edges of the gel which is an intrinsic property of the dye and/or the fluorescence signal from tryptophan residues of native 
BLG. Both effects can contribute to the positive signal for unheated BLG in the top of the gel. It may also partly contribute to the positive signal of the high-MW aggregates of wet-heated BLG making difficult to quantitatively interpret the presence of reducing carbonyl groups in the wet-heated samples.

Dry heating showed high fluorescence when heated in the presence of lactose at high and low temperatures, and not when heated in the absence of lactose. The signal for glycation structures was observed for all proteins that were also visible with Coomassie staining (Figure 3.3). A positive signal with glycation staining was also observed for the BLG monomer of D-HT and D-HT-Lac and the high-MW aggregates. The same is also true for BLG-NT. However, the relative glycation staining intensity of the aggregates from heated and glycated BLG is higher than the high-MW band visible in BLG-NT.

a

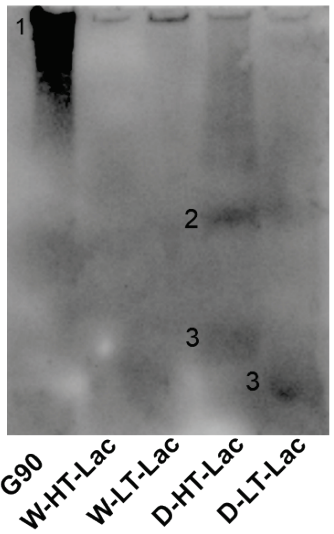

b

Aggregates
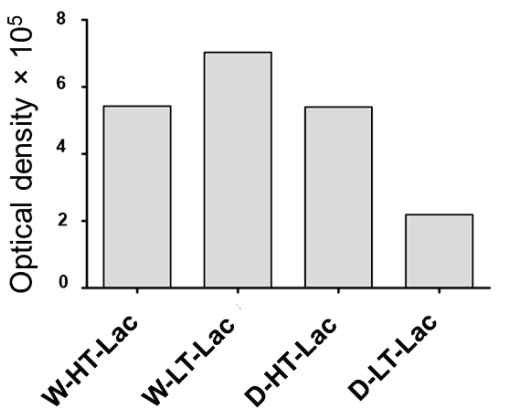

BLG dimers

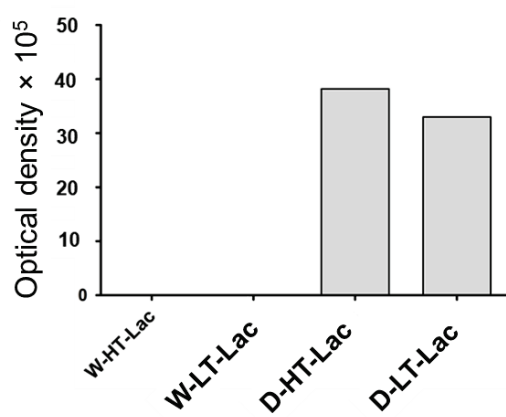

BLG monomers

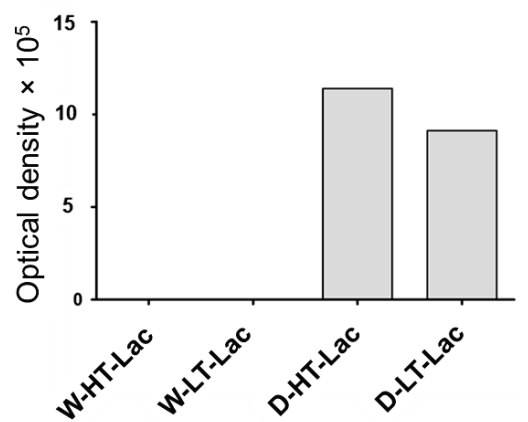

Figure 3.3: (a) Membrane image of CML western blot measured of BLG heated in the presence of lactose (Lac) in a wet system (W) or a dry system (D) at low temperatures (LT) or high temperatures (HT). G90: soy protein extract glycated with glucose for $90 \mathrm{~min}$ (positive control). Numbers indicate aggregates (1), BLG dimers (2), and BLG monomers (3). (b) Optical density of bands visible on the CML western blot categorized in high-MW aggregates, BLG dimers, and BLG monomers as indicated on the membrane.

The band of wet-heated BLG at low temperature showed higher intensity than wet-heated BLG at HT, which is in contradiction to the total CML quantities. This can be explained by the lower accessibility of the CML antibody to CML structures if they are buried inside of the aggregate. This effect might have more impact in HT treated samples because of the more compact structure of the aggregates. These data show that under wet heating conditions glycation 
structures and CML are mainly detected in high-MW aggregates, while under dry heating conditions they are observed in all protein factions.

\subsubsection{Formation of fibril structures}

The ThT-assay was conducted to monitor the formation of fibril structures and exposure of $\beta$-sheet structures upon heating and glycation of BLG. Results are shown in Figure 3.4.

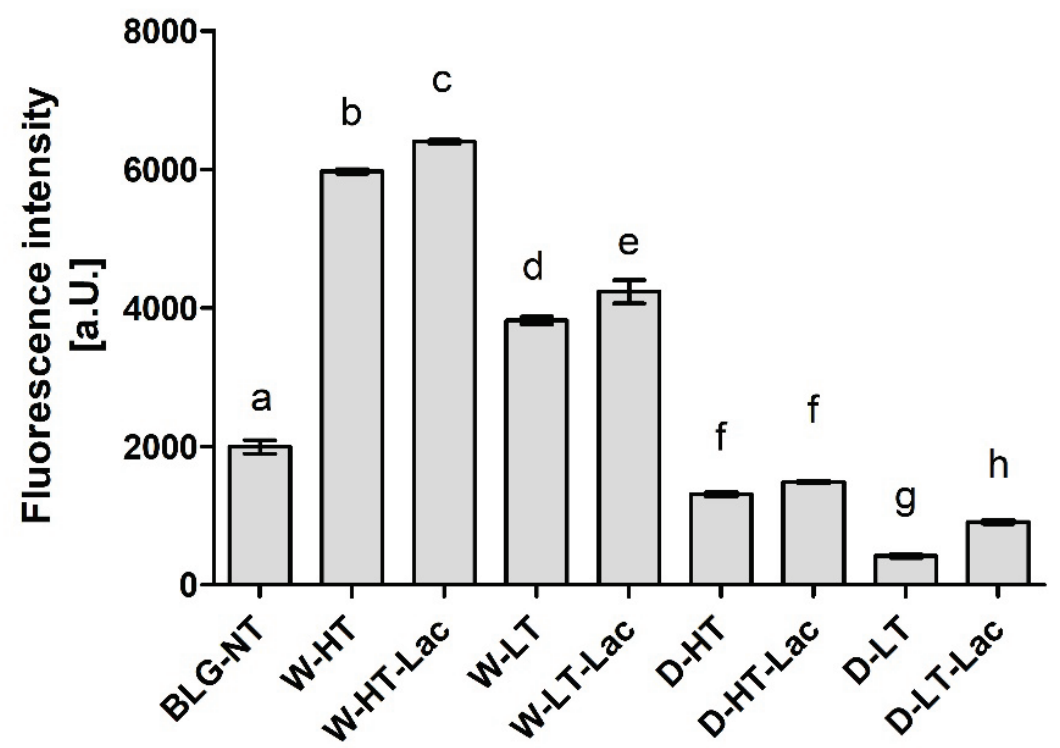

Figure 3.4: ThT fluorescence intensity after incubation with BLG heated in the absence of lactose or in the presence of lactose (Lac) in a wet system (W) or a dry system (D) under low temperatures (LT) or high temperatures (HT). BLG-NT: unheated BLG. Error bars represent standard deviation of technical duplicates. Letters indicate significant differences between the BLG groups. $p$-values $<0.05$ are considered statistically significant, as analysed with one-way ANOVA and Tukey post hoc comparison test.

Highest fluorescence intensity was observed for wet-heated BLG and increased with higher heating temperature. When heated under dry conditions, the fluorescence intensity did not increase above the level of BLG-NT, indicating that no additional $\beta$-sheet structures were exposed. These results indicate that $\beta$-sheet structures are exposed and/or formed when BLG is heated under wet conditions independent of the presence of lactose. At the same time, this effect is not observed under dry heating conditions. This indicates that the exposure of $\beta$-sheet structures is facilitated under wet heating conditions while the presence of lactose plays a minor role independent of the humidity conditions.

\subsubsection{Binding of SRAGE to heated and glycated BLG}

Binding of sRAGE to heated and glycated BLG was monitored using sRAGE inhibition ELISA where high inhibition indicates high sRAGE binding affinity (Figure 3.5). 
a

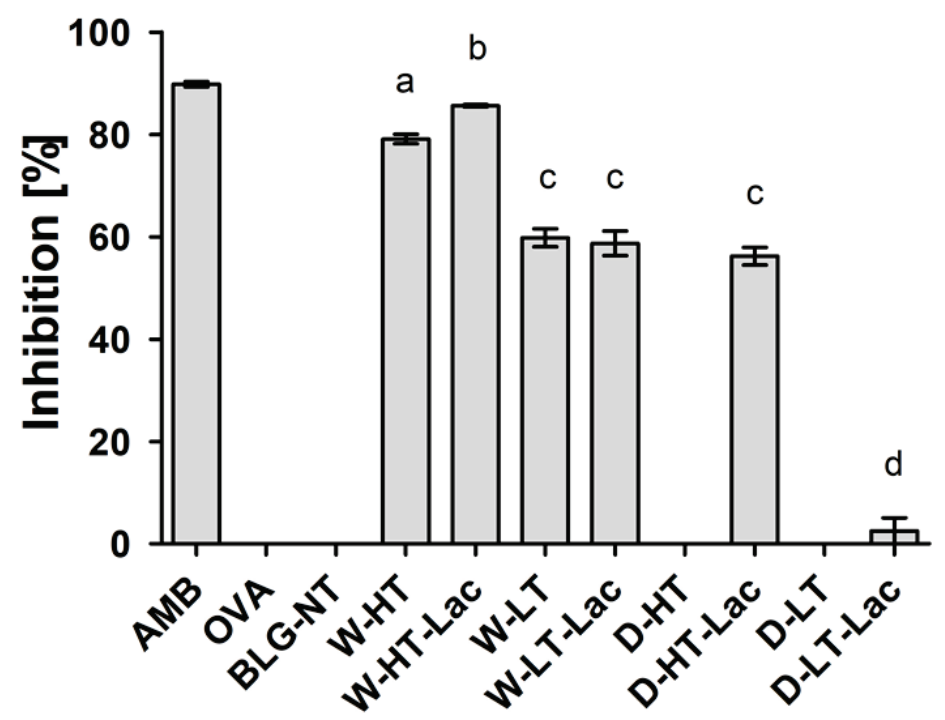

b

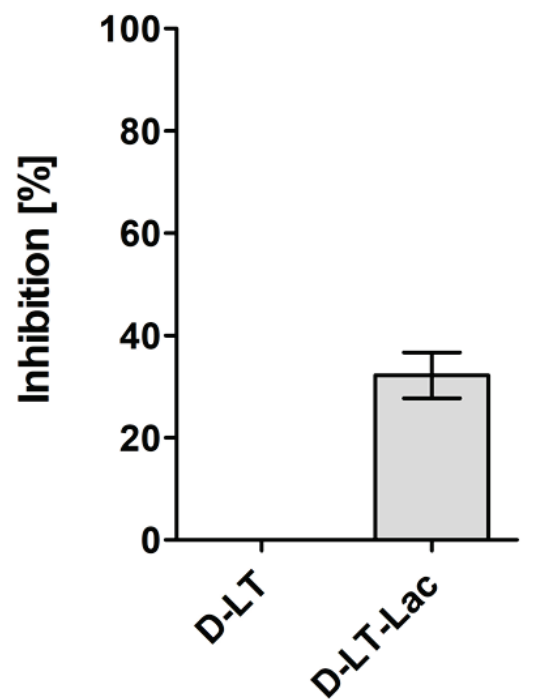

Figure 3.5: (a) Inhibition of sRAGE binding in competition ELISA by BLG heated in wet system (W) and dry system (D) in the absence of lactose or presence of lactose (Lac) at high or low temperature (HT and LT) for all treatments at a protein concentration $25 \mathrm{ug} / \mathrm{mL}$. AMB: amyloid- $\beta$ (positive control), OVA: ovalbumin (negative control). (b) Results of inhibition sRAGE ELISA for D-BLG-LT and D-LT-La at a protein concentration $100 \mu \mathrm{g} / \mathrm{mL}$. Error bars represent standard deviation of technical triplicates. Letters indicate significant differences between the BLG groups. p-values $<0.05$ are considered statistically significant, as analysed with one-way ANOVA with Tukey post hoc comparison test.

BLG-NT did not show any binding affinity to sRAGE while BLG heated in wet systems, both with and without lactose, showed increased sRAGE binding affinity compared to BLG-NT. Wet heating at higher temperature resulted in $28 \%$ higher sRAGE binding affinity than wet heating at lower temperature. At HT, sRAGE showed 8\% higher binding to W-HT-Lac than $\mathrm{W}-\mathrm{HT}$, while at low temperatures no lactose dependent difference was observed. In contrast to the wet system, BLG heated without lactose in a dry system (at either LT or HT) did not show any binding affinity for sRAGE. D-HT showed a similar sRAGE binding affinity as the LT wet-heated samples. BLG heated in dry system with lactose at low temperature (D-LT-Lac) showed the lowest sRAGE binding compared to the other samples; however the binding increased with higher protein concentration (Figure 3.5b), indicating that sRAGE does show binding affinity but lower than for the other samples.

Western blot analysis was used to directly identify which fractions on the SDS-PAGE were responsible for the sRAGE binding determined for heated and glycated BLG in the sRAGE inhibition ELISA. These results are shown in Figure 3.6. 
a

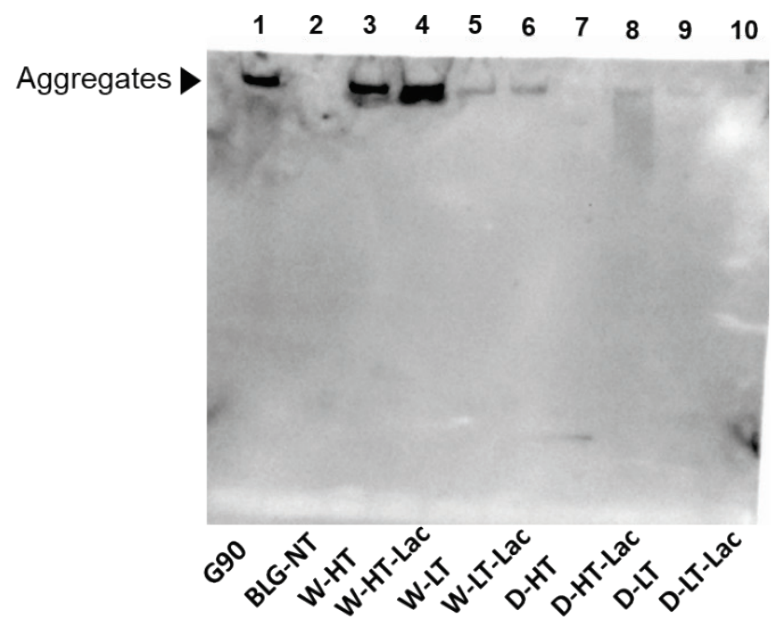

b

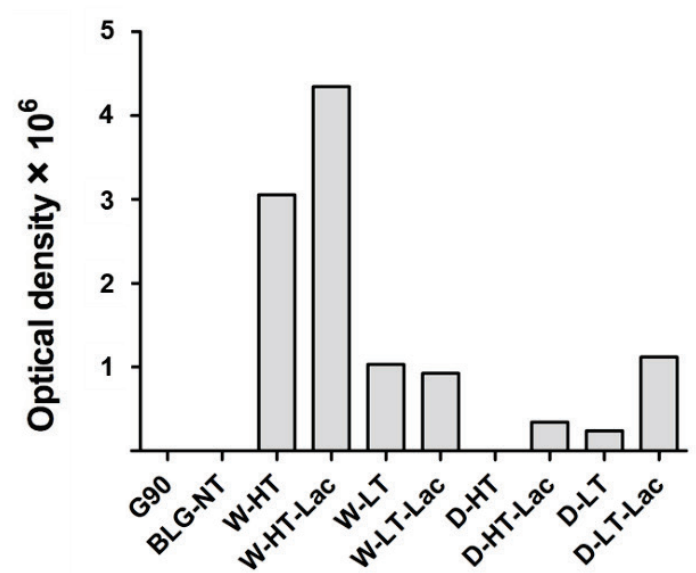

Figure 3.6: Membrane of sRAGE western blot for BLG heated in the absence of lactose or presence of lactose (Lac) under wet conditions (W) or dry conditions (D) at high temperatures (HT) or low temperatures (LT). (b) Optical density of the bands showing sRAGE binding affinity. G90: soy protein extract glycated with glucose for $90 \mathrm{~min}, 100^{\circ} \mathrm{C}$, wet conditions (positive control).

No binding of sRAGE to the monomeric form of BLG was observed in any of the heat-treated BLG samples except for dry heating at low temperature (Figure 3.6a, lane 9). The faint band in the lower part of lane 7 is most likely an artefact, as no protein was seen at this position on the SDS-PAGE. The fraction showing highest affinity to sRAGE were high-MW aggregates of BLG observed in wet-heated samples, especially those heated at HT (lanes 3-4). Aggregates of wet-heated samples with lactose showed $\sim 30 \%$ higher intensity than samples heated without lactose, suggesting that both aggregation but also glycation play a role in sRAGE binding. The same tendency of slightly increasing sRAGE binding in the presence of lactose under wet conditions, was also observed in the ELISA. At LT wet heating, no increased signal intensity was observed when lactose was present. In the dry system at HT, sRAGE binding to the smear formed at MW $>53 \mathrm{kDa}$ was observed for lactose-containing sample. At LT dry heating a faint band was observed for aggregates of lactose-free heated BLG. The signal intensity of BLG heated in the presence of lactose under dry conditions, based on the optical density (Figure 3.6b), increased by $\sim 75 \%$. The relative binding intensity of BLG heated under different conditions are in line with the ELISA results (Figure 3.5). These results indicate that aggregation promotes sRAGE binding affinity to a greater extent than glycation.

\subsubsection{IgE binding to heated and glycated $B L G$}

IgE binding dot blot was conducted to screen the available plasma and sera for their IgE binding affinity to untreated BLG as well as heated and glycated BLG under wet or dry conditions at HT. The results of the 12 different sera/plasma samples from Table 3.1 are shown in Figure 3.7. Based on the dot blot results, the sera were pooled (see Table 3.2) to perform IgE western blots. 


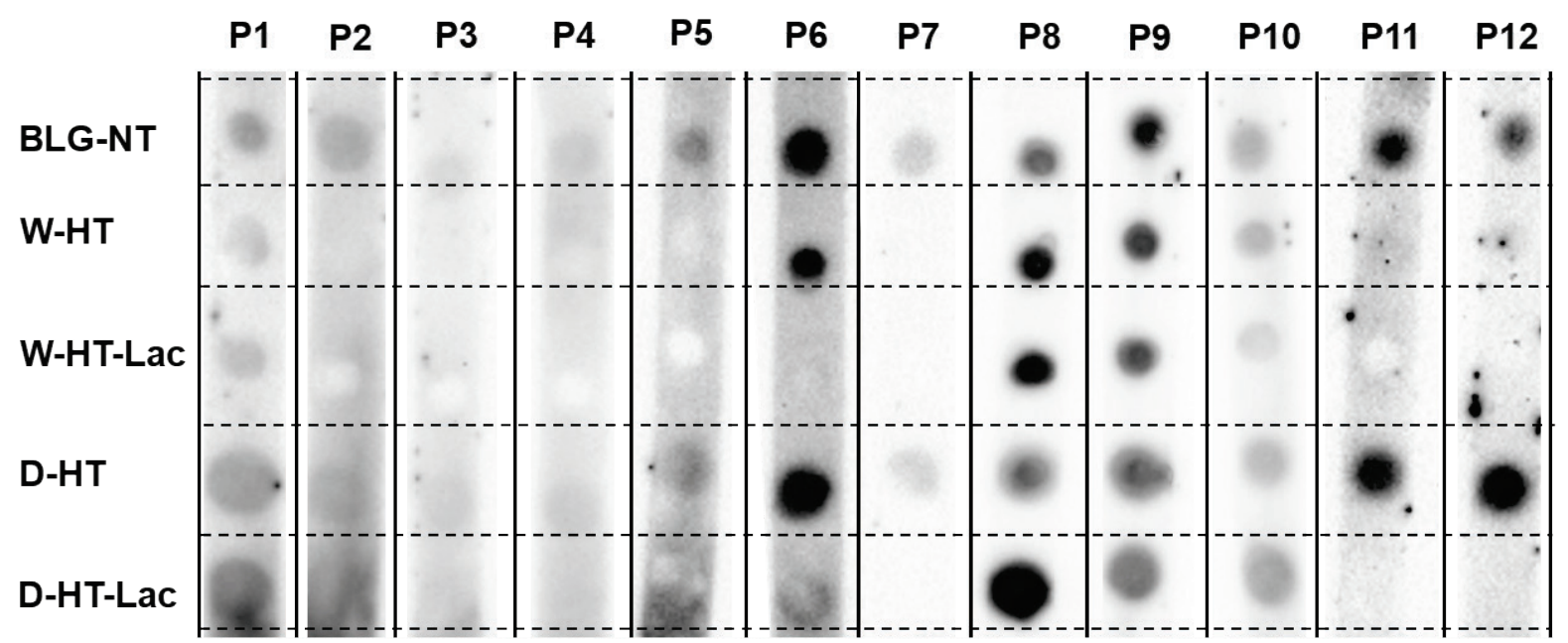

Figure 3.7: IgE dot blot membranes of sera from 12 different patients $(\mathrm{P})$ tested for their binding affinity to unheated BLG (BLG-NT) and BLG heated at high temperatures (HT) either under wet (W) or dry (D) conditions, both in the absence of lactose (BLG) or in the presence of lactose (Lac).

No binding to BLG was observed for the sera of patient 3 and only weak binding to unheated BLG for the sera of patient 4. All other sera showed a positive binding to BLG-NT.

Four different profiles for IgE binding to heated and glycated BLG were observed. The sera described as IgE binding profiles 1-4 were pooled (see Table 3.2 for details) to perform western blots (Figure 3.8). Sera 7, 11, and 12 showed only binding to unheated BLG and BLG heated in the absence of lactose under dry conditions. Serum 2 and serum 5 also showed a similar profile of binding to BLG to sera 7,11, and 12; however, because of the high background, it could not be excluded that they also show binding to BLG heated in the presence of lactose under dry conditions. Therefore, they were not included in pool 1.

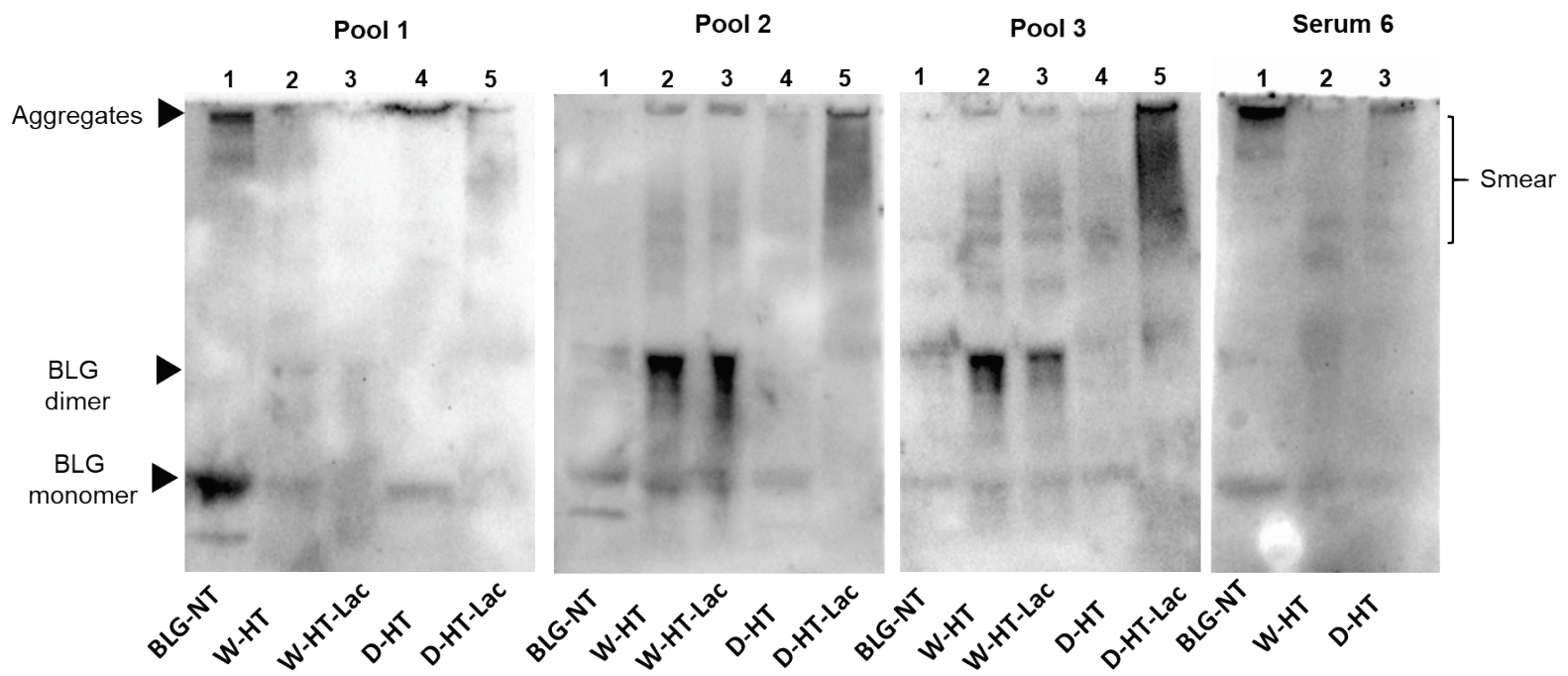

Figure 3.8: IgE western blot membranes of unheated BLG (BLG-NT) as well as BLG heated at high temperatures (HT) either under wet (W) or dry (D) conditions, both in the absence of lactose or in the presence of lactose (Lac). Sera of cow's milk allergic patients were pooled. Pool 1: sera 7, 11, 12. Pool 2: serum 8 and serum 9. Pool 3: serum 1 and serum 10. 
Western blots confirmed the results observed in dot blot and indicated that the binding of $\operatorname{IgE}$ occurs to both BLG monomer and the aggregates, with strongest binding for BLG-NT and D-HT (pool 1, lane 4 and 5). A band below the BLG monomer band was also observed in unheated BLG although this band was not seen on the SDS-PAGE (Figure 3.1a). While the binding intensity for BLG-NT was equal between the monomer and the aggregates, in D-HT the binding intensity to the aggregates was $\sim 30 \%$ higher than to the monomer (Figure 3.8 , pool 1, lane 4). Weak binding was also observed for the BLG monomer in samples heated in the absence of lactose under wet conditions and to the smear of BLG heated in the presence of lactose under dry conditions (Figure 3.8, pool 1, lane 2 and 5). Pool 2 showed binding to all samples, with higher binding to wet-heated BLG independent of the presence of lactose and to dry-heated BLG in the presence of lactose. Western blots showed IgE binding to the BLG monomer and the BLG dimer in unheated BLG. When heated under wet conditions (Figure 3.8, pool 2, lane 2 and lane 3), binding was observed to the BLG monomer, BLG dimer, and the aggregates. The dimer showed the highest IgE binding intensity with $\sim 50 \%$ and $\sim 60 \%$ of the total optical density of W-HT and W-HT-Lac, respectively. BLG heated under dry conditions showed binding to the BLG monomer and to a smear $>53 \mathrm{kDa}$, with higher binding when heated in the presence of lactose (Figure 3.8, pool 2, lane 5) compared to heating in the absence of lactose (Figure 3.8, pool 2, lane 4). Additionally, in the presence of lactose, the aggregates also showed high IgE binding. Pool 3 showed equal binding to unheated and all heated BLG. This sample showed the same IgE binding pattern as pool 2, except for the smear of D-HT-Lac (Figure 3.8, pool 3, lane 5) that showed higher intensity than in pool 2. Serum 6 showed a unique binding pattern with strong binding to unheated BLG, and BLG heated in the absence of lactose for dry and wet heating conditions. A weak binding was also observed for BLG heated under dry conditions in the presence of lactose but not to the equivalent sample heated under wet conditions. Interestingly, the binding intensity was higher to the aggregates than to the monomer, for both BLG-NT (Figure 3.8, serum 6, lane 1) and D-HT (serum 6, lane 3) with $\sim 30 \%$ and $\sim 55 \%$, respectively. For BLG heated under wet conditions in the absence of lactose, the binding was also observed to the monomer and dimer but less to the aggregates.

To summarise, the results of $\operatorname{IgE}$ dot blot indicate high individual variations in the IgE binding profiles to heated and glycated BLG and allowed the grouping into four binding affinity profiles. Wet-heated BLG showed reduced IgE binding when compared to non-treated BLG for 5 out of 10 sera giving the positive signal, independent of the presence of lactose. Dry heating of BLG without lactose did not affect IgE binding compared to non-treated BLG. On the other hand, BLG dry-heated in the presence of lactose increased IgE binding compared to both untreated BLG and dry-heated BLG without lactose, revealing an effect of glycation on the sIgE binding capacity. Results showed which BLG fractions were responsible for IgE binding observed in the dot blot analysis, indicating a shift of IgE binding towards higher MW fractions (BLG dimers and aggregates) formed upon heating. 


\subsection{Discussion}

Food processing promotes the changes of the immunogenic and antigenic properties of food allergens [3], among others via MR. In this study, we showed that during processing of BLG both the temperature and $\mathrm{a}_{\mathrm{w}}$ (wet vs. dry heating) are important factors affecting its immunogenicity. Wet heating of BLG, independent of the presence of lactose in the sample, promotes the formation of aggregates recognised by sRAGE and IgE from CM allergic patients. In contrast to wet heating the aggregates formed upon dry heating showed differences in an immunogenic profile of the samples heated in the presence or absence of lactose, therefore revealing contribution of glycation to the formation of both sRAGE and $\operatorname{IgE}$ binding epitopes.

Both glycation and aggregation of BLG depends on the applied heating conditions. Glycation of milk proteins is promoted at low $\mathrm{a}_{\mathrm{w}}$ of 0.31-0.98 [19]. At the same time, heating at high humidity conditions facilitates the aggregation of BLG via disulphide linkages [20,21] but leads to a relative lower levels of glycation structures compared to dry heating [22,23]. This effect was also observed in this study where the formation of CML and detection of glycation structures on BLG was significantly higher in dry-heated BLG than in wet-heated BLG. This was confirmed by CML western blot (Figure 3.3) showing highest levels of CML in D-HT-Lac detected in monomers, dimers, and aggregates of BLG while in the wet-heated samples the CML appeared only in the aggregates. Next to that, more glycation structures formed during heating of BLG under dry conditions in the presence of lactose were detected by the glycation staining (Figure 3.2). On the other hand, the formation of high-MW aggregates was independent of the presence of lactose in wet-heated samples compared to dry-heated samples. However, aggregation was also observed in the sample heated under dry conditions with lactose. It has already been described that glycation-induced modifications of lysine and arginine can increase the flexibility of the protein structure and leads to the formation of covalent crosslinking between different amino acid residues. Both facilitates protein denaturation and aggregation $[16,24]$ and influences the morphology of the protein aggregates [25,26]. Additionally, glycation strongly affects the size of these aggregates when heated under dry conditions but may also contributes to structural differences of the formed aggregates under both humidity conditions [1]. However, reactant mobility during the wet heating also affects the aggregation rate of proteins, where higher inter-molecular mobility results in higher protein aggregation [27]. The observed differences in aggregation of wet-heated BLG vs. dry-heated BLG are in line with the findings of Deng et al. [1] who showed increased formation of polymers and oligomers in wet-heated BLG compared to dry-heated BLG. The authors also showed that the dry heating of $\mathrm{BLG}$ at $130{ }^{\circ} \mathrm{C}$ increased its oligomerisation and polymerisation and was mainly affected by the presence of lactose. On the other hand, the wet heating led to more exposure of $\beta$-sheet structures in the soluble aggregates than dry heating. These findings stay in line with our results showing a higher content of surface-exposed $\beta$-sheets structures in the wet-heated BLG independent of the presence of lactose in the sample. The formation of aggregates in both wet and dry heating conditions was shown to have a great impact of the formation of sRAGE 
binding ligands. Three different patterns of sRAGE binding affinity (Figure 3.6) were observed, depending on the heating temperature and the $a_{w}$ of the system. First, when heated in the wet system high sRAGE binding was observed to the formed aggregates, regardless of the presence of lactose. Secondly, sRAGE binding occurred independent of the presence of CML but increased with higher exposure of $\beta$-sheet structures after wet heating (Figure 3.3 and Figure 3.4). Finally, in the dry-heated system, sRAGE binding was observed only to BLG heated in the presence of lactose (high-MW fractions), revealing an impact of glycation under dry heating conditions (Figure 3.6). Being a promiscuous receptor, sRAGE binds not only to AGEs but also to amyloid- $\beta$, S100 protein, and HGMB1 [11]. Those ligands share a common property to act as oligomers, highlighting the potential of sRAGE to recognize high-MW structures [12]. Next to the aggregation itself, the glycation-induced aggregation was already pointed out to be responsible for the formation of sRAGE ligands under dry heating conditions; however this was not directly proven [13]. With the western blot analysis of sRAGE binding we confirmed these findings, proving that under the dry heating conditions of BLG glycation without aggregation does not lead to increased sRAGE binding. Consequently, the changes in sRAGE binding were accompanied by the changes in IgE binding affinity by (treatment-dependent) formation of neo-epitopes or destruction of existing epitopes. Several studies indicated that both glycation and aggregation, contribute to changes in cellular recognition and allergic sensitisation $[1,4,13,28,29]$. The results of dot blot with the sera of CM allergic patients showed high individual variations in the IgE binding to heated and glycated BLG. Four different profiles of IgE binding affinity were observed which showed, depending on the used conditions, either increased or diminished IgE binding to heat-treated BLG. The dot blot analysis revealed that wet heating reduces $\operatorname{IgE}$ binding independent of the presence of lactose which was observed in 5 out of 10 sera giving a positive signal with non-treated BLG (Figure 3.7). Therefore, glycation appears to play a minor role in changing $\operatorname{IgE}$ binding when BLG is heated under wet conditions. For dry-heated samples, IgE binding was only decreased when lactose was present during heating (Figure 3.7), indicating the masking of epitopes by the attached sugar moiety. These differences indicate that humidity applied during the heat processing as well as glycation are important factors influencing IgE binding affinity. The western blot results (Figure 3.8) obtained for four pools of sera to heated BLG allowed to detect the fractions and bands responsible for IgE reactivity observed in dot blot. Three different fractions present in non-treated BLG were recognised by IgE: BLG monomer, BLG dimer, and oligomers in the top of the gel. Binding of IgE to the oligomers present in non-treated BLG was always accompanied with the positive binding to the oligomers present in dry-heated sample without lactose suggesting the existence of similar epitopes in these two samples (Figure 3.8, pool 1 and serum 6). Interestingly, the aggregates formed during the wet heating showed $\operatorname{IgE}$ reactivity only in case of half of the tested sera indicating a lactose-independent decrease of IgE binding affinity. It has been shown in the past that the free cysteine $(\mathrm{C} 121)$ is strongly involved in the aggregation of BLG when heated in a wet system and this results in the formation of covalently linked aggregates [21]. Due to the higher translational motion in the wet system 
compared to the dry system the formation of these covalent linkages is favoured in the wet system leading to higher extend of aggregation. This might also result in the embedding or exposure of different IgE epitopes when comparing the two humidity conditions. The observation of IgE binding for half of the patients stay in line with a previous finding that reported decreased IgE binding to BLG when heated above $90{ }^{\circ} \mathrm{C}$ under wet conditions [9,30,31]. Additionally, Kleber and Hinrichs [31] postulated that protein aggregation may decreases IgE binding affinity. However, our study points out that there are different MW fractions formed during wet and dry heating of BLG that can be recognised by IgE of some patients. This was lactose-independent after wet heating of BLG and was mostly found to higher MW fractions $>$ BLG dimers. The same patients also show higher IgE binding to dry-heated $\mathrm{BLG}$ in the presence of lactose compared to the lactose-free control. The most immuno-reactive fraction was a high-MW smear of dry-heated BLG in the presence of lactose which also showed the presence of glycation structures and CML (Figure 3.8). This was also true for the BLG monomer and dimer in this sample but IgE binding was not observed to these fractions in the same pool of sera. This indicates that MR may has a double effect in sensitisation. First, it can lead to masking of epitopes in the BLG monomer and dimer as described previously also for other food allergens [8,32,33]. Secondly, the formation of glycation-induced aggregates can enhance IgE binding via neo-epitope formation. The study of Vissers et al. [34] showed reduced allergenicity of MR-modified peanut allergen Ara h 1 in $\operatorname{IgE}$ binding test while enhanced $\beta$-hexominidase release from basophils upon incubation with the same MR-modified allergen. The authors suggested that MR-induced aggregates of Ara $\mathrm{h} 1$ could be responsible for the observed increased capacity of antigen to cross-link the IgE and initiate the mediator release from RBL-2H3 cells. Similar observations were also made for other protein families such as peanut proteins and scallop tropomyosin [8,35-37]. Thus, the influence of MR on IgE binding seems to depend on physicochemical properties of proteins (hydrophobicity, size, amino acid composition, charge) as well as on the conditions of the MR (type of sugar, time, $\mathrm{a}_{\mathrm{w}}, \mathrm{pH}$, temperature, presence of salts) [36,38].

Different IgE binding profiles observed in this study indicate the high individual differences between CM allergic patients and demonstrates the importance of involving better characterised CM allergic patients' sera in the IgE binding study. That would allow a prediction to be made towards the influence of aggregation and glycation of BLG on its allergenicity. This would help to optimize processing conditions towards less immunoreactive products which is especially relevant in the production of infant formula. Furthermore, it should be considered that both aggregation and glycation affect protein digestibility. Antigens with resistance to gastrointestinal digestion are commonly understood to be the most potent allergens in terms of $\mathrm{IgE}$ binding [39]. It is known that glycation-induced aggregates are more resistant to in vitro gastrointestinal digestion [26]. Therefore, aggregates might have higher physiological relevance than aggregates formed in the absence of sugar even though they were as potent in stimulating sRAGE binding and IgE binding as aggregates formed in the absence of sugar. 


\subsection{Conclusions}

sRAGE binding is highest when BLG is heated under wet conditions and is mostly determined by aggregation rather than formation of MRPs. Under dry heating conditions, sRAGE binding is mostly affected by the presence of lactose but a strict distinction between the effect of the formation of MRPs and glycation-induced aggregation could not be made. Also IgE binding seems to be affected by aggregation and glycation; however high inter-individual differences do not allow clear differentiation between the effects of the used heating conditions on allergic sensitisation. Therefore, more individuals need to be screened to get more insight in the role of aggregation and glycation on sRAGE binding and IgE binding affinity of thermally processed BLG. However, this data suggests that different heating conditions of BLG result in the formation of different $\mathrm{sRAGE}$ ligands and $\operatorname{IgE}$ epitopes and that the $\mathrm{a}_{\mathrm{w}}$ during the processing of milk compounds contributes to the pattern of sensitisation. 


\section{References}

1. Deng, Y.; Govers, C.; Bastiaan-Net, S.; van der Hulst, N.; Hettinga, K.; Wichers, H.J. Hydrophobicity and aggregation, but not glycation, are key determinants for uptake of thermally processed $\beta$-lactoglobulin by THP-1 macrophages. Food Research International 2019, 120, 102-113, doi:10.1016/j.foodres.2019.01.038.

2. Ames, J.M. Control of the Maillard reaction in food systems. Trends in Food Science and Technology 1990, 1, 150-154, doi:10.1016/0924-2244(90)90113-d.

3. Rahaman, T.; Vasiljevic, T.; Ramchandran, L. Effect of processing on conformational changes of food proteins related to allergenicity. Trends in Food Science and Technology 2016, 49, 24-34, doi:10.1016/j.tifs.2016.01.001.

4. Roth-Walter, F.; Berin, M.C.; Arnaboldi, P.; Escalante, C.R.; Dahan, S.; Rauch, J.; Jensen-Jarolim, E.; Mayer, L. Pasteurization of milk proteins promotes allergic sensitization by enhancing uptake through Peyer's patches. Allergy: European Journal of Allergy and Clinical Immunology 2008, 63, 882-890, doi:10.1111/j.1398-9995.2008.01673.x.

5. Kim, J.S.; Nowak-Wgrzyn, A.; Sicherer, S.H.; Noone, S.; Moshier, E.L.; Sampson, H.A. Dietary baked milk accelerates the resolution of cow's milk allergy in children. Journal of Allergy and Clinical Immunology 2011, 128, 125-131.e122, doi:10.1016/j.jaci.2011.04.036.

6. Nowak-Wegrzyn, A.; Bloom, K.A.; Sicherer, S.H.; Shreffler, W.G.; Noone, S.; Wanich, N.; Sampson, H.A. Tolerance to extensively heated milk in children with cow's milk allergy. Journal of Allergy and Clinical Immunology 2008, 122, 342-347.e342, doi:10.1016/j.jaci.2008.05.043.

7. Esmaeilzadeh, H.; Alyasin, S.; Haghighat, M.; Nabavizadeh, H.; Esmaeilzadeh, E.; Mosavat, F. The effect of baked milk on accelerating unheated cow's milk tolerance: A control randomized clinical trial. Pediatric Allergy and Immunology 2018, 29, 747-753, doi:10.1111/pai.12958.

8. Taheri-Kafrani, A.; Gaudin, J.C.; Rabesona, H.; Nioi, C.; Agarwal, D.; Drouet, M.; Chobert, J.M.; Bordbar, A.K.; Haertle, T. Effects of heating and glycation of $\beta$-lactoglobulin on its recognition by ige of sera from cow milk allergy patients. Journal of Agricultural and Food Chemistry 2009, 57, 4974-4982, doi:10.1021/jf804038t.

9. Ehn, B.M.; Ekstrand, B.; Bengtsson, U.; Ahlstedt, S. Modification of IgE Binding during Heat Processing of the Cow's Milk Allergen $\beta$-Lactoglobulin. Journal of Agricultural and Food Chemistry 2004, 52, 13981403, doi:10.1021/jf0304371.

10. Ott, C.; Jacobs, K.; Haucke, E.; Navarrete Santos, A.; Grune, T.; Simm, A. Role of advanced glycation end products in cellular signaling. Redox Biology 2014, 2, 411-429, doi:10.1016/j.redox.2013.12.016.

11. Fritz, G. RAGE: A single receptor fits multiple ligands. Trends in Biochemical Sciences 2011, 36, 625-632, doi:10.1016/j.tibs.2011.08.008.

12. Kierdorf, K.; Fritz, G. RAGE regulation and signaling in inflammation and beyond. Journal of Leukocyte Biology 2013, 94, 55-68, doi:10.1189/jlb.1012519.

13. Liu, F.; Teodorowicz, M.; Wichers, H.J.; Van Boekel, M.A.J.S.; Hettinga, K.A. Generation of Soluble Advanced Glycation End Products Receptor (sRAGE)-Binding Ligands during Extensive Heat Treatment of Whey Protein/Lactose Mixtures Is Dependent on Glycation and Aggregation. Journal of Agricultural and Food Chemistry 2016, 64, 6477-6486, doi:10.1021/acs.jafc.6b02674.

14. Perkins, T.N.; Oczypok, E.A.; Dutz, R.E.; Donnell, M.L.; Myerburg, M.M.; Oury, T.D. The Receptor for Advanced Glycation Endproducts is a Critical Mediator of Type 2 Cytokine Signaling in the Lungs. The Journal of allergy and clinical immunology 2019, 10.1016/j.jaci.2019.03.019, doi:10.1016/j.jaci.2019.03.019.

15. Ngoc, L.P.; Gold, D.R.; Tzianabos, A.O.; Weiss, S.T.; Celedón, J.C. Cytokines, allergy, and asthma. Current Opinion in Allergy and Clinical Immunology 2005, 5, 161-166, doi:10.1097/01.all.0000162309.97480.45.

16. Cardoso, H.B.; Wierenga, P.A.; Gruppen, H.; Schols, H.A. Maillard induced aggregation of individual milk proteins and interactions involved. Food Chemistry 2019, 276, 652-661, doi:10.1016/j.foodchem.2018.10.061.

17. De Jongh, H.H.J.; Gröneveld, T.; De Groot, J. Mild isolation procedure discloses new protein structural properties of $\beta$-lactoglobulin. Journal of Dairy Science 2001, 84, 562-571, doi:10.3168/jds.S00220302(01)74508-0.

18. Troise, A.D.; Fiore, A.; Roviello, G.; Monti, S.M.; Fogliano, V. Simultaneous quantification of amino acids and Amadori products in foods through ion-pairing liquid chromatography-high-resolution mass spectrometry. Amino Acids 2015, 47, 111-124, doi:10.1007/s00726-014-1845-5.

19. Pereyra Gonzales, A.S.; Naranjo, G.B.; Leiva, G.E.; Malec, L.S. Maillard reaction kinetics in milk powder: Effect of water activity at mild temperatures. International Dairy Journal 2010, 20, 40-45, doi:10.1016/j.idairyj.2009.07.007. 
20. Hoffmann, M.A.M.; Van Mil, P.J.J.M. Heat-Induced Aggregation of $\beta$-Lactoglobulin: Role of the Free Thiol Group and Disulfide Bonds. Journal of Agricultural and Food Chemistry 1997, 45, 2942-2948, doi:10.1021/jf960789q.

21. Roefs, S.P.F.M.; De Kruif, K.G. A Model for the Denaturation and Aggregation of $\beta$-Lactoglobulin. European Journal of Biochemistry 1994, 226, 883-889, doi:10.1111/j.1432-1033.1994.00883.x.

22. Fenaille, F.; Morgan, F.; Parisod, V.; Tabet, J.C.; Guy, P.A. Solid-state glycation of $\beta$-lactoglobulin by lactose and galactose: Localization of the modified amino acids using mass spectrometric techniques. Journal of Mass Spectrometry 2004, 39, 16-28, doi:10.1002/jms.539.

23. Akıllığlu, H.G.l.; Çelikbıçak, O.m.r.; Salih, B.; Gökmen, V. Monitoring protein glycation by electrospray ionization (ESI) quadrupole time-of-flight (Q-TOF) mass spectrometer. Food Chemistry 2017, 217, 65-73, doi:10.1016/j.foodchem.2016.08.088.

24. Iannuzzi, C.; Irace, G.; Sirangelo, I. Differential effects of glycation on protein aggregation and amyloid formation. Frontiers in Molecular Biosciences 2014, 1, doi:10.3389/fmolb.2014.00009.

25. Bouma, B.; Kroon-Batenburg, L.M.J.; Wu, Y.P.; Brünjes, B.; Posthuma, G.; Kranenburg, O.; De Groot, P.G.; Voest, E.E.; Gebbink, M.F.B.G. Glycation Induces Formation of Amyloid Cross- $\beta$ Structure in Albumin. Journal of Biological Chemistry 2003, 278, 41810-41819, doi:10.1074/jbc.M303925200.

26. Pinto, M.S.; Léonil, J.; Henry, G.; Cauty, C.; Carvalho, A.F.; Bouhallab, S. Heating and glycation of $\beta$ lactoglobulin and $\beta$-casein: Aggregation and in vitro digestion. Food Research International 2014, 55, 7076, doi:10.1016/j.foodres.2013.10.030.

27. Gulzar, M.; Bouhallab, S.; Jardin, J.; Briard-Bion, V.; Croguennec, T. Structural consequences of dry heating on alpha-lactalbumin and beta-lactoglobulin at pH 6.5. Food Research International 2013, 51, 899906, doi:10.1016/j.foodres.2013.02.025.

28. Liu, F.; Teodorowicz, M.; Van Boekel, M.A.J.S.; Wichers, H.J.; Hettinga, K.A. The decrease in the IgGbinding capacity of intensively dry heated whey proteins is associated with intense Maillard reaction, structural changes of the proteins and formation of RAGE-ligands. Food and Function 2016, 7, 239-249, doi:10.1039/c5fo00718f.

29. Perusko, M.; van Roest, M.; Stanic-Vucinic, D.; Simons, P.J.; Pieters, R.H.H.; Cirkovic Velickovic, T.; Smit, J.J. Glycation of the Major Milk Allergen $\beta$-Lactoglobulin Changes Its Allergenicity by Alterations in Cellular Uptake and Degradation. Molecular Nutrition and Food Research 2018, 62, doi:10.1002/mnfr.201800341.

30. Bu, G.; Luo, Y.; Zheng, Z.; Zheng, H. Effect of heat treatment on the antigenicity of bovine $\alpha$-lactalbumin and $\beta$-lactoglobulin in whey protein isolate. Food and Agricultural Immunology 2009, 20, 195-206, doi:10.1080/09540100903026116.

31. Kleber, N.; Maier, S.; Hinrichs, J. Antigenic response of bovine $\beta$-lactoglobulin influenced by ultra-high pressure treatment and temperature. Innovative Food Science and Emerging Technologies 2007, 8, 39-45, doi:10.1016/j.ifset.2006.05.001.

32. Cellmer, T.; Bratko, D.; Prausnitz, J.M.; Blanch, H.W. Protein aggregation in silico. Trends in Biotechnology 2007, 25, 254-261, doi:10.1016/j.tibtech.2007.03.011.

33. Scheurer, S.; Lauer, I.; Foetisch, K.; Moncin, M.S.M.; Retzek, M.; Hartz, C.; Enrique, E.; Lidholm, J.; Cistero-Bahima, A.; Vieths, S. Strong allergenicity of Pru av 3, the lipid transfer protein from cherry, is related to high stability against thermal processing and digestion. Journal of Allergy and Clinical Immunology 2004, 114, 900-907, doi:10.1016/j.jaci.2004.06.017.

34. Vissers, Y.M.; Iwan, M.; Adel-Patient, K.; Stahl Skov, P.; Rigby, N.M.; Johnson, P.E.; Mandrup Müller, P.; Przybylski-Nicaise, L.; Schaap, M.; Ruinemans-Koerts, J., et al. Effect of roasting on the allergenicity of major peanut allergens Ara h 1 and Ara h 2/6: The necessity of degranulation assays. Clinical and Experimental Allergy 2011, 41, 1631-1642, doi:10.1111/j.1365-2222.2011.03830.x.

35. Gruber, P.; Vieths, S.; Wangorsch, A.; Nerkamp, J.; Hofmann, T. Maillard reaction and enzymatic browning affect the allergenicity of Pru av 1, the major allergen from cherry (Prunus avium). Journal of agricultural and food chemistry 2004, 52, 4002-4007.

36. Blanc, F.; Vissers, Y.M.; Adel-Patient, K.; Rigby, N.M.; Mackie, A.R.; Gunning, A.P.; Wellner, N.K.; Skov, P.S.; Przybylski-Nicaise, L.; Ballmer-Weber, B., et al. Boiling peanut Ara h 1 results in the formation of aggregates with reduced allergenicity. Molecular Nutrition and Food Research 2011, 55, 1887-1894, doi:10.1002/mnfr.201100251.

37. Rahaman, T.; Vasiljevic, T.; Ramchandran, L. Conformational changes of $\beta$-lactoglobulin induced by shear, heat, and pH-Effects on antigenicity. Journal of Dairy Science 2015, 98, 4255-4265, doi:10.3168/jds.2014-9010.

38. Iwan, M.; Vissers, Y.M.; Fiedorowicz, E.; Kostyra, H.; Kostyra, E.; Savelkoul, H.F.J.; Wichers, H.J. Impact of maillard reaction on immunoreactivity and allergenicity of the hazelnut allergen cor a 11. Journal of Agricultural and Food Chemistry 2011, 59, 7163-7171, doi:10.1021/jf2007375. 
39. Taylor, S.L.; Lemanske, R.F.; Bush, R.K.; Busse, W.W. Food allergens: Structure and immunologic properties. Annals of Allergy 1987, 59, 93-99. 



\section{Chapter 4}

Binding of CML-modified as well as heat-glycated $\beta$-lactoglobulin to receptors for AGEs is determined by charge and hydrophobicity

This chapter has been published as:

Hannah E. Zenker, Malgorzata Teodorowicz, Arifa Ewaz, R. J. Joost van Neerven, Huub F. J. Savelkoul, Nicolette W. De Jong, Harry J. Wichers, Kasper A. Hettinga (2020). Binding of $C M L$-modified as well as heat-glycated $\beta$-lactoglobulin to receptors for AGEs is determined by charge and hydrophobicity. International Journal of Molecular Sciences, 21, 4567. 


\begin{abstract}
:
Intake of dietary advanced glycation end products (AGEs) is associated with inflammation-related health problems. $\mathrm{N}^{\varepsilon}$-carboxymethyllysine (CML) is one of the best characterised AGEs in processed food. AGEs have been described as ligands for receptors present on antigen presenting cells. However, changes in protein secondary and tertiary structure also induce binding to AGE receptors. We aimed to discriminate the role of different protein modifications in binding to AGE receptors. Therefore, $\beta$-lactoglobulin (BLG) was chemically modified with glyoxylic acid to produce CML and compared to BLG glycated with lactose. Secondary structure was monitored with circular dichroism, while hydrophobicity and formation of $\beta$-sheet structures was measured with ANS-assay and ThT-assay, respectively. Aggregation was monitored using native-PAGE. Binding to sRAGE, CD36, and galectin-3 was measured using inhibition ELISA. Even though no changes in secondary structure were observed in all tested samples, binding to AGE receptors increased with CML concentration of CML-modified BLG. The negative charge of CML was a crucial determinant for the binding of protein bound CML, while binding of glycated BLG was determined by increasing hydrophobicity. This shows that sRAGE, galectin-3, and CD36 bind to protein bound CML and points out the role of negatively charged AGEs in binding to AGE receptors.
\end{abstract}




\subsection{Introduction}

$\beta$-lactoglobulin (BLG) is the main component of the whey protein fraction that contributes $\sim 10 \%$ to the total protein in cow's milk and has been described as one of the major allergens in cow's milk [1]. Moreover, it is one of the few proteins in cow's milk that is not present in human breastmilk. Its amino acid sequence consist of 162 amino acids, including 16 lysine residues, 3 arginine residues, and 1 free cysteine [2], which makes it prone to glycation via the Maillard reaction (MR) as well as heat induced unfolding. This may result in the formation of advanced glycation end products (AGEs) and irreversible structural changes of BLG upon heating. Formation of AGEs as a result of the MR can occur endogenously or exogenously. Exogenous AGEs have a source in thermally processed foods, where protein is heated in the presence of reducing sugars. This is considered to contribute to $10 \%$ of the AGE pool in the body [3]. There is a growing body of evidence that AGEs contribute to a number of inflammation-related health issues such as chronic inflammation, atherosclerosis, and allergy [4-6]. In fact, in vivo animal studies with glycated food proteins confirmed their potential to activate inflammatory pathways and showed the contribution of high dietary intake of AGEs on inflammation-mediated health implications [7,8]. Furthermore, it was reported that glycation of food proteins enhances their uptake by antigen presenting cells (APCs) and affects T-cell proliferation [9-11].

Antigen uptake and initiation of immunological responses to AGEs is mediated by AGE-receptor/ligand interactions on the surface of APCs [12]. A number of AGE-binding receptors on the surface of innate immune cells have been described in previous studies, such as the receptor for AGEs (RAGE), CD36, galectin-3 (Gal-3) as part of the AGE-R complex, scavenger class A type I and type II [13-17]. Next to AGEs, these pattern recognition receptors can also bind to other structures and some share other ligands such amyloid beta for RAGE and CD36, as well as bacterial lipopolysaccharides for RAGE and Gal-3. [18-20]. Lysine modification with $\mathrm{N}^{\varepsilon}$-carboxymethyllysine (CML) is one of the most abundant as well as one of the best characterised AGEs in processed milk [21,22]. CML has been the target of previous studies, determining the effect of AGEs in receptor mediated immune responses [23-25]. Only few studies looked at the role of specific AGEs while limiting 3D-folding modifications during the glycation process $[23,26]$. However, disentangling these effects is crucial, as protein aggregation, heating and glycation induced increase of hydrophobicity and $\beta$-sheet structures have also been reported as determinants for uptake of glycated food proteins by macrophages and the binding to AGE receptors [27-29]. In this study, chemical modification of the milk allergen BLG was performed to obtain a specific modification of lysine to CML, which was then compared to BLG glycated with lactose below the denaturation temperature of BLG, to avoid heat-induced structural changes of the protein. Binding to the soluble form of RAGE (sRAGE), which shows identical binding to the extracellular ligands as RAGE [30], as well as binding to CD36 and Gal-3 was assessed with inhibition ELISA tests to assess the respective role of various protein modifications in receptor binding. 


\subsection{Materials and Methods}

\subsubsection{Chemicals}

Lyophilised BLG from bovine milk ( $>90 \%$ purity) was purchased from Merck (Darmstadt, Germany). Novex ${ }^{\mathrm{TM}}$ Wedge Well ${ }^{\mathrm{TM}} 14 \%$ tris-glycine gel, Novex ${ }^{\mathrm{TM}}$ tris-glycine native sample buffer $(2 \mathrm{x})$, and Novex ${ }^{\mathrm{TM}}$ tris-glycine native running buffer (10x) were purchased from Thermo Fischer (Massachusetts, USA). Coomassie brilliant blue R-250 was obtained from Biorad (Hercules, California, USA). CML and CML-d2 were purchased from Polypeptide laboratories (Strasbourg, France). MS grade acetonitrile was purchased from Actu-All chemicals (Oss, Netherlands). Ultra-pure water was prepared by an ELGA LabWater Purelab Plus water system (Celle, Germany). Soluble Advanced Glycation End Product-Specific Receptor Human E. coli (RD172116100) was purchased from Biovendor (Brno, Czech Republic). Anti-RAGE antibody (monoclonal mouse IgG2B clone, MAB11451), recombinant human CD36/SR-BIII Fc chimera, recombinant human galectin-3 protein, and human galectin-3 antibody (Monoclonal mouse IgG2B clone) were purchased from R\&D systems (Minneapolis, Minnesota, USA). HRP conjugated anti-mouse polyclonal goat (P0447) and polyclonal rabbit anti-mouse antibody/biotinylated were obtained from Dako (Glostrup, Denmark). Goat AntiHuman IgG/HRP was purchased from SouthernBiotech (Birmingham, Minnesota, USA). TMB substrate $\left(3,3^{\prime}, 5,5^{\prime}\right.$-tetramethylbenzidine $)$ for high sensitivity ELISA and streptavidin-PolyHRP80 were purchased from sdt-reagents (Baesweiler, Germany). Ovalbumin (OVA) was purchased from InvivoGen (San Diego, California, USA). Bovine Serum Albumin Fraction V (BSA) was obtained from Roche (Basel, Switzerland). Amyloid- $\beta$ (1-42) ultra-pure HFIP was purchased from Westburg (Leusden, the Netherlands). All other chemicals were purchased from Merck (Darmstadt, Germany).

\subsubsection{CML introduction in BLG}

CML was introduced in BLG using the method by Glorieux et al. [25] with slight modifications. Briefly, BLG was dissolved in $10 \mathrm{mM}$ phosphate saline buffer (PBS) at $\mathrm{pH}$ 7.4. Glyoxylic acid monohydrate was added in three different molar ratios of glyoxylic acid to lysine residues. These ratios were 1:1, 3:1, and 5:1, respectively. Subsequently, sodium cyanoborohydride was added in a ratio $8.8 \mathrm{mmol} / \mathrm{g} \mathrm{BLG}$ and the solutions were incubated for $20 \mathrm{~h}$ at $40^{\circ} \mathrm{C}$ in a heating block (Labtherm Graphit, Liebisch, Germany). Incubation of BLG at $40{ }^{\circ} \mathrm{C}$ for $20 \mathrm{~h}$ was performed as control (C1). After incubation, samples were dialysed at $4{ }^{\circ} \mathrm{C}$ using a $\mathrm{MWCO}$ of 6-8000 Spectra/Por membrane (Thermo Fisher Scientific, Waltham, Massachusetts, USA) to remove residual glyoxylic acid. All samples were prepared in duplicate. All solutions were freeze dried and dissolved in water. 


\subsubsection{Glycation of $B L G$}

BLG was glycated with lactose at $60{ }^{\circ} \mathrm{C}$ to minimise thermally induced protein aggregation. Incubation was conducted over saturated potassium fluoride solution to keep the water activity $\left(\mathrm{a}_{\mathrm{w}}\right)$ at 0.23 . Heating was conducted for $12 \mathrm{~h}, 24 \mathrm{~h}$, and $48 \mathrm{~h}$ in the presence of lactose. BLG heated under the same conditions in the absence of lactose was taken as heating control. After heating, BLG was immediately cooled down and dissolved in water before storage at $-20{ }^{\circ} \mathrm{C}$ and stored until further analysis.

\subsubsection{Quantification of CML using LC-MS/MS}

CML was quantified after borohydride reduction and acidic hydrolysis and solid phase extraction were conducted considering previous methods [31,32]. Quantification was conducted using external calibration with d2-CML as internal standard. Analysis was performed using a Nexera UPLC system (Shimadzu Corporation, Kyoto, Japan) coupled with a LCMS-8050 triple quadrupole mass spectrometer (Shimadzu Corporation, Kyoto, Japan). The UPLC unit consisted of a SIL-30AC autosampler, a LC-20ADXR solvent delivery module, DGU-20ASR degassing unit, a CTO-20AC column oven and a FCV-20AH2 valve unit. The samples $(5 \mu \mathrm{L})$ were injected on a Kinetex HILIC $2.6 \mu \mathrm{m}, 2.1 \mathrm{~mm} \times 100 \mathrm{~mm}$ (Phenomenex, Torrance, California, USA). The flow rate was set at $0.4 \mathrm{~mL} / \mathrm{min}$ and the column temperature at $30{ }^{\circ} \mathrm{C}$. The mobile phases consisted of $0.1 \%$ formic acid (solvent $\mathrm{A}$ ), acetonitrile with $0.1 \%$ formic acid (solvent $\mathrm{B}$ ) and $50 \mathrm{mmol} / \mathrm{L}$ ammonium formate (solvent $\mathrm{C}$ ) with the following elution profile (time in $[\mathrm{min}] /[\% \mathrm{~B}] /[\% \mathrm{C}]):(0 / 80 / 10),(0.8 / 80 / 10),(3.5 / 40 / 10),(6.5 / 40 / 10)$, $(8.0 / 80 / 10)$ and (10.0/80/10). MS data were collected for 10 mins. Positive ionisation mode was used for all MS analyses. The voltage of the turbo ion-spray ionization was $4.0 \mathrm{kV}$. The temperature of electrospray ionization probe, desolvation line, and heat block were set at $300{ }^{\circ} \mathrm{C}, 250^{\circ} \mathrm{C}$, and $400^{\circ} \mathrm{C}$, respectively. The pressure of the collision-induced dissociation gas was $4 \mathrm{kPa}$ whereas the flow rates of the drying gas, nebulizer gas, and heating gas were set at $10 \mathrm{~mL} / \mathrm{min}, 3 \mathrm{~mL} / \mathrm{min}$, and $10 \mathrm{~mL} / \mathrm{min}$, respectively. The electrode voltage of Q1 pre bias (collision cell energy (CE) entrance potential), collision cell Q2 (CE), Q3 pre bias (CE exit potential), parent and fragment ion $\mathrm{m} / \mathrm{z}$ of the multiple reaction monitoring transitions were optimized using support software (Shimadzu Corporation, Kyoto, Japan). Precursor ions were $205.200 \mathrm{~m} / \mathrm{z}$ and $207.200 \mathrm{~m} / \mathrm{z}$ for CML and CML-d2, respectively. Product ions were $84.050 \mathrm{~m} / \mathrm{z}, 130.050 \mathrm{~m} / \mathrm{z}, 56.150 \mathrm{~m} / \mathrm{z}$ and $84.050 \mathrm{~m} / \mathrm{z}, 130.200 \mathrm{~m} / \mathrm{z}, 56.100 \mathrm{~m} / \mathrm{z}$ for CML and CML-d2, respectively. The second and third product ion yield was selected as structural confirmation based on the optimized selected reaction monitoring transition, whereas the first product ion was used for quantification.

\subsubsection{Quantification of free available amino groups}

Free amino groups were measured using o-phthaldialdehyde (OPA)-assay to monitor overall formation of MPRs other than CML. OPA-assay was conducted following a method published 
by Mulet-Cabero et al. [33] with some modifications. Samples were diluted with $10 \mathrm{mM}$ phosphate buffer saline (PBS) and $10 \mu \mathrm{L}$ were pipetted in a transparent polystyrene 96-well plate (Greiner, Kremsmünster, Germany). To each well, $190 \mu \mathrm{L}$ OPA reagent was added and the plate was incubated in the dark for $15 \mathrm{~min}$. L-Leucine was used for the calibration curve in a concentration range between 0.4 to $4 \mathrm{mM}$. Absorbance was measured at $340 \mathrm{~nm}$ using Infinite ${ }^{\circledR} 200$ PRO NanoQuant with i-control software (Tecan, Männedorf, Switzerland).

\subsubsection{Secondary structure}

Secondary structure was analysed with far UV-circular dichroism (CD). Measurements were conducted using a Jasco J-715 spectropolarimeter (Jasco, Tokyo, Japan). Samples were diluted to $0.15 \mathrm{mg} / \mathrm{mL}$ protein concentration. The secondary structure was recorded with far UV between a 180 to $260 \mathrm{~nm}$ using a 15 times quartz cuvette with a path length of $0.1 \mathrm{~cm}$ at $20^{\circ} \mathrm{C}$.

\subsubsection{Surface hydrophobicity}

Surface hydrophobicity was determined using 8-anilino-1-naphthalenesulfonic acid (ANS)-assay according to a method Alizadeh-Pasdar et al. [34] with some modifications. Briefly, samples were diluted to $0.5 \mathrm{mg} / \mathrm{mL}$ and mixed with $0.8 \mathrm{mM}$ ANS solution in a ratio $1 / 20(\mathrm{v} / \mathrm{v})$. After incubation for $10 \mathrm{~min}$ in the dark, fluorescence was measured with an excitation wavelength of $390 \mathrm{~nm}$ and emission wavelength of $470 \mathrm{~nm}$.

\subsubsection{Thioflavin T(ThT)-assay}

The ThT-assay was performed to determine a possible increase in amyloid- $\beta$ structures. Samples were diluted to a protein concentration of $2 \mathrm{mg} / \mathrm{mL}$ with $10 \mathrm{mM}$ PBS (pH 7.4). Subsequently $20 \mu \mathrm{L}$ sample were mixed with $20 \mu \mathrm{L}$ aqueous ThT-solution $(1.25 \mathrm{mg} / \mathrm{mL}$ ThT) and mixed with $120 \mu \mathrm{L}$ PBS. Samples were incubated for $10 \mathrm{~min}$ at room temperature in the dark. Fluorescence intensity was measured with an excitation wavelength of $450 \mathrm{~nm}$ and emission wavelength of $480 \mathrm{~nm}$. All samples were measured in duplicate and corrected for the blank (PBS with ThT-solution). To correct for autofluorescence samples were measured at the same dilution as in the assay and signal was subtracted when applicable.

\subsubsection{Native gel electrophoresis}

Native gel electrophoresis was performed to monitor possible formation of aggregates in the samples. Samples were diluted to equal protein concentrations in $10 \mathrm{mM}$ PBS (pH 7.4) and mixed with native samples buffer $(1: 1(\mathrm{v} / \mathrm{v}))$. Those solutions were loaded onto the gel with a final protein content of $10 \mu \mathrm{g}$ in each pocket. The gels were run at $120 \mathrm{~V}$ for $90 \mathrm{~min}$ in $1 \mathrm{x}$ native running buffer and subsequently stained with Coomassie brilliant blue R-250. Images were taken using a Universal Hood III (Biorad, Hercules, USA) and Image Lab 4.1 software (Biorad, Hercules, USA). 


\subsubsection{Inhibition ELISA assay for receptor binding}

Binding to the receptors for AGEs was determined with inhibition ELISA as described by Zenker et al. [29]. Briefly, samples were diluted with $10 \mathrm{mM}$ PBS to $100 \mu \mathrm{g} / \mathrm{mL}$ protein concentration. Free CML was measured at a concentration of $2 \mathrm{mg} / \mathrm{mL}$. Dilutions were incubated for $45 \mathrm{~min}$ at $37{ }^{\circ} \mathrm{C}$ on a Nunc ${ }^{\mathrm{TM}}$ 96-Well Polypropylene MicroWell ${ }^{\mathrm{TM}}$ (Thermo Fisher Scientific, Massachusetts, USA) with the receptors at concentrations of $0.5 \mu \mathrm{g} / \mathrm{mL}$ for sRAGE, $0125 \mu \mathrm{g} / \mathrm{mL}$ for CD36, and $0.4 \mu \mathrm{g} / \mathrm{mL}$ for Gal-3, respectively. Subsequently, the solutions were added to a high binding transparent Nunc-Immuno ${ }^{\text {TM }}$ MicroWellTM 96-well solid plate (Thermo Fisher Scientific, Massachusetts, USA), blocked with soy protein glycated with glucose for $90 \mathrm{~min}$ at $100{ }^{\circ} \mathrm{C}(\mathrm{G} 90)$ and incubated for $1 \mathrm{~h}$ at $37^{\circ} \mathrm{C}$. After washing, the plates were incubated for $30 \mathrm{~min}$ at room temperature with the specific anti-receptor antibody: anti-RAGE, anti-Gal-3 or anti-his antibody for CD36. Subsequently incubation for $30 \mathrm{~min}$ at room temperature was performed with the respective detection antibody: polyclonal goat anti-mouse Antibody/HRP, polyclonal rabbit anti-mouse antibody/ biotinylated, and goat anti-human IgG/HRP. For Gal-3, an additional incubation step was performed with streptavidin for $15 \mathrm{~min}$ at room temperature before detection with 3,3',5,5'-tetramethylbenzidine solution. Absorbance was measured at wavelength $450 \mathrm{~nm}$ with wavelength $620 \mathrm{~mm}$ as reference wavelength. To evaluate the role of charge in binding to the receptors for AGEs different concentrations of sodium chloride $(\mathrm{NaCl})$ were used. The dilution buffer for the samples contained $0.13 \mathrm{M} \mathrm{NaCl}$. This was supplemented to reach $0.2 \mathrm{M}$ and $0.3 \mathrm{M} \mathrm{NaCl}$ in the final solution of the receptor/sample mixture, respectively. All samples were measured in technical triplicates.

\subsubsection{Statistical analysis}

Statistical analysis was conducted using IBM SPSS version 23. For multiple sample comparison, one-way ANOVA and Tukey post hoc comparison test was used. Results were considered statistical different at $p<0.05$.

\subsection{Results}

\subsubsection{Chemical modification and glycation}

To analyse binding of CML on BLG to receptors, the protein was chemically modified with glyoxal to CML (BLG-CML). To distinguish the effect of lysine blockage via the MR with lactose, without heat-induced structural changes, BLG was glycated with lactose (BLG-Lac) at $60{ }^{\circ} \mathrm{C}$, at $\mathrm{a}_{\mathrm{w}} 0.23$ for 12,24 , and $48 \mathrm{~h}$. Moreover, subsequent chemical CML modification of glycated BLG was used to evaluate whether this changed receptor binding epitopes. The level of CML modification was determined using LC-MS/MS (Table 4.1). 
Table 4.1: $\mathrm{N}^{\varepsilon}$-carboxymethyllysine (CML) content of differentially treated $\beta$-lactoglobulin (BLG). BLG was non-treated (NT), chemically modified with glyoxal to obtain CML at different degree of modification $\left(1,3\right.$, and 5), glycated with lactose (Lac) by heating at $60{ }^{\circ} \mathrm{C}$ for $12 \mathrm{~h}, 24 \mathrm{~h}$, and $48 \mathrm{~h}$; heated at $60{ }^{\circ} \mathrm{C}$ for $12 \mathrm{~h}, 24 \mathrm{~h}$, and $48 \mathrm{~h}$ in the absence of any sugars $(\mathrm{H})$, and glycated by heating with lactose followed by CML induction with glyoxal. CML-modified lysine was calculated based on theoretical levels of lysine available in BLG. Results are given as mean \pm standard deviation $(n=2)$. Statistical differences were tested using one-way ANOVA with Tukey post-hoc test. Significant differences are considered at $p<0.05$, where two variables have different letters if they are significantly different.

\begin{tabular}{ccc}
\hline Sample & CML content [mg/g protein] & CML-modified lysine [\%] \\
\hline BLG-NT & $0.4 \pm 0.3 \mathrm{a}$ & $0.39 \pm 0.3 \mathrm{a}$ \\
BLG-CML-1 & $28.0 \pm 0.1 \mathrm{~b}$ & $17 \pm 0.0 \mathrm{~b}$ \\
BLG-CML-3 & $56.1 \pm 0.1 \mathrm{~cd}$ & $34 \pm 0.1 \mathrm{de}$ \\
BLG-CML-5 & $62.6 \pm 1.3 \mathrm{~d}$ & $38 \pm 0.8 \mathrm{~d}$ \\
BLG-Lac-12 & $2.0 \pm 0.2 \mathrm{a}$ & $1.2 \pm 0.1 \mathrm{a}$ \\
BLG-Lac-24 & $3.7 \pm 0.4 \mathrm{a}$ & $2.2 \pm 0.2 \mathrm{a}$ \\
BLG-Lac-48 & $4.4 \pm 0.3 \mathrm{a}$ & $2.7 \pm 0.2 \mathrm{a}$ \\
BLG-H-12 & $1.6 \pm 1.9 \mathrm{a}$ & $1.0 \pm 1.2 \mathrm{a}$ \\
BLG-H-24 & $0.3 \pm 0.0 \mathrm{a}$ & $0.2 \pm 0.0 \mathrm{a}$ \\
BLG-H-48 & $0.4 \pm 0.2 \mathrm{a}$ & $0.2 \pm 0.1 \mathrm{a}$ \\
BLG-Lac-12-CML & $46.4 \pm 2.9 \mathrm{c}$ & $28 \pm 1.8 \mathrm{c}$ \\
BLG-Lac-24-CML & $50.3 \pm 7.8 \mathrm{c}$ & $31 \pm 4.7 \mathrm{~cd}$ \\
BLG-Lac-48-CML & $34.5 \pm 1.9 \mathrm{~b}$ & $16 \pm 0.9 \mathrm{~b}$ \\
\hline
\end{tabular}

The level of CML-modified lysine and arginine residues increased with a higher ratio of glyoxylic acid/BLG, resulting in 17\% modified residues in BLG-CML-1, 34 \% in BLG-CML-3, and 38\% in BLG-CML-5. BLG heated in the absence of lactose (BLG-H) and BLG heated in the presence of lactose (BLG-Lac) contained much lower levels of CML than BLG-CML samples, regardless of the heating time. Modification of BLG with CML after glycation (BLG-Lac-CML) showed higher levels of CML modification with shorter heating time, resulting in $28 \%, 31 \%$, and $16 \%$ CML-modified residues in BLG-Lac-12-CML, BLG-Lac-24-CML, and BLG-Lac-48-CML, respectively. To determine the extent of heat- and glycation-induced modification in BLG-H and BLG-Lac, free amino groups were quantified using the OPA-assay (Figure 4.1).

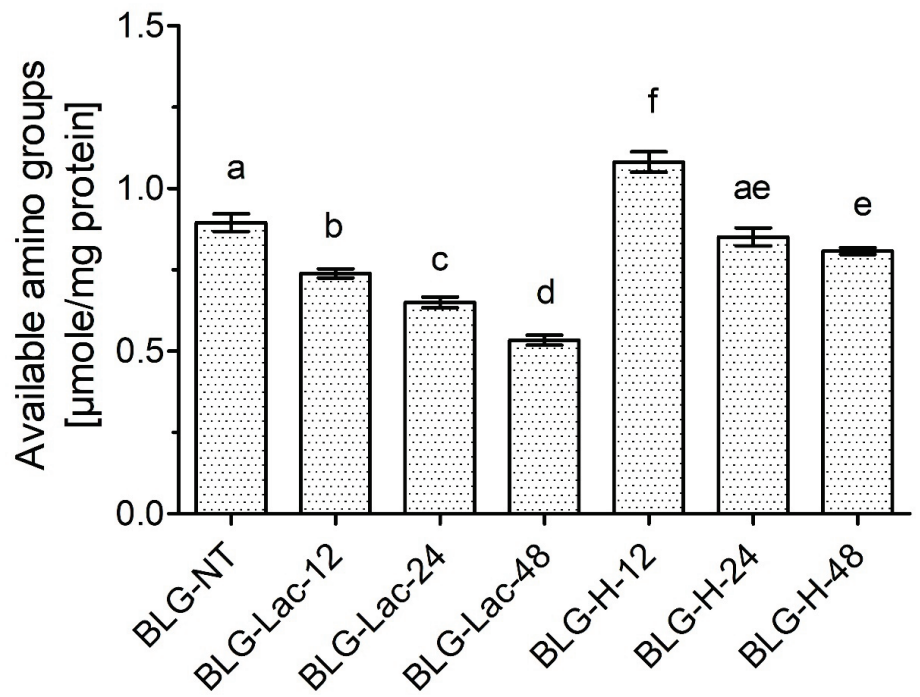

Figure 4.1: Available amino groups of $\beta$-lactoglobulin (BLG), non-treated (NT), glycated with lactose (Lac) by heating at $60{ }^{\circ} \mathrm{C}$ for $12 \mathrm{~h}, 24 \mathrm{~h}$, and $48 \mathrm{~h}$, as well as heated at $60{ }^{\circ} \mathrm{C}$ for $12 \mathrm{~h}, 24 \mathrm{~h}$, and $48 \mathrm{~h}$ in the absence of any sugars $(\mathrm{H})$. Error bars represent standard deviation of technical replicates $(n=3)$. Statistical differences were tested using one-way ANOVA with Tukey post-hoc test. Significant differences were considered at $p<0.05$, where two variables have different letters if they are significantly different. 
When BLG was heated in the presence of lactose, the number of free amino groups decreased with longer heating time. At the same time, heating in the absence of lactose first increased the levels of free amino groups after $12 \mathrm{~h}$ of heating (BLG-H-12), but subsequently decreased with prolonged heating time to the level of BLG-NT.

\subsubsection{Structural changes}

Hydrophobicity relative to untreated BLG was measured using the ANS-assay (Figure 4.2).

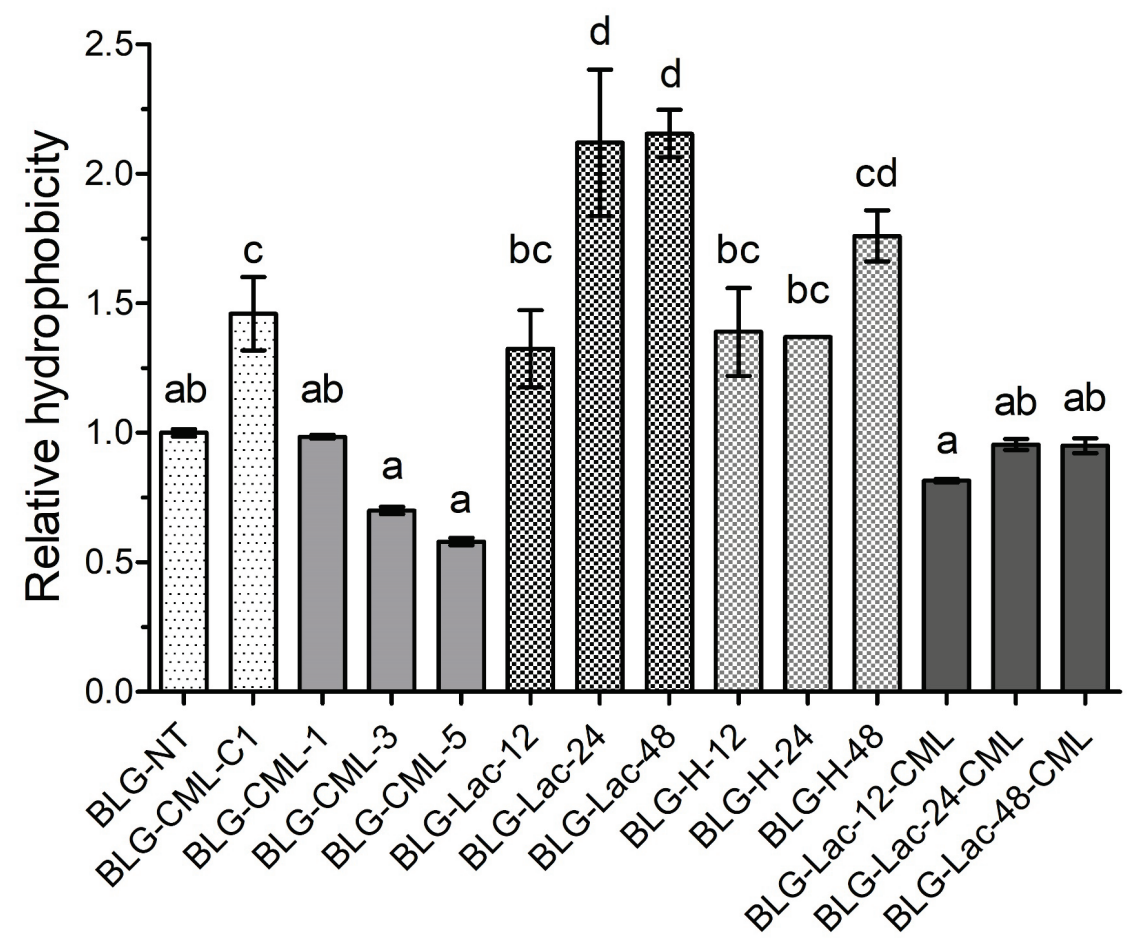

Figure 4.2: Hydrophobicity of $\beta$-lactoglobulin (BLG) samples relative to non-treated (NT) BLG, chemical modification control without addition of glyoxylic acid (C1), chemically modified to introduce $\mathrm{N}^{\varepsilon}$-carboxymethyllysine (CML) at different degree of modification (1,3, and 5), glycated with lactose (Lac) by heating at $60^{\circ} \mathrm{C}$ for $12 \mathrm{~h}, 24 \mathrm{~h}$, and $48 \mathrm{~h}$; heated at $60^{\circ} \mathrm{C}$ for $12 \mathrm{~h}, 24 \mathrm{~h}$, and $48 \mathrm{~h}$ in the absence of any sugars $(\mathrm{H})$, and glycated by heating with lactose followed by $\mathrm{CML}$ induction with glyoxal. Error bars represent standard deviation of technical replicates $(\mathrm{n}=2)$. Statistical differences were tested using one-way ANOVA with Tukey post-hoc test. Significant differences were considered at $p<0.05$, where two variables have different letters if they are significantly different.

BLG-CML did not show significant differences in relative hydrophobicity compared to BLG-NT, independent of the level of modification. At the same time, BLG-Lac showed significantly higher levels of hydrophobicity compared to BLG-NT after $24 \mathrm{~h}$ and $48 \mathrm{~h}$ heating time. Heating in the absence of lactose did not change hydrophobicity of BLG until $24 \mathrm{~h}$ of heating, however it increased after $48 \mathrm{~h}$ heating. Modification of BLG-Lac samples with glyoxylic acid to form additional CML, resulted in decreased hydrophobicity of BLG-Lac-24-CML and BLG-Lac-48-CML compared to the respective BLG-Lac samples and reached comparable levels as for BLG-NT. 
CD-spectra were monitored to determine changes in the secondary structure of BLG by heating, glycation, and chemical modification, respectively (supplementary material: Figure 4-S1). The CD-spectra of all samples showed no deviation from the spectra of BLG-NT.

ThT-assay was performed to monitor changes in the level of $\beta$-sheets upon treatment of BLG (Figure 4.3). BLG-CML-3 and BLG-CML-5 revealed significantly higher fluorescence intensity compared to BLG-NT, with the tendency of higher fluorescence intensity with increasing level of modification in BLG-CML samples. Also BLG-Lac samples showed a higher signal compared to BLG-NT. BLG-H-24 has significantly higher fluorescence intensity compared to BLG-NT but not compared to the other BLG-H samples. BLG-Lac-CML samples showed higher fluorescence intensity than BLG-NT, however fluorescence intensity did not differ between BLG-Lac-CML samples.

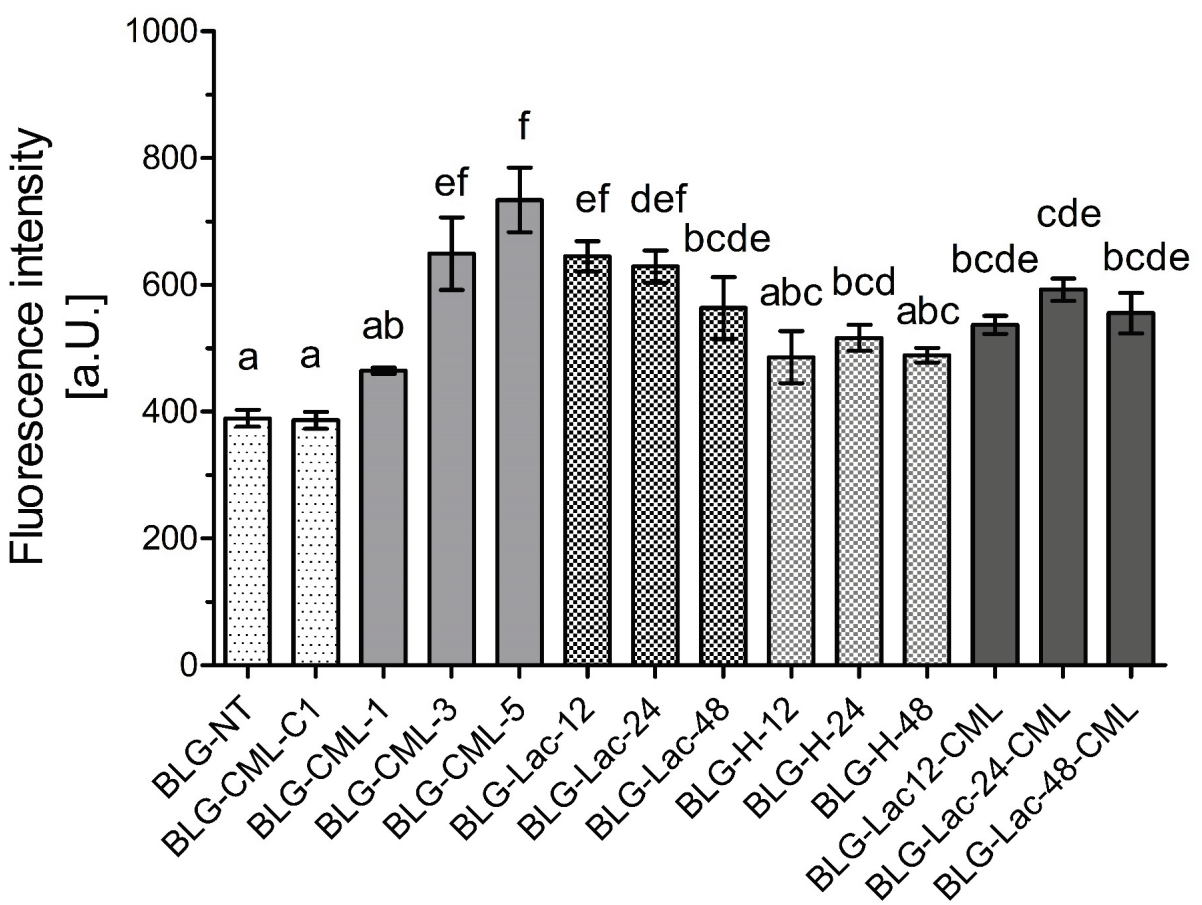

Figure 4.3: Thioflavin-T assay of $\beta$-lactoglobulin (BLG), non-treated (NT), control for chemical modification (C1), chemically modified BLG to introduce $\mathrm{N}^{\varepsilon}$-carboxymethyllysine (CML) at different levels of CML, glycated with lactose (Lac) by heating at $60{ }^{\circ} \mathrm{C}$ for $12 \mathrm{~h}, 24 \mathrm{~h}$, and $48 \mathrm{~h}$; heated at $60{ }^{\circ} \mathrm{C}$ for $12 \mathrm{~h}, 24 \mathrm{~h}$, and $48 \mathrm{~h}$ in the absence of lactose $(\mathrm{H})$, and glycated by heating with lactose followed by CML induction with glyoxal. Fluorescence intensity was corrected for the autofluorescence of the samples and fluorescence of the blank. Significant differences were tested using one-way ANOVA with Tukey post-hoc test, considered as significant at $\mathrm{p}<0.05$ between technical replicates $(\mathrm{n}=2)$, where two variables have different letters if they are significantly different.

Gel-electrophoretic separation was conducted under native conditions (native PAGE) to monitor the occurrence of protein aggregation after the treatments (Figure 4.4). Native PAGE, separates the proteins by a combination by charge and size without changing the structure of the protein. Analysis showed that no aggregation had occurred. 


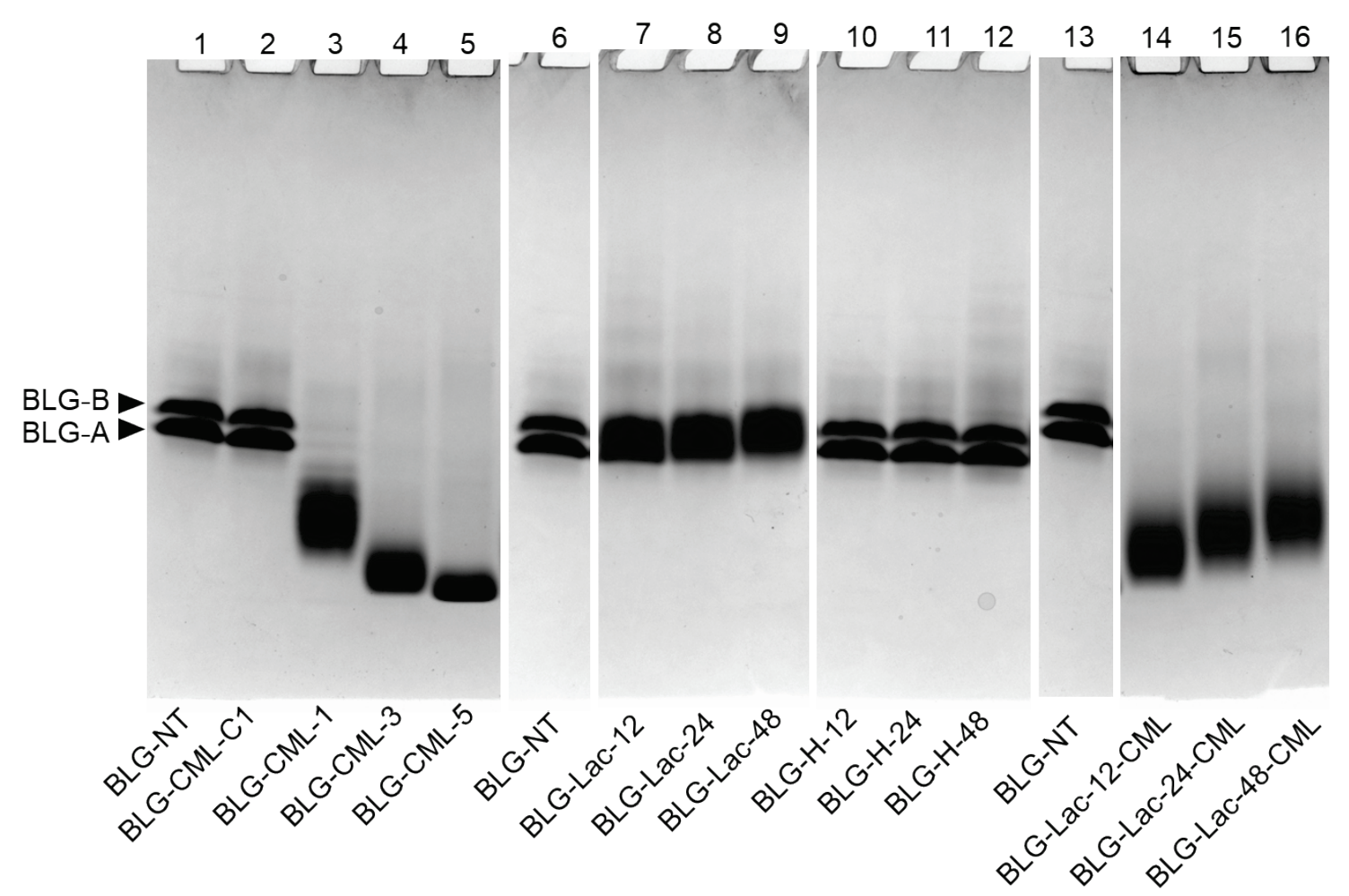

Figure 4.4: Native-PAGE of $\beta$-lactoglobulin (BLG), non-treated (NT), chemical modification control (C1), chemically modified to introduce $\mathrm{N}^{\varepsilon}$-carboxymethyllysine (CML) at different degree of modification $(1,3$, and 5), glycated with lactose (Lac) by heating at $60^{\circ} \mathrm{C}$ for $12 \mathrm{~h}, 24 \mathrm{~h}$, and $48 \mathrm{~h}$; heated at $60{ }^{\circ} \mathrm{C}$ for $12 \mathrm{~h}, 24 \mathrm{~h}$, and $48 \mathrm{~h}$ in the absence of any sugars $(\mathrm{H})$, and glycated by heating with lactose followed by CML induction with glyoxal. BLG-NT of lane 1 and 13 are identical and were on the same gel as samples in lane 2-5 and lane 14-16, whereas BLG-NT in lane 6 was run on the same gel as samples in lane 7-12.

BLG-NT and BLG-C1 (lane 1 and lane 2) showed two distinct bands corresponding to the variant $\mathrm{A}$ and $\mathrm{B}$ that show slight differences of their isoelectric point and therefore can be separated via native gel electrophoresis [35]. BLG-CML samples (lane 3-5) showed one broad band and higher level of CML modification caused further migration through the gel accompanied with decreased broadening of the band. Whereas in SDS-PAGE under reducing conditions, only minimal differences in migration behaviour of BLG-CML samples were observed (data not shown). BLG-Lac (lane 7-9) samples showed one broad band at the same position as the two bands of BLG-NT. Only BLG-Lac-48 showed a slightly lesser migration. BLG-H (lane 10-12) samples showed no difference to BLG-NT, independent from the heating time. BLG-Lac-CML (lane 14-16) samples showed one broad band at a lower position compared to BLG-NT and BLG-Lac samples. As in BLG-CML samples, the BLG moved faster through the gel upon higher level of CML modification.

\subsubsection{Receptor binding}

Binding of CD36, Gal-3, and sRAGE was determined with inhibition ELISA, where higher inhibition indicates more binding to receptor ligands (Figure 4.5). 

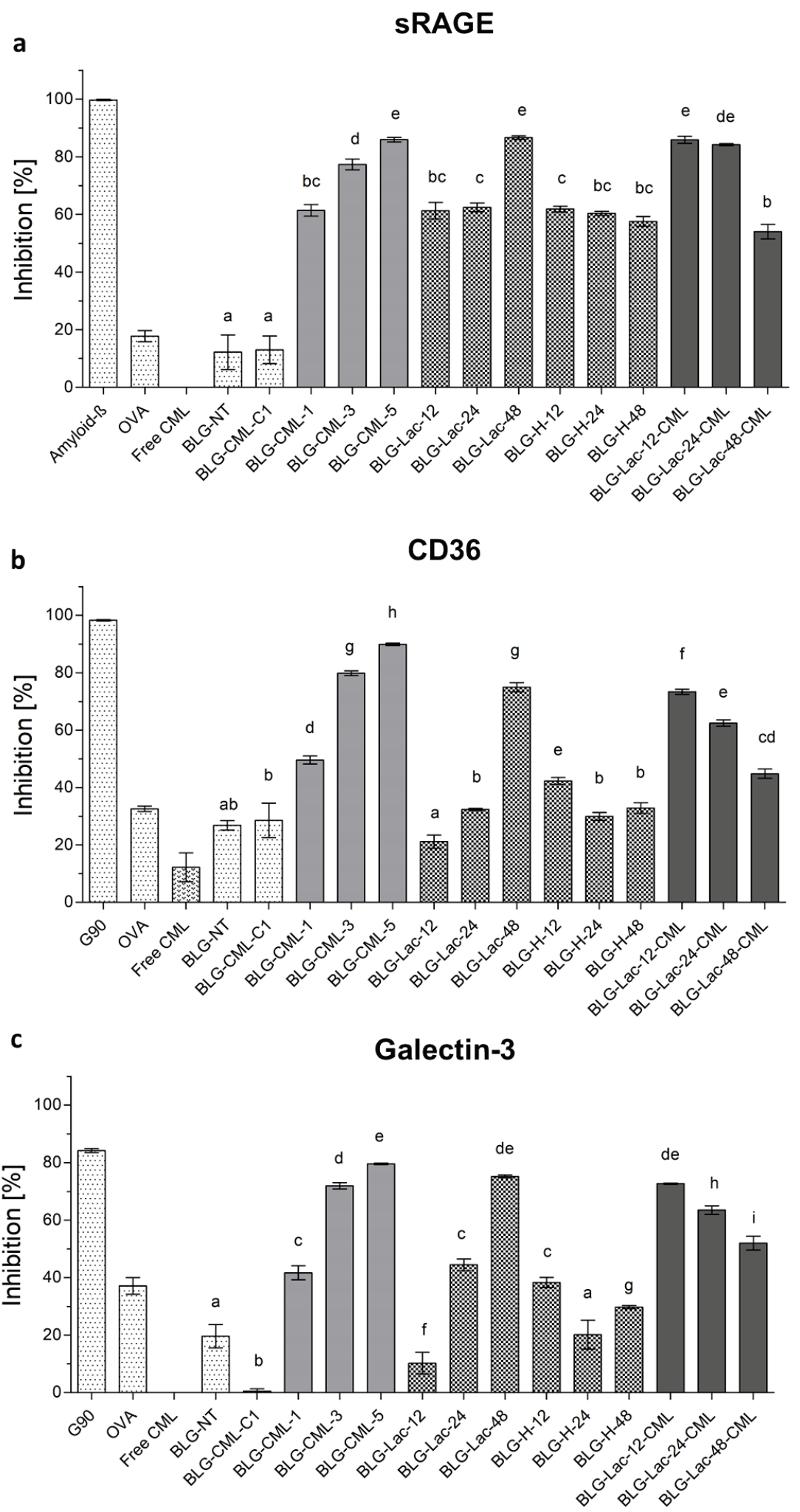

Figure 4.5: Inhibition ELISA for binding of (a) sRAGE, (b) CD36, and (c) galectin-3 to $\beta$-lactoglobulin (BLG), non-treated (NT), control for chemical modification (CML-C1), chemically modified BLG with $\mathrm{N}^{\varepsilon}$-carboxymethyllysine (CML) at different levels of CML, glycated with lactose (Lac) by heating at $60{ }^{\circ} \mathrm{C}$ for $12 \mathrm{~h}, 24 \mathrm{~h}$, and $48 \mathrm{~h}$; heated at $60^{\circ} \mathrm{C}$ for $12 \mathrm{~h}, 24 \mathrm{~h}$, and $48 \mathrm{~h}$ in the absence of any sugars $(\mathrm{H})$, and glycated by heating with lactose followed by CML induction with glyoxal, with ovalbumin (OVA) as negative control, and glycated soy protein (G90) as positive control for CD36 and galectin-3, as well as amyloid- $\beta$ as positive control for sRAGE. Protein concentrations were set to $100 \mu \mathrm{g} / \mathrm{mL}$, while free CML was used at $2 \mathrm{mg} / \mathrm{mL}$. Significant differences were tested using one-way ANOVA with Tukey post-hoc test, considered as significant at $p<0.05$ between technical replicates $(n=3)$, where two variables have different letters if they are significantly different. 
All receptors showed increased binding to BLG-CML samples compared to BLG-NT which increased with higher CML levels. At the same time binding to free CML was only observed for CD36, however this was lower than the binding to OVA. BLG-Lac samples showed higher binding upon prolonged heating time, however only starting after $24 \mathrm{~h}$ for both CD36 and Gal-3. In contrast, sRAGE binding increased already for BLG-Lac-12, remained on the same level in BLG-Lac-24 and then increased again for BLG-Lac-48. BLG-H samples revealed no heating time-dependent trend for binding to all receptors and, overall, displayed either similar or lower binding compared to the BLG-Lac sample heated for the same duration. For CD36, only BLG-H-12 showed higher binding than BLG-NT, while for Gal-3 both BLG-H-12 and BLG-H-48 showed higher levels of binding. For sRAGE, the BLG-H samples all showed a level of binding that was similar to the BLG-Lac samples, and significantly increased compared to BLG-NT. BLG-Lac-CML samples showed higher binding the more CML was present in the sample, which followed a stepwise increase for binding to CD36 and Gal-3, while sRAGE showed similar binding to BLG-Lac-12 and BLG-Lac-24 and only decreased for BLG-Lac-48.

Receptor binding with different concentrations of $\mathrm{NaCl}$ was performed to assess the role of charge in binding of BLG-CML-5 and BLG-Lac-48 to AGE receptors (Figure 4.6).

a

SRAGE

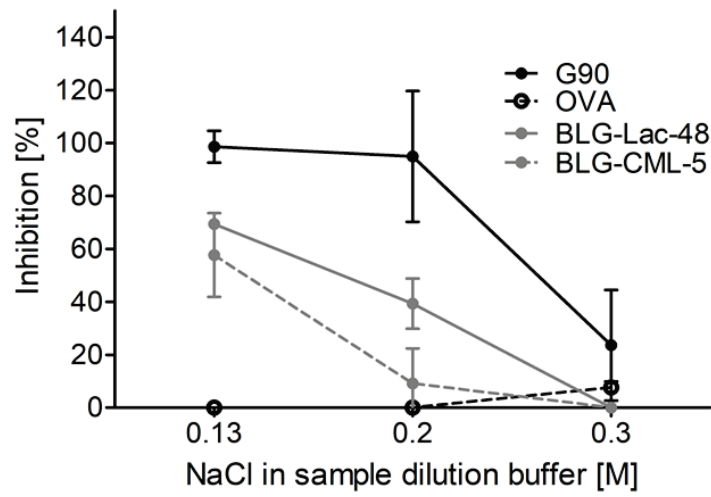

b

CD36

C
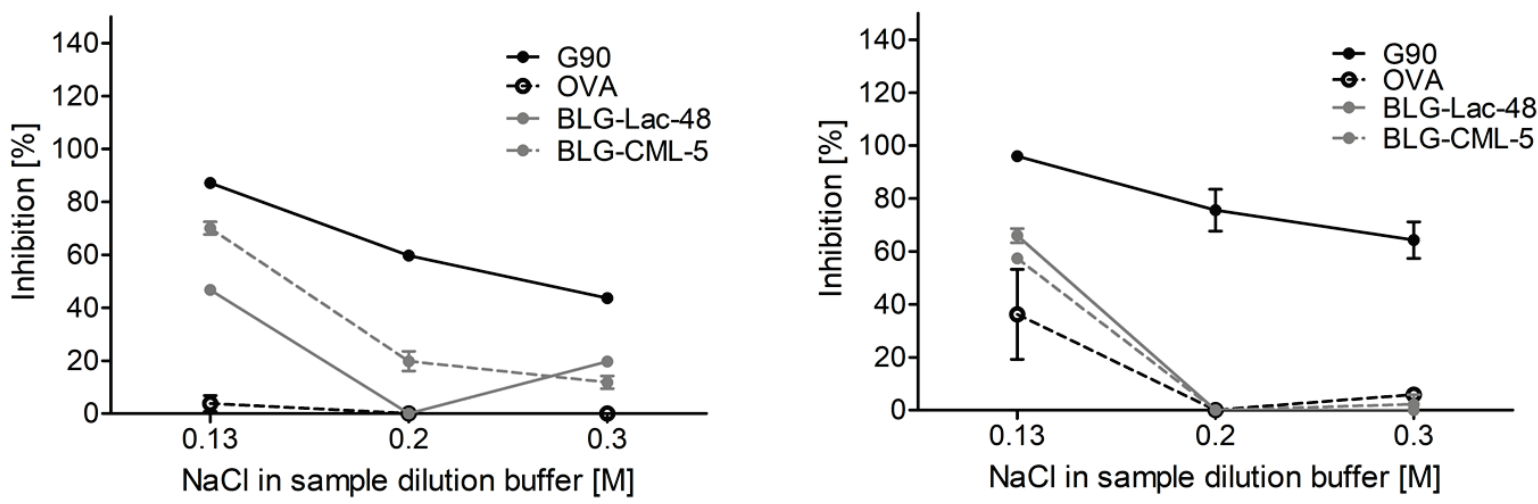

Figure 4.6: Inhibition ELISA for binding of (a) sRAGE, (b) CD36, and (c) galectin-3 to $\beta$-lactoglobulin (BLG), chemically modified BLG with $\mathrm{N}^{\varepsilon}$-carboxymethyllysine (BLG-CML-5), BLG dry-heated in the presence of lactose (Lac) for $48 \mathrm{~h}$ using different concentrations of sodium chloride $(\mathrm{NaCl})$ in the sample dilution buffer. Protein concentrations were set to $100 \mu \mathrm{g} / \mathrm{mL}$. Error bars represent standard deviation of technical replicates $(\mathrm{n}=3)$. 
With increasing salt concentration of the sample dilution buffer to block the negative charge of CML, the binding to all receptors of BLG-Lac-48 and BLG-CML-5 decreased. For CD36 and Gal-3 no binding was observed already at $0.2 \mathrm{M} \mathrm{NaCl}$ in the sample dilution buffer, while sRAGE showed a gradual decrease in binding from $0.13 \mathrm{M}$ to $0.3 \mathrm{M} \mathrm{NaCl}$. Also the positive control showed lower binding with increasing $\mathrm{NaCl}$ concentration, starting at $0.2 \mathrm{M} \mathrm{NaCl}$ for CD36 and Gal-3, while sRAGE showed a decrease only at $0.3 \mathrm{M} \mathrm{NaCl}$.

\subsection{Discussion}

CML is not only the most commonly used marker of MR in food but also an important biomarker of protein modifications in vivo [36,37]. CML modifications in vivo were shown to contribute to increased levels of inflammation markers in serum [38,39]. However, disentangling the effect of the presence of AGEs and 3D-changes of the protein structure upon heating induced glycation was often not possible. Recent studies highlighted the importance of separating the effect of aggregation, heating-induced exposure of hydrophobic as well as $\beta$-sheet structures and the formation of AGEs in order to explore the role of AGEs in inflammation [27-29]. In this study BLG was chemically modified with glyoxylic acid to induce CML and structural changes were closely monitored. The binding to sRAGE, CD36, and Gal-3 was evaluated to assess the immunoreactive potential of CML-modified proteins.

Modification of BLG with glyoxylic acid resulted in the formation of CML-modified BLG without changing the 3D-structure of the protein. This was illustrated by the increasing CML levels at higher ratio of glyoxylic acid to BLG (Table 4.1), lack of additional structural modifications (supplementary material: Figure 4-S1) and aggregation (Figure 4.4). Levels of CML in liquid and powdered dairy products have been reported in a wide range between $2-210 \mu \mathrm{g} / \mathrm{g}$ protein. Where already small amounts are found in raw milk and increase with heating intensity and prolonged storage at higher temperatures (up to $50{ }^{\circ} \mathrm{C}$ for 4 months) [40]. In contrast, during the incubation of BLG in the presence of lactose only low amounts of CML were formed which was expected for the mild heat treatment and the short heating time $\left(60{ }^{\circ} \mathrm{C}\right.$, for maximum $48 \mathrm{~h}$ ). However, free amino groups decreased with prolonged incubation times (Figure 4.1), indicating that the MR occurred but did not proceed beyond the early stage, most likely resulting in the formation of other MR products (MRPs) than CML. The heating conditions used to induce protein glycation as well as the MR itself can promote protein aggregation [41]. This is a crucial determinant as it has been shown before that heating- and glycation-induced aggregation of BLG results in the formation of sRAGE binding ligands $[28,29]$. Native PAGE confirmed that in this well-defined system no aggregates were formed in any of the samples (Figure 4.4). However, faster movement through the native PAGE (Figure 4.4) also indicated that protein charge changed, especially in BLG-CML and BLG-Lac-CML. This was confirmed by the same mobility of all BLG-CML samples in SDS-PAGE gels where charge is not affecting mobility of the proteins (data not shown). The different charge seemed to be dependent on the CML content as CML gives an additional 
negative charge to each modified lysine. The broadening of the bands, being most distinct in BLG-CML-1 and BLG-Lac samples, indicated the presence of a wide range of molecules modified differently, in extent and/or position.

Further structural analysis revealed that the chemical modification of BLG with CML did not result in CML level-dependent changes in hydrophobicity (Figure 4.2) and of the secondary structure (supplementary material: Figure 4-S1). This is also in line with previous findings on the model protein OVA which was chemically modified following the same procedure [23]. Also BLG-Lac and BLG-H samples showed no changes in secondary structure compared to BLG-NT, which is in line with the results of Enomoto et al. [42] who reported that neither glycation nor heating under dry heating conditions at $50^{\circ} \mathrm{C}$ significantly affected the secondary structure of BLG. However, the ThT-assay showed an apparent increase of $\beta$-sheet structures with increasing level of modification in BLG-CML samples, which is in contrast with the CD measurements (supplementary material: Figure 4-S1). It is most commonly accepted that ThT binds to the cross $\beta$-structure of amyloid fibrils and thus is suitable to give an indication about their presence and relative quantities. However, it has also been shown to bind to hydrophobic structures [43]. This could explain the discrepancies between CD measurements (supplementary material: Figure 4-S1) and ThT-assay (Figure 4.3) for BLG-Lac and BLG-H samples as they showed increased hydrophobicity (Figure 4.2). Moreover, ThT is positively charged and the signal intensity of ThT-fibril/protein complexes can be affected by the charge state of the ThT ligand [44]. Native PAGE (Figure 4.4) indicated that the chemically modified samples were more negatively charged the higher the level of CML. This is in line with the data of ThT binding assuming that in this case ThT interacts with the negative charge. This could possibly explain the discrepancies between the results from CD (supplementary material: Figure 4-S1) and ThT measurements (Figure 4.3) for BLG-CML samples. This interpretation is supported by the general opinion that the chemical modification with glyoxylic acid is considered as a very specific method that solely results in CML modification of lysine residues without affecting the secondary structure [23]. BLG-Lac and BLG-H samples showed significant differences in surface hydrophobicity after $24 \mathrm{~h}$ incubation and $48 \mathrm{~h}$ incubation, respectively (Figure 4.2). This is in line with the findings of Morgan et al. [45] who showed that ANS binding increases upon dry heating of BLG (relative humidity of $65 \%$, at $50{ }^{\circ} \mathrm{C}$ ) and is even higher when BLG is heated in the presence of lactose. Structural changes of BLG-Lac samples were also confirmed by the native PAGE (Figure 4.4), that showed a broader band for BLG-Lac samples. However, this could also be the result of glycation-induced side-chain modifications on BLG-Lac samples, as indicated by the OPA-assay (Figure 4.1). To summarise, chemical modification of BLG did not result in detectable 3D-structural changes but did induce a negative charge to the lysine residues. At the same time, glycation of BLG increased the surface hydrophobicity (Figure 4.2). However, after chemical modification of BLG-Lac samples with CML, hydrophobicity decreased again, which is possibly related to the addition of a negative charge on lysine residues. 
Dietary AGEs have previously been described as potent ligands for a number of cell surface receptors expressed on APCs including RAGE, CD36 and Gal-3 as the extracellular unit of the AGE-R complex [46]. However, the knowledge on the particular binding sides of these receptors to MR-modified proteins is very limited because of complexity of the structural rearrangements during the heat treatment and glycation. For instance, heating that is required to form AGEs via the MR, as well as the MR itself, promote protein aggregation which was already shown to induce an interaction with sRAGE [28,29]. Structural analysis of BLG-CML showed that the tertiary and secondary structure of BLG is maintained upon modification. Moreover, no aggregates were observed on the native PAGE excluding protein unfolding or aggregation as the reason of increased binding to the receptors observed for BLG-CML. Both CML-modified samples (BLG-CML and BLG-Lac-CML) showed CML content-dependent increased binding to all tested receptors (Figure 4.5), indicating the role of this specific AGE in promoting the binding to the selected receptors. This is in agreement with previous literature which described CML as ligand for sRAGE in vivo and in vitro [24,47]. However, glycation of the tested proteins was not selective for CML and structural changes were not monitored.

The investigated receptors are multiligand receptors that show binding to several structural elements. The role of amyloid structures, aggregation and hydrophobicity has previously been discussed in relation to binding to these receptors and cellular uptake in macrophages as well as a wide spectrum of lectin structures for Gal-3 [20,27,29,48,49]. Ohgami et al. [14] showed that CD36 in CHO-CD36 cells binds to AGE-OVA that carried a significant amount of CML, while for Gal-3 Vlassara et al. [17] reported that it shows high affinity binding to glycated BSA with unknown CML content. The results presented in this study are the first that directly show the role of CML in binding to CD36 and Gal-3. Based on the results of native PAGE and inhibition ELISA with various salt concentrations (Figure 4.6), it is hypothesized that the negative charge of CML is the crucial determinant to induce binding to sRAGE, CD36 and Gal-3. For sRAGE this is in agreement with the findings by Xue et al. [50], who showed that CML-modified peptides and CML-modified BSA bind to the positively charged cavity within the V domain of sRAGE. In contrast, a study conducted by Buetler et al. [26] showed that BLG which had $10-40 \%$ of its lysine chemically modified to introduce CML did not show binding of antibody-captured GST-RAGE by using the Biacore technique. However, to evaluate the binding, a buffer containing $5 \mathrm{mM}$ calcium chloride was used in this study. Comparable to the effect of $\mathrm{NaCl}$, where the positively charged sodium cation can interact with the negative charge of CML, this could decrease sRAGE binding (Figure 4.6). As reviewed by Collot-Teixeira et al. [49], CD36 binds to oxidised low density lipoprotein (oxLDL) which is suggested to occur via a positively charged moiety that binds to negatively charged ligands, such as oxLDL. According to these authors, the binding site within CD36 for oxLDL and AGEs are identical. Moreover, the role of charge in binding to murine CD36 ectodomain has also been postulated for diacylglycerol ligands [51], thus supporting the hypothesis that also for CD36 the negatively charged CML moiety of BLG-CML is essential for binding to the receptor. Galectins in general bind to carbohydrates, which is considered to occur as a result of 
hydrophilic interactions via hydrogen bonds, and hydrophobic interactions, specifically the $\mathrm{CH}-\pi$ interaction [52]. This explains the binding affinity of Gal-3 to lectins and lipopolysaccharides but not to BLG-CML with the hypothesis of a charge-dependent recognition. The binding mechanism of ligands to Gal-3 is in many cases unknown, emphasising the importance of further studies to better understand the binding affinity of Gal-3 and its interaction with protein-bound CML.

Interestingly, the binding to the AGEs receptors tested here also increased with longer incubation times of BLG-Lac samples, indicating that glycation with other MRPs than CML also plays a role in modulating the receptor recognition of BLG, while CML levels were much lower compared to BLG-CML samples (Table 4.1). This could be explained by the increasing hydrophobicity of BLG-Lac samples (Figure 4.2), which has been shown to promote the uptake of heated and glycated BLG in macrophages [27]. At the same time, BLG-Lac-CML samples showed no increase in hydrophobicity compared to BLG-NT (Figure 4.2) and lower levels of CML compared to BLG-CML samples (Table 4.1), while binding to the receptors was still high (Figure 4.5). This suggests that other MRPs, that induce a negative charge on lysine residues, could be involved in the increased binding to the AGE receptors. This is also supported by the decreasing binding of BLG-Lac-48 with increasing salt concentration and highlights the importance to closely monitor the degree of glycation in processed food.

In this study, it was shown that BLG bound CML is a ligand for the receptors present on APCs: RAGE, CD36 and Gal-3. Although the levels of CML induced in this study are higher than what is normally observed in processed milk and dairy products, this study suggests a role of CML in immunomodulation by dietary AGEs. Moreover, this study demonstrated that not only CML but also other MR-induced modifications result in binding to AGE receptors, because glycated BLG with low levels of CML also induced binding to these receptors. The role of dietary AGEs in inflammatory disease is still under debate due to lacking possibilities to differentiate between exogenous and endogenous AGEs, limited knowledge of the metabolic transit, and possible biases of some in vivo studies for instance by high caloric index of the study material as well as the presence of reactive oxidative species [53]. It is possible that smaller MR-modified digestion-derived peptides reach the mucosal immune system in the gastrointestinal tract [54] and that intact BLG is sampled from the intestinal lumen via DCs and thus can be involved in mucosal immunity [55]. However, further studies are needed to evaluate the bioavailability of CML-modified protein as well as CML-modified digestion-derived peptides and their possible immunomodulatory effect in vivo.

\subsection{Conclusions}

Chemical modification of BLG to introduce CML on lysine residues resulted in a CML concentration-dependent increase of binding to sRAGE, CD36, and Gal-3, confirming that protein-bound CML is a ligand for these AGE receptors. Next to BLG-CML, BLG-Lac-48 was also a potent ligand for the AGE receptors, which was positively correlated with increasing 
hydrophobicity upon longer heating time of BLG-Lac. The reduced receptor binding upon increased salt concentration indicated that the negative charge induced to the lysine residues by CML was a crucial determinant for binding of BLG-CML samples to AGE receptors. The same effect of salt concentration was also observed for the BLG-Lac-48 sample suggesting that, next to hydrophobicity other MRPs that induce a negative charge to lysine residues can contribute to the binding of glycated proteins. These findings showed that heating and glycation of food proteins results in structural modifications amongst which hydrophobicity and MRPs carrying a negative charge were found to be important determinants to predict possible immunological consequences. This also highlights the possible physiological relevance of CML in processed food as well as other MRPs that induce a negative charge to amino acid residues. At the same time, bioavailability of these MRPs and the relevance in aetiology of adverse inflammation in vivo remains to be better investigated. 


\section{Supplementary material}
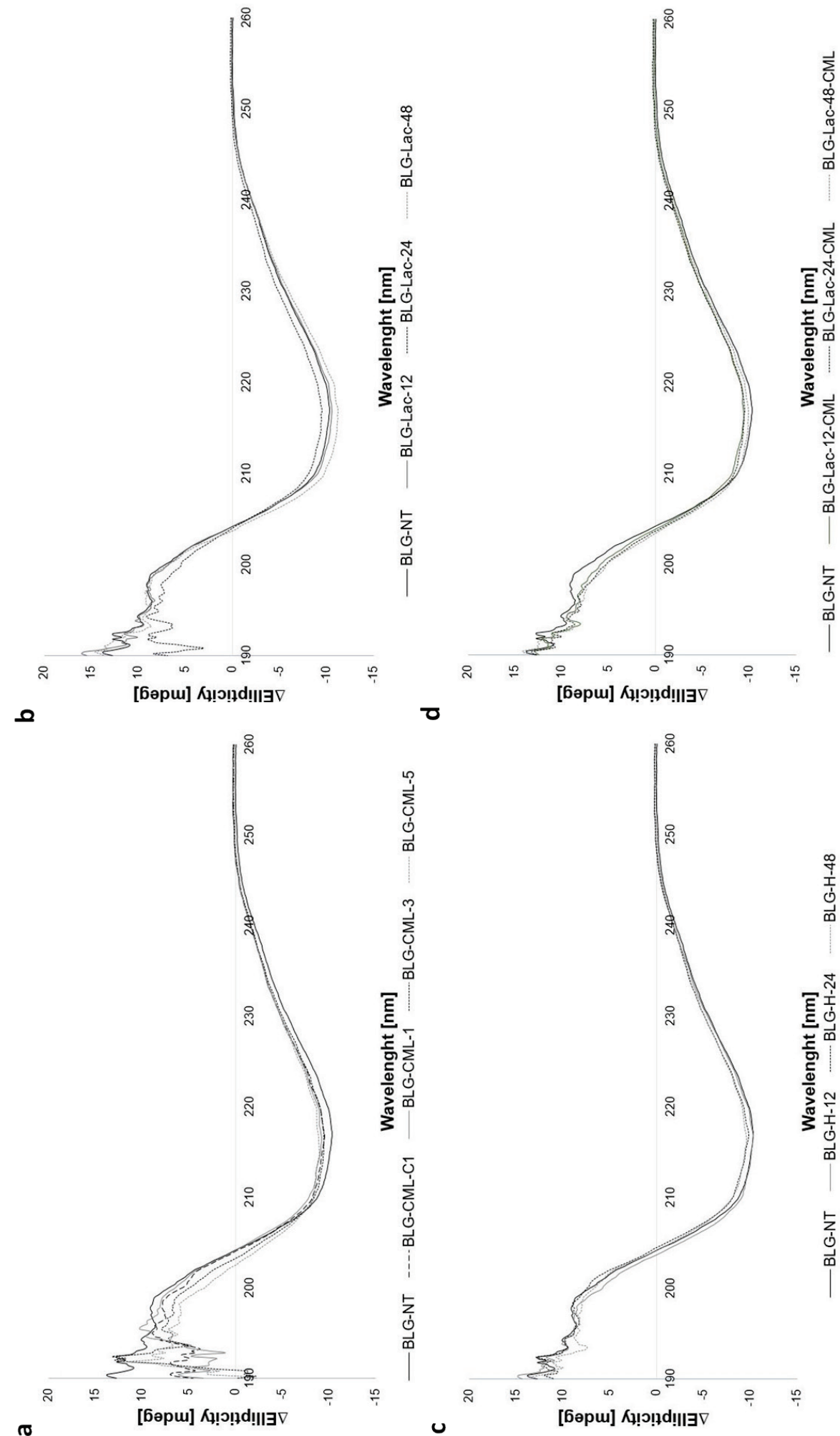

Figure 4-S1: Far-UV circular dichroism spectra of (a) $\beta$-lactoglobulin (BLG), non-treated (NT), chemical modification control without addition of glyoxylic acid (C1), chemically modified to introduce $\mathrm{N}^{\varepsilon}$-carboxymethyllysine (CML) at different degree of modification (1, 3, and 5), (b) BLG glycated with lactose (Lac) at $60{ }^{\circ} \mathrm{C}$ for $12 \mathrm{~h}, 24 \mathrm{~h}$, and $48 \mathrm{~h}$, (c) $\mathrm{BLG}$ heated in the absence of lactose $(\mathrm{H})$ at $60{ }^{\circ} \mathrm{C}$ for $12 \mathrm{~h}, 24 \mathrm{~h}$, and $48 \mathrm{~h}$, and (d) BLG glycated and subsequently chemically modified. 


\section{References}

1. Martorell-Aragonés, A.; Echeverría-Zudaire, L.; Alonso-Lebrero, E.; Boné-Calvo, J.; Martín-Muñoz, M.F.; Nevot-Falcó, S.; Piquer-Gibert, M.; Valdesoiro-Navarrete, L.; Food allergy committee of, S. Position document: IgE-mediated cow's milk allergy. Allergologia et Immunopathologia 2015, 43, 507-526, doi:10.1016/j.aller.2015.01.003.

2. Alexander, L.J.; Hayes, G.; Pearse, M.J.; Stewart, A.F.; Willis, I.M.; Mackinlay, A.G. Complete sequence of the bovine $\beta$-lactoglobulin cDNA. Nucleic Acids Res. 1989, 17, 6739, doi:10.1093/nar/17.16.6739.

3. Uribarri, J.; Cai, W.; Sandu, O.; Peppa, M.; Goldberg, T.; Vlassara, H. Diet-derived advanced glycation end products are major contributors to the body's AGE pool and induce inflammation in healthy subjects. In Annals of the New York Academy of Sciences, New York Academy of Sciences: 2005; Vol. 1043, pp 461466.

4. Smith, P.K.; Masilamani, M.; Li, X.M.; Sampson, H.A. The false alarm hypothesis: Food allergy is associated with high dietary advanced glycation end-products and proglycating dietary sugars that mimic alarmins. Journal of Allergy and Clinical Immunology 2017, 139, 429-437, doi:10.1016/j.jaci.2016.05.040.

5. Di Pino, A.; Currenti, W.; Urbano, F.; Scicali, R.; Piro, S.; Purrello, F.; Rabuazzo, A.M. High intake of dietary advanced glycation end-products is associated with increased arterial stiffness and inflammation in subjects with type 2 diabetes. Nutr. Metab. Cardiovasc. Dis. 2017, 27, 978-984, doi:10.1016/j.numecd.2017.06.014.

6. Uribarri, J.; del Castillo, M.D.; de la Maza, M.P.; Filip, R.; Gugliucci, A.; Luevano-Contreras, C.; MacíasCervantes, M.H.; Markowicz Bastos, D.H.; Medrano, A.; Menini, T., et al. Dietary advanced glycation end products and their role in health and disease. Advances in Nutrition 2015, 6, 461-473, doi:10.3945/an.115.008433.

7. Peppa, M.; Uribarri, J.; Cai, W.; Lu, M.; Vlassara, H. Glycoxidation and Inflammation in Renal Failure Patients. Am. J. Kidney Dis. 2004, 43, 690-695, doi:10.1053/j.ajkd.2003.11.022.

8. $\quad$ Leung, C.; Herath, C.B.; Jia, Z.; Goodwin, M.; Mak, K.Y.; Watt, M.J.; Forbes, J.M.; Angus, P.W. Dietary glycotoxins exacerbate progression of experimental fatty liver disease. J. Hepatol. 2014, 60, 832-838, doi:10.1016/j.jhep.2013.11.033.

9. Van Der Lugt, T.; Weseler, A.R.; Gebbink, W.A.; Vrolijk, M.F.; Opperhuizen, A.; Bast, A. Dietary advanced glycation endproducts induce an inflammatory response in human macrophages in vitro. Nutrients 2018, 10, doi:10.3390/nu10121868.

10. Hilmenyuk, T.; Bellinghausen, I.; Heydenreich, B.; Ilchmann, A.; Toda, M.; Grabbe, S.; Saloga, J. Effects of glycation of the model food allergen ovalbumin on antigen uptake and presentation by human dendritic cells. Immunology 2010, 129, 437-445, doi:10.1111/j.1365-2567.2009.03199.x.

11. Ilchmann, A.; Burgdorf, S.; Scheurer, S.; Waibler, Z.; Nagai, R.; Wellner, A.; Yamamoto, Y.; Yamamoto, H.; Henle, T.; Kurts, C., et al. Glycation of a food allergen by the Maillard reaction enhances its T-cell immunogenicity: Role of macrophage scavenger receptor class A type I and II. Journal of Allergy and Clinical Immunology 2010, 125, 175-183.e111, doi:10.1016/j.jaci.2009.08.013.

12. Teodorowicz, M.; Van Neerven, J.; Savelkoul, H. Food processing: The influence of the maillard reaction on immunogenicity and allergenicity of food proteins. Nutrients 2017, 9, doi:10.3390/nu9080835.

13. Ott, C.; Jacobs, K.; Haucke, E.; Navarrete Santos, A.; Grune, T.; Simm, A. Role of advanced glycation end products in cellular signaling. Redox Biology 2014, 2, 411-429, doi:10.1016/j.redox.2013.12.016.

14. Ohgami, N.; Nagai, R.; Ikemoto, M.; Arai, H.; Kuniyasu, A.; Horiuchi, S.; Nakayama, H. CD36, a Member of the Class B Scavenger Receptor Family, as a Receptor for Advanced Glycation End Products. Journal of Biological Chemistry 2001, 276, 3195-3202, doi:10.1074/jbc.M006545200.

15. Ohgami, N.; Nagai, R.; Miyazaki, A.; Ikemoto, M.; Arai, H.; Horiuchi, S.; Nakayama, H. Scavenger Receptor Class B Type I-mediated Reverse Cholesterol Transport Is Inhibited by Advanced Glycation End Products. Journal of Biological Chemistry 2001, 276, 13348-13355, doi:10.1074/jbc.M011613200.

16. Araki, N.; Higashi, T.; Mori, T.; Shibayama, R.; Kawabe, Y.; Kodama, T.; Takahashi, K.; Shichiri, M.; Horiuchi, S. Macrophage Scavenger Receptor Mediates the Endocytic Uptake and Degradation of Advanced Glycation End Products of the Maillard Reaction. European Journal of Biochemistry 1995, 230, 408-415, doi:10.1111/j.1432-1033.1995.0408h.x.

17. Vlassara, H.; Li, Y.M.; Imani, F.; Wojciechowicz, D.; Yang, Z.; Liu, F.T.; Cerami, A. Identification of galectin-3 as a high-affinity binding protein for advanced glycation end products (AGE): a new member of the AGE-receptor complex. Mol Med 1995, 1, 634-646.

18. Kierdorf, K.; Fritz, G. RAGE regulation and signaling in inflammation and beyond. Journal of Leukocyte Biology 2013, 94, 55-68, doi:10.1189/jlb.1012519.

19. Gough, P.J.; Gordon, S. The role of scavenger receptors in the innate immune system. Microbes Infect. 2000, 2, 305-311, doi:10.1016/S1286-4579(00)00297-5. 
20. Díaz-Alvarez, L.; Ortega, E. The Many Roles of Galectin-3, a Multifaceted Molecule, in Innate Immune Responses against Pathogens. Mediators Inflamm. 2017, 2017, doi:10.1155/2017/9247574.

21. Milkovska-Stamenova, S.; Mnatsakanyan, R.; Hoffmann, R. Protein carbonylation sites in bovine raw milk and processed milk products. Food Chemistry 2017, 229, 417-424, doi:10.1016/j.foodchem.2017.02.102.

22. Pischetsrieder, M.; Henle, T. Glycation products in infant formulas: Chemical, analytical and physiological aspects. Amino Acids 2012, 42, 1111-1118, doi:10.1007/s00726-010-0775-0.

23. Heilmann, M.; Wellner, A.; Gadermaier, G.; Ilchmann, A.; Briza, P.; Krause, M.; Nagai, R.; Burgdorf, S.; Scheurer, S.; Vieths, S., et al. Ovalbumin modified with pyrraline, a maillard reaction product, shows enhanced T-cell immunogenicity. Journal of Biological Chemistry 2014, 289, 7919-7928, doi:10.1074/jbc.M113.523621.

24. Kislinger, T.; Fu, C.; Huber, B.; Qu, W.; Taguchi, A.; Yan, S.D.; Hofmann, M.; Yan, S.F.; Pischetsrieder, M.; Stern, D., et al. N(E)-(carboxymethyl)lysine adducts of proteins are ligands for receptor for advanced glycation end products that activate cell signaling pathways and modulate gene expression. Journal of Biological Chemistry 1999, 274, 31740-31749, doi:10.1074/jbc.274.44.31740.

25. Glorieux, G.; Helling, R.; Henle, T.; Brunet, P.; Deppisch, R.; Lameire, N.; Vanholder, R. In vitro evidence for immune activating effect of specific AGE structures retained in uremia. Kidney Int. 2004, 66, 1873 1880, doi:10.1111/j.1523-1755.2004.00961.x.

26. Buetler, T.M.; Leclerc, E.; Baumeyer, A.; Latado, H.; Newell, J.; Adolfsson, O.; Parisod, V.; Richoz, J.; Maurer, S.; Foata, F., et al. Ne-carboxymethyllysine-modified proteins are unable to bind to RAGE and activate an inflammatory response. Molecular Nutrition and Food Research 2008, 52, 370-378, doi:10.1002/mnfr.200700101.

27. Deng, Y.; Govers, C.; Bastiaan-Net, S.; van der Hulst, N.; Hettinga, K.; Wichers, H.J. Hydrophobicity and aggregation, but not glycation, are key determinants for uptake of thermally processed $\beta$-lactoglobulin by THP-1 macrophages. Food Research International 2019, 120, 102-113, doi:10.1016/j.foodres.2019.01.038.

28. Liu, F.; Teodorowicz, M.; Wichers, H.J.; Van Boekel, M.A.J.S.; Hettinga, K.A. Generation of Soluble Advanced Glycation End Products Receptor (sRAGE)-Binding Ligands during Extensive Heat Treatment of Whey Protein/Lactose Mixtures Is Dependent on Glycation and Aggregation. Journal of Agricultural and Food Chemistry 2016, 64, 6477-6486, doi:10.1021/acs.jafc.6b02674.

29. Zenker, H.E.; Ewaz, A.; Deng, Y.; Savelkoul, H.F.J.; Van Neerven, R.J.J.; De Jong, N.; Wichers, H.J.; Hettinga, K.A.; Teodorowicz, M. Differential effects of dry vs. Wet heating of $\beta$-lactoglobulin on formation of sRAGE binding ligands and sIgE epitope recognition. Nutrients 2019, 11, doi:10.3390/nu11061432.

30. Bongarzone, S.; Savickas, V.; Luzi, F.; Gee, A.D. Targeting the Receptor for Advanced Glycation Endproducts (RAGE): A Medicinal Chemistry Perspective. J. Med. Chem. 2017, 60, 7213-7232, doi:10.1021/acs.jmedchem.7b00058

31. Akilliołlu, H.G.; Gökmen, V. Effects of hydrophobic and ionic interactions on glycation of casein during Maillard reaction. Journal of Agricultural and Food Chemistry 2014, 62, 11289-11295, doi:10.1021/jf5038954.

32. Delatour, T.; Hegele, J.; Parisod, V.; Richoz, J.; Maurer, S.; Steven, M.; Buetler, T. Analysis of advanced glycation endproducts in dairy products by isotope dilution liquid chromatography-electrospray tandem mass spectrometry. The particular case of carboxymethyllysine. J. Chromatogr. A 2009, 1216, 2371-2381, doi:10.1016/j.chroma.2009.01.011.

33. Mulet-Cabero, A.I.; Rigby, N.M.; Brodkorb, A.; Mackie, A.R. Dairy food structures influence the rates of nutrient digestion through different in vitro gastric behaviour. Food Hydrocolloids 2017, 67, 63-73, doi:10.1016/j.foodhyd.2016.12.039.

34. Alizadeh-Pasdar, N.; Li-Chan, E.C.Y. Application of PRODAN fluorescent probe to measure surface hydrophobicity of proteins interacting with $\kappa$-carrageenan. Food Hydrocolloids 2001, 15, 285-294, doi:10.1016/S0268-005X(01)00027-3.

35. Ng-Kwai-Hang, K.F.; Kim, S. Different amounts of $\beta$-lactoglobulin A and B in milk from heterozygous AB cows. International Dairy Journal 1996, 6, 689-695, doi:10.1016/0958-6946(95)00069-0.

36. Kawabata, K.; Yoshikawa, H.; Saruwatari, K.; Akazawa, Y.; Inoue, T.; Kuze, T.; Sayo, T.; Uchida, N.; Sugiyama, Y. The presence of Ne-(Carboxymethyl) lysine in the human epidermis. Biochimica et Biophysica Acta - Proteins and Proteomics 2011, 1814, 1246-1252, doi:10.1016/j.bbapap.2011.06.006.

37. Bartakova, V.; Kollarova, R.; Kuricova, K.; Sebekova, K.; Belobradkova, J.; Kankova, K. Serum carboxymethyl-lysine, a dominant advanced glycation end product, is increased in women with gestational diabetes mellitus. Biomed. Pap. 2016, 160, 70-75, doi:10.5507/bp.2015.045.

38. Gaens, K.H.J.; Ferreira, I.; Van De Waarenburg, M.P.H.; Van Greevenbroek, M.M.; Van Der Kallen, C.J.H.; Dekker, J.M.; Nijpels, G.; Rensen, S.S.; Stehouwer, C.D.A.; Schalkwijk, C.G. Protein-Bound Plasma NE-(Carboxymethyl)lysine Is Inversely Associated with Central Obesity and Inflammation and Significantly Explain a Part of the Central Obesity-Related Increase in Inflammation: The Hoorn and 
CODAM Studies. Arterioscler. Thromb. Vasc. Biol. 2015, 35, 2707-2713, doi:10.1161/ATVBAHA.115.306106.

39. Gaens, K.H.J.; Niessen, P.M.G.; Rensen, S.S.; Buurman, W.A.; Greve, J.W.M.; Driessen, A.; Wolfs, M.G.M.; Hofker, M.H.; Bloemen, J.G.; Dejong, C.H., et al. Endogenous formation of NE(carboxymethyl)lysine is increased in fatty livers and induces inflammatory markers in an in vitro model of hepatic steatosis. J. Hepatol. 2012, 56, 647-655, doi:10.1016/j.jhep.2011.07.028.

40. Prosser, C.G.; Carpenter, E.A.; Hodgkinson, A.J. N $\varepsilon$-carboxymethyllysine in nutritional milk formulas for infants. Food Chemistry 2019, 274, 886-890, doi:10.1016/j.foodchem.2018.09.069.

41. Cardoso, H.B.; Wierenga, P.A.; Gruppen, H.; Schols, H.A. Maillard induced aggregation of individual milk proteins and interactions involved. Food Chemistry 2019, 276, 652-661, doi:10.1016/j.foodchem.2018.10.061.

42. Enomoto, H.; Li, C.P.; Morizane, K.; Ibrahim, H.R.; Sugimoto, Y.; Ohki, S.; Ohtomo, H.; Aoki, T. Glycation and phosphorylation of $\beta$-lactoglobulin by dry-heating: Effect on protein structure and some properties. Journal of Agricultural and Food Chemistry 2007, 55, 2392-2398, doi:10.1021/jf062830n.

43. Biancalana, M.; Koide, S. Molecular mechanism of Thioflavin-T binding to amyloid fibrils. Biochimica et Biophysica Acta - Proteins and Proteomics 2010, 1804, 1405-1412, doi:10.1016/j.bbapap.2010.04.001.

44. Gade Malmos, K.; Blancas-Mejia, L.M.; Weber, B.; Buchner, J.; Ramirez-Alvarado, M.; Naiki, H.; Otzen, D. ThT 101: a primer on the use of thioflavin T to investigate amyloid formation. Amyloid 2017, 24, 1-16, doi:10.1080/13506129.2017.1304905.

45. Morgan, F.; Léonil, J.; Mollé, D.; Bouhallab, S. Modification of bovine $\beta$-lactoglobulin by glycation in a powdered state or in an aqueous solution: Effect on association behavior and protein conformation. Journal of Agricultural and Food Chemistry 1999, 47, 83-91, doi:10.1021/jf9804387.

46. Teodorowicz, M.; Hendriks, W.H.; Wichers, H.J.; Savelkoul, H.F.J. Immunomodulation by processed animal feed: The role of maillard reaction products and advanced glycation end-products (AGEs). Frontiers in Immunology 2018, 9, doi:10.3389/fimmu.2018.02088.

47. Thornalley, P.J.; Battah, S.; Ahmed, N.; Karachalias, N.; Agalou, S.; Babaei-Jadidi, R.; Dawnay, A. Quantitative screening of advanced glycation endproducts in cellular and extracellular proteins by tandem mass spectrometry. Biochemical Journal 2003, 375, 581-592, doi:10.1042/BJ20030763.

48. Fritz, G. RAGE: A single receptor fits multiple ligands. Trends in Biochemical Sciences 2011, 36, 625-632, doi:10.1016/j.tibs.2011.08.008.

49. Collot-Teixeira, S.; Martin, J.; McDermott-Roe, C.; Poston, R.; McGregor, J.L. CD36 and macrophages in atherosclerosis. Cardiovasc. Res. 2007, 75, 468-477, doi:10.1016/j.cardiores.2007.03.010.

50. Xue, J.; Rai, V.; Singer, D.; Chabierski, S.; Xie, J.; Reverdatto, S.; Burz, D.S.; Schmidt, A.M.; Hoffmann, R.; Shekhtman, A. Advanced glycation end product recognition by the receptor for AGEs. Structure 2011, 19, 722-732, doi:10.1016/j.str.2011.02.013.

51. Jimenez-Dalmaroni, M.J.; Xiao, N.; Corper, A.L.; Verdino, P.; Ainge, G.D.; Larsen, D.S.; Painter, G.F.; Rudd, P.M.; Dwek, R.A.; Hoebe, K., et al. Soluble CD36 ectodomain binds negatively charged diacylglycerol ligands and acts as a co-receptor for TLR2. PLoS ONE 2009, 4, doi:10.1371/journal.pone.0007411.

52. Modenutti, C.P.; Capurro, J.I.B.; Di Lella, S.; Martí, M.A. The Structural Biology of Galectin-Ligand Recognition: Current Advances in Modeling Tools, Protein Engineering, and Inhibitor Design. Front. Chem. 2019, 7, doi:10.3389/fchem.2019.00823.

53. Delgado-Andrade, C.; Fogliano, V. Dietary Advanced Glycosylation End-Products (dAGEs) and Melanoidins Formed through the Maillard Reaction: Physiological Consequences of their Intake. Annu. Rev. Food Sci. Technol. 2018, 9, 271-291, doi:10.1146/annurev-food-030117-012441.

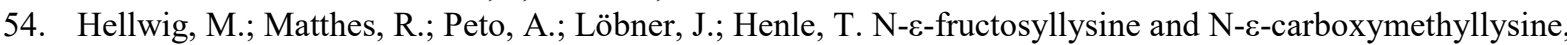
but not lysinoalanine, are available for absorption after simulated gastrointestinal digestion. Amino Acids 2014, 46, 289-299, doi:10.1007/s00726-013-1501-5.

55. Allen, F.; Tong, A.A.; Huang, A.Y. Unique transcompartmental bridge: Antigen-presenting cells sampling across endothelial and mucosal barriers. Frontiers in Immunology 2016, 7, doi:10.3389/fimmu.2016.00231. 


\section{Chapter 5}

Enhanced uptake of processed bovine $\beta$-lactoglobulin by antigen presenting cells: Identification of receptors and implications for immunogenicity

This chapter is based on:

Malgorzata Teodorowicz, Hannah E. Zenker, Arifa Ewaz, Theodoros Tsallis, Andreas Mauser, Sabrina Gensberger-Reigl, Nicolette W. De Jong, Kasper A. Hettinga, Harry J. Wichers, R. J. Joost van Neerven, Huub F. J. Savelkoul. Enhanced uptake of processed bovine $\beta$-lactoglobulin by antigen presenting cells: Identification of receptors and implications for immunogenicity. Submitted for publication 


\begin{abstract}
:
$\beta$-lactoglobulin (BLG) is a major cow's milk allergen encountered by the immune system of infants fed with milk-based formulas. To determine the effect of processing on immunogenicity and allergenicity of milk proteins, we characterised the mechanisms by which heated and glycated BLG are recognised and internalised by antigen presenting cells (APCs). Also, the effect of heat-induced structural changes as well as gastrointestinal digestion on immunogenicity of BLG was evaluated. The binding and uptake of BLG isolated from raw cow's milk heated alone (BLG-H) or with lactose or glucose (BLG-Lac and BLG-Glu) to the receptors present on APCs were analysed by ELISA and cell binding assays. Physicochemical analyses characterised the effect of heating and glycation on the structure, while immunogenicity of BLG preparations was evaluated before and after simulated infant in vitro digestion. Heated and glycated BLG showed enhanced binding to RAGE, galectin-3 (Gal-3), CD36, and SR-AI, without enhanced secretion of pro-inflammatory cytokines. Gal-3 and CD36 and SR-AI, but not RAGE-binding, induced internalisation of heated and glycated BLG. Receptor affinity of BLG was dependent on aggregation as well as on increased hydrophobicity and exposure of $\beta$-sheets. Digested BLG-Lac and BLG-Glu maintained the binding to sRAGE and Gal-3 and were detected on the surface of APCs. Glycation of milk may thus enhance immunogenicity by triggering innate (via RAGE) as well adaptive immune response (via Gal-3), however implications for allergic sensitisation remain unclear.
\end{abstract}




\subsection{Introduction}

Cow's milk (CM) is an example of a food that is subjected to specific thermal processing, dependent on the type of product produced from it. Heating provokes structural modifications of milk proteins via amongst others denaturation, aggregation and the Maillard reaction (MR) [1], leading to increased immunogenicity and possibly also allergenicity of milk proteins [2]. $\beta$-lactoglobulin (BLG), the most abundant whey protein (WP) that is not present in breast milk, has been described as one of the major allergens causing CM allergy [3]. In infants fed with $\mathrm{CM}$ formulas, BLG is thus one of the first foreign antigens encountering the mucosal immune system of the gastrointestinal tract [4]. Therefore, a number of studies have been performed in order to understand the relative importance of heat-induced changes of immunogenicity and allergenicity of BLG [5-10]. Denatured BLG, in contrast to the native form, was shown to induce significantly higher infiltration of mononuclear inflammatory cells in the gastroduodenal mucosa of sensitised rats. This observation indicates a more intense local immunologic response towards the heated form of BLG, compared to its native form [11]. Also, pasteurization-induced aggregates of BLG were shown to play a role in allergic sensitisation. Roth-Walter and colleagues showed that aggregated BLG is predominantly taken up from the intestinal lumen by the Peyer's patches instead of via transcytosis through enterocytes [12]. Similarly, cross-linked BLG was increasingly endocytosed by dendritic cells (DCs), in a food allergy-murine model leading to the development of Th2-associated environment [13]. Lastly, the Maillard reaction (MR) was also shown to play a role in enhanced immunogenicity of processed BLG. Glycated WP increased mRNA expression of pro-inflammatory cytokines tumour necrosis factor $\alpha$ (TNF- $\alpha$ ), interleukin (IL) $1 \beta$ and IL-6, as well as increased phagocytic activity of a murine macrophage cell line [14]. Furthermore, also aggregated BLG appears to be recognised by the receptor for advanced glycation end products (RAGE) expressed on antigen presenting cells (APCs) [15-17]. RAGE has been postulated to play a role in the development of food allergies upon interaction advanced glycation end products (AGEs) formed in the food due to the glycation [18].

Nevertheless, the relative importance of glycation vs. aggregation on immunogenicity and allergenicity of milk proteins, including BLG as one of the major milk allergens, remains unclear. For instance, Perusko et al. [8] reported an increased uptake of glycated BLG by mice bone marrow-derived DCs compared to non-treated BLG, but BLG heated in the absence of sugar was not included in their study. In contrast, the study of Deng et al. [19] emphasized the heat-induced formation of amyloid-like structures, aggregates and increased hydrophobicity as the most important features predisposing heat processed proteins to be recognised by APCs. The processing-related structural changes that enhance immunogenicity of BLG are therefore not fully understood. Thus, exploring the molecular mechanisms of interaction between heat-treated BLG, as a potential antigen present in infant nutrition, and the human APCs is of particular interest. The aim of the present study was firstly to evaluate and compare heat and glycation induced changes in immunoreactivity of BLG. Secondly, to specify the receptors 
involved in binding and internalisation of heated and glycated BLG in order to reveal mechanisms responsible for triggering innate and/or adaptive immunity. Lastly, to evaluate the immunogenicity of heated and glycated BLG after enzymatic digestion in an infant in vitro digestion model.

\subsection{Materials and Methods}

\subsubsection{Chemicals}

The Recombinant Factor C Endotoxin Detection Assay was purchased from Hyglos GmbH (Bernried, Germany). Anti-his antibody (\# 148052751) was obtained from Qiagen (Venlo, The Netherlands). Roswell Park Memorial Institute 1640 Medium (RPMI 1640), fetal bovine serum (FBS), Alexa Fluor 647 Protein Labelling Kit, Fluorescein-EX Protein Labelling Kit, oxidised low-density lipoprotein (50-150 $\mu \mathrm{g} / \mathrm{mL}$, \#L34357), and cytochalasin D (0.5 $\mu \mathrm{M}$, \#PHZ1063) were purchased from Thermo Fischer Scientific (Waltham, Massachusetts, USA). Anti-BLG antibodies (\#ab112893) and 33DFTG (10 mM, \#AOB37408) were obtained from Abcam (Cambridge, UK) and Aobius (Gloucester, Massachusetts, USA), respectively. The culture of human acute monocytic leukaemia cell line (THP-1) was obtained from the American Type Culture Collection (Manassas, Verginia, USA). Cytometric bead array (CBA) kit (Human Inflammatory Cytokine Kit was purchased from BD Bioscience (Franklin Lakes, New Jersey, USA). Mini-protean TGX precast gels were purchased from Bio-Rad (Hercules, California, USA). Soluble RAGE (\#RD172116100) was purchased from BioVendor (Brno, Czech Republic). Polyclonal goat anti-mouse Antibody/HRP (\#P0447) and polyclonal rabbit anti-mouse antibody/biotinylated (\#E0464) were purchased from Dako (Jena, Germany). Intracellular Fixation \& Permeabilization Buffer Set and Fixable Viability Dye eFluor 506 were obtained from eBioscience (San Diego, California, USA). G3-C12 (400 $\mu$ M, \#RP20329) and ovalbumin were purchased from GenScript (Piscataway, New Jersey, USA) and InvivoGen (San Diego, California, USA), respectively. FPS-ZM1 (100-250 nM, \#553030) was purchased from Merck Millipore, Burlington, Massachusetts, USA). IL-4 and GM-CSF protein were purchased from Peprotech (Cranbury, New Jersey, USA). NE-(carboxy [2H2]methyl)-1-lysine (d2-CML), Ne-(carboxymethyl)-1-lysine (CML), furosine, and furosine-d4 were purchased from Polypeptide laboratories (Strasbourg, France). CD36 (\#1955-CD), anti-RAGE antibody (\#MAB11451), and anti-Gal-3 antibody (\#MAB11541) were purchased from R\&D system (Minneapolis, Minnesota, USA). Bovine serum albumin was obtained from Roche (Basel, Switzerland). TMB substrate (3,3',5,5'-tetramethylbenzidine) for high sensitivity ELISA was purchased from sdt-reagents (Baesweiler, Germany). All other chemicals were purchased from Sigma Aldrich (St. Louise, Missouri, USA).

\subsubsection{Isolation, treatment and fractionation of BLG and WP}

Raw milk was obtained from the Department of Animal Sciences, Wageningen University \& Research (Wageningen, The Netherlands). The WP fraction was purified from the raw bovine 
milk as described before by Perdijk at al. [20]. BLG was purified and isolated as described by De Jongh et al. [21] using anion exchange chromatography DEAE Sepharose C-6B (GE healthcare, Chicago, Illinois, USA). Isolated BLG was lyophilised and a purity $>94 \%$ was measured as described by Deng et al. [19]. The lipopolysaccharide (LPS) removal was performed according to the protocol described by Teodorowicz et al. [22] and the recombinant factor $\mathrm{C}$ endotoxin detection assay was used to monitor the LPS levels. LPS-free BLG and WP were heated in a wet system above the denaturation temperature by heating it in phosphate buffer (PBS) at $\mathrm{pH} 7.4$ applying $100{ }^{\circ} \mathrm{C}$ for $90 \mathrm{~min}$ in the presence $(1: 1 \mathrm{w} / \mathrm{w})$ of lactose (BLG/WP-Lac), glucose (BLG/WP-Glu) and in the absence of lactose (BLG/WP-H). After the heating step BLG and WP were fractionated using Amicon Ultracell 100k and Amicon Ultracell 3k filters (Amicon, UFC910024, Millipore Corporation, Bedford, Massachusetts, USA). Proteins were loaded first onto the Amicon Ultracell 100k filter and washed 7 times with PBS followed by centrifugation $\left(3363 \times \mathrm{g}, 10 \mathrm{~min}, 25^{\circ} \mathrm{C}\right)$. The filtrates were collected, pooled and subsequently loaded onto Amicon Ultracell $3 \mathrm{k}$ filter in order to concentrate the collected fraction. The protein concentration in both fractions (above and below $100 \mathrm{kDa}$ ) was measured using NanoDrop ND1000. Both fractions were aliquoted before storage at $-20{ }^{\circ} \mathrm{C}$.

\subsubsection{Thioflavin-T(ThT)-assay}

ThT-assay was conducted to monitor the formation of fibril structures during heating according to the previously described protocol [15]. Briefly, samples were diluted to a protein concentration of $0.25 \mathrm{mg} / \mathrm{mL}$ and mixed with $4 \mathrm{mM}$ ThT dissolved in PBS at a ratio 7:1 (v/v). Samples were measured in duplicate using the Infinite ${ }^{\circledR} 200$ PRO NanoQuant and i-control software (Tecan, Männedorf, Switzerland) at the excitation wavelength $450 \mathrm{~nm}$ and the emission wavelength $475 \mathrm{~nm}$.

\subsubsection{Surface hydrophobicity}

Hydrophobicity was measured using 8-anilino-1-naphthalenesulfonic acid (ANS) assay according to the previously described protocol [19] with the addition that samples were diluted to a protein concentration of $0.5 \mathrm{mg} / \mathrm{mL}$. All samples were measured in duplicate in a 96-well black polysterene plate using the Infinite ${ }^{\circledR} 200$ PRO NanoQuant and i-control software (Tecan, Männedorf, Switzerland) at excitation wavelength $390 \mathrm{~nm}$ and emission wavelength $470 \mathrm{~nm}$.

\subsubsection{Quantification of $N^{\varepsilon}$-carboxymethyllysine and furosine using $u H P L C-M S / M S$}

$\mathrm{N}^{\varepsilon}$-carboxymethyllysine (CML) was quantified using uHPLC-ESI-MS/MS according to a method described previously $[15,23]$. Briefly, samples were hydrolysed with $6 \mathrm{M}$ hydrochloric acid at $110^{\circ} \mathrm{C}$ for $22 \mathrm{~h}$ and hydrochloric acid was removed under nitrogen flow. Dried samples were dissolved with acetonitrile $(\mathrm{ACN}) /$ water 1:1 (v/v) and spiked with CML-d2 as well as furosine-d4 to a final concentration of $250 \mathrm{ng} / \mathrm{mL}$. Analytes were separated on a Kinetex $2.6 \mu$ HILCI 100A, $100 \times 2.1 \mathrm{~mm}$ (Phenomenex, Torrance, California, USA) at $35^{\circ} \mathrm{C}$ column temperature. Eluent A was ultrapure water with $0.1 \%$ formic acid, eluent B was ACN 
with $0.1 \%$, and eluent $\mathrm{C}$ was $50 \mathrm{mM}$ ammonium formate. Flow rate was set to $0.4 \mathrm{~mL} / \mathrm{min}$ using the following gradient (time $[\mathrm{min}] /$ eluent $\mathrm{B}[\%] /$ eluent $\mathrm{C}[\%]):(0 / 80 / 10),(0.8 / 80 / 10)$, $(3.5 / 40 / 10),(6.5 / 80 / 10),(8.0 / 80 / 10),(11 / 80 / 10)$. Electron ionization was conducted in positive mode. Spray voltage was set to $3500{ }^{\circ} \mathrm{C}$, vaporising temperature was $250{ }^{\circ} \mathrm{C}$, and sheath gas pressure was $60 \mathrm{psig}$. Capillary temperature was set to $290{ }^{\circ} \mathrm{C}$. For furosine parent ion $\mathrm{M}+[\mathrm{H}+] 255.1 \mathrm{~m} / \mathrm{z}$ and fragment ion $84.4 \mathrm{~m} / \mathrm{z}$ were monitored (collision energy (CE) 19 and tube lens offset (TL) 75) as well as $130.0 \mathrm{~m} / \mathrm{z}$ (CE: 15, TL 75), while d4-furosine was monitored with $\mathrm{M}+[\mathrm{H}+] 259.1 \mathrm{~m} / \mathrm{z}$ and fragment $88.0 \mathrm{~m} / \mathrm{z}$ (CE 20, TL 72), $134.0 \mathrm{~m} / \mathrm{z}$ (CE 13, TL 72), and $196.0 \mathrm{~m} / \mathrm{z}$ (CE 13, TL 72). CML was monitored using $\mathrm{M}+[\mathrm{H}+] 205.3 \mathrm{~m} / \mathrm{z}, 84.0 \mathrm{~m} / \mathrm{z}$ (CE 18, TL 75), and $130.0 \mathrm{~m} / \mathrm{z}$ (CE 15, TL 75) while d2-CML was monitored with $\mathrm{M}+[\mathrm{H}+] 207.3 \mathrm{~m} / \mathrm{z}, 84.0 \mathrm{~m} / \mathrm{z}$ (CE 19, TL 75), and $130.0 \mathrm{~m} / \mathrm{z}$ (CE 15, TL 75).

\subsubsection{Qualitative screening of non-enzymatic post translational modifications (nePTMs)}

For the analysis of nePTMs, all samples were dialysed against demineralised water for $30 \mathrm{~h}$ with a molecular cut-off of $3.5 \mathrm{kDa}$. The samples were freeze dried and reconstituted in tris(hydroxymethyl)aminomethane hydrochloride buffer $(100 \mathrm{mmol} / \mathrm{L}, \mathrm{pH} 7.8)$. After this, reduction and alkylation of disulphides was conducted with 1, 4-dithiothreitol and iodoacetamide. Enzymatic hydrolysis was performed with Glu-C at $37{ }^{\circ} \mathrm{C}$ overnight and stopped by adding formic acid. After dilution to a final concentration of $0.1 \mu \mathrm{g} / \mu \mathrm{L}$, the peptide mixture was analysed by reversed phase micro liquid chromatography. For this, an Ultimate 3000 RS system (degasser, binary nano flow pump, autosampler, column oven; ThermoFisher, Dreieich, Germany) was coupled to a 6500 + QTrap mass spectrometer (AB Sciex, Darmstadt, Germany) equipped with an electrospray ionization source. Analyst 1.6.3 was applied for instrument control as well as for data acquisition. A YMC Triart C18 (500 $\mu \mathrm{m}$ inner diameter, $100 \mathrm{~mm}$ length, $3 \mu \mathrm{m}$ particle size) column was used at $35^{\circ} \mathrm{C}$ with the following gradient: $\mathrm{A}$, formic acid (0.1\%); B, ACN with formic acid ( $0.1 \%$ ), flow rate $30 \mu \mathrm{L} / \mathrm{min}$; [time (min) $/ \% \mathrm{~B}$ ]: $15 / 2,5 / 2,55 / 42.5,55.5 / 95,65 / 95$. An aliquot of $5 \mu \mathrm{L}$ was injected. All flow eluting before $2.0 \mathrm{~min}$ and after $55 \mathrm{~min}$ was discarded by a two-position valve prior to MS analysis. All measurements were performed in positive ionization mode. The ion source was operated at $350{ }^{\circ} \mathrm{C}$ with a voltage of $+5000 \mathrm{~V}$, the curtain gas set to $40 \mathrm{psi}$, the nebulizer gas to $40 \mathrm{psi}$, and the heating gas to $60 \mathrm{psi}$. All data were acquired in the scheduled multiple reaction monitoring mode (sMRM) with three transitions per peptide. Each sample was analysed in triplicate. With this method, 12 modified peptides representing 15 different modifications on 25 different amino acid side chains were monitored [24]. For data evaluation, MultiQuant 3.0 software was used.

\subsubsection{Inhibition ELISA with recombinant receptors}

Inhibition ELISA was conducted to determine binding of the processed BLG to the following receptors: soluble form of RAGE (sRAGE), galectin-3 (Gal-3) and two receptors from the scavenger receptor family: scavenger receptor class A type I (SR-AI) and CD36 according to the protocol described by Zenker et al. [15]. Briefly, transparent high binding ELISA plate was 
coated overnight with glycated soy extract (SE) followed by blocking for $1 \mathrm{~h}$ with $3 \%$ bovine serum albumin (v/w) and washing with $0.05 \%(\mathrm{v} / \mathrm{v})$ Tween-20 in PBS. The BLG samples in the range of the dilutions were pre-incubated with recombinant receptors $45 \mathrm{~min}$ prior to adding to the coated and blocked ELISA plate. The sample/receptor mixture was incubated in the ELISA plate for $1 \mathrm{~h}$ at $37^{\circ} \mathrm{C}$. The plate was washed and incubated (30 min at room temperature) with anti-receptor antibodies: anti-RAGE, anti-Gal-3 or anti-his antibody for receptors containing His tag. After washing the plate was incubated with detection antibody: polyclonal goat anti-mouse Antibody/HRP, polyclonal rabbit anti-mouse antibody/ biotinylated, goat anti-human IgG/HRP. The signal was detected with TMB and a colour reaction was measured at $450 \mathrm{~nm}$ vs. $620 \mathrm{~nm}$ reference using a Filter Max F5 multi-mode microplate reader (Molecular Devices, San Jose, California, USA). Each sample was measured in triplicate. Amyloid- $\beta$ for sRAGE and CD36 and SE for Gal-3 were used as a positive control, while native ovalbumin was used as a negative control. Percentage of inhibition was calculated using the following formula:

$$
\text { Inhibition }[\%]=\left(\mathrm{Abs}_{\mathrm{Max}}-\left(\mathrm{Abs}_{\text {Sample }}-\mathrm{Abs}_{\mathrm{Min}}\right)\right) / \mathrm{Abs}_{\mathrm{Max}} \times 100
$$

where Abs Max is the absorbance obtained from receptor without competition agent; Abs Min is the absorbance obtained from blank sample (PBS), Abssample is the absorbance obtained from the mixture of receptor and each sample.

\subsubsection{Native-PAGE electrophoresis}

Gel electrophoresis under non-reducing conditions was performed to monitor protein aggregates formed during heat treatment of BLG. Samples were mixed with native PAGE sample buffer (62.5 mM Tris, 25\% glycerol, 1\% bromophenol blue, $\mathrm{pH} 6.8$ ) and loaded on Mini-protean TGX precast gels. Gels were run at $100 \mathrm{~V}$ for 90 min using running buffer containing $25 \mathrm{mM}$ Tris and $192 \mathrm{mM}$ glycine and stained with GelCode Blue Stain Reagent. Images of the stained gels were obtained using a Universal Hood III (Bio-Rad, Hercules, California, USA) and Image Lab 4.1 software (Bio-Rad, Hercules, California, USA).

\subsubsection{Isolation and culturing of monocyte-derived DCs (MoDCs)}

Peripheral blood mononuclear cells (PBMCs) were isolated by density centrifugation from fresh blood obtained from healthy anonymous donors as described previously [20]. In short, CD14+ cells were isolated on a separation magnet (BD IMagnet, BD Biosciences) according to the manufacturer's instructions. Per well $10^{5}$ monocytes were cultured in 96 cells wells flat bottom plates in RPMI 1640 and 10\% FBS, normocin $(100 \mu \mathrm{g} / \mathrm{ml})$, penicillin and streptomycin (100 U/ml). Monocytes were differentiated into DCs by culturing them for six days in the presence of $20 \mathrm{ng} / \mathrm{mL}$ IL-4 and GM-CSF protein. After six days, immature DCs were used for binding and internalisation assay. 


\subsubsection{Culture of human acute monocytic leukaemia cell line (THP-1)}

The THP-1 cells were obtained as described before [25]. Macrophage phenotype was induced by stimulating THP-1 cells with $10 \mathrm{ng} / \mathrm{mL}$ PMA for $48 \mathrm{~h}$. Differentiated cells were washed twice in supplemented medium and were allowed to rest by incubating them for another $24 \mathrm{~h}$ in supplemented medium. Afterwards, the cells were used directly for the binding and/or uptake assay or incubated $24 \mathrm{~h}$ in the presence of BLG $(25,125,1000 \mu \mathrm{g} / \mathrm{mL})$ followed by the detection of cytokines in the supernatant. The supernatant was collected and human cytokine concentrations (IL-6, IL-8, IL-1 $\beta$, TNF- $\alpha$, and IL-10) were determined using the CBA kit, according to the manufacturer's instructions. The samples were analysed by flow cytometry (CytoFLEX Flow Cytometer, Beckman Coulter, Brea, California, USA). The results were normalised to cytokine levels of unstimulated macrophages cultured in the medium.

\subsubsection{Binding and internalisation assay}

To detect the BLG that was internalised by THP-1 cells, anti-BLG antibodies were labelled using the Alexa Fluor 647 protein labelling kit or Fluorescein-EX protein labelling kit. Initially, the antibodies were concentrated by ultrafiltration $(7000 \times \mathrm{G})$ using Microsep Advance centrifugal devices with Omega membrane with $3 \mathrm{kDa}$ cut-off (PALL Corporation, New York, USA), to a final concentration of $2 \mathrm{mg} / \mathrm{mL}$. Then, the antibodies were labelled with the Alexa Fluor 647 dye, following the procedure as described by the manufacturer. The binding and internalisation of BLG samples was evaluated using PMA-differentiated THP-1 macrophages and MoDCs. The cells were incubated with BLG or WP samples $(125 \mu \mathrm{g} / \mathrm{mL})$ for $2 \mathrm{~h}$. Then, the cells were washed with FACS buffer, detached from the plate and were transferred to a round-bottom 96-well NUNC plate (Thermo Fisher Scientific, Waltham, Massachusetts, USA), on ice. Subsequently, immunostaining with anti-BLG dye-conjugated antibodies was performed. Initially, the cells were stained extracellularly $\left(30 \mathrm{~min}, 4{ }^{\circ} \mathrm{C}\right.$, in the dark) with fluorescein isothiocyanate (FITC) conjugated anti-BLG antibodies, to assess the extracellular binding of the protein followed by fixation and permeabilization using intracellular fixation and permeabilization buffer set. After centrifugation $\left(3 \mathrm{~min}, 300 \times \mathrm{g}, 4^{\circ} \mathrm{C}\right)$, the cells were incubated with AlexaFluor 647-conjugated anti-BLG antibodies (30 min, $4{ }^{\circ} \mathrm{C}$, in the dark), to stain intracellularly the internalised BLG. Finally, after two washes with permeabilization buffer, the cells were resuspended in FACS buffer and were analysed by flow cytometry (CytoFLEX LX Flow Cytometer, Beckman Coulter, Brea, California, USA). The viability of the cells was monitored using Fixable Viability Dye eFluor 506.

\subsubsection{Inhibition of binding and internalisation of BLG by THP-1 cells}

To perform the inhibition of binding and internalisation of BLG by THP-1 cells, the cells were differentiated with PMA, as described in paragraph 5.2.10. After the $24 \mathrm{~h}$ resting step, the cells were treated with the chosen inhibitors: FPS-ZM1 as RAGE inhibitor, oxidised low-density lipoprotein (oxLDL) as CD36 inhibitor; G3-C12 and 33DTFG as Gal-3 inhibitor and fucoidan 
as inhibitor for the SR-A1. Finally, dynasore was used as inhibitor of clathrin-depended endocytosis, while macropinocytosis and phagocytosis were inhibited by cytochalasin $\mathrm{D}$. FPS-ZM1, ox-LDL, G3-C12, 33DFTG, fucoidan, dynasore, and cytochalasin D. After 45 min of incubation with the inhibitors, the BLG protein samples were added and the cells were incubated for two additional hours. Extracellular and intracellular staining followed, as described in paragraph 5.2.11. The samples were analysed by flow cytometry (CytoFLEX LX Flow Cytometer, Beckman Coulter, Brea, California, USA).

\subsubsection{In vitro digestion of BLG in infant gastrointestinal static in vitro model}

An infant gastrointestinal static in vitro model was used in order to mimic the digestive conditions of the gastric phase (GP) and the intestinal phase (IP) of full-term infants as described before by Ménard et al. [26]. During the GP, simulated gastric fluid ( $94 \mathrm{mM}$ sodium chloride; $13 \mathrm{mM}$ potassium chloride; $\mathrm{pH}$ 5.3) was added and the $\mathrm{pH}$ was adjusted to 5.3 with $0.1 \mathrm{M}$ hydrochloric acid followed by the addition of pepsin and lipase. Enzyme activities were set at $268 \mathrm{U} / \mathrm{ml}$ of gastric content for pepsin and $19 \mathrm{U} / \mathrm{ml}$ of gastric content for lipase. The GP was completed with an incubation at $37^{\circ} \mathrm{C}$ for $1 \mathrm{~h}$, while mixing. The IP was initiated with the addition of simulated intestinal fluid (164 mM sodium chloride, $10 \mathrm{mM}$ potassium chloride, $85 \mathrm{mM}$ of sodium bicarbonate $\mathrm{pH}$ 6.6) after which the $\mathrm{pH}$ was adjusted to 6.6 with $0.1 \mathrm{M}$ sodium bicarbonate. Then, in this order, pancreatin and bovine bile extract. Calcium chloride stock solution was added in the beginning of the IP at a concentration of $3 \mathrm{mM}$ within the volume of the intestinal fluid. Bovine bile extract was added to a final content of $3.1 \mathrm{mM}$ of bile salts and the pancreatin covered the intestinal lipase activity required of $90 \mathrm{U} / \mathrm{ml}$ of intestinal content and the trypsin activity needed i.e. $16 \mathrm{U} / \mathrm{ml}$ of intestinal content. The IP was completed with an incubation at $37^{\circ} \mathrm{C}$ for $2 \mathrm{~h}$, while mixing. At the start and end of both phases, the $\mathrm{pH}$ was measured for all samples. At the end of the IP, the $\mathrm{pH}$ was adjusted to 6.8. The digestion was finalised by inactivating the digestive enzymes with $1 \mathrm{mM}$ Pefabloc.

\subsubsection{Statistical analysis}

Statistical analysis were conducted using GraphPad Prism. For multiple sample comparison, one-way ANOVA was used and Tukey post hoc comparison test, if not mentioned otherwise. Results were considered statistical different at $p<0.05$ if not mentioned otherwise.

\subsection{Results}

\subsubsection{Chemical characterization of processed BLG}

Bovine BLG isolated from raw milk was heated: (1) in the presence of glucose (BLG-Glu), (2) in the presence of lactose (BLG-Lac), and (3) without sugar (BLG-H). WP, isolated from raw bovine milk, was subjected to the same treatment in order to study the effect of presence of all WPs simultaneously on the structural and functional changes of BLG. Prior to the heat treatment, both BLG and WP were depleted from LPS contamination. The remaining levels of 
LPS in the samples used in the functional in vitro assays were below $2 \mathrm{pg} / \mathrm{mL}$ (supplementary material: Figure 5-S1). To describe the influence of heating and glycation on the structure of BLG the exposure of $\beta$-sheets as well as hydrophobic structures was measured. Exposure of both, $\beta$-sheets and hydrophobicity showed significantly higher levels than non-treated BLG (BLG-NT) already after heating in the absence of reducing sugars (Figure 5.1a and b).

a

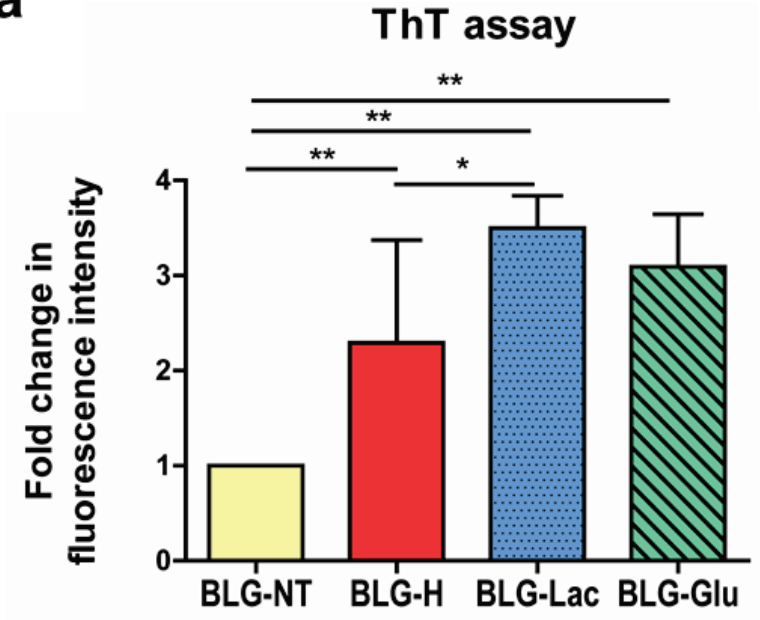

b

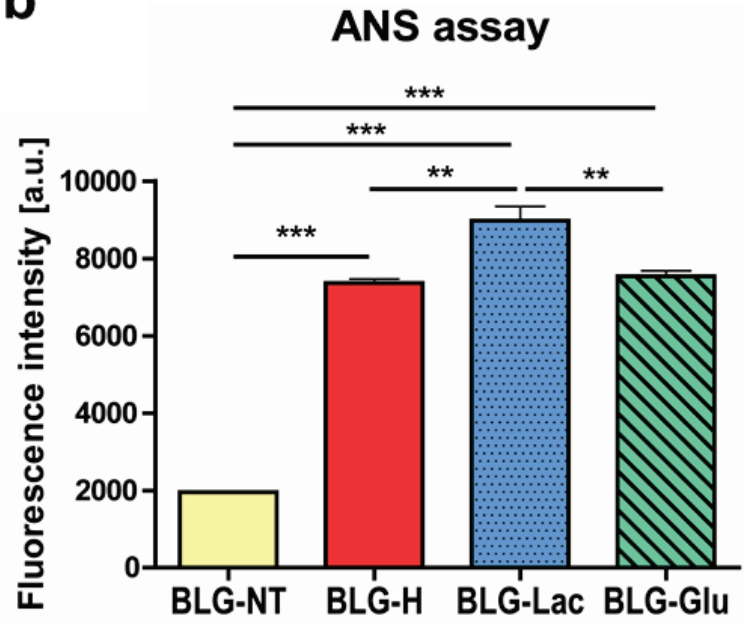

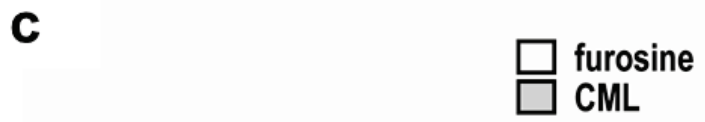
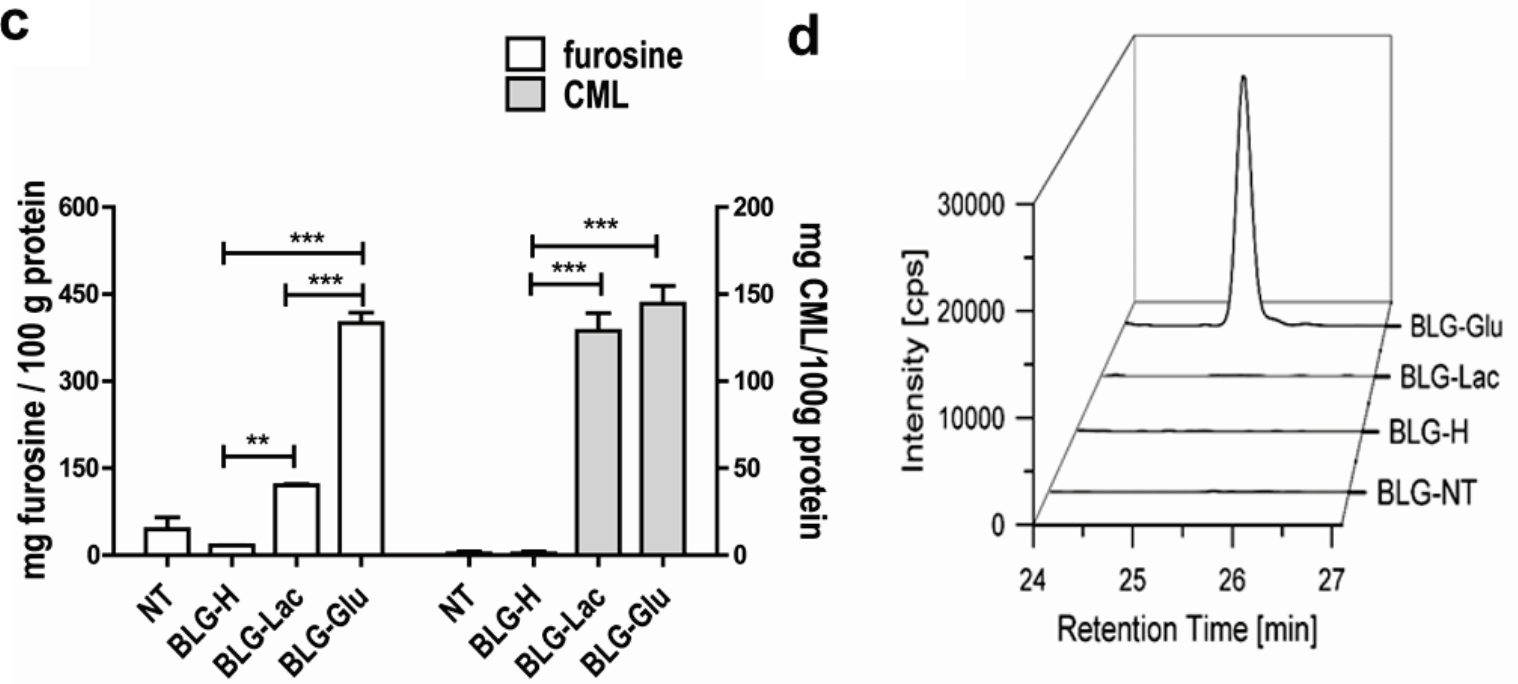

Figure 5.1: Biochemical characteristic of heated and glycated BLG. (a) formation/exposure of the fibril structures measured with ThT-assay, (b) changes in hydrophobicity measured with ANS assay, (c) level of glycation expressed as amount of formed $\mathrm{N}^{\varepsilon}$-carboxymethyllysine (CML) and furosine, (d) LC-sMRM chromatogram of methylglyoxal-dihydroxyimidazoline on AQSAPLR[+72.0]VYVEE in BLG-Glu. Three MRM transitions are displayed. BLG: non-treated (BLG-NT), heated (BLG-H), heated with lactose (BLG-Lac) or heated with glucose (BLG-Glu). Data shown as mean \pm SD of triplicate wells and are representative of at least three independent experiments. Significant differences analysed with one-way ANOVA with Tukey post hoc comparison test; $* \mathrm{p}<0.05 ; * * \mathrm{p}<0.01, * * * \mathrm{p}<0.001$.

Hydrophobicity and exposure of $\beta$-sheet structures further increased in BLG-Lac compared to BLG-H, whereas BLG-Glu was comparable to BLG-H (Figure 5.1a and b). However, BLG-Lac showed significantly higher fluorescence intensity as compared to BLG-H indicating a more hydrophobic nature of, additionally, glycated proteins. In order to determine the level of the intermediate and advanced MRPs, furosine and CML were quantified in all samples. The level of furosine and CML was significantly higher in the BLG-Lac and BLG-Glu when compared 
to BLG-NT and BLG-H (Figure 5.1c). The levels of furosine detected in BLG-Glu were significantly higher than in BLG-Lac, while the CML levels were comparable in both samples. Finally, the post translational modification (nePTM) profile of BLG-Glu vs. BLG-Lac was analysed to screen for modifications, which may be specific for a sample including 15 nePTMs on 25 bindings sites [24]. Only methylglyoxal-dihydroxyimidazoline (MG-DH1) on R40 was exclusively detected in BLG-Glu (Figure 5.1d) while all other nePTMs were either detectable in all or in none of the samples. Therefore, glycation of BLG in the presence of sugars in the wet heating model was confirmed by detection of furosine, CML and nePTM profiling while the heat-induced structural changes were demonstrated by exposure of $\beta$-sheets and hydrophobic patterns.

\subsubsection{Heated and glycated BLG and WP bind to SRAGE, Gal-3, CD36 and SR-AI}

The next step in our study was to relate the biochemical changes of BLG and WP to its biological and functional properties, by studying direct interaction with human immune cells. Initially, we aimed to identify the receptors responsible for the binding of processed and non-processed BLG. For that purpose, screening of receptors expressed on APCs, including sRAGE, Gal-3, and two receptors of the scavenger family: CD36 and SR-AI, was performed, with inhibition ELISA (Figure 5.2). The binding of BLG-NT to all four receptors did not differ from the negative control while BLG-H showed a high binding to all studied receptors, which was further increased for the glycated proteins. The differences of receptor inhibition between heated and glycated BLG reached a maximum value of $18 \%$ for the CD36 receptor (Figure 5.2a) suggesting high relevance of heat-induced structural changes in formation of the receptors ligands. The type of sugar used for glycation (glucose vs. lactose) had a marginal impact on the level of binding to the studied receptors. Heating of BLG in a presence of other WPs resulted in a significantly lower binding to Gal-3, SR-AI, and CD36 when compared to pure BLG at the same concentration, suggesting that the binding as observed in WP is mainly the result of modification of BLG. 
a

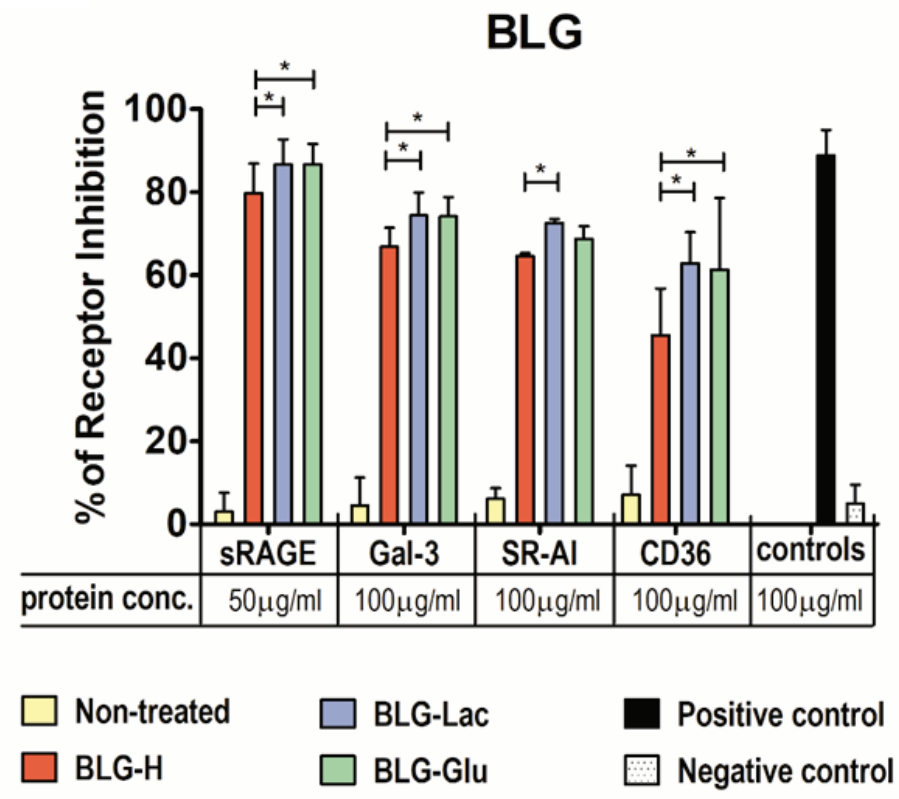

b

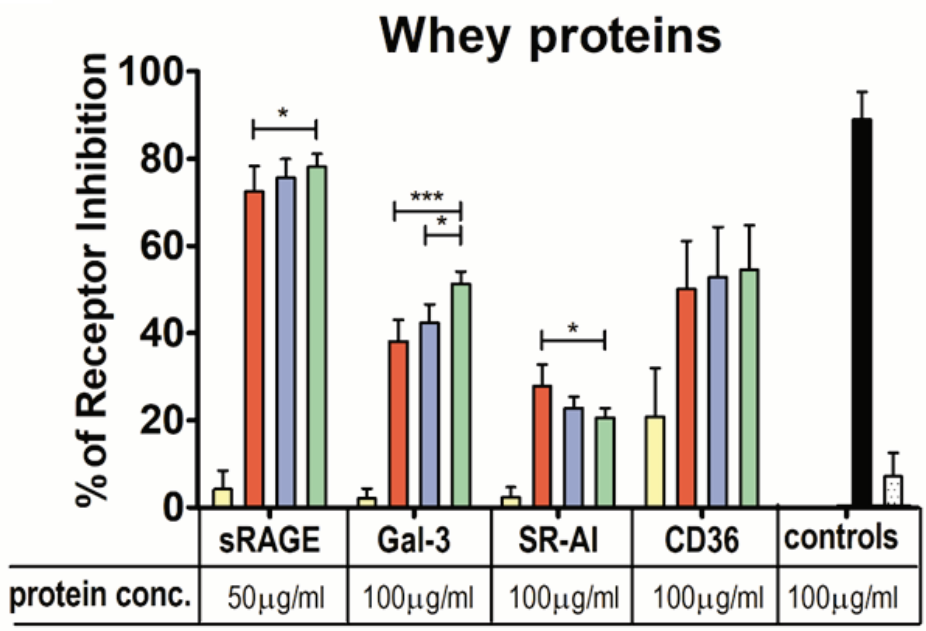

Figure 5.2: Inhibition of sRAGE, Gal-3, CD36 and SR-AI by BLG and whey proteins measured in competition ELISA. BLG (a) and WP (b), non-treated or heated in the absence of sugar (BLG-H) or in the presence of lactose or glucose (BLG-Glu, BLG-Lac) were pre-incubated with the recombinant forms of sRAGE, Gal-3, CD36 and SR-AI prior adding to the ELISA plate coated with glycated soy protein extract. The data are expressed as percentage of inhibition by the use of non-inhibited signal as the maximum value. Positive control: highly glycated soy protein extract; Negative control: ovalbumin. Data shown as mean \pm SD of triplicate wells and are representative of at least three independent experiments on three different batches of processed BLG. Significant differences analysed with one-way ANOVA with Tukey post hoc comparison test; $* \mathrm{p}<0.05 ; * * \mathrm{p}<0.01$, $* * * \mathrm{p}<0.001$.

\subsubsection{Heated and glycated BLG and WP bind to THP-1 macrophages and get internalised via both actin- and clathrin-dependent endocytosis mechanisms}

To confirm the inhibition ELISA results, we performed binding and uptake assays of non-processed and heated BLG and WP, using THP-1 macrophages and MoDCs (Figure 5.3). 
a

Binding THP-1 cells

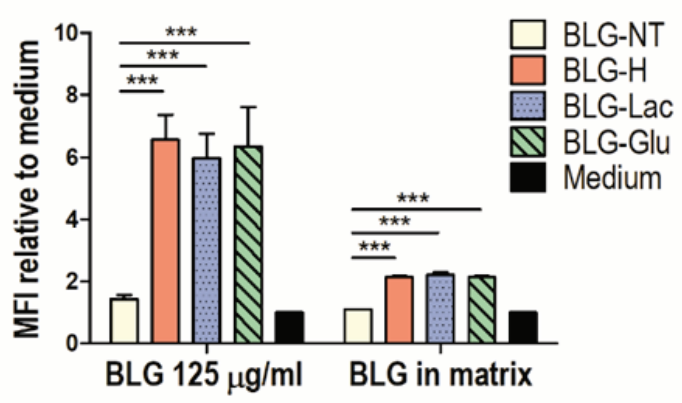

C

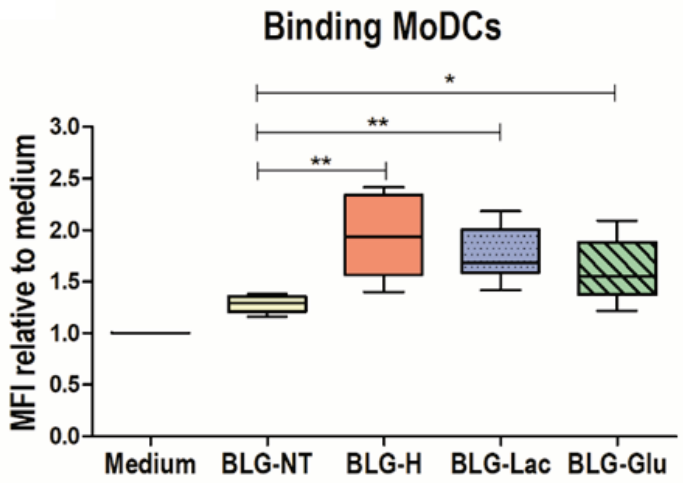

b

Internalisation THP-1 cells

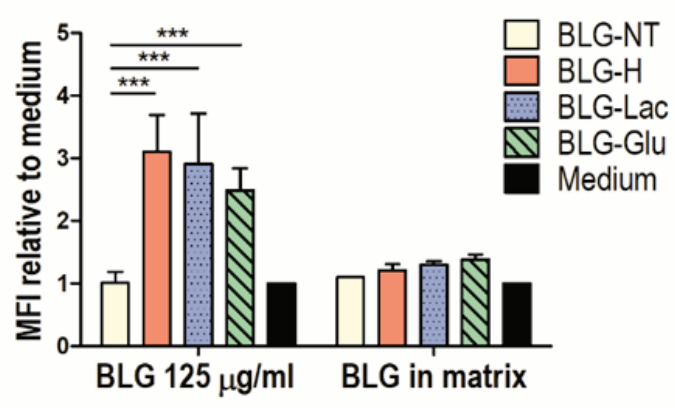

d

Internalisation MoDCs

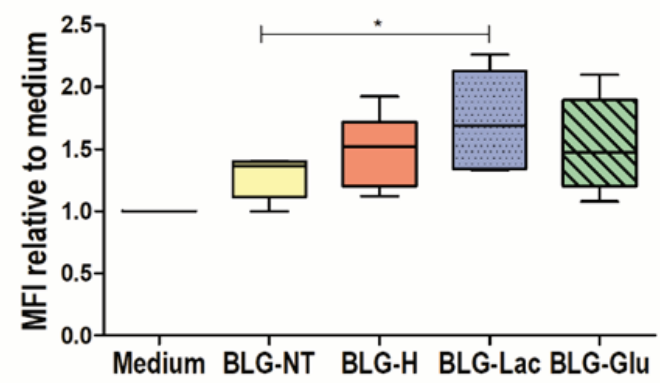

Figure 5.3: Binding and internalisation of processed BLG by human THP-1 macrophages (a, b) and human monocyte derived DCs (c, d). PMA differentiated THP-1 macrophages or MoDCs were incubated $2 \mathrm{~h}$ in a presence or absence of BLG: non-treated (BLG-NT), heated (BLG-H), heated with lactose (BLG-Lac) or heated with glucose (BLG-Glu) followed by extracellular staining with FITC conjugated anti-BLG antibodies and intracellular staining with Alexa Fluor 647 conjugated anti-BLG antibodies. The level of fluorescence was measured by flow cytometry and expressed as a relative to medium control. Data for THP-1 macrophages (a, b) shown as mean \pm SD of triplicate wells and are representative of at least three independent experiments. Data for MoDcs shown as mean \pm SD of nine (c) or six (d) healthy donors. Significant differences analysed with one-way ANOVA with Tukey post hoc comparison test; * $\mathrm{p}<0.05 ; * * \mathrm{p}<0.01, * * * \mathrm{p}<0.001$.

To be able to distinguish the binding of BLG from internalisation of BLG, anti-BLG antibodies labelled with two different fluorescent dyes were used, to perform extracellular and intracellular staining. BLG heated in the absence and presence of sugars bound to the surface of THP-1 macrophages, and was also detected intracellularly, but BLG-NT neither bound to nor entered the cells. Moreover, BLG present in WP was equally bound to and internalised by the THP-1 macrophages. The concentration of BLG in WP is approximately $50 \%$; therefore, its binding and internalisation by APCs is lower compared with BLG-NT but detectable with anti-BLG antibodies (Figure 5.3a and b). No significant differences between BLG heated in the presence or absence of sugar were observed in terms of binding and internalisation. This same pattern was noted for binding to and internalisation by human MoDCs, although the level of internalisation was lower when compared to THP-1 macrophages (Figure 5.3c and d). To describe a more detailed mechanism of internalisation of heated and glycated BLG we inhibited 
the major endocytosis pathways. Cytochalasin D was used to block the actin-dependent endocytosis mechanisms pinocytosis and phagocytosis, while a dynamin inhibitor, dynasore, was used to block the clathrin-dependent endocytosis mechanism. Both cytochalasin D and dynasore significantly reduced the uptake of heated and glycated BLG, indicating that both the actin-dependent endocytosis mechanisms and the receptor-mediated endocytosis mechanisms are involved in the uptake of processed BLG (Figure 5.4b).

a

Inhibition of binding

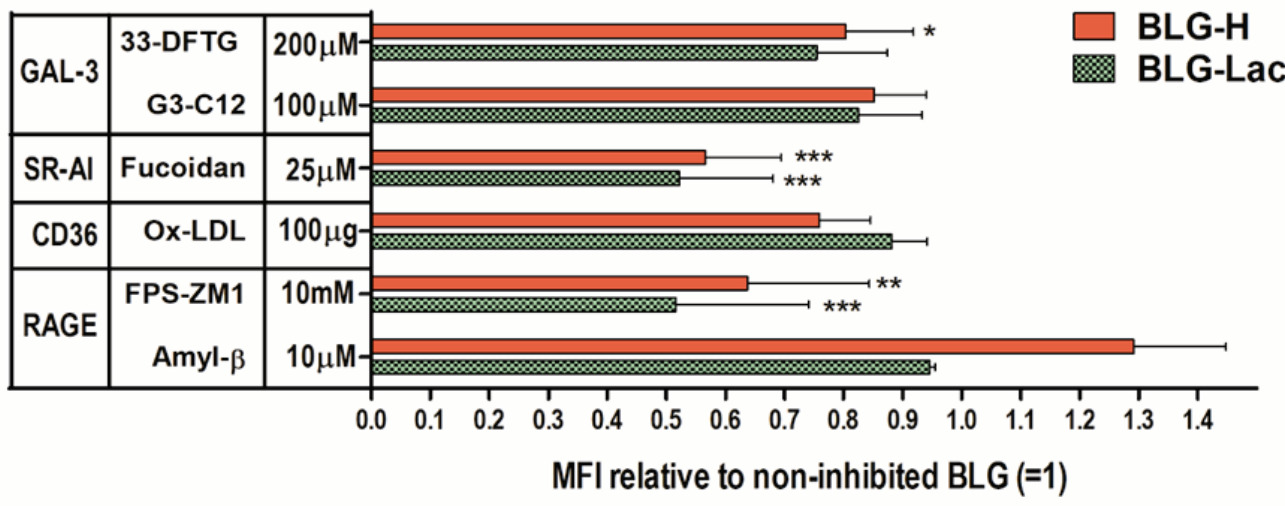

b

\section{Inhibition of internalisation}

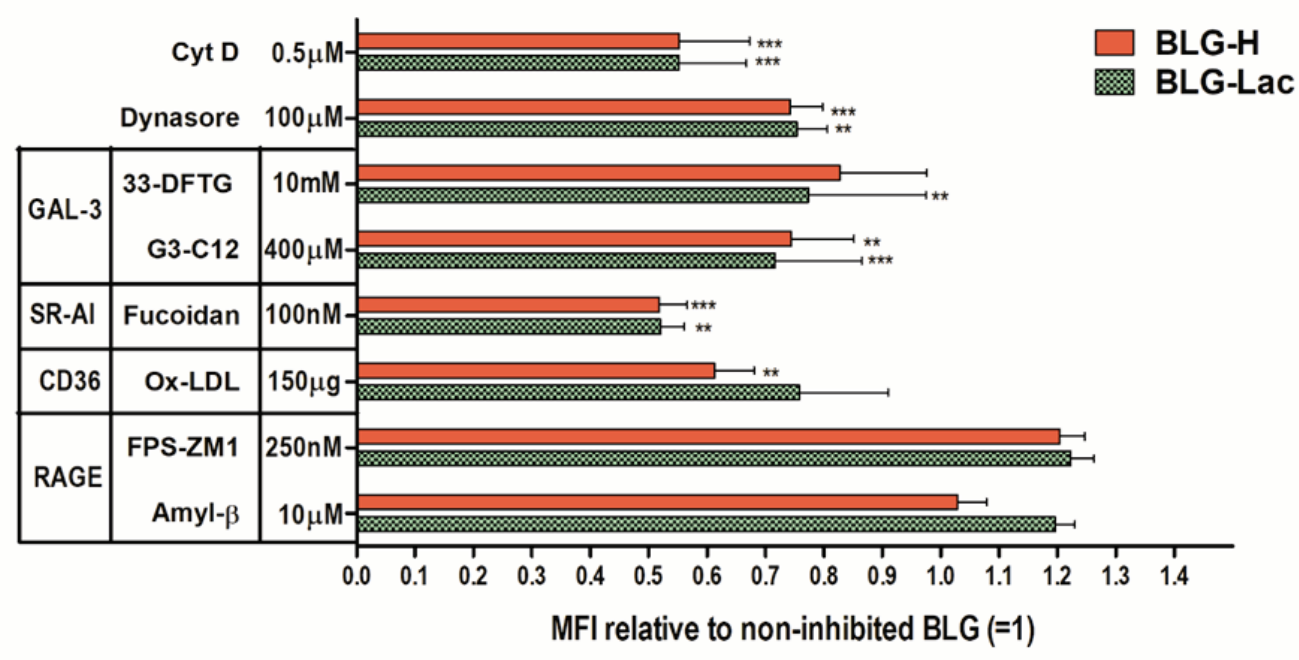

Figure 5.4: Inhibition of binding and internalisation of processed BLG by human THP-1 macrophages. PMA differentiated THP-1 macrophages were pre-incubated with endocytosis inhibitors: dynasore and cytochalasin D (Cyt D) or inhibitors of specific receptors: amyloid- $\beta$ and FPS-ZM1 for RAGE; Oxidized low-density lipoprotein (Ox-LDL) for CD36; fucoidan for SR-AI, short peptides 33-DFTG and G3-C12 for Gal-3. Followed by pre-incubation with inhibitor the cells were incubated in a presence or absence of BLG: BLG heated in the absence of reducing sugars (BLG-H) or heated with lactose (BLG-Lac) and stained extracellularly (a) or intracellularly (b) with Alexa Fluor 647 conjugated anti-BLG antibodies. The level of fluorescence was measured by flow cytometry and expressed as a relative to non-inhibited THP-1 cells. Data shown as mean \pm SD of triplicate wells and are representative of at three independent experiments. Significant differences analysed with one-way ANOVA with Tukey post hoc comparison test; $* \mathrm{p}<0.05 ; * * \mathrm{p}<0.01, * * * \mathrm{p}<0.001$. 
Therefore, we blocked the receptors: RAGE, CD36, SR-AI and Gal-3 which expression on the surface of the PMA-differentiated THP-1 cells was first confirmed by flow cytometry (Supplementary Figure 5-S2). We observed the reduced binding of the BLG for the various receptors, demonstrating that the receptor with the highest binding capability was SR-AI followed by RAGE, Gal-3 and finally CD36 (Figure 5.4a). Finally, we used the anti-BLG antibodies labelled with different dyes for extra- and intracellular staining to distinguish between the receptors directly involved in binding and internalisation of heated and glycated BLG. The inhibitors of SR-AI > Gal-3 > CD36 significantly reduced the uptake of both heated and glycated BLG, pointing at the receptors from the SRs family, but also Gal-3, as the main receptors involved in receptor-mediated endocytosis. An inhibitor of RAGE (FPS-ZM1) did not significantly affect uptake of processed BLG (Figure 5.4b) while it was shown to reduce the external binding to RAGE. No significant differences in the blocking efficiency between heated and glycated BLG were observed.

\subsubsection{Internalisation of BLG does not impact the secretion of pro-inflammatory cytokines by} THP-1 macrophages

To study the physiological consequences of the binding and internalisation of heated and glycated BLG by THP-1 macrophages, the levels of the cytokines IL- 6 , IL- $1 \beta$, TNF- $\alpha$, IL-10 were determined in the cell culture medium after $24 \mathrm{~h}$ incubation with BLG. No significant increase of any of the measured cytokines was observed upon incubation of cells with processed BLG, when compared to the medium control or to BLG-NT (supplementary Figure 5-S3a). These findings demonstrated that uptake of processed BLG does not result in direct release of pro-inflammatory cytokines. However, when THP-1 cells were first pre-incubated with BLG-Lac followed by the re-stimulation of the cells with LPS, enhanced levels of IL-6 and IL-8 were measured compared to the cells pre-incubated with BLG-H and BLG-NT (supplementary material Figure 5-S3b).

\subsubsection{Agglomerates formed during heating and glycation of BLG show higher potential to bind to the receptor present on APCs than the low molecular weight fractions}

As the next step, we aimed to specify which fractions of heated and glycated BLG are responsible for binding and internalisation by THP-1 macrophages. For that reason, we fractionated processed BLG into two fractions with molecular weight (MW) above and below $100 \mathrm{kDa}$. The purity of the fractions was checked by Native-PAGE, which showed that fraction with MW>100 kDa was not contaminated with monomeric BLG (Figure 5.5c). 
a

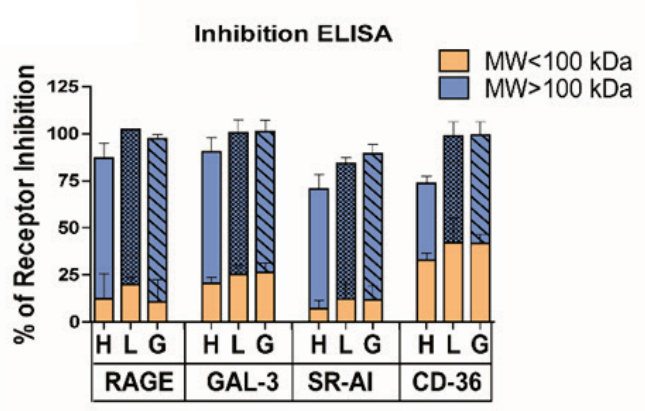

b
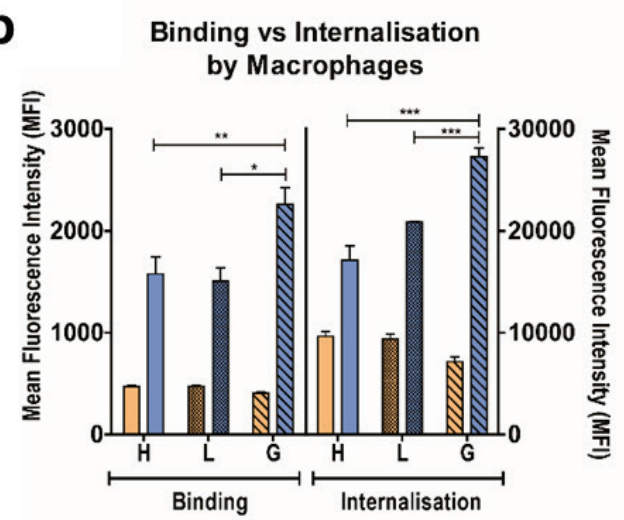

C

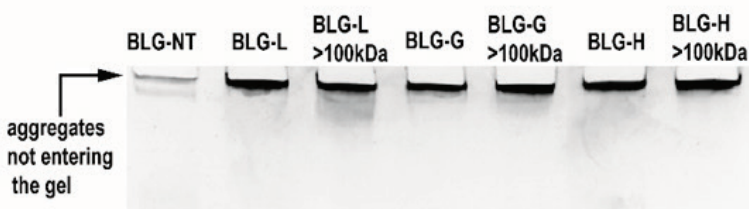

Figure 5.5: Binding and internalisation of aggregates vs. low molecular fractions of heated and glycated BLG. (a) Processed BLG: heated $(\mathrm{H})$, heated with lactose $(\mathrm{L})$ or heated with glucose $(\mathrm{G})$ was fractionated using Amicon-Ultra Centrifugal Filters into two fractions: high molecular weight fraction $>100 \mathrm{kDa}$ and low molecular fraction $<100 \mathrm{kDa}$. Both fractions were subjected to (a) receptor binding assay using inhibition ELISA, (b) binding/internalisation assay using THP-1 macrophages. Binding to THP-1 macrophages was detected with extracellular staining using FITC conjugated anti-BLG antibodies (b, left Y axis) and internalised BLG was measured by intracellular staining with Alexa Fluor 647 conjugated anti-BLG antibodies (b, right Y axis). (c) Composition of the BLG samples as well as the purity of the fraction $>100 \mathrm{kDa}$ was analysed by native PAGE. Data shown as mean \pm SD of triplicate wells and are representative of at three (a) or two (b) independent experiments. Significant differences analysed with one-way ANOVA with Tukey post hoc comparison test; $* \mathrm{p}<0.05 ; * * \mathrm{p}<0.01, * * * \mathrm{p}<0.001$.

Moreover, the protein separation on the gel reveals that heating promotes the formation of aggregates that were visible on the top of the gel in all the samples, independent of the presence of sugar during heating. Subsequently, both fractions were analysed in receptor binding ELISA allowing to identify the fraction with $\mathrm{MW}>100 \mathrm{kDa}$ as the most potent for binding to all studied receptors (Figure 5.5a). Finally, the binding assay employing THP-1 macrophages showed more potent binding and internalisation of the aggregates (Figure 5.5a). This shows that heat induced aggregation is a major force promoting internalisation of heated and glycated BLG by the receptors present on APCs. Interestingly, aggregates obtained from BLG-Glu were shown to bind and be internalised significantly more efficient than the aggregates obtained from BLG-H and BLG-Lac (Figure 5.5b). 


\subsubsection{Glycated BLG agglomerates are partially resistant to digestion}

Lastly, we verified the physiological relevance of BLG aggregates by subjecting them to an in vitro digestion model mimicking gastrointestinal digestion in the infant's stomach and small intestine. At first, the binding of the BLG digest to sRAGE, Gal-3, CD36 and SR-AI was evaluated in an ELISA receptor binding test and compared to the binding of enzyme matrix and digest of BLG-NT (Figure 5.6a).

a

\section{Receptor binding}

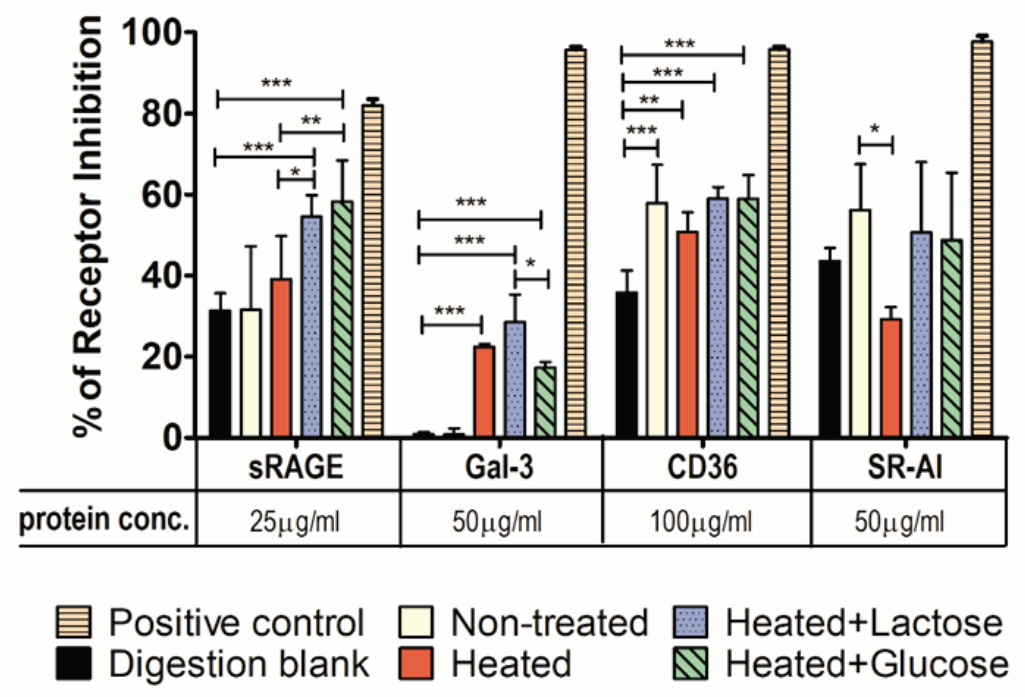

b

Binding to THP-1

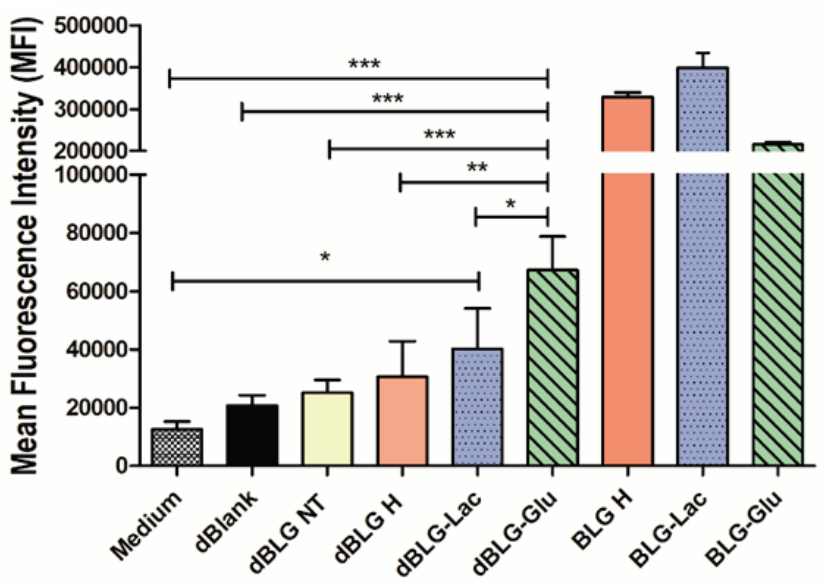

Figure 5.6: Immunoreactivity of heated and glycated BLG after enzymatic digestion in infant gastrointestinal static in vitro model. BLG: Non-treated, heated (BLG-H), heated with lactose (BLG-Lac) or heated with glucose (BLG-Glu) were subjected to gastric and intestinal phase of enzymatic digestion and immunogenicity of digested samples was measured as (a) binding to sRAGE, Gal-3, CD36 and SR-AI in inhibition ELISAs, (b) binding assay to THP-1 macrophages using Alexa Fluor 647 conjugated anti-BLG antibodies for flow cytometry detection. Data shown as mean $\pm \mathrm{SD}$ of triplicate wells and are representative of at three (a) or two (b) independent experiments. Significant differences analysed with one-way ANOVA with Tukey post hoc comparison test; * $\mathrm{p}<0.05$; $* * \mathrm{p}<0.01, * * * \mathrm{p}<0.001$. 
Digests of BLG-Glu and BLG-Lac showed a significantly enhanced binding to sRAGE when compared to digests of BLG-H and BLG-NT. Gal-3 showed significantly higher binding to digests of BLG-H, BLG-Glu, and BLG-Lac as compared to BLG-NT. The binding of the digests of BLG-H, BLG-Glu, and BLG-Lac to the scavenger receptors (CD36 and SR-AI) was on a comparable (BLG-Glu and BLG-Lac) or lower (BLG-H) level than the binding to the digest of BLG-NT. Next, the binding of all BLG digests to the THP-1 macrophages was studied. The binding of digested BLG was in general significantly reduced when compared to undigested BLG. However, the digested BLG-Glu was still successfully detected on the surface of THP-1 macrophages by fluorescently labelled anti-BLG antibodies (Figure 5.6b). Peptides released from BLG-Glu retained $30 \%$ of the binding capacity of non-digested material showing significantly higher binding compared to BLG-NT, BLG-H, and BLG-Lac. Digested BLG-Lac showed a similar trend which, however, was not statistically significant. This result shows that aggregates formed especially during heating of BLG in the presence of glucose maintain their immunogenicity after in vitro gastrointestinal digestion.

\subsection{Discussion}

CM allergy is one of the most common food allergies in early childhood [27] and heat processing of milk has been implicated in increased allergenicity of CM proteins $[2,12,13]$. The first step of allergic sensitisation is internalisation of antigen by APCs and presentation to T-cells. Heat-treated BLG was already shown in murine in vivo studies to be taken up more efficiently through the Peyer's patches than through absorptive epithelial cells, allowing the protein to interact with APCs [12]. However, the mechanisms by which heated but also glycated BLG is recognised by APCs and the relevance of these interactions to allergic sensitisation remain unclear. In this study we described mechanisms by which heat treated and glycated BLG is recognised by APCs. We evaluated the relative importance of aggregation vs. glycation as well as glycation with glucose vs. lactose in terms of receptor binding and internalisation. Lastly, since an immunogenicity of processed BLG in vivo would be modulated by gastrointestinal digestion, we therefore included an infant digestion model of BLG to come closer to the actual in vivo situation.

Cellular binding assays using THP-1 macrophages revealed enhanced binding and uptake of heated and glycated BLG but no differences between these two treatments were observed (Figure 5.3). This suggests that enhanced internalisation of non-digested BLG is dominantly caused by heating and to a lesser extent by glycation. Increased binding and uptake of both heated and glycated BLG was observed also in human MoDCs confirming in primary cells the results observed in the THP-1 model. Using receptor specific inhibition ELISA we identified RAGE, Gal-3, CD36 and SR-AI as the receptors recognizing heated and glycated BLG but not BLG-NT (Figure 5.1). This finding was supported by cellular assays showing that pre-incubation of the cells with receptor-specific inhibitors significantly reduced binding of heated and glycated BLG to THP-1 macrophages (Figure 5.4). These results confirm previous 
finding which indicated RAGE, Gal-3 and receptors from the scavenger family as the main receptors recognizing glycated food proteins [28-32]. Also BLG heated and glycated in the presence of other WPs showed the binding to the studied receptors in ELISA and was detectable on the surface of THP-1 macrophages using anti-BLG antibodies. Therefore, despite the structural changes and protein crosslinking caused by heating in the presence of WPs, the BLG was recognised by studied receptors. This illustrates a major influential role of BLG, as one of the components of the WP fraction, in interacting with APCs. Interaction of glycated BLG with APC was reported previously $[8,19,28]$, but has never been directly compared with heated BLG from the perspective of binding and internalisation by APCs.

To explore further effects of heating vs. glycation on the immunogenicity of BLG, we tested separately the binding and internalisation of size-separated aggregates vs. low molecular weight fractions obtained from BLG-H, BLG-Glu and BLG-Lac. Aggregated BLG showed higher binding to all studied receptors as well as more efficient uptake by THP-1 macrophages than lower molecular weight fractions (Figure 5.5). Increased exposure of $\beta$-sheet structures and hydrophobic patterns detected on BLG-H, BLG-Glu and BLG-Lac suggest that these structures drive the binding of aggregated BLG to studied receptors. The amyloid structure, defined as predominantly containing cross $\beta$-sheet patterns [33], may promote binding of heated BLG to RAGE and CD36 since both receptors are already known to bind amyloid- $\beta$ [34,35]. Next to exposed $\beta$-sheets, hydrophobicity is a second physicochemical feature dictating the immune response [36] for instance of the well-known damage-associated molecular patterns like the lipid-A fraction of LPS or peptidoglycan [37]. Hydrophobic patterns exposed on the surface of protein due to the heat treatment may interact non-specifically with each other forming aggregates of different sizes [37,38] subsequently leading to the exposure of additional $\beta$-sheets. This processes, as observed also in our study, created all together the immunogenic profile of processed BLG recognised by APCs. This stays in line with the findings of Deng et al. [19] who previously suggested that heat-induced structural changes, but not glycation, predispose BLG to be recognised by THP-1 cells.

Although, for non-fractionated BLG, heating seemed to be a driving force for binding to the receptors, the aggregates isolated from BLG-Glu showed enhanced binding and uptake by THP-1 cells compared to the aggregates isolated from BLG-H and BLG-Lac. This indicates that glycation of BLG, especially with glucose, also plays a role in the generation of specific binding ligands for receptors present on APCs. Glucose, having a shorter carbonic chain than lactose, was shown to be more reactive and modifying more amino groups of BLG than lactose [39]. This was confirmed in our study by higher levels of furosine detected in BLG-Glu compared to BLG-Lac. Furosine indicates the level of early MR products (Amadori products) like fructosyllysine or lactulosyllysine. Therefore, the higher level of Amadori products detected in BLG-Glu may further explain the enhanced binding of BLG-Glu to THP-1 cells which may be potentially mediated by fructosyllysine-specific receptors [40]. Another explanation of the enhanced binding of BLG-Glu to THP-1 macrophages provides the MG-DH1 
modification detected only in BLG-Glu. Methylglyoxal (MGO), a highly reactive compound formed due to the spontaneous degradation of glucose, may further react with lysine and arginine residues forming MGO-modified proteins [41]. MGO-modified proteins were shown to be highly immuno-reactive [42] possibly also via interaction with RAGE [43]. Therefore, MGO-modifications of BLG-Glu may contribute to its interaction with APCs. This reveals an essential difference between glycation of milk proteins with naturally present lactose during e.g. milk processing and the glycation with glucose typically used to illustrate an effect of glycation of food proteins $[8,29,30]$.

As both heat-induced and glycation-induced aggregates are internalised by APCs via specific receptors (Figure 5.4 and Figure 5.5), we subsequently evaluated if the aggregates retain their receptor binding capacity after in vitro enzymatic digestion mimicking the infants' gastrointestinal conditions. Although the binding of glycated proteins to studied receptors was already shown [15,17,29-31], the susceptibility of the binding sites to enzymatic digestion has not been well studied. Our data showed that BLG-Glu and BLG-Lac were still recognised by sRAGE after digestion, demonstrating significantly higher binding compared to BLG-NT and BLG-H. Moreover, digested BLG-Glu was detected on the surface of APCs indicating the binding to the receptors. Blocking experiments with the RAGE antagonist FPS-ZM1 demonstrated that RAGE is not involved in internalisation of processed BLG confirming its role in signal transduction. Internalisation may thus occur through Gal-3, which showed the binding to the digests of BLG-H, BLG-Lac and BLG-Glu. The binding of digests of glycated and heated BLG to scavenger receptors was not higher than BLG-NT and control sample containing enzymes only (Figure 5.6). This suggests that aggregation is a dominant factor determining the binding capacity of BLG to scavenger receptors, although the role of these receptors after digestion is minor. Summarizing, our results indicate that the molecular mechanisms via which digested glycated BLG triggers an immune response are mediated via RAGE on the level of innate immunity and via Gal-3 on the level of the adaptive immune compartment.

RAGE is known to be implicated in a wide range of inflammatory reactions including systemic but also local intestinal and airway inflammation [44,45]. In murine models of asthma and allergic airway inflammation, RAGE has been shown to promote the expression of the type 2 cytokines IL-5 and IL-13 [46], but also IL-33 leading to the accumulation of type 2 innate lymphoid cell in the lungs [47]. These studies demonstrate an essential role of RAGE in allergic airway inflammation, however the link between RAGE and the development of food allergy is not directly proven yet. Smith et al. [18] in the false alarm hypothesis, proposed that AGEs present in the diet contribute to the development of food allergies via interaction with RAGE consequently priming immune signalling. RAGE is highly expressed on DCs, macrophages, T-lymphocytes, and B-cells [44] regulating such a processes as migration of DCs to the lymph nodes [48] as well as induction of T-cell proliferation [49]. Therefore, the authors of the false alarm hypothesis suggested that the signalling and priming of immune cells by RAGE-activated 
APCs is likely important [18]. Our study supports this hypothesis by showing that RAGE ligands formed as an effect of glycation of BLG retain their activity after enzymatic digestion. This suggests that in vivo, the relative importance of glycation is higher than that of heat-induced aggregation. In the used model, the binding and uptake of BLG did not trigger the direct release of pro-inflammatory cytokines, however the re-stimulation of the THP-1 macrophages with LPS lead to enhanced IL-6 and IL-8 responses (supplementary material: Figure 5-S3) suggesting priming of the cells. However, to understand better the role of glycation in allergic sensitisation other models, like human DCs, are needed.

\subsection{Conclusions}

In conclusion, this study showed that heat treatment of BLG generates ligands for RAGE, Gal-3, CD-36 and SR-AI as a results of both (1) heat treatment with as consequence increased hydrophobicity, exposure of $\beta$-sheets, and aggregation, and (2) glycation (predominantly with glucose) possibly connected to the formation of fructosyllysine and/or MGO. The importance of glycation in vivo was suggested after gastrointestinal digestion of aggregates, showing that glycated aggregates are less sensitive to digestion and therefore maintain their binding capacity to RAGE and Gal-3. On the basis of these results, we propose that post-digestion retained immunogenicity of glycated BLG may be mediated via RAGE as a signalling pathway, and via Gal-3 as a putative receptor responsible for enhanced antigen uptake and processing, possibly activating the adaptive immune system. However, future studies are needed to confirm this in humans and animal models of allergic sensitisation. 


\section{Supplementary material}

\section{LPS contamination}

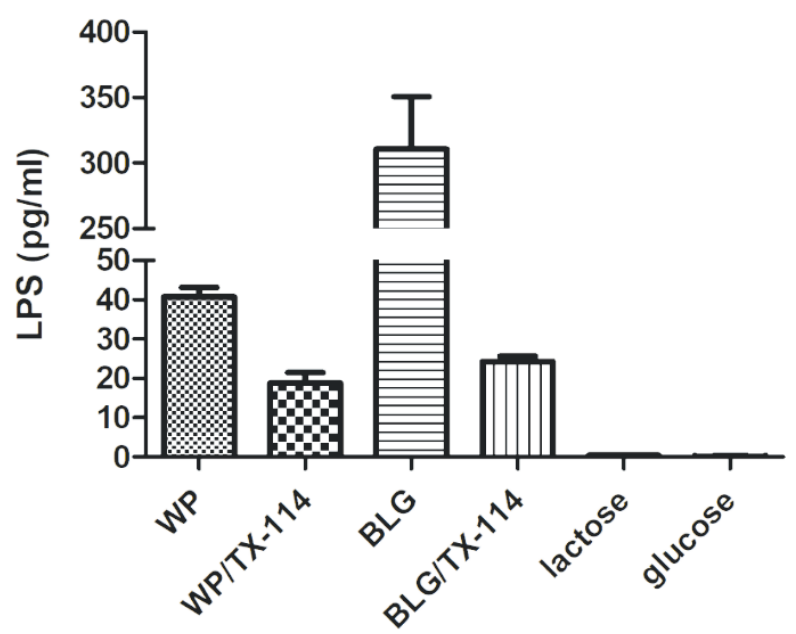

Figure 5-S1: LPS content in the BLG and WP samples before and after LPS removal. LPS was removed from the samples using Triton-X 114 method and the LPS contamination was measured using Endozyme ${ }^{\circledR}$ II assay. The levels of LPS the samples after Triton-X 114 purification were low: WP $18.83 \mathrm{pg} / \mathrm{ml} \pm 2.674$ and BLG $24.32 \mathrm{pg} / \mathrm{ml}$ \pm 1.320 reaching after dilution in in vitro test concentrations below $2 \mathrm{pg} / \mathrm{ml}$. Spike control (data not shown) showed that the matrix does not influence the readout in whey and BLG. Sugars used for glycation of WP and BLG were LPS free.

a

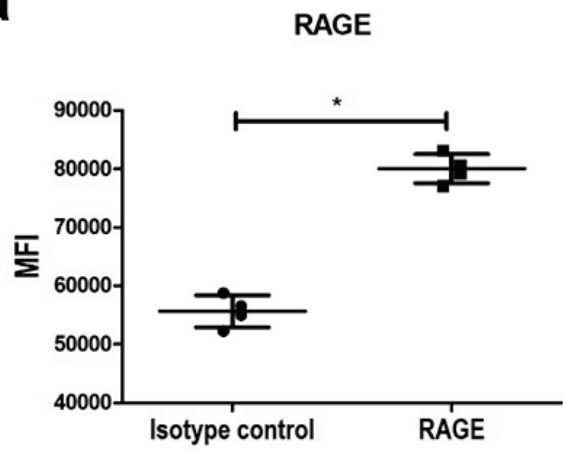

C

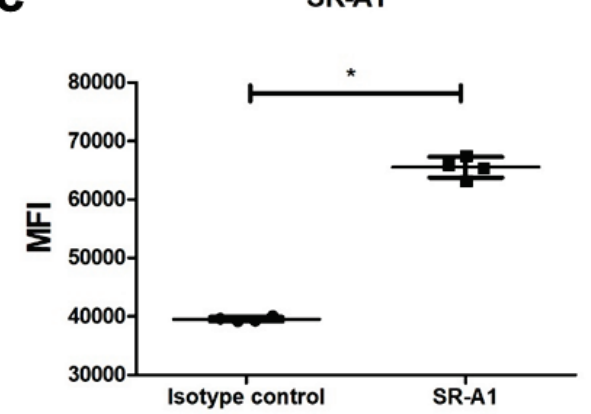

b

b $\quad$ CD36

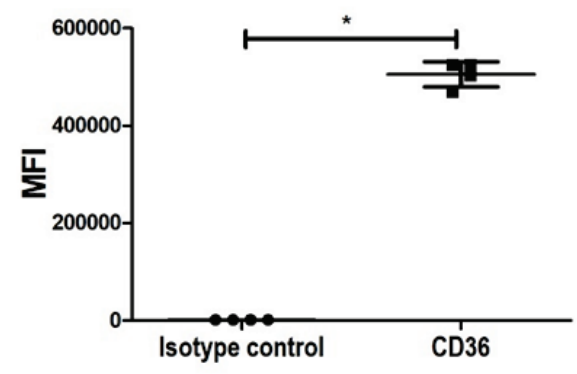

d

GAL-3

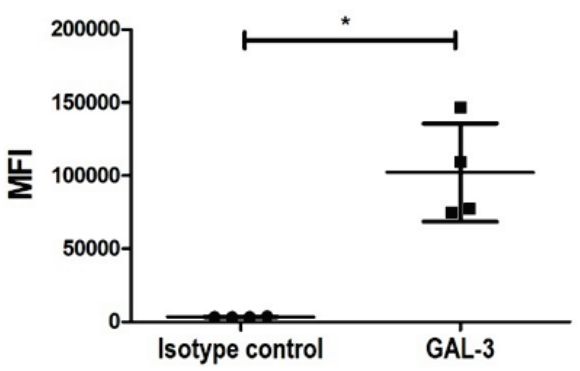

Figure 5-S2: Expression of receptors that are involved in the uptake process of glycated BLG on PMA-differentiated THP-1 macrophages. The samples were analysed with flow cytometry. The vertical scatter plots resemble the MFIs obtained from cells treated either with the specific anti-receptor antibodies or with respective isotype controls. The error bars represent the standard deviation. The statistical significance of the data was evaluated by performing Mann-Whitney, two-tailed statistical analysis. n.s. $\mathrm{p}>0.05, * \mathrm{p}<0.05$. 
a

24h stimulation with BLG [125 $\mu \mathrm{g} / \mathrm{ml}]$

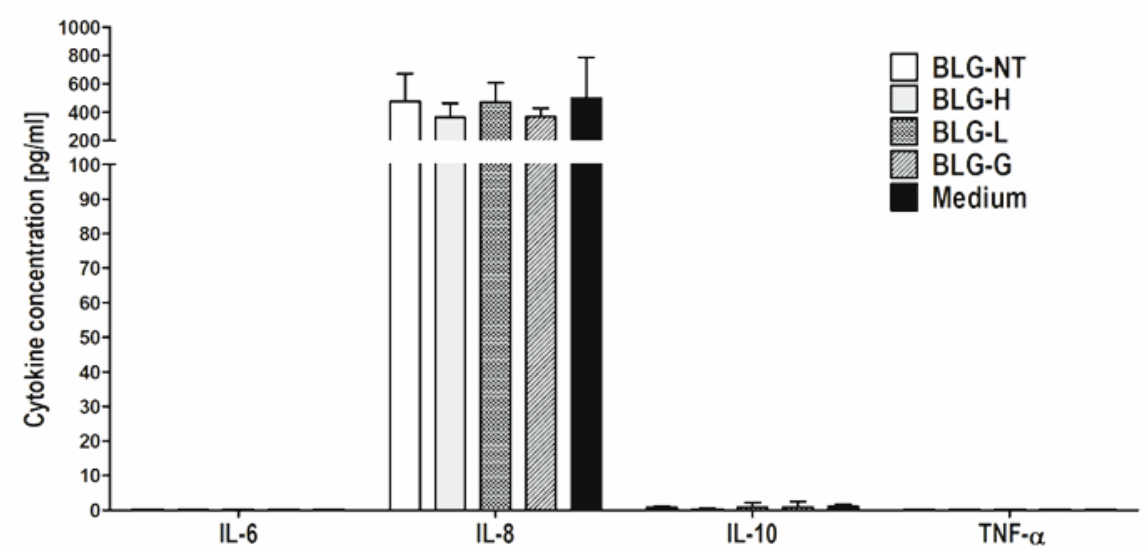

b

$3 \mathrm{~h}$ stimulation with BLG [125 $\mu \mathrm{g} / \mathrm{ml}]+$ re-stimulation with LPS

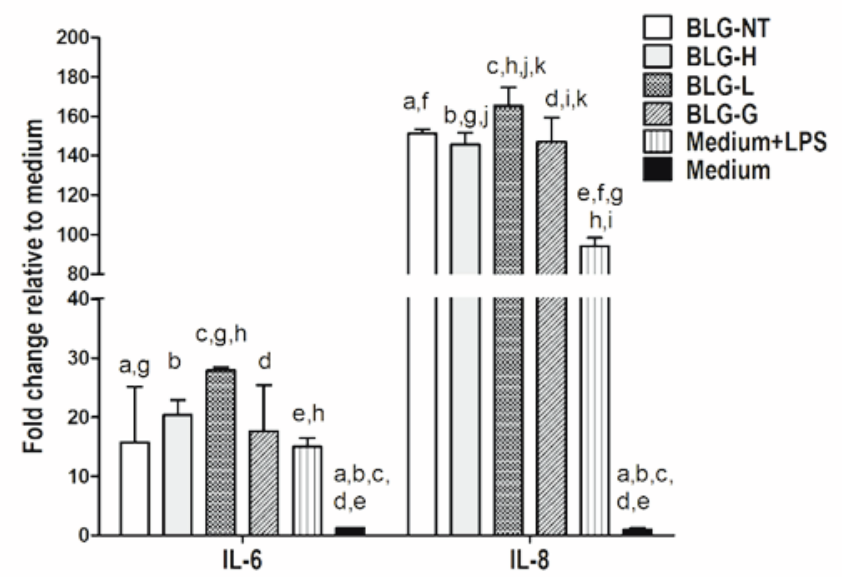

Figure 5-S3: The secretion of pro-inflammatory cytokines by THP-1 macrophages after 24 hours-long incubation with glycated and heated BLG (a) or 3 hours-long incubation with glycated and heated BLG followed with re-stimulation with LPS (b). PMA differentiated THP-1 macrophages were incubated in a presence of BLG: non-treated (BLG-NT), heated (BLG-H), heated with lactose (BLG-Lac) or heated with glucose (BLG-Glu) for $24 \mathrm{~h}$ (a) or $3 \mathrm{~h}$-long followed by re-stimulation with LPS (b). The levels of cytokines in supernatants (IL-1 $\beta$, IL-6, IL-8, IL-10 and TNF-a) were assessed with flow cytometry. Data shown as mean \pm SD of triplicate wells and are representative of two independent experiments. Significant differences analysed with one-way ANOVA with Tukey post hoc comparison test are indicated with the same letters. Statistically significant differences were considered at $\mathrm{p}<0.05$. 


\section{References}

1. Teodorowicz, M.; Van Neerven, J.; Savelkoul, H. Food Processing: The Influence of the Maillard Reaction on Immunogenicity and Allergenicity of Food Proteins. Nutrients 2017, 9, doi:10.3390/nu9080835.

2. Abbring, S.; Kusche, D.; Roos, T.C.; Diks, M.A.P.; Hols, G.; Garssen, J.; Baars, T.; van Esch, B.C.A.M. Milk processing increases the allergenicity of cow's milk-Preclinical evidence supported by a human proof-of-concept provocation pilot. Clinical and Experimental Allergy 2019, 49, 1013-1025, doi:10.1111/cea.13399.

3. Martorell-Aragonés, A.; Echeverría-Zudaire, L.; Alonso-Lebrero, E.; Boné-Calvo, J.; Martín-Muñoz, M.F.; Nevot-Falcó, S.; Piquer-Gibert, M.; Valdesoiro-Navarrete, L.; Food allergy committee of, S. Position document: IgE-mediated cow's milk allergy. Allergologia et Immunopathologia 2015, 43, 507-526, doi:10.1016/j.aller.2015.01.003.

4. Golkar, A.; Milani, J.M.; Vasiljevic, T. Altering allergenicity of cow's milk by food processing for applications in infant formula. Critical reviews in food science and nutrition 2019, 59, 159-172, doi:10.1080/10408398.2017.1363156.

5. $\quad$ El Mecherfi, K.E.; Curet, S.; Lupi, R.; Larré, C.; Rouaud, O.; Choiset, Y.; Rabesona, H.; Haertlé, T. Combined microwave processing and enzymatic proteolysis of bovine whey proteins: the impact on bovine $\beta$-lactoglobulin allergenicity. Journal of Food Science and Technology 2019, 56, 177-186, doi:10.1007/s13197-018-3471-9.

6. Corzo-Martínez, M.; Soria, A.C.; Belloque, J.; Villamiel, M.; Moreno, F.J. Effect of glycation on the gastrointestinal digestibility and immunoreactivity of bovine $\beta$-lactoglobulin. International Dairy Journal 2010, 20, 742-752, doi:10.1016/j.idairyj.2010.04.002.

7. Kurpiewska, K.; Biela, A.; Loch, J.I.; Lipowska, J.; Siuda, M.; Lewiński, K. Towards understanding the effect of high pressure on food protein allergenicity: $\beta$-lactoglobulin structural studies. Food Chemistry 2019, 270, 315-321, doi:10.1016/j.foodchem.2018.07.104.

8. Perusko, M.; van Roest, M.; Stanic-Vucinic, D.; Simons, P.J.; Pieters, R.H.H.; Cirkovic Velickovic, T.; Smit, J.J. Glycation of the Major Milk Allergen $\beta$-Lactoglobulin Changes Its Allergenicity by Alterations in Cellular Uptake and Degradation. Molecular Nutrition and Food Research 2018, 62, doi:10.1002/mnfr.201800341.

9. Lindholm Bøgh, K.; Barkholt, V.; Bernhard Madsen, C. The Sensitising Capacity of Intact $\beta$-Lactoglobulin Is Reduced by Co-Administration with Digested $\beta$-Lactoglobulin. International Archives of Allergy and Immunology 2013, 161, 21-36, doi:10.1159/000343042.

10. Bu, G.; Luo, Y.; Zheng, Z.; Zheng, H. Effect of heat treatment on the antigenicity of bovine $\alpha$-lactalbumin and $\beta$-lactoglobulin in whey protein isolate. Food and Agricultural Immunology 2009, 20, 195-206, doi:10.1080/09540100903026116.

11. Rytkönen, J.; Karttunen, T.J.; Karttunen, R.; Valkonen, K.H.; Jenmalm, M.C.; Alatossava, T.; Björkstén, B.; Kokkonen, J. Effect of heat denaturation on beta-lactoglobulin-induced gastrointestinal sensitization in rats: Denatured $\beta \mathrm{LG}$ induces a more intensive local immunologic response than native $\beta \mathrm{LG}$. Pediatric Allergy and Immunology 2002, 13, 269-277, doi:10.1034/j.1399-3038.2002.01028.x.

12. Roth-Walter, F.; Berin, M.C.; Arnaboldi, P.; Escalante, C.R.; Dahan, S.; Rauch, J.; Jensen-Jarolim, E.; Mayer, L. Pasteurization of milk proteins promotes allergic sensitization by enhancing uptake through Peyer's patches. Allergy: European Journal of Allergy and Clinical Immunology 2008, 63, 882-890, doi:10.1111/j.1398-9995.2008.01673.x.

13. Stojadinovic, M.; Pieters, R.; Smit, J.; Velickovic, T.C. Cross-linking of $\beta$-lactoglobulin enhances allergic sensitization through changes in cellular uptake and processing. Toxicological Sciences 2014, 140, 224235, doi:10.1093/toxsci/kfu062.

14. Chun, S.H.; Lee, H.A.; Lee, K.B.; Kim, S.H.; Park, K.Y.; Lee, K.W. Effects of glycated whey protein concentrate on pro-inflammatory cytokine expression and phagocytic activity in RAW264.7 macrophages. Biol. Pharm. Bull. 2016, 39, 199-206, doi:10.1248/bpb.b15-00596.

15. Zenker, H.E.; Ewaz, A.; Deng, Y.; Savelkoul, H.F.J.; Van Neerven, R.J.J.; De Jong, N.; Wichers, H.J.; Hettinga, K.A.; Teodorowicz, M. Differential effects of dry vs. Wet heating of $\beta$-lactoglobulin on formation of sRAGE binding ligands and sIgE epitope recognition. Nutrients 2019, 11, doi:10.3390/nu11061432.

16. Liu, F.; Teodorowicz, M.; Van Boekel, M.A.J.S.; Wichers, H.J.; Hettinga, K.A. The decrease in the IgGbinding capacity of intensively dry heated whey proteins is associated with intense Maillard reaction, structural changes of the proteins and formation of RAGE-ligands. Food and Function 2016, 7, 239-249, doi:10.1039/c5fo00718f.

17. Liu, F.; Teodorowicz, M.; Wichers, H.J.; Van Boekel, M.A.J.S.; Hettinga, K.A. Generation of Soluble Advanced Glycation End Products Receptor (sRAGE)-Binding Ligands during Extensive Heat Treatment of Whey Protein/Lactose Mixtures Is Dependent on Glycation and Aggregation. Journal of Agricultural and Food Chemistry 2016, 64, 6477-6486, doi:10.1021/acs.jafc.6b02674. 
18. Smith, P.K. Do advanced glycation end-products cause food allergy? Current Opinion in Allergy and Clinical Immunology 2017, 17, 325-331, doi:10.1097/aci.0000000000000385.

19. Deng, Y.; Govers, C.; Bastiaan-Net, S.; van der Hulst, N.; Hettinga, K.; Wichers, H.J. Hydrophobicity and aggregation, but not glycation, are key determinants for uptake of thermally processed $\beta$-lactoglobulin by THP-1 macrophages. Food Research International 2019, 120, 102-113, doi:10.1016/j.foodres.2019.01.038.

20. Perdijk, O.; van Neerven, R.J.J.; van den Brink, E.; Savelkoul, H.F.J.; Brugman, S. Bovine lactoferrin modulates dendritic cell differentiation and function. Nutrients 2018, 10, doi:10.3390/nu10070848.

21. De Jongh, H.H.J.; Gröneveld, T.; De Groot, J. Mild isolation procedure discloses new protein structural properties of $\beta$-lactoglobulin. Journal of Dairy Science 2001, 84, 562-571, doi:10.3168/jds.S00220302(01)74508-0.

22. Teodorowicz, M.; Perdijk, O.; Verhoek, I.; Govers, C.; Savelkoul, H.F.J.; Tang, Y.; Wichers, H.; Broersen, K. Optimized triton X-114 assisted lipopolysaccharide (LPS) removal method reveals the immunomodulatory effect of food proteins. PLoS ONE 2017, 12, doi:10.1371/journal.pone.0173778.

23. Troise, A.D.; Fiore, A.; Roviello, G.; Monti, S.M.; Fogliano, V. Simultaneous quantification of amino acids and Amadori products in foods through ion-pairing liquid chromatography-high-resolution mass spectrometry. Amino Acids 2015, 47, 111-124, doi:10.1007/s00726-014-1845-5.

24. Meltretter, J.; Wüst, J.; Pischetsrieder, M. Comprehensive analysis of nonenzymatic post-translational $\beta$ lactoglobulin modifications in processed milk by ultrahigh-performance liquid chromatography-tandem mass spectrometry. Journal of Agricultural and Food Chemistry 2013, 61, 6971-6981, doi:10.1021/jf401549j.

25. Verlaet, A.; van der Bolt, N.; Meijer, B.; Breynaert, A.; Naessens, T.; Konstanti, P.; Smidt, H.; Hermans, N.; Savelkoul, H.F.J.; Teodorowicz, M. Toll-like receptor-dependent immunomodulatory activity of pycnogenol囚. Nutrients 2019, 11, doi:10.3390/nu11020214.

26. Ménard, O.; Bourlieu, C.; De Oliveira, S.C.; Dellarosa, N.; Laghi, L.; Carrière, F.; Capozzi, F.; Dupont, D.; Deglaire, A. A first step towards a consensus static in vitro model for simulating full-term infant digestion. Food Chemistry 2018, 240, 338-345, doi:10.1016/j.foodchem.2017.07.145.

27. Flom, J.D.; Sicherer, S.H. Epidemiology of cow's milk allergy. Nutrients 2019, 11, doi:10.3390/nu11051051.

28. Heilmann, M.; Wellner, A.; Gadermaier, G.; Ilchmann, A.; Briza, P.; Krause, M.; Nagai, R.; Burgdorf, S.; Scheurer, S.; Vieths, S., et al. Ovalbumin modified with pyrraline, a maillard reaction product, shows enhanced T-cell immunogenicity. Journal of Biological Chemistry 2014, 289, 7919-7928, doi:10.1074/jbc.M113.523621.

29. Moghaddam, A.E.; Hillson, W.R.; Noti, M.; Gartlan, K.H.; Johnson, S.; Thomas, B.; Artis, D.; Sattentau, Q.J. Dry roasting enhances peanut-induced allergic sensitization across mucosal and cutaneous routes in mice. Journal of Allergy and Clinical Immunology 2014, 134, 1453-1456, doi:10.1016/j.jaci.2014.07.032.

30. Ilchmann, A.; Burgdorf, S.; Scheurer, S.; Waibler, Z.; Nagai, R.; Wellner, A.; Yamamoto, Y.; Yamamoto, H.; Henle, T.; Kurts, C., et al. Glycation of a food allergen by the Maillard reaction enhances its T-cell immunogenicity: Role of macrophage scavenger receptor class A type I and II. Journal of Allergy and Clinical Immunology 2010, 125, 175-183.e111, doi:10.1016/j.jaci.2009.08.013.

31. Vlassara, H.; Li, Y.M.; Imani, F.; Wojciechowicz, D.; Yang, Z.; Liu, F.T.; Cerami, A. Identification of galectin-3 as a high-affinity binding protein for advanced glycation end products (AGE): a new member of the AGE-receptor complex. Mol Med 1995, 1, 634-646.

32. Ohgami, N.; Nagai, R.; Ikemoto, M.; Arai, H.; Kuniyasu, A.; Horiuchi, S.; Nakayama, H. CD36, a Member of the Class B Scavenger Receptor Family, as a Receptor for Advanced Glycation End Products. Journal of Biological Chemistry 2001, 276, 3195-3202, doi:10.1074/jbc.M006545200.

33. Bromley, E.H.C.; Krebs, M.R.H.; Donald, A.M. Aggregation across the length-scales in $\beta$-lactoglobulin. Faraday Discuss. 2005, 128, 13-27, doi:10.1039/b403014a.

34. Akhter, F.; Akhter, A.; Kesari, K.K.; Javed, R.; Ruokolainen, J.; Vuorinen, T. RAGE exacerbate amyloid beta $(\mathrm{A} \beta)$ induced alzheimer pathology: A systemic overview. In Environmental Science and Engineering, Springer Berlin Heidelberg: 2019; 10.1007/978-3-319-96511-6 9pp 159-170.

35. Doens, D.; Valiente, P.A.; Mfuh, A.M.; Vo, A.; Tristan, A.; Carreño, L.; Quijada, M.; Nguyen, V.T.; Perry, G.; Larionov, O.V., et al. Identification of Inhibitors of CD36-Amyloid Beta Binding as Potential Agents for Alzheimer's Disease. ACS Chem. Neurosci. 2017, 8, 1232-1241, doi:10.1021/acschemneuro.6b00386.

36. Moyano, D.F.; Goldsmith, M.; Solfiell, D.J.; Landesman-Milo, D.; Miranda, O.R.; Peer, D.; Rotello, V.M. Nanoparticle hydrophobicity dictates immune response. J. Am. Chem. Soc. 2012, 134, 3965-3967, doi:10.1021/ja2108905.

37. Seong, S.Y.; Matzinger, P. Hydrophobicity: An ancient damage-associated molecular pattern that initiates innate immune responses. Nat. Rev. Immunol. 2004, 4, 469-478, doi:10.1038/nri1372.

38. Nicolai, T.; Britten, M.; Schmitt, C. $\beta$-Lactoglobulin and WPI aggregates: Formation, structure and applications. Food Hydrocolloids 2011, 25, 1945-1962, doi:10.1016/j.foodhyd.2011.02.006. 
39. Chevalier, F.; Chobert, J.M.; Popineau, Y.; Nicolas, M.G.; Haertlé, T. Improvement of functional properties of $\beta$-lactoglobulin glycated through the Maillard reaction is related to the nature of the sugar. International Dairy Journal 2001, 11, 145-152, doi:10.1016/S0958-6946(01)00040-1.

40. Brandt, R.; Landmesser, C.; Vogt, L.; Hehmke, B.; Hanschke, R.; Kasbohm, J.; Hartmann, K.; Jäger, B.; Krantz, S.; Michaelis, D. Differential expression of fructosyllysine-specific receptors on monocytes and macrophages and possible pathophysiological significance. Diabetologia 1996, 39, 1140-1147, doi:10.1007/BF02658499.

41. Thornalley, P.J.; Langborg, A.; Minhas, H.S. Formation of glyoxal, methylglyoxal and 8-deoxyglucosone in the glycation of proteins by glucose. Biochemical Journal 1999, 344, 109-116, doi:10.1042/02646021:3440109.

42. Westwood, M.E.; Argirov, O.K.; Abordo, E.A.; Thornalley, P.J. Methylglyoxal-modified arginine residues - A signal for receptor-mediated endocytosis and degradation of proteins by monocytic THP-1 cells. Biochim. Biophy. Acta Mol. Cell Res. 1997, 1356, 84-94, doi:10.1016/S0167-4889(96)00154-1.

43. Xue, J.; Rai, V.; Singer, D.; Chabierski, S.; Xie, J.; Reverdatto, S.; Burz, D.S.; Schmidt, A.M.; Hoffmann, R.; Shekhtman, A. Advanced glycation end product recognition by the receptor for AGEs. Structure 2011, 19, 722-732, doi:10.1016/j.str.2011.02.013.

44. Palanissami, G.; Paul, S.F.D. RAGE and Its Ligands: Molecular Interplay Between Glycation, Inflammation, and Hallmarks of Cancer-a Review. Horm. Cancer 2018, 9, 295-325, doi:10.1007/s12672018-0342-9.

45. Body-Malapel, M.; Djouina, M.; Waxin, C.; Langlois, A.; Gower-Rousseau, C.; Zerbib, P.; Schmidt, A.M.; Desreumaux, P.; Boulanger, E.; Vignal, C. The RAGE signaling pathway is involved in intestinal inflammation and represents a promising therapeutic target for Inflammatory Bowel Diseases. Mucosal Immunol. 2019, 12, 468-478, doi:10.1038/s41385-018-0119-z.

46. Milutinovic, P.S.; Alcorn, J.F.; Englert, J.M.; Crum, L.T.; Oury, T.D. The receptor for advanced glycation end products is a central mediator of asthma pathogenesis. American Journal of Pathology 2012, 181, 1215-1225, doi:10.1016/j.ajpath.2012.06.031

47. Oczypok, E.A.; Milutinovic, P.S.; Alcorn, J.F.; Khare, A.; Crum, L.T.; Manni, M.L.; Epperly, M.W.; Pawluk, A.M.; Ray, A.; Oury, T.D. Pulmonary receptor for advanced glycation end-products promotes asthma pathogenesis through IL-33 and accumulation of group 2 innate lymphoid cells. Journal of Allergy and Clinical Immunology 2015, 136, 747-756.e744, doi:10.1016/j.jaci.2015.03.011.

48. Manfredi, A.A.; Capobianco, A.; Esposito, A.; De Cobelli, F.; Canu, T.; Monno, A.; Raucci, A.; Sanvito, F.; Doglioni, C.; Nawroth, P.P., et al. Maturing dendritic cells depend on RAGE for in vivo homing to lymph nodes. Journal of Immunology 2008, 180, 2270-2275, doi:10.4049/jimmunol.180.4.2270.

49. Dumitriu, I.E.; Baruah, P.; Valentinis, B.; Voll, R.E.; Herrmann, M.; Nawroth, P.P.; Arnold, B.; Bianchi, M.E.; Manfredi, A.A.; Rovere-Querini, P. Release of high mobility group box 1 by dendritic cells controls $\mathrm{T}$ cell activation via the receptor for advanced glycation end products. Journal of Immunology 2005, 174, 7506-7515, doi:10.4049/jimmunol.174.12.7506. 


\section{Chapter 6}

Peptide release after simulated infant in vitro digestion of dry-heated cow's milk protein and transport of potentially immunoreactive peptides across the Caco-2 cell monolayer

This chapter is based on:

Hannah E. Zenker, Harry J. Wichers, Monic M. M. Tomassen, Sjef Boeren, Nicolette W. De Jong, Kasper A. Hettinga (2020). Peptide release after simulated infant in vitro digestion of dry-heated cow's milk protein and transport of potentially immunoreactive peptides across the Caco-2 cell monolayer. Nutrients 12(8), 2483. 


\begin{abstract}
:
Dry heating of cow's milk protein, as applied in the production of "baked milk", facilitates the resolution of cow's milk allergy symptoms upon digestion. The heating and glycation-induced changes of the protein structure can affect both digestibility and immunoreactivity. The immunological consequences may be due to changes in the peptide profile of the digested dry-heated milk protein. Therefore, cow's milk protein powder was heated at low temperature $\left(60{ }^{\circ} \mathrm{C}\right)$ and high temperature $\left(130^{\circ} \mathrm{C}\right)$ and applied to simulated infant in vitro digestion. Digestion-derived peptides after $10 \mathrm{~min}$ and $60 \mathrm{~min}$ in the intestinal phase were measured using LC-MS/MS. Moreover, digests after $10 \mathrm{~min}$ intestinal digestion were applied to a Caco-2 cell monolayer. T-cell epitopes were analysed using a prediction software, while sIgE binding epitopes were identified based on literature. The largest number of sIgE binding epitopes was found in unheated samples, while T-cell epitopes were equally represented in all samples. Transport of glycated peptide indicated a preference for glucosyllysine and lactosyllysine-modified peptides, while transport of peptides containing epitopes structures was limited. This showed that the release of immunoreactive peptides can be affected by the applied heating conditions, however availability of peptides containing epitopes might be limited.
\end{abstract}




\subsection{Introduction}

Cow's milk protein (MP) consists of two major protein fractions, casein and whey protein, and is an important protein source in infant nutrition. Heating and glycation of MP has been shown to alter its digestibility and immunogenicity. Dry heating, as applied in this study, is not commonly used in the dairy industry, however has an important role in mimicking the heat treatment, when MP powder is baked into a muffin or waffle. These products are often referred to as "baked milk" and have been shown to accelerate the resolution of cow's milk allergy symptoms in allergic children [1]. Under these heating conditions (low water activity $\left(\mathrm{a}_{\mathrm{w}}\right)$, high sugar content, high temperature), protein aggregation and modifications via the Maillard reaction (MR) are favoured [2]. The MR is the reaction between primary amino-groups of proteins, peptides and amino acids and the reactive carbonyl group of reducing sugars, for instance lactose. During the early stage of the MR, the initial condensation to the Amadori product occurs followed by a rearrangement to lactosyllysine or glucosyllysine. In the advanced stage of the MR, a pool of different advanced glycation end products (AGEs) are formed [3]. Amongst these, $\mathrm{N}^{\varepsilon}$-carboxymethyllysine (CML) has been used as a marker for the advanced stage of the MR and is one of the most abundant AGEs in processed dairy products [4,5]. The extent of the MR can affect the digestibility and immunoreactivity of MP. With respect to digestibility, the effect of thermal processing of milk and dairy products on peptides generation during gastrointestinal digestion in vitro and in vivo has been subject to a several studies [6-11]. Moreover, it was shown that lysine blockage via the MR affects peptide size distribution after simulated infant in vitro digestion of infant formula [12] and that glycation of isolated milk proteins changes the composition of the peptides in the digest [13]. Next to this, heating and glycation can also affect immunogenicity and allergenicity of MP [14]. For example, binding of immunoglobulin E ( $\mathrm{IgE}$ ) to either isolated MP or MP in mixture has been shown to be decreased for extensively glycated milk proteins, possibly related to a masking effect on epitopes [15-17]. However, the effects of glycation and protein aggregation under the applied heating conditions are difficult to disentangle and can both affect IgE binding [18]. Moreover, Corzo-Martínez et al. [19] also showed that impaired digestibility may increase the residual allergenicity after in vitro digestion, comparing heat-glycated and unheated $\beta$-lactoglobulin (BLG). Differences in the peptide profiles after ingestion of dry-heated MP vs. unheated MP could affect the immunological response by differential preservation or glycation induced-modification of linear specific IgE (sIgE) binding epitopes. Moreover, the generation of peptides carrying a glycation structure can modulate the inflammatory response by binding to the receptors for AGEs on antigen presenting cells $[14,20]$. Binding of AGEs to AGE receptors has particularly been shown for protein-bound CML and pyrraline [21,22], while for peptide bound AGEs this was only demonstrated for CML [20]. The availability of AGE-modified peptides to the gastrointestinal immune system by means of translocation across the epithelial barrier is an important determinant in the immunological response to a foreign antigen. The metabolic transit of AGEs has been shown in previous literature on the excretion 
of CML and pyrraline in urine $[23,24]$. Moreover, the translocation across the Caco-2 cell monolayer has been shown for lactosylated and CML-modified dipeptides [25]. However, to our knowledge the transport of food derived glycated peptides larger than two amino acids has not yet been investigated. Transport of larger glycated peptides can be an important factor for the binding of AGE-modified peptides as it has been suggested that CML is more abundant in fractions of in vitro digests that are larger than $1 \mathrm{kDa}$ [26]. Therefore, transport of larger AGE-modified peptides could also contribute to the pool of dietary derived AGEs. This could be crucial as it has been shown on the example of CML that binding to AGE receptors is dependent on the concentration in which the CML is present in the vicinity of the receptors [22]. In this study, the peptide profiles of low temperature (LT) and high temperature (HT) heated MP after simulated infant in vitro digestion was compared to that of non-treated milk (NT). The most abundant glycation induced post translational modifications (PTMs), including CML and pyrraline as potential AGE receptor ligands, were monitored before and after transport across a Caco-2 cell monolayer. Special attention was given to sIgE binding epitopes and T-cell epitopes to asses immunomodulatory potential of the digest on the peptide level.

\subsection{Materials and Methods}

\subsubsection{Chemicals}

Dulbecco's Modified Eagles Medium supplemented with high glucose, HEPES, L-glutamine (42430082), both with and without phenol red as well as trypsin-EDTA (0.25\%) with phenol red, and HyClone ${ }^{\mathrm{TM}}$ Fetal Bovine Serum were purchased from Thermo Fisher Scientific (Waltham, USA). All other chemicals were obtained from Merck KGaA (Darmstadt, Germany).

\subsubsection{Preparation of milk powders and heat treatment}

Liquid raw cow's MP concentrate was obtained from FrieslandCampina (Wageningen, Netherlands) and was composed of micellar casein (MCI88 liquid) and whey protein (acid WPC80 liquid) in the ratio 80:20. After the addition of lactose in the ratio 1:1.5 (protein/lactose) the solutions were freeze dried. Heat treatment was applied at two different temperatures and durations as described elsewhere [27]. Briefly, for LT heated MP (LT-MP), the powder was heated for 3 weeks at $60{ }^{\circ} \mathrm{C}\left(\mathrm{a}_{\mathrm{w}}\right.$ 0.23) and for HT heated MP (HT-MP) the powder was heated for $10 \mathrm{~min}$ at $130{ }^{\circ} \mathrm{C}\left(\mathrm{a}_{\mathrm{w}} 0.23\right)$. An unheated part of the milk powder was as heating control (NT-MP).

\subsubsection{Infant in vitro digestion}

Simulated infant in vitro digestion was conducted in duplicate as published elsewhere and was based on the protocol by Ménard et al. [28] with adaptions specific for the type of product described elsewhere [27]. Briefly, protein concentration of the meal was set to $1.2 \%$. Digestion in the gastric phase (GP) was conducted for $60 \mathrm{~min}$ with a pepsin activity set to $268 \mathrm{U} / \mathrm{mL}$ and 
at $\mathrm{pH}$ 5.3, however without the use of gastric lipase. Digestion in the intestinal phase (IP) was conducted for 60 min using pancreatin adjusted for its trypsin activity that was set to $16 \mathrm{U} / \mathrm{mL}$ digest and at $\mathrm{pH}$ 6.6. Samples were taken after $10 \mathrm{~min}$ and $60 \mathrm{~min}$ in the IP and stopped by the addition of $0.5 \mathrm{mM}$ Pefabloc in the ratio Pefabloc/digest of $1 / 20(\mathrm{v} / \mathrm{v})$.

\subsubsection{Caco-2 cell culture}

The Caco-2 cell line was purchased from the American Type Culture Collection (Manassas, Virginia, USA). They were cultured in Dulbecco's Modified Eagles Medium (DMEM) supplemented with $10 \%$ heat inactivated fetal bovine serum (FBS) at $37{ }^{\circ} \mathrm{C}$ and in humidified atmosphere containing 5\% $\mathrm{CO}_{2}$. Cells were sub-cultured weekly upon confluence $85-95 \%$ using trypsination. Caco-2 cells were used from passage 30-40 and seeded into 24-well transwells (Greiner Bio-One, Kremsmünster, Austria) at a concentration of $0.225 \times 10^{6}$ cells $/ \mathrm{mL}$ in DMEM with $10 \%$ heat inactivated FBS. The medium was changed, apical $(150 \mu \mathrm{L})$ and basolateral $(700 \mu \mathrm{L})$ every 2-3 days and cells were used for the transport experiment after 21 days of incubation. Before transport experiments, the transepithelial electrical resistance (TEER) value was measured and only wells with a TEER value higher than $750 \Omega * \mathrm{~cm} 2$ were used.

\subsubsection{Transport across the Caco-2 cell monolayer}

Digest were diluted 1:1 with DMEM without phenol red supplemented with $0.1 \%$ penicillin-streptomycin $(10,000 \mathrm{U} / \mathrm{mL})$ and applied to the apical side of the Caco-2 cell monolayer. TEER was measured at $37^{\circ} \mathrm{C}$ using a Millicell-ERS $\Omega$ Meter (Millipore, Molshein, France) and samples were incubated for $2 \mathrm{~h}$ with the Caco-2 cells at $37{ }^{\circ} \mathrm{C}$ and $5 \% \mathrm{CO}_{2}$ saturation. After that, TEER was measured and samples were taken from the basolateral side. Each sample was applied in duplicate. Samples were kept at $-20^{\circ} \mathrm{C}$ until further analysis.

\subsubsection{Peptide analysis}

Digests after $10 \mathrm{~min}$ in the IP contained $3.6 \mathrm{mg} / \mathrm{mL}, 3.7 \mathrm{mg} / \mathrm{mL}, 3.6 \mathrm{mg} / \mathrm{mL}$ protein in NT-MP, LT-MP, and HT-MP, respectively. Digest after $60 \mathrm{~min}$ in the IP contained $4.2 \mathrm{mg} / \mathrm{mL}$, $3.5 \mathrm{mg} / \mathrm{mL}, 3.8 \mathrm{mg} / \mathrm{mL}$ protein in NT-MP, LT-MP, and HT-MP, respectively. Samples were mixed 1:1 with trichloroacetic acid (20\%) and centrifuged $\left(10 \mathrm{~min}, 3500 \times \mathrm{g}, 4{ }^{\circ} \mathrm{C}\right)$. The supernatants were cleaned using an in-house stage tip following a protocol described by Dingess et al. [29]. All samples were concentrated to compensate for the dilution during trichloroacetic acid precipitation.

Peptides were analysed on a on a Thermo nLC 1000 system (Thermo Fisher Scientific, Waltham, Massachusetts, USA) coupled to a LTQ orbitrap XL (Thermo Fisher Scientific, Waltham, Massachusetts, USA) for peptides in the in vitro digest or Q Exactive HF-X X (Thermo Fisher Scientific, Waltham, Massachusetts, USA) for peptides on the basolateral side as well as glycated peptides. Each sample was measured once. Chromatographic separation was 
conducted over a $0.10 * 250 \mathrm{~mm}$ ReproSil-Pur 120 C18-AQ $1.9 \mu \mathrm{m}$ beads analytical column. A gradient consisting of acetonitrile in water, spiked with $0.1 \%$ formic acid was used. Acetonitrile increased from $9 \%$ to $34 \%$ within 50 min using a flow rate of $0.5 \mu \mathrm{L} / \mathrm{min}$. Full scan positive mode spectra were measured in the Orbitrap between m/z 380 and 1400 using high resolution (60,000). CID LTQ or HCD (Q Exactive HF-X) fragmentation was applied using isolation width of $2 \mathrm{~m} / \mathrm{z}$ respectively $1.2 \mathrm{~m} / \mathrm{z}$ and $30 \%$ respectively $24 \%$ normalised collision energy (CE). MSMS scans were recorded in the data dependent mode for 2-3 respectively 2-5+ charged peaks in the MS scan. For glycated peptides measured by the Q Exactive HF-X, a step CE (20-30-40) was used based on the method published by Liu et al. [30]. LC-MS/MS runs were processed using the MaxQuant version 1.6.3.4 with the Andromeda search engine [31]. Digestion mode was set to "unspecific". A fixed modification was set for the formation of propionamide on cysteines, while variable modifications were set for acetylation of the peptide N-terminus, deamidation of asparagine and glutamine, as well as oxidation of methionine.

Peptides were identified using a bovine database from Uniprot (https://www.uniprot.org) that includes all bovine milk proteins observed by Boggs et.al. [32] (PRIDE PXD003011) in combination with a database for common contaminants. Peptides with a minimum length of 8 amino acids and maximum peptide length of 25 amino acids were identified. Both peptide and protein false discovery rates were set to $1 \%$. Post translational modifications were included for lactosylation $(+324 \mathrm{Da})$, hexose modification $(+162 \mathrm{Da}), \mathrm{N}^{\varepsilon}$-carboxymethyllysine modification $(+58 \mathrm{Da})$, and pyrraline modification $(+108 \mathrm{Da})$. For simplicity glucosyllysine was used to referred to the hexose modification, although also other hexoses could result in this mass shift. Phosphorylated and glycated peptides were not included in the quantitation during the MaxQuant search. Due to the limited number of measurements as well as the limitations in obtaining quantitative data from glycated peptides, data were reported as peptide count.

\subsubsection{Data analysis}

Data were filtered for peptides derived from the six major milk proteins: $\alpha_{\mathrm{s} 1}$-casein, $\alpha_{\mathrm{s} 2}$-casein, $\beta$-casein, $\beta$-lactoglobulin, and $\alpha$-lactalbumin. All peptides with score $>80$ were used for the overall peptide profiles, while for the sIgE binding epitopes and T-cell epitopes, only peptides with a score $>100$ were used. For total peptide count per sample in the digest, each duplicate digestion was filtered separately for non-modified peptides (intensity $>0$ ) and for phosphorylated and glycated peptides (identification by matching and/or by MS/MS). For all further analysis, only peptides identified in both digestions of the same heat treatment were reported.

\subsection{8 sIgE binding epitope identification}

sIgE binding epitopes were identified by comparison of peptide sequences with sIgE binding epitopes as reviewed previously [33]. Peptides were reported as potential sIgE binding epitopes if their sequence matched $\geq 80 \%$ of the sequence of a known $\operatorname{sgE}$ binding epitope. 


\subsubsection{T-cell epitope prediction}

T-cell epitopes were predicted using IEDB MHC Class II Binding Prediction software (http://tools.iedb.org/mhcii/, 02.06.2020) where an MHC class II allele reference set was obtained from (https://help.iedb.org/hc/en-us/articles/114094151851, 02.06.2020). The default method "IEDB recommended 2.2" was used for T-cell epitope predictions. All peptides within the size range 15-24 amino acids length, which was previously be reported as the size range for T-cell epitopes, were applied to the prediction software [34]. Peptides were reported as potential T-cell epitopes following the recommendations of the prediction tool, where each peptide reaching a percentile rank $<10.0 \%$ can be considered as potential T-cell epitope.

\subsection{Results}

\subsubsection{Identification of peptides in in vitro digests}

Peptides released upon infant in vitro digestion after 10 and $60 \mathrm{~min}$ in the IP were analysed using LC-MS/MS. Only peptides derived from the six major MPs, $\alpha_{\mathrm{s} 1}$-casein, $\alpha_{\mathrm{s} 2}$-casein, $\beta$-casein, $\kappa$-casein, BLG, and $\alpha$-lactalbumin (ALA) were considered in the data analysis. Dry heating of MP decreased the number of peptides released upon infant in vitro digestion (Figure 6.1), where HT heating resulted in even less peptides than LT heating after $10 \mathrm{~min}$ ( $315 \pm 36$ vs. $369 \pm 26$ peptides) and $60 \mathrm{~min}(207 \pm 1$ vs. $246 \pm 7$ peptides $)$ in the IP.

a

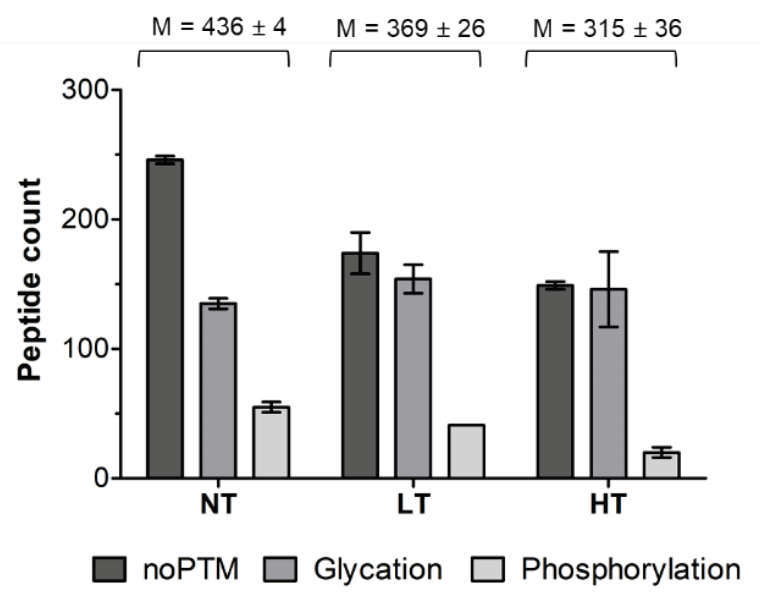

b

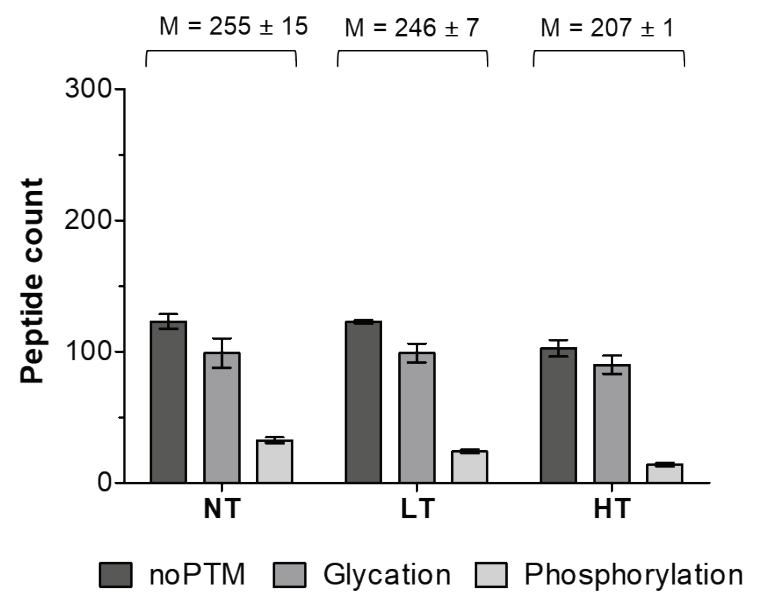

Figure 6.1: Total count of non-modified, glycated and phosphorylated digestion-derived peptides derived from cow's milk protein. Samples were non-treated (NT), heated at low temperatures (LT), and heated at high temperature (HT) (a) after $10 \mathrm{~min}$ in the intestinal phase and (b) after $60 \mathrm{~min}$ in the intestinal phase. Number of peptides without post translational modification (noPTM), glycated, and phosphorylated peptides were compared. The minimum length for identification was 8 amino acids. Error bars represent the standard deviation of duplicate digestions. The mean $(\mathrm{M})$ of the total count of peptides per treatment and digestion time point \pm standard deviation for duplicate digestions is shown above the bars.

Differences in the modification state of the peptides (non-modified vs. glycated vs. phosphorylated peptides) were higher after $10 \mathrm{~min}$ than after $60 \mathrm{~min}$ in the IP. After $10 \mathrm{~min}$ in the IP, heated samples showed comparable levels of glycated and non-modified peptides, while the NT-MP sample had 2-fold more non-modified peptides than glycated peptides. At the same 
time, the number of phosphorylated peptides was 4.6-fold lower in HT-MP compared to NT-MP after $10 \mathrm{~min}$ in the IP, while LT-MP only showed a 1.6-fold decrease. This trend continued until $60 \mathrm{~min}$ in the IP, however to a lesser extent. Most peptides after $10 \mathrm{~min}$ in the IP were derived from $\beta$-casein, followed by BLG and $\alpha_{\mathrm{s} 1}$-casein, while a smaller number of peptides originated from $\alpha_{\mathrm{s} 2}$-casein, followed by $\kappa$-casein, and ALA (supplementary material: Figure 6-S1a). This trend did not change after $60 \mathrm{~min}$ in the IP (supplementary material: Figure 6-S1b).

In line with the number of peptides per protein, peptides generated after $10 \mathrm{~min}$ in the IP covered large parts of the protein sequences of $\beta$-casein, BLG, and $\alpha$-caseins (Figure 6.2a).

a

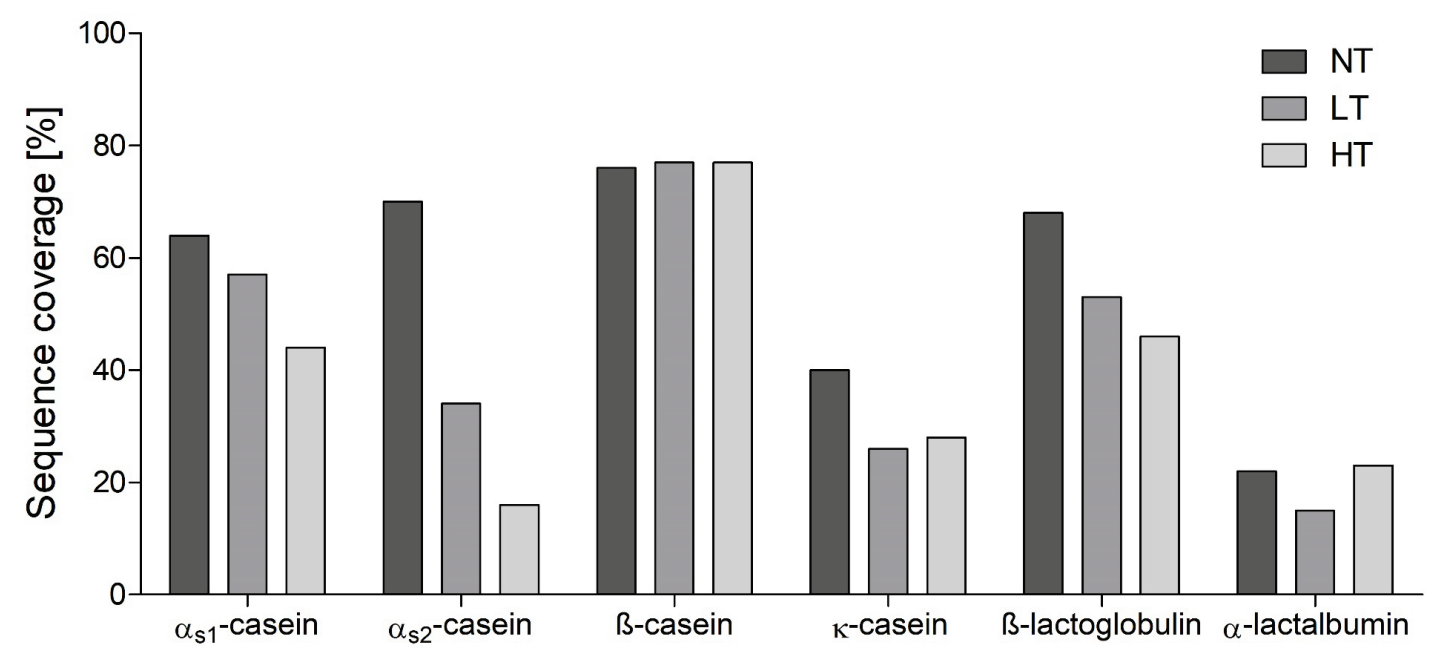

b

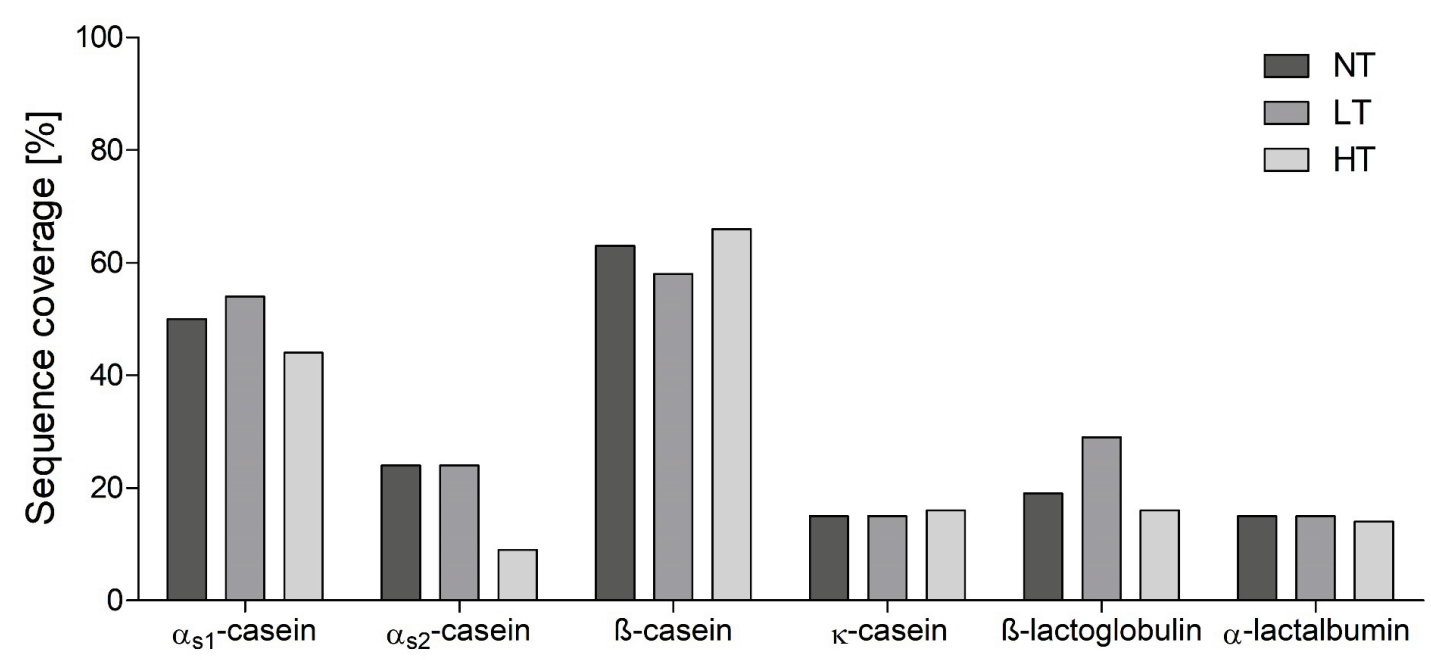

Figure 6.2: Sequence coverage of the 6 main milk proteins by digestion-derived peptides, with and without post translational modification, derived from in vitro digests of cow's milk protein (a) after $10 \mathrm{~min}$ in the intestinal phase and (b) after $60 \mathrm{~min}$ in the intestinal phase. Samples were non-treated (NT), heated at low temperature (LT), and heated at high temperature (HT). 
Sequence coverage was higher for NT-MP compared to LT-MP and HT-MP. This difference was highest for the $\alpha$-caseins and BLG, while $\beta$-casein showed no changes. After $60 \mathrm{~min}$ in the IP, only $\alpha_{\mathrm{s} 2}$-casein showed remarkably lower sequence coverage in HT-MP compared to NT-MP and LT-MP (Figure 6.2b). Due to the larger differences observed after $10 \mathrm{~min}$ in the IP, and the possibility of an immune response already at this stage of digestion, we focused mainly on the samples from $10 \mathrm{~min}$ in the IP.

In Figure 6.3, peptide sequence alignment is shown for peptides generated after $10 \mathrm{~min}$ in the IP. Independent from the heat treatment, all proteins showed specific regions that were similarly covered in all samples, however with different numbers of peptides generated in the same region.

\section{a}

\section{$\alpha_{s 1-c a s e i n}$}

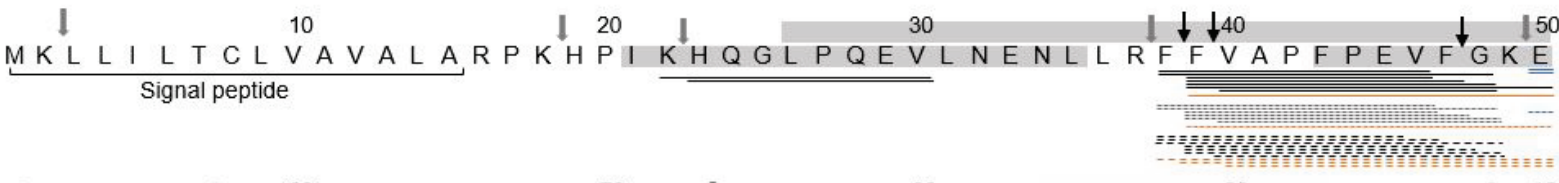

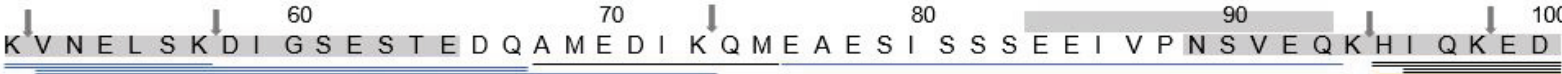
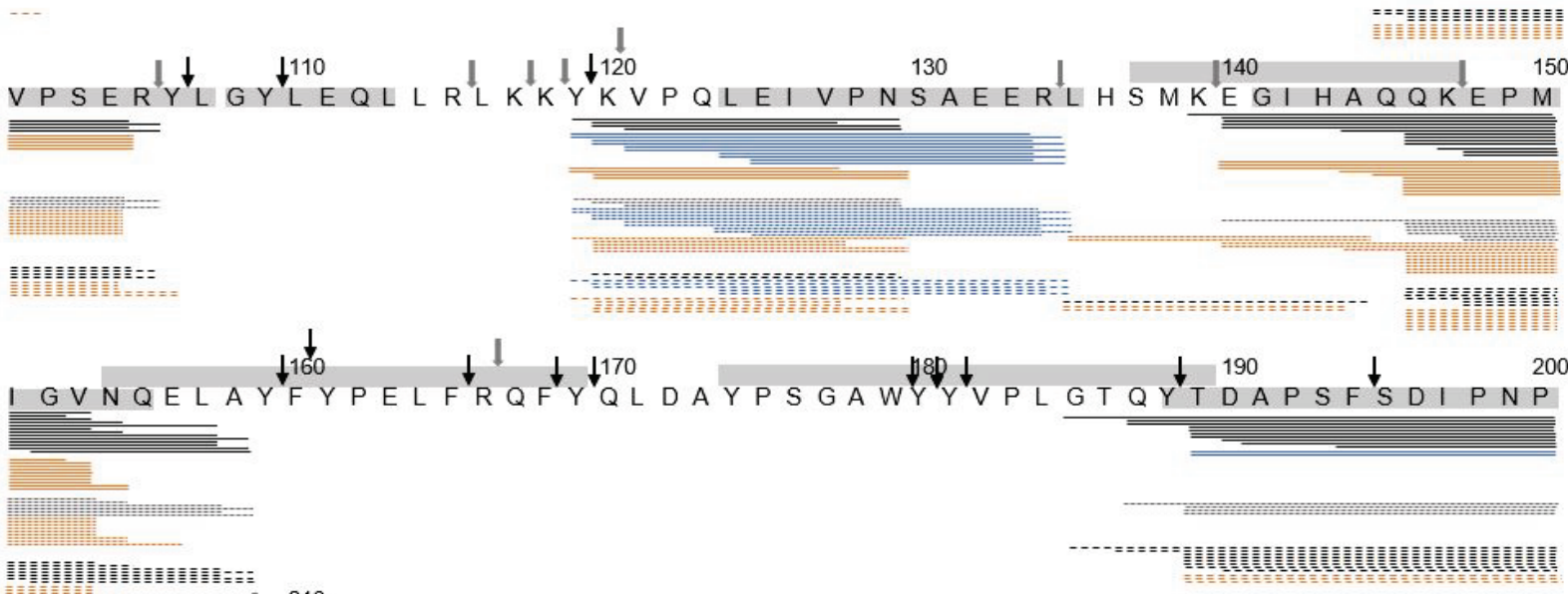

\footnotetext{
UI

I GSEN SEK T T M P L W

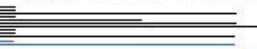

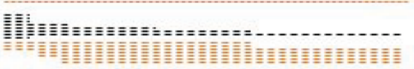


b (continuation Figure 6.3)

\section{$\alpha_{s 2-c a s e i n}$}

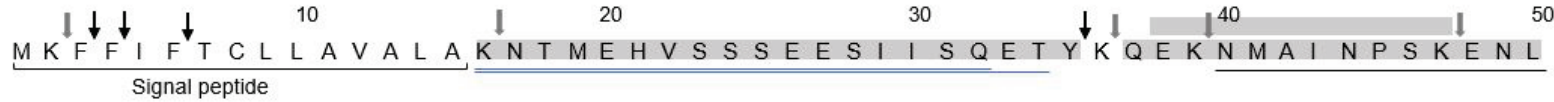

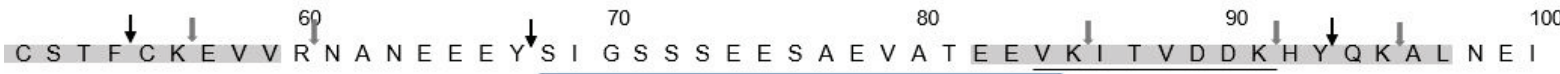

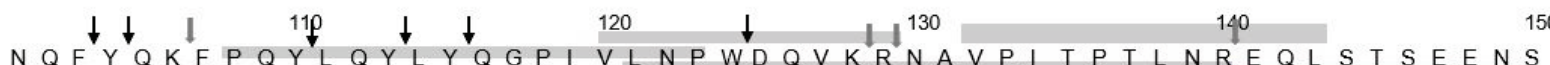

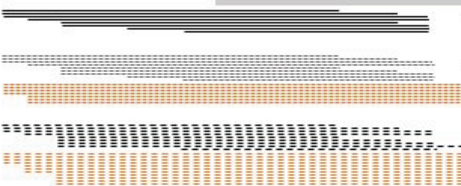

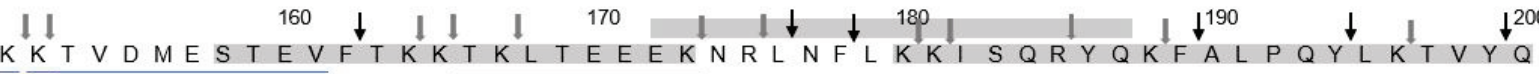

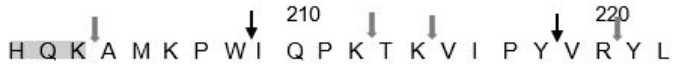

C

\section{$\beta$-casein}

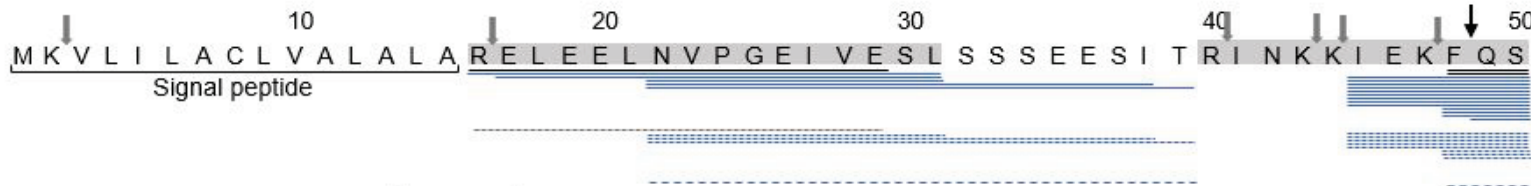

$\begin{array}{lllllll}60 & \downarrow & \downarrow & 80 & 90 & 100\end{array}$
EEQQQTEDELQDKI HPFAQTQSLVYPFPGPI PNSLPQNIPPLTQTPVVVP

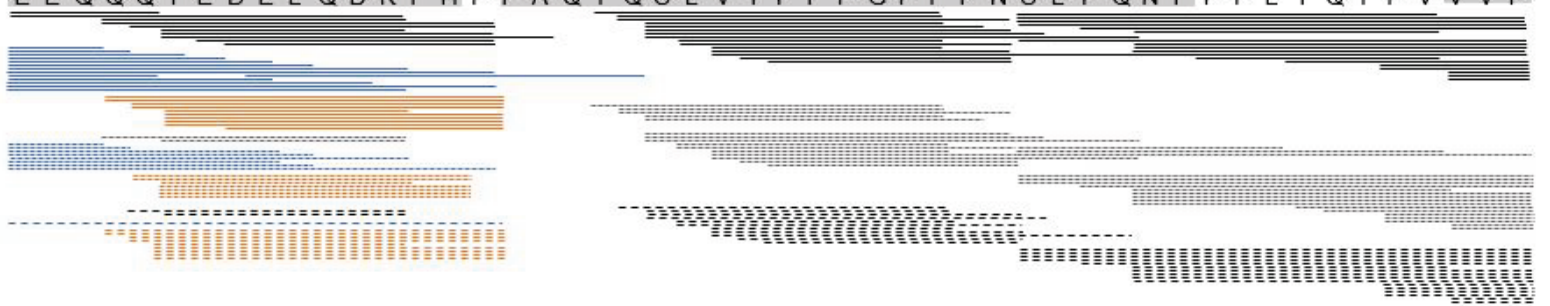

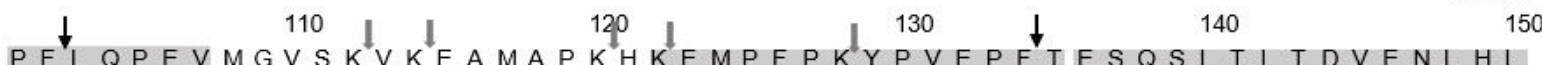

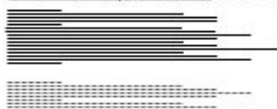
H-

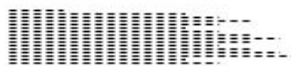

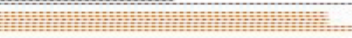

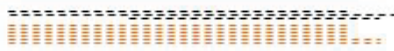

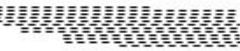

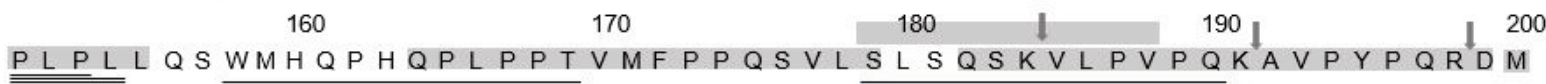

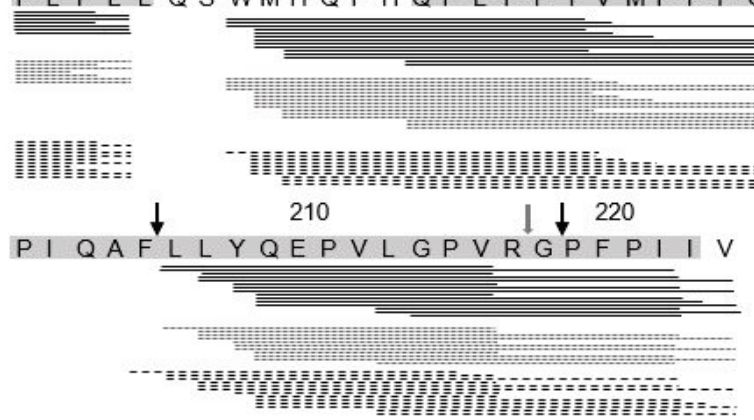


d (continuation Figure 6.3)

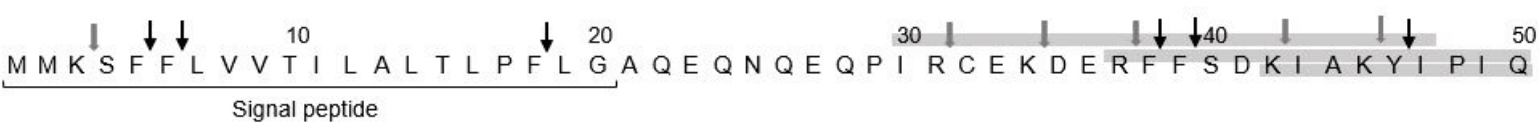

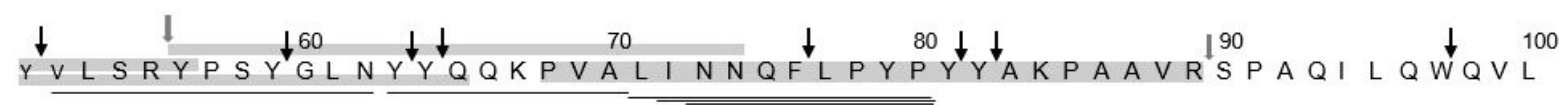

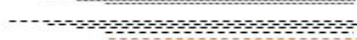

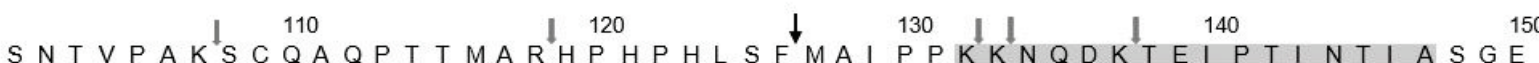
N 160 170 180 190 PTSTPTTEAVESTVATLEDSPEVI ESPPEINTVQVTSTAV

e

\section{$\boldsymbol{\beta}$-lactoglobulin}

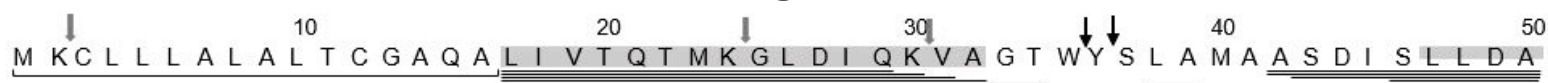
Signal peptide

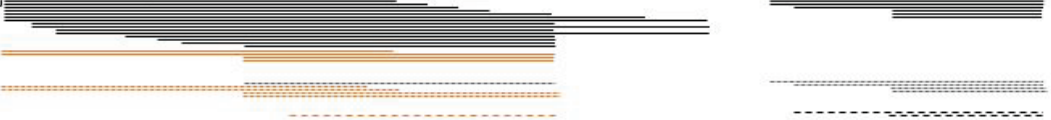

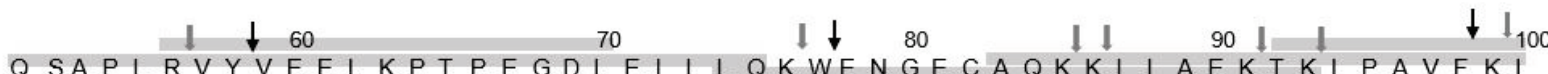
QSAPLRVYVEELKPTPEGDLEILLQKWENGECAQKKIIAEKTKIPAVFKI

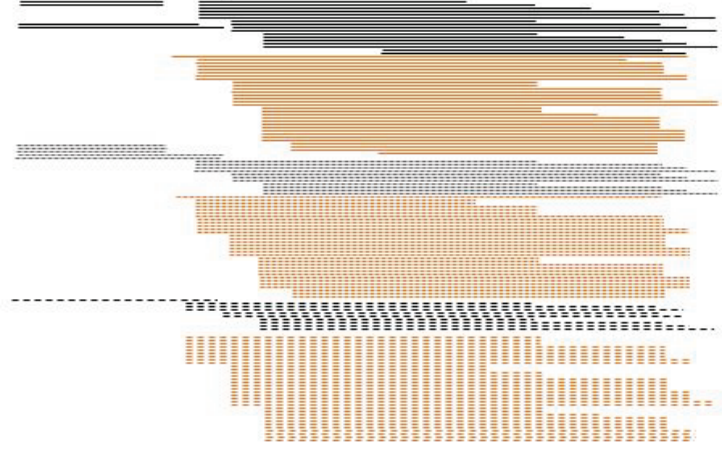

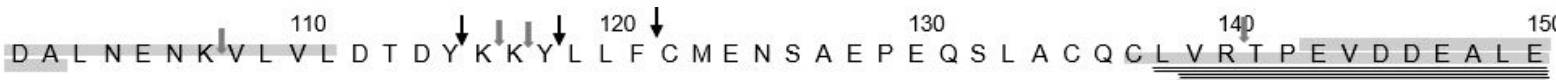

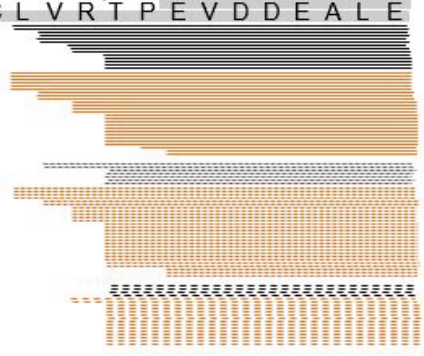

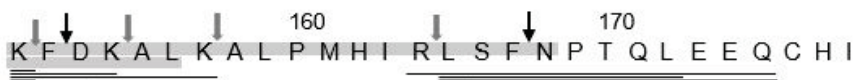

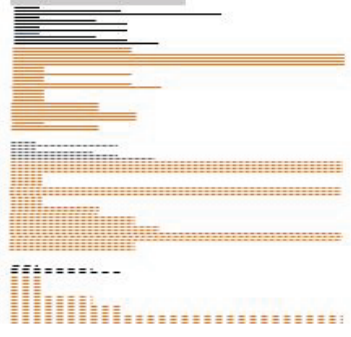




\section{f (continuation Figure 6.3) $\quad \boldsymbol{\alpha}$-lactalbumin}

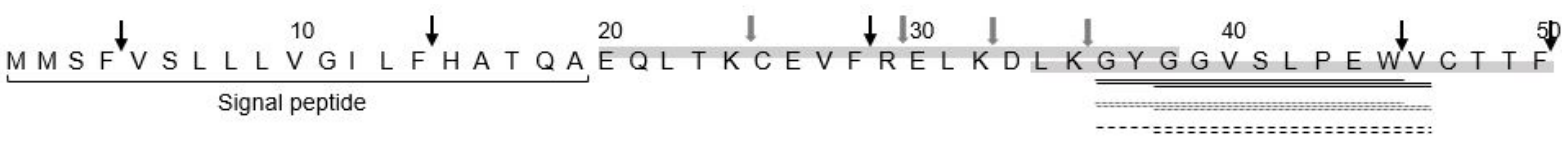
HTSG G $Y^{\downarrow}$ T Q A I V Q N N DSTEYGLFQINNKI WCKDDQNPHSSN I CNI SCDKF

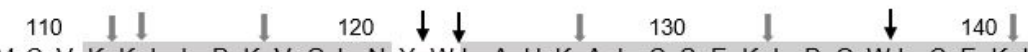
DDDLTDDI MCVKKILDKVGI NYWLAHKALCSEKLDQWLCEKL

Figure 6.3: Sequence alignment of digestion-derived peptides from the six major milk proteins (a-f) identified after $10 \mathrm{~min}$ in the intestinal phase of simulated infant in vitro digestion of non-treated cow's milk protein $(-)$, heated at low temperature (----), and heated at high temperature (-- - ). Glycated peptides (orange), phosphorylated peptides (blue), trypsin cleavage sites $(\downarrow)$, chymotrypsin cleavage sites $(\downarrow)$. Grey highlights indicated IgE binding epitopes according to [33]. Trypsin and chymotrypsin cleavage sites were determined using Expasy Bioinformatics Resource Portal (https://web.expasy.org/peptide_cutter/ last visited 08.06.2020).

In all proteins, most differences in peptide distribution along the protein sequence were observed between HT-MP and the other samples. The peptides derived from BLG (Figure 6.3e) came from three main regions (f17-39, f56-73, and f138-161) and only minor differences were observed between heat treatments in f56-73, while in f17-39 and f138-161, much less peptides were found in HT-MP compared to NT-MP and LT-MP. In contrast, peptides derived from

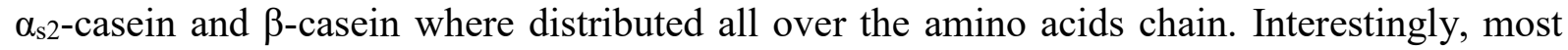
differences in caseins were observed as a result of the absence of phosphorylated peptides in

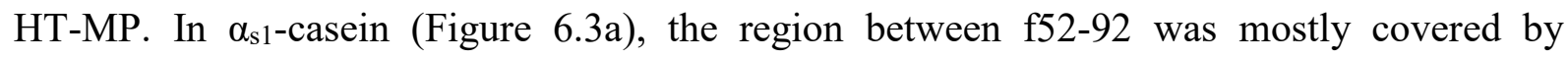
phosphorylated peptides in NT-MP and LT-MP, while this region did not lead to the formation of peptides in HT-MP. Moreover, the number of peptides covering the same sequence part f52-92 was much lower in LT-MP than NT-MP. Similar observations, where the number of phosphorylated peptides was lower in at least one of the heated samples compared to NT-MP, were also made for $\alpha_{\mathrm{s} 2}$-casein f16-32, f68-84, f141-161(Figure 6.3b), $\beta$-casein f22-39 and f48-66 (Figure 6.3c), and $\kappa$-casein f165-182 (Figure 6.3d). In contrast, glycated peptides only had a minimal effect on differences in sequence coverage when comparing samples. In $\alpha_{\mathrm{s} 1}$-casein (Figure 6.3a), the regions f135-138 and f210-213 and in $\beta$-casein (Figure 6.3c) the region 191-197 were covered in LT-MP and HT-MP as a result of the presence of glycated peptides. The presence of glycated peptide however affected the number of peptides which arise from specific areas of the proteins. This was especially seen for the region f140-155 of $\alpha_{\mathrm{s} 1}$-casein in NT-MP, f113-128 of $\alpha_{\mathrm{s} 2}$-casein, and f179-197 of $\beta$-casein in both LT-MP and HT-MP.

With progressing intestinal digestion, only little changes were observed in the peptide alignment along the protein sequence of $\alpha_{\mathrm{s} 1}$-casein, $\beta$-casein, $\kappa$-casein, and ALA (supplementary material: Figure 6-S2). In contrast, BLG two resistant areas f57-73 and f139-154 as well as $\alpha_{\mathrm{s} 1}$-casein at f119-134. 


\subsubsection{Identification of SIgE epitopes and T-cell epitopes in the in vitro digests}

sIgE binding epitopes were identified by comparison with known epitopes from literature (Table 6.1) [33]. Peptides were reported as potential sIgE binding epitopes when at least $80 \%$ of the peptide sequence matched a known sIgE epitope sequence. Peptides derived from BLG contained $18 \mathrm{sIgE}$ epitopes, followed by 16 derived from $\alpha_{\mathrm{s} 1}$-casein, 14 from $\beta$-casein, 3 from

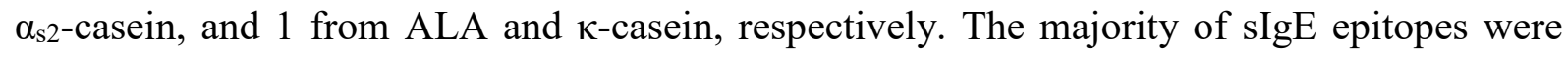
found in peptides derived from NT-MP, however up to $69 \%$ of $\alpha_{\mathrm{s}}$-casein derived sIgE epitopes and $77 \%$ of $\beta$-casein derived sIgE epitopes were also found in either one or both heated samples. The peptides $\alpha_{\mathrm{s} 1}$-casein f189-213, $\alpha_{\mathrm{s} 2}$-casein f116-128, and $\beta$-casein f96-110 were only found in heated samples, however their length only differed by a maximum of 4 amino acid from a similar peptide found in NT-MP and those 4 amino acids were not covering an additional sequence part of the sIgE binding epitope. 
Table 6.1: sIgE binding epitopes identified in digestion-derived peptides after $10 \mathrm{~min}$ in the intestinal phase. Peptides were identified in cow's milk protein, non-treated (NT), heated at low temperature (LT), and heated at high temperature (HT), after simulated infant in vitro digestion and derived from casein (cn), $\beta$-lactoglobulin (BLG), and $\alpha$-lactalbumin (ALA). Amino acids (AAs) position indicates the position within the proteins including the signal peptide. Peptides carrying a post translational modifications (PTM) are marked with phosphorylation (Phos), where phosphorylated serine (S) and threonine (T) residues are highlighted in bold and underline.

\begin{tabular}{|c|c|c|c|c|c|c|}
\hline Protein & Sample & Peptide sequence & $\begin{array}{l}\text { AAs } \\
\text { position }\end{array}$ & $\begin{array}{l}\text { sIgE epitope } \\
\text { AAs position }\end{array}$ & PTM & \\
\hline \multirow[t]{16}{*}{$\alpha_{\mathrm{s} 1-\mathrm{cn}}$} & NT,LT,HT & 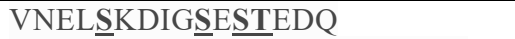 & $52-67$ & $54-63$ & Phos & \\
\hline & NT,LT,HT & 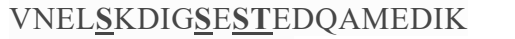 & $52-73$ & $54-63$ & Phos & \\
\hline & NT,LT,HT & KVPQLEEIVPN̄S $\overline{\mathrm{AEE}}$ & $120-133$ & $124-135$ & Phos & \\
\hline & NT,LT,HT & 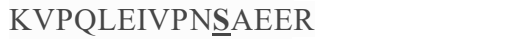 & $120-134$ & $124-135$ & Phos & \\
\hline & NT,LT & VPQLEIVPNS吕EER & $121-134$ & $124-135$ & Phos & \\
\hline & NT,LT,HT & LEIVPNSAAEE & $124-133$ & $124-135$ & Phos & \\
\hline & NT,LT,HT & LEIVPNSEAEER & $124-134$ & $124-135$ & Phos & \\
\hline & NT & EIVPNS馬ER & $125-134$ & $124-135$ & Phos & \\
\hline & NT & KEGIHAQQKEPMIGV & $139-153$ & $137-147$ & $\mathrm{~N} / \mathrm{A}$ & \\
\hline & NT & EGIHAQQKEPMIGV & $140-153$ & $141-155$ & $\mathrm{~N} / \mathrm{A}$ & \\
\hline & NT,HT & GTQYTDAPSFSDIPNPI & $185-201$ & $186-200$ & $\mathrm{~N} / \mathrm{A}$ & \\
\hline & NT,LT,HT & QYTDAPSFSDIPNPI & $187-201$ & $186-200$ & $\mathrm{~N} / \mathrm{A}$ & \\
\hline & NT & QYTDAPSFSDIPNPIGSENSEK & $187-208$ & $188-209$ & $\mathrm{~N} / \mathrm{A}$ & \\
\hline & NT,LT,HT & TDAPSFSDIPNPIGSENSEK & $189-208$ & $188-209$ & $\mathrm{~N} / \mathrm{A}$ & \\
\hline & NT,LT,HT & 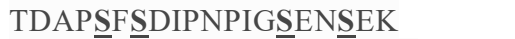 & $189-208$ & $188-209$ & Phos & \\
\hline & NT & TDAPSFSDIPNPIGSENSEKT & $189-209$ & $188-209$ & $\mathrm{~N} / \mathrm{A}$ & \\
\hline \multirow[t]{3}{*}{$\alpha_{\mathrm{s} 2}-\mathrm{cn}$} & NT & KNTMEHV $\underline{\text { SSSEE}}$ EIIISQ & $16-32$ & $16-35$ & Phos & \\
\hline & NT & 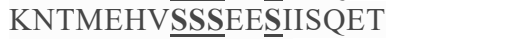 & $16-34$ & $16-35$ & Phos & \\
\hline & HT & QGPIVLNPWDQVK & $116-128$ & $120-129$ & $\mathrm{~N} / \mathrm{A}$ & \\
\hline \multirow[t]{14}{*}{$\beta-\mathrm{cn}$} & NT,LT & RELEELNVPGEIVE & $16-29$ & $16-31$ & $\mathrm{~N} / \mathrm{A}$ & \\
\hline & NT & RELEELNVPGEIVESIL & $16-31$ & $16-31$ & Phos & $*$ \\
\hline & NT & ELEELNVPGEIVESLL & $17-31$ & $16-31$ & Phos & \\
\hline & NT & TEDELQDKIHPFA & $56-68$ & $60-69$ & $\mathrm{~N} / \mathrm{A}$ & \\
\hline & NT,LT,HT & SLVYPFPGPIPNS & $72-84$ & $70-85$ & $\mathrm{~N} / \mathrm{A}$ & \\
\hline & NT,LT,HT & PVVVPPFLQPE & $96-106$ & $98-107$ & $\mathrm{~N} / \mathrm{A}$ & \\
\hline & NT,LT,HT & PVVVPPFLQPE & $96-107$ & $98-107$ & $\mathrm{~N} / \mathrm{A}$ & \\
\hline & NT,LT,HT & PVVVPPFLQPEVMG & $96-109$ & $98-107$ & $\mathrm{~N} / \mathrm{A}$ & \\
\hline & LT,HT & PVVVPPFLQPEVMGV & $96-110$ & $98-107$ & $\mathrm{~N} / \mathrm{A}$ & \\
\hline & NT,LT,HT & VVPPFLQPE & $98-106$ & $98-107$ & $\mathrm{~N} / \mathrm{A}$ & \\
\hline & NT,LT,HT & VVPPFLQPEV & $98-107$ & $98-107$ & $\mathrm{~N} / \mathrm{A}$ & $*$ \\
\hline & NT,LT,HT & EMPFPKYPVEPF & $123-134$ & $122-135$ & $\mathrm{~N} / \mathrm{A}$ & \\
\hline & NT,LT & QPLPPTVMFPPQS & $164-176$ & $164-179$ & $\mathrm{~N} / \mathrm{A}$ & \\
\hline & NT,LT,HT & QPLPPTVMFPPQSV & $164-177$ & $164-179$ & $\mathrm{~N} / \mathrm{A}$ & \\
\hline$\kappa-\mathrm{cn}$ & NT & KNQDKTEIPTINT & $133-145$ & $132-147$ & $\mathrm{~N} / \mathrm{A}$ & \\
\hline \multirow[t]{18}{*}{$\mathrm{BLG}$} & NT & LIVTQTMKGLDIQ & $17-29$ & $17-32$ & $\mathrm{~N} / \mathrm{A}$ & \\
\hline & NT & LIVTQTMKGLDIQKV & $17-31$ & $17-32$ & $\mathrm{~N} / \mathrm{A}$ & \\
\hline & NT & LIVTQTMKGLDIQKVA & $17-32$ & $17-32$ & $\mathrm{~N} / \mathrm{A}$ & \\
\hline & NT & LIVTQTMKGLDIQKVAGT & $17-34$ & $17-32$ & $\mathrm{~N} / \mathrm{A}$ & \\
\hline & NT & LIVTQTMKGLDIQKVAGTWYS & $17-37$ & $17-32$ & $\mathrm{~N} / \mathrm{A}$ & \\
\hline & NT & LIVTQTMKGLDIQKVAGTWYSLA & $17-39$ & $17-32$ & $\mathrm{~N} / \mathrm{A}$ & \\
\hline & NT & IVTQTMKGLDIQKVAGT & $18-34$ & $17-32$ & $\mathrm{~N} / \mathrm{A}$ & \\
\hline & NT & IVTQTMKGLDIQKVAGTWYSLA & $18-39$ & $17-32$ & $\mathrm{~N} / \mathrm{A}$ & \\
\hline & NT & VTQTMKGLDIQKVAGT & $19-34$ & $17-32$ & $\mathrm{~N} / \mathrm{A}$ & \\
\hline & NT & VTQTMKGLDIQKVAGTWYSLA & $19-39$ & $17-32$ & $\mathrm{~N} / \mathrm{A}$ & \\
\hline & NT,LT,HT & VYVEELKPTPEGDLE & $57-71$ & $56-70$ & $\mathrm{~N} / \mathrm{A}$ & \\
\hline & NT,LT,HT & VYVEELKPTPEGDLEI & $57-72$ & $56-70$ & $\mathrm{~N} / \mathrm{A}$ & \\
\hline & NT,LT & VYVEELKPTPEGDLEIL & $57-73$ & $56-70$ & $\mathrm{~N} / \mathrm{A}$ & \\
\hline & NT,LT,HT & YVEELKPTPEGDLE & $58-71$ & $56-70$ & $\mathrm{~N} / \mathrm{A}$ & \\
\hline & NT,LT,HT & YVEELKPTPEGDLEI & $58-72$ & $56-70$ & $\mathrm{~N} / \mathrm{A}$ & \\
\hline & NT,LT & YVEELKPTPEGDLEIL & $58-73$ & $56-70$ & $\mathrm{~N} / \mathrm{A}$ & \\
\hline & NT & LVRTPEVDDEALEK & $138-151$ & $136-150$ & $\mathrm{~N} / \mathrm{A}$ & \\
\hline & NT & LVRTPEVDDEALEKFDK & $138-154$ & $137-156$ & $\mathrm{~N} / \mathrm{A}$ & \\
\hline ALA & NT & KILDKVGIN & $113-121$ & $112-121$ & $\mathrm{~N} / \mathrm{A}$ & \\
\hline
\end{tabular}

Peptides were reported as sIgE binding epitopes if their sequence contained at least $80 \%$ of the sequence of an sIgE binding epitope. Peptides matching exactly the sIgE binding epitope sequence are indicated (*). 
Additionally, glycated peptides that matched sequence parts of sIgE binding epitopes were identified after $10 \mathrm{~min}$ in the IP (Table 6.2). Most of such peptides were found in BLG, however only 6 of them were exclusively found in heated samples and covered similar sequence parts as peptides that were also found in NT-MP. Glycated peptides matching the sequence of an sIgE binding epitope from $\alpha_{\mathrm{s} 2}$-casein and $\beta$-casein were exclusively found in heated samples. For $\alpha_{\mathrm{s} 1}$-casein, 3 out of 4 glycated peptides with sequence homology to an sIgE binding epitope were only found in HT-MP.

Table 6.2: $\operatorname{sgE}$ binding epitopes ${ }^{1}$ identified in glycated digestion-derived peptides after $10 \mathrm{~min}$ in the intestinal phase. Peptides were identified in cow's milk protein, non-treated (NT), heated at low temperature (LT), and heated at high temperature (HT), after in vitro digestion and derived from casein (cn) and $\beta$-lactoglobulin (BLG). Amino acids (AAs) position indicates the position within the proteins including the signal peptide. Peptides with post translational modification (PTM) on lysine (K) to lactosyllysine (Lac), glucosyllysine (Gluc), $\mathrm{N}^{\varepsilon}$-carboxymethyllysine (CML), and pyrraline (Pyr), are reported and modified $\mathrm{K}$ residues are highlighted in bold and underline with modification site probability given in brackets if multiple options were identified.

\begin{tabular}{|c|c|c|c|c|c|}
\hline Protein & Sample & Peptide sequence & $\begin{array}{l}\text { AAs } \\
\text { position }\end{array}$ & $\begin{array}{l}\text { sIgE epitope } \\
\text { AAs position }\end{array}$ & $\overline{\text { PTM }}$ \\
\hline \multirow[t]{5}{*}{$\alpha_{\mathrm{s} 1-\mathrm{cn}}$} & NT,LT & EGIHAQQ $\underline{K E P M I G V}$ & $140-153$ & $141-155$ & Lac \\
\hline & HT & TDAPSFSDIPNPIGSENSEK & $189-208$ & $188-209$ & Lac \\
\hline & HT & TDAPSFSDIPNPIGSENSEKTTMPL & $189-213$ & $188-209$ & Gluc \\
\hline & HT & TDAPSFSDIPNPIGSENSE页TTMPL & $189-213$ & $188-209$ & Lac \\
\hline & NT,LT & EGIHAQQ $\underline{K E P M I G V ~}$ & $140-153$ & $141-155$ & Lac \\
\hline \multirow[t]{11}{*}{$\alpha_{\mathrm{s} 2-\mathrm{cn}}$} & LT,HT & LYQGPIVLNPWDQV $\underline{\mathbf{K}}$ & $114-128$ & $120-129$ & Lac \\
\hline & LT,HT & LYQGPIVLNPWDQV $\underline{\mathbf{K}}$ & $114-128$ & $120-129$ & Gluc \\
\hline & LT,HT & LYQGPIVLNPWDQV트 & $114-128$ & $120-129$ & CML \\
\hline & LT,HT & LYQGPIVLNPWDQV产 & $114-128$ & $120-129$ & Pyr \\
\hline & LT,HT & YQGPIVLNPWDQVK & $115-128$ & $120-129$ & Lac \\
\hline & LT,HT & YQGPIVLNPWDQV产 & $115-128$ & $120-129$ & Gluc \\
\hline & LT,HT & YQGPIVLNPWDQV六 & $115-128$ & $120-129$ & CML \\
\hline & HT & QGPIVLNPWDQV트 & $116-128$ & $120-129$ & Lac \\
\hline & HT & QGPIVLNPWDQV $\underline{\overline{\mathbf{K}}}$ & $116-128$ & $120-129$ & Gluc \\
\hline & HT & QGPIVLNPWDQV $\underline{\overline{\mathbf{K}}}$ & $116-128$ & $120-129$ & CML \\
\hline & HT & QGPIVLNPWDQVK & $116-128$ & $120-129$ & Pyr \\
\hline \multirow{3}{*}{$\beta$-cn } & LT,HT & EMPFPKYYPVPF & $123-134$ & $122-135$ & Lac \\
\hline & LT,HT & EMPFP页YPVEPF & $123-134$ & $122-135$ & Gluc \\
\hline & HT & SLSQSK̄(1)VLPVPQK(1)AVPYPQ & $179-197$ & $182-199$ & $\mathrm{Lac}$ \\
\hline \multirow[t]{25}{*}{ BLG } & LT,HT & LIVTQTMKGLDIQ & $17-29$ & $17-32$ & $\mathrm{Lac}$ \\
\hline & NT & 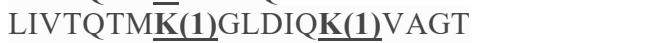 & $17-34$ & $17-32$ & Lac \\
\hline & $\mathrm{LT}$ & RVYVEEL & $56-71$ & $56-70$ & Lac \\
\hline & NT & RVYVEEL $\underline{\text { K}}$ PTPEGDLEI & $56-72$ & $56-70$ & Lac \\
\hline & NT & VYVEELKPTPEGDLE & $57-70$ & $56-70$ & Lac \\
\hline & NT,LT,HT & VYVEELL & $57-71$ & $56-70$ & Lac \\
\hline & NT,LT,HT & VYVEELL్ & $57-71$ & $56-70$ & Gluc \\
\hline & NT,LT,HT & VYVEELL̄ & $57-71$ & $56-70$ & CML \\
\hline & NT,LT,HT & VYVEEL吕PTPEGDLE & $57-71$ & $56-70$ & Pyr \\
\hline & NT,LT,HT & VYVEEL $\overline{\mathbf{K}}$ PTPEGDLEI & $57-72$ & $56-70$ & Lac \\
\hline & NT,LT,HT & VYVEEL $\bar{K} P T P E G D L E I$ & $57-72$ & $56-70$ & Gluc \\
\hline & NT,LT,HT & YVEELKPTPEGDLE & $58-71$ & $56-70$ & $\mathrm{Lac}$ \\
\hline & NT,LT,HT & YVEELKPTPEGDLE & $58-71$ & $56-70$ & Gluc \\
\hline & NT,LT,HT & YVEELK & $58-71$ & $56-70$ & CML \\
\hline & NT,LT,HT & YVEELK & $58-71$ & $56-70$ & Pyr \\
\hline & LT,HT & YVEEL产PTPEGDLEI & $58-72$ & $56-70$ & Lac \\
\hline & LT,HT & YVEELK PTPEGDLEI & $58-72$ & $56-70$ & Gluc \\
\hline & LT,HT & YVEELKPTPEGDLEI & $58-72$ & $56-70$ & CML \\
\hline & NT,HT & YVEEL KPTPEGDLEIL & $58-73$ & $56-70$ & Lac \\
\hline & NT & LVRTPĒVDDEALE $\underline{\mathbf{K}(\mathbf{1}) F D \underline{\mathbf{K}(\mathbf{1})}}$ & $138-154$ & $137-156$ & Lac \\
\hline & NT & LVRTPEVDDEALE $\underline{\underline{\mathbf{K}(\mathbf{1})}}$ FD $\underline{\overline{\mathbf{K}(\mathbf{1})}}$ & $138-154$ & $137-156$ & Pyr \\
\hline & NT,LT & LVRTPEVDDEALE $\underline{\mathbf{K ( 1 )}}$ FD $\underline{\mathbf{K}(\mathbf{1})}$ AL $\underline{\mathbf{K}(\mathbf{1}) A L P M}$ & $138-161$ & $137-156$ & Lac \\
\hline & NT,LT & LVRTPEVDDEALEKFDK(0.8)A $L \overline{\mathbf{K}(\mathbf{0 . 2})}$ ALPM & $138-161$ & $137-156$ & Gluc \\
\hline & NT,LT & LVRTPEVDDEALEK(1)FDKALKALPM & $138-161$ & $137-156$ & CML \\
\hline & NT,LT & LVRTPEVDDEALEK(1)FDK(1)ALKALPM & $138-161$ & $137-156$ & Pyr \\
\hline
\end{tabular}

${ }^{1}$ Peptides were reported as sIgE binding epitopes if their sequence contained at least $80 \%$ of the sequence of an sIgE binding epitope. Peptides matching exactly the sIgE binding epitope sequence are indicated $(*)$ 
T-cell epitopes were predicted using IEDB MHC Class II Binding Prediction software. All modified and non-modified peptides that were predicted as potential T-cell binding epitopes are shown in Table 6.3.

Table 6.3: Potential T-cell epitopes identified after $10 \mathrm{~min}$ in the intestinal phase. Digestion-derived peptides identified from cow's milk protein, non-treated (NT), dry-heated at low temperature (LT), and dry-heated at high temperature (HT) after in vitro digestion, identified from casein (cn) and $\beta$-lactoglobulin (BLG). Amino acids (AAs) position indicating the position within the proteins including the signal peptide. Unmodified peptides and peptides with post translational modifications (PTM), via phosphorylation (Phos), as well as modification to glucosyllysine (Gluc), lactosyllysine ( $\mathrm{Lac}$ ), $\mathrm{N}^{\varepsilon}$-carboxymethyllysin (CML), and pyrraline (Pyr) were reported. Modified AAs are indicated in bold and underline.

\begin{tabular}{|c|c|c|c|c|c|c|}
\hline Protein & Sample & Sequence & HLA-allele & $\begin{array}{l}\text { AAs } \\
\text { position }\end{array}$ & PTM & $\begin{array}{l}\text { Perc. } \\
\text { rank }\end{array}$ \\
\hline \multirow[t]{4}{*}{$\alpha_{\mathrm{s} 1-\mathrm{cn}}$} & NT, LT & EAESISSSEEIVPNSVEQ & $\begin{array}{l}\text { HLA-DQA1*03:01/ } \\
\text { DQB1*03:02; } \\
\text { HLA-DQA1*04:01/ } \\
\text { DQB1*04:02 }\end{array}$ & $76-93$ & Phos & 5.3 \\
\hline & NT, LT & YKVPQLEIVPNㅍAEE & $\begin{array}{l}\text { HLA-DRB1 }{ }^{* 04: 05 ;} \\
\text { HLA-DQA1 }{ }^{*} 04: 01 / \\
\text { DQB1 } * 04: 02 ; \\
\text { HLA-DQA1*03:01/ } \\
\text { DQB1 } * 03: 02\end{array}$ & $119-133$ & Phos & $\begin{array}{l}1.9 \\
4.1 \\
5.8\end{array}$ \\
\hline & NT, LT, HT & YKVPQLEIVPNSAEER & $\begin{array}{l}\text { HLA-DRB } 1 * 04: 05 ; \\
\text { HLA-DQA } 1 * 04: 01 / \\
\text { DQB1 }{ }^{*} 04: 02 ; \\
\text { HLA-DQA } 1 * 03: 01 / \\
\text { DQB } 1 * 03: 02\end{array}$ & $119-134$ & Phos & $\begin{array}{l}2.2 \\
5.9 \\
6.5\end{array}$ \\
\hline & NT, LT, HT & KVPQLEIVPNㅁAEER & 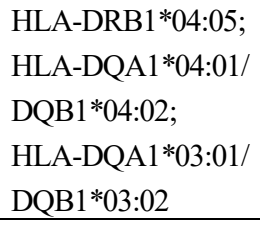 & $120-134$ & Phos & $\begin{array}{l}1.9 \\
5.6 \\
5.9\end{array}$ \\
\hline \multirow[t]{2}{*}{$\alpha_{\mathrm{s} 2}-\mathrm{cn}$} & NT, LT, HT & SIGSSSEESAEVATEEV & $\begin{array}{l}\text { HLA-DQA1*04:01/ } \\
\text { DQB1*04:02; } \\
\text { HLA-DQA1*03:01/ } \\
\text { DQB1*03:02 }\end{array}$ & $68-84$ & N/A & $\begin{array}{l}0.14 \\
0.18\end{array}$ \\
\hline & $\begin{array}{l}\text { LT,HT } \\
\text { LT,HT } \\
\text { LT,HT } \\
\text { LT,HT }\end{array}$ & 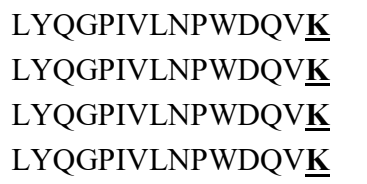 & $\begin{array}{l}\text { HLA-DRB1 } * 13: 02 \\
\text { HLA-DRB1 } * 13: 02 \\
\text { HLA-DRB1 } * 13: 02 \\
\text { HLA-DRB1 } * 13: 02\end{array}$ & $\begin{array}{l}114-128 \\
114-128 \\
114-128 \\
114-128\end{array}$ & $\begin{array}{l}\text { Gluc } \\
\text { Lac } \\
\text { CML } \\
\text { Pyr }\end{array}$ & $\begin{array}{l}9.7 \\
9.7 \\
9.7 \\
9.7\end{array}$ \\
\hline$\beta$-cn & HT & SLTLTDVENLHLPLP & $\begin{array}{l}\text { HLA-DPA1*03:01/ } \\
\text { DPB1*04:02 }\end{array}$ & $139-153$ & N/A & 6.3 \\
\hline \multirow[t]{2}{*}{ BLG } & $\begin{array}{l}\text { NT } \\
\text { NT }\end{array}$ & $\begin{array}{l}\text { VTQTMKGLDIQKVAGT } \\
\text { ASDISLLDAQSAPLRV }\end{array}$ & $\begin{array}{l}\text { HLA-DRB4*01:01 } \\
\text { HLA-DRB4*01:01; } \\
\text { HLA-DRB } 1 * 01: 01 ; \\
\text { HLA-DRB } 1 * 13: 02 ; \\
\text { HLA-DRB } 1 * 12: 01 \\
\text { HLA-DQA1 }{ }^{*} 03: 01 / \\
\text { DQB1 } * 03: 02\end{array}$ & $\begin{array}{l}19-34 \\
42-57\end{array}$ & $\begin{array}{l}\text { N/A } \\
\text { N/A }\end{array}$ & $\begin{array}{l}7.9 \\
4.0 ; \\
6.6 ; \\
7.9 ; \\
8.2 ; \\
9.0\end{array}$ \\
\hline & HT & SDISLLDAQSAPLRV & $\begin{array}{l}\text { HLA-DRB } 4 * 01: 01 ; \\
\text { HLA-DRB } 1 * 01: 01 ; \\
\text { HLA-DRB } 1 * 12: 01 ; \\
\text { HLA-DRB } 1 * 13: 02 ; \\
\text { HLA-DRB } 1 * 09: 01\end{array}$ & $43-57$ & N/A & $\begin{array}{l}3.3 \\
4.4 \\
6.2 \\
6.3 \\
7.2\end{array}$ \\
\hline
\end{tabular}


Overall, 13 potential T-cell epitopes were found in the digest, with most epitopes deriving from $\alpha_{\mathrm{s} 1}$-casein and $\alpha_{\mathrm{s} 2}$-casein, followed by BLG, and $\beta$-casein. In the digest of NT-MP, 7 T-cell epitopes were found of which 5 were also found in at least one of the heated samples. LT and HT heating resulted in the release of 9 T-cell epitopes, respectively, with 6 solely found in heated samples. Of these, $40 \%$ were found in the digest of LT-MP and HT-MP were also glycated.

\subsubsection{Peptides identified at the basolateral compartment of the Caco-2 cell monolayer}

To study the epithelial transport, in vitro digests sampled after 10 minutes in the IP were applied to a Caco-2 cell monolayer. The number of peptides found in the basolateral compartment for each sample decreased with heating intensity. Observed were 181, 129, and 121 peptides in NT-MP, LT-MP, and HT-MP, respectively. Moreover, most peptides were derived from

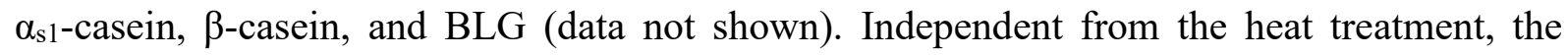
majority of peptides was found in the size range between 8-10 and 11-13 amino acids (Figure 6.4). Compared to the composition in the digest before transport relatively higher numbers of peptides in the size range between 8-10 and 11-13 were found (supplementary material: Figure 6-S3). Interestingly, peptides up to 24 amino acids long were identified on the basolateral side of the Caco-2 cells, however at low numbers.

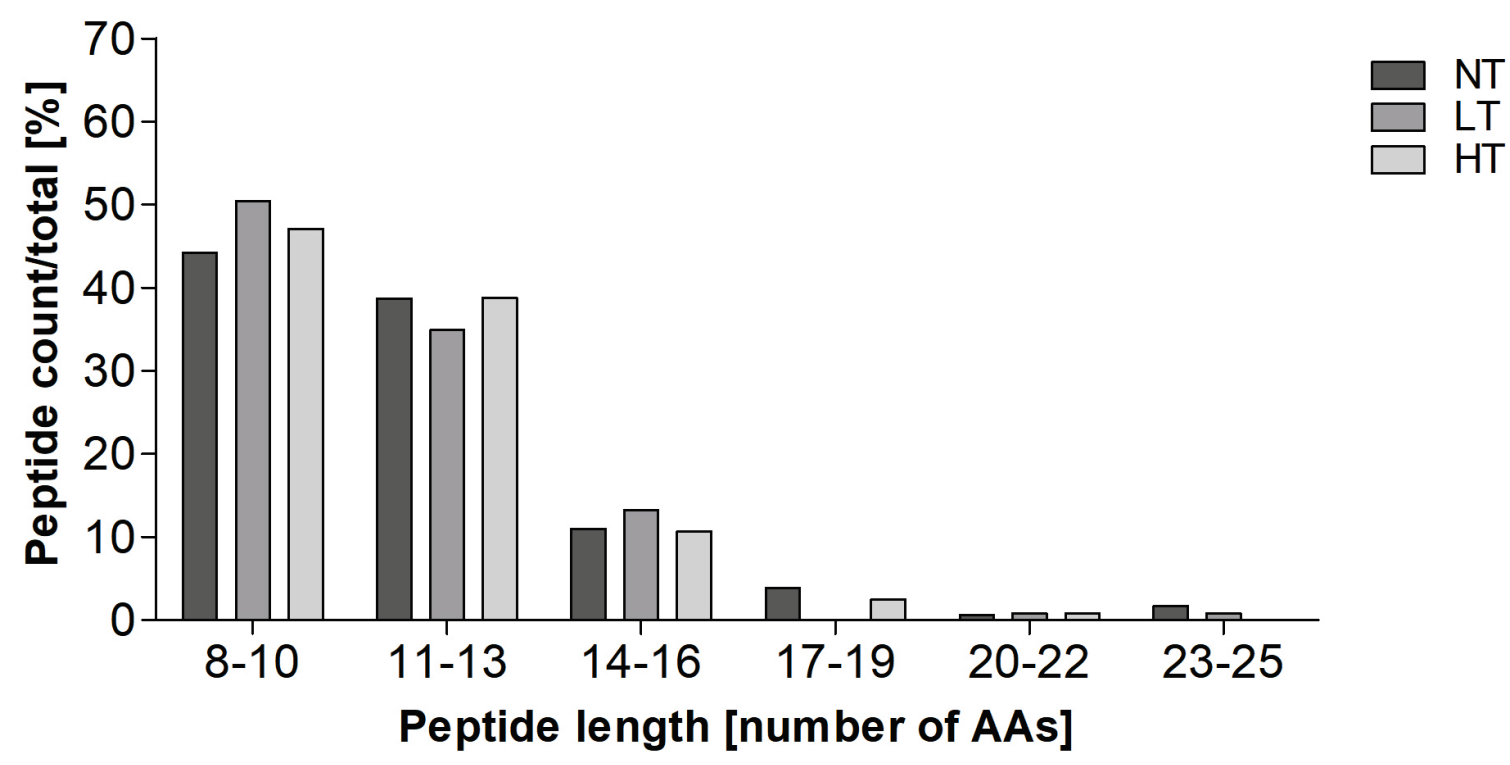

Figure 6.4: Peptide length distribution on the basolateral side of digestion-derived peptides, sampled after 10 min in the intestinal phase from simulated infant in vitro digests of cow's milk protein, non-treated (NT), heated in the presence of lactose at low temperature (LT), and high temperature (HT), expressed as peptide count relative to the total number (NT: 181, LT: 129, HT: 121) of peptides in one sample.

In NT-MP less glycated peptides were found on the basolateral side (37\%), compared to LT-MP (50\%) and HT-MP (56\%). The percentage of glycated peptides on the basolateral side increased in all samples compared to the percentage of glycated peptides relative to all glycated 
and non-modified peptides in the digest before transport $(35 \pm 0 \%, 47 \pm 1 \%, 49 \pm 5 \%$ for NT-MP, LT-MP, and HT-MP, respectively). In all samples, the majority of those glycated peptides was modified to lactosyllysine, followed by modification to glucosyllysine, pyrraline and CML. Interestingly, the largest increase was observed for the relative number of lactosyllysine and glucosyllysine-modified peptides found on the basolateral side compared to the digest (supplementary material: Figure 6-S3). This effect was larger in heated samples than in NT-MP. Heated samples also showed slightly increasing relative numbers of CML-modified peptides on the basolateral side, while relative numbers of pyrraline-modified peptides showed were comparable to the digest.

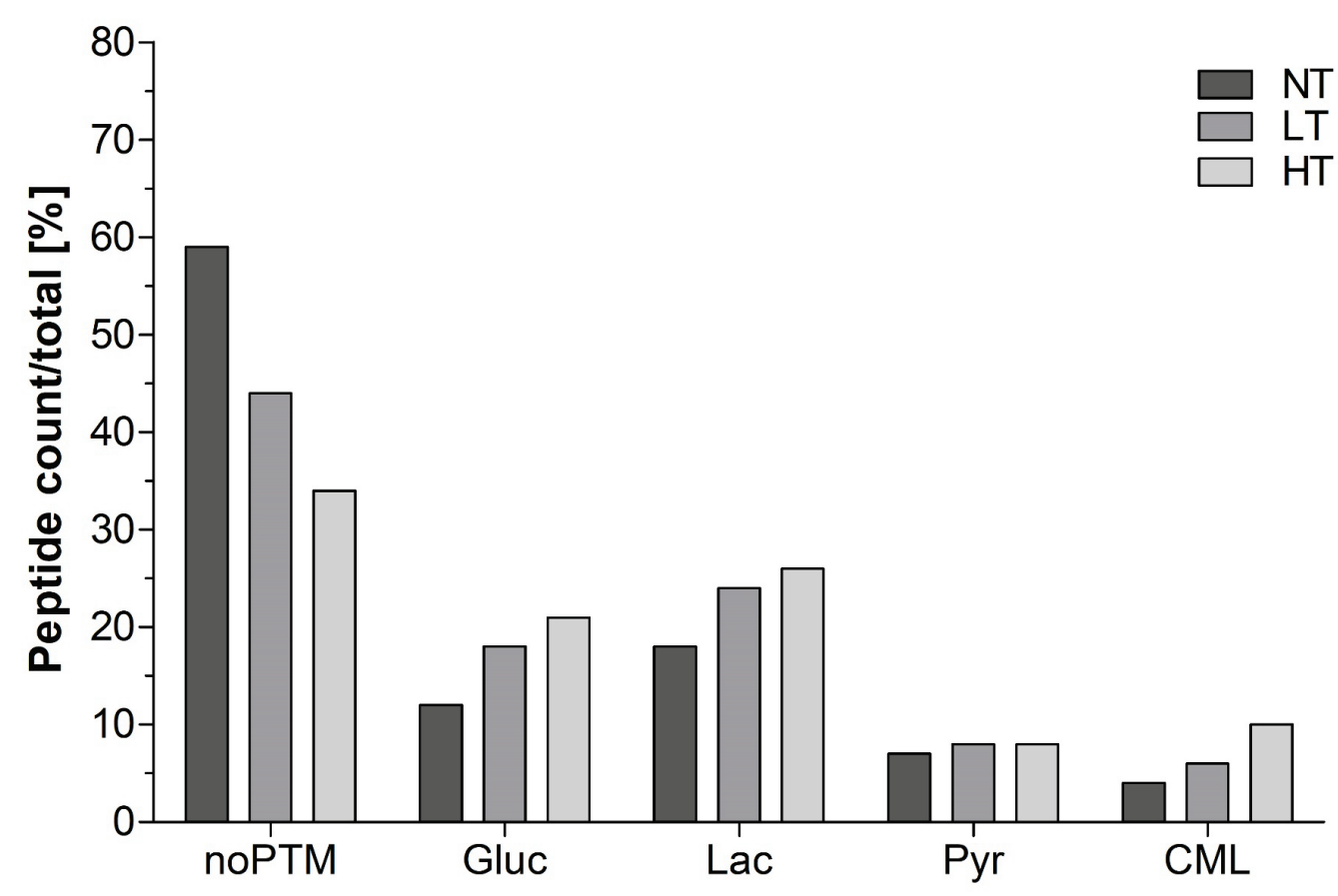

Figure 6.5: Digestion-derived peptides identified on the basolateral side of Caco-2 cells exposed to in vitro digests of cow's milk protein, non-treated (NT), heated in the presence of lactose at low temperature (LT), and high temperature (HT). Peptides without posttranslational modification (noPTM), as well as modification to glucosyllysine (Gluc), lactosyllysine (Lac), pyrraline (Pyr), and $\mathrm{N}^{\varepsilon}$-carboxymethyllysine (CML) are shown expressed as peptide count relative to the total number (NT: 181, LT: 129, HT: 121) of peptides in one sample.

\subsection{4 sIgE binding epitopes on the basolateral side of the Caco-2 cell monolayer}

Peptides identified at the basolateral side that carried at least $80 \%$ of the sequence of a known sIgE epitope are shown in Table 6.4. Similar to the observations in the digest (Table 6.1) most epitopes were found in peptides derived from BLG, however only two of these peptides were unmodified. Moreover, only $19 \%$ of the glycated and non-glycated $\operatorname{sgE}$ binding epitopes found in the digest (Table 6.1 and Table 6.2) were also found on the basolateral side (Table 6.4). Contrastingly, on average the total number of glycated and non-modified peptides found on the basolateral side corresponded to $49 \%$ of the number of glycated and non-modified peptides in 
the digest. Two of the peptides containing an sIgE epitope derived from $\alpha_{\mathrm{s} 1}$-casein (f52-67 and f123-133) were not identified in the digests before the Caco-2 cell experiment (Table 6.1), however these peptides could derive from other precursor peptides (e.g. phosphorylated f56-67 and f124-133). Additionally, a peptide derived from BLG (f57-71) in non-modified and glycated form was previously found in all samples, while identification on the basolateral side was only possible in NT-MP.

Table 6.4: Digestion-derived peptides covering sIgE binding epitope ${ }^{1}$ sequences, identified on the basolateral side of the Caco-2 cell monolayer. Peptides were generated after digestion of cow's milk protein, non-treated (NT), heated at low temperature (LT), and heated at high temperature (HT), in an infant in vitro model. Amino acids (AAs) position indicates the position within the proteins including the signal peptide. Peptides were identified from $\alpha_{\mathrm{s} 1}$-casein $\left(\alpha_{\mathrm{s} 1}-\mathrm{cn}\right), \beta$-casein $(\beta$-cn), and $\beta$-lactoglobulin (BLG). Peptides with and without post translational modification (PTM) to lactosyllysine (Lac), glucosyllysine (Gluc), $\mathrm{N}^{\varepsilon}$-carboxymethyllysine (CML), and pyrraline (Pyr) are shown, where modified lysine residues $(\mathrm{K})$ are bold and underline.

\begin{tabular}{|c|c|c|c|c|c|c|}
\hline Protein & Sample & Peptide sequence & $\begin{array}{l}\text { AAs } \\
\text { position }\end{array}$ & $\begin{array}{l}\text { sIgE } \\
\text { epitope } \\
\text { AAs } \\
\text { position }\end{array}$ & PTM & \\
\hline \multirow[t]{4}{*}{$\alpha_{\mathrm{s} 1-\mathrm{cn}}$} & NT,LT & VNELSKDIGSESTEDQ & $52-67$ & $54-63$ & N/A & \\
\hline & $\mathrm{NT}, \mathrm{LT}$ & KVPQLEIVPNSAEE & $120-133$ & $124-135$ & N/A & \\
\hline & $\mathrm{NT}, \mathrm{LT}$ & QLEIVPNSAEE & $123-133$ & $124-135$ & N/A & \\
\hline & NT,LT,HT & LEIVPNSAEER & $124-134$ & $124-135$ & $\mathrm{~N} / \mathrm{A}$ & \\
\hline \multirow[t]{3}{*}{$\beta$-cn } & NT, LT & PVVVPPFLQPEV & $96-107$ & $98-107$ & N/A & \\
\hline & NT, LT, HT & VVPPFLQPE & $98-106$ & $98-107$ & N/A & \\
\hline & NT, LT, HT & VVPPFLQPEV & $98-107$ & $98-107$ & $\mathrm{~N} / \mathrm{A}$ & $*$ \\
\hline \multirow[t]{8}{*}{ BLG } & NT, LT, HT & VYVEELKPTPEGDLE & $57-71$ & $56-70$ & $\mathrm{~N} / \mathrm{A}$ & \\
\hline & NT & VYVEELKPTPEGDLE & $57-71$ & $56-70$ & CML & \\
\hline & NT & VYVEELKPTPEGDLE & $57-71$ & $56-70$ & $\mathrm{Lac}$ & \\
\hline & NT & VYVEELKPTPEGDLE & $57-71$ & $56-70$ & Pyr & \\
\hline & NT, HT & YVEELK $\overline{P T P E G D L E ~}$ & $58-71$ & $56-70$ & N/A & \\
\hline & $\mathrm{NT}, \mathrm{LT}, \mathrm{HT}$ & YVEELKPTPEGDLE & $58-71$ & $56-70$ & CML & \\
\hline & NT, LT, HT & YVEEL K'PTPEGDLE & $58-71$ & $56-70$ & $\mathrm{Lac}$ & \\
\hline & $\mathrm{NT}, \mathrm{LT}, \mathrm{HT}$ & YVEEL KPTPEGDLE & $58-71$ & $56-70$ & Pyr & \\
\hline
\end{tabular}

${ }^{1}$ Peptides were reported as sIgE binding epitopes if their sequence contained at least $80 \%$ of the sequence of an sIgE binding epitope. Digestion-derived peptides covering the exact sequence of an $\operatorname{sIgE}$ binding epitope are indicated $(*)$.

From the T-cell epitopes identified in the digest, only one T-cell epitope derived from $\alpha_{\mathrm{s} 1}$-casein was found in HT-MP (f68-84). This data suggested an overall low passage of T-cell epitopes and $\operatorname{sIgE}$ binding epitope.

\subsection{Discussion}

\subsubsection{Heat treatment dependent differences in peptide profiles}

Dry-heated MP at LT and HT was subjected to simulated infant in vitro digestion and peptides were identified after $10 \mathrm{~min}$ and $60 \mathrm{~min}$ in the IP. As most differences between heat treatments in the digests were observed after $10 \mathrm{~min}$ in the IP, at which time the mucosal immune system in the gastrointestinal tract may already encounter antigens, the focus was set to this digestion time point. Heat treatment of MP resulted in a decreasing number of peptides upon digestion after $10 \mathrm{~min}$ in the IP compared to NT-MP which became less distinct after $60 \mathrm{~min}$ in the IP (Figure 6.1). The absence of peptides can be a result of both increased and impaired hydrolysis [7]. However, in our previous study we showed that HT dry heating impairs hydrolysis after 
$10 \mathrm{~min}$ and $60 \mathrm{~min}$ in the IP suggesting that the absence of peptides results from decreased hydrolysis [27]. Next to this, it is also possible that a larger pool of different linear and crosslinking MR products (MRPs) can result in lower number of peptides as only the most abundant modifications were monitored. At the same time, the relative number of glycated peptides identified in the digest of heated samples was higher compared to NT-MP (Figure 6.1a). Most of the peptides were modified to glucosyllysine and lactosyllysine (supplementary material: Figure 6-S4) and already a large proportion of lactoyslated peptides was observed in NT-MP. The comparison of peptide intensities, however, indicated that the quantities of glycated peptides in the heated samples were higher than in NT-MP (supplementary material: Figure 6-S5). This was in agreement with the findings of Milkovska-Stamenova et al. [35], who found 50 lactosylation sites in raw milk which increased to only 70-80 in ultra high temperature treated milk. At the same time, quantification of the glycated peptides in their study showed much lower levels in raw milk compared to processed dairy products.

Most peptides were derived from $\alpha_{\mathrm{s} 1}$-casein, $\beta$-casein, and BLG (supplementary material: Figure 6-S1). For the two casein this is probably related to the relative higher concentration compared to the other proteins. For BLG this is also related to the larger number of glycated peptides, of which each was counted as a separate peptide (Figure 6.3e). A heat treatment dependent decrease of sequence coverage after $10 \mathrm{~min}$ in the IP was especially observed for the two $\alpha$-caseins and BLG (Figure 6.2 and Figure 6-S1a). For BLG, this originated from the absence or low number of peptides in the regions f17-39, f88-116, and f164-174 (Figure 6.3e). BLG, as a globular protein, is more sensitive to heating induced structural modifications compared to casein [36]. Moreover, it contains 16 lysine residues and 2 arginine residues, which makes it prone to glycation via the MR [37]. The regions f17-39 and f88-116 are rich in lysine residues, explaining the impairment of peptide generation especially in heated samples from this area via tryptic hydrolysis. The region f164-175 is located on the outside of the globular protein, partly incorporated in a $\beta$-strand and $\alpha$-helix structure, which makes it rather easily accessible for digestive enzymes. However, it has been shown that upon heating in solution a $\alpha-\beta$ transition occurs, contributing to the aggregation of BLG via hydrophobic interactions [38]. This could explain the absence of peptides in the f164-175 region in, as HT heating promotes the aggregation of BLG, but not in LT-MP and NT-MP. For $\alpha$-caseins, a heating dependent decrease of sequence coverage was mainly reflected by the absence of phosphorylated peptides in HT-MP (Figure 6.3a and b) and is in line with the lower number of phosphorylated peptides (Figure 6.1a). Dephosphorylation has been reported upon heating in solution of caseinate at HT $\left(140{ }^{\circ} \mathrm{C}\right)$ [39]. Both, hydrolysis of phosphoserine as well as $\beta$-elimination may induce dephosphorylation of casein. Michael addition subsequently to $\beta$-elimination results in the formation of the protein crosslinking [39], which may also explain the lower number of peptides in HT-MP from sequence parts that are more phosphorylated. A study from Wada et al. [40] showed that dephosphorylation could decrease digestibility of heated dairy products. This is in line with the low digestibility of HT-MP observed in our previous study [27]. Next to 
digestibility, dephosphorylation could also decrease sIgE binding capacity, indicating that overall sIgE binding capacity to linear sIgE binding epitopes could be lower for HT-MP [41]. In contrast to this, the region $\mathrm{f} 22-39$ of $\beta$-casein, showed increasing number of phosphorylated peptides in HT with progressing digestion (supplementary material: Figure 6-S2c), indicating that a slower release of peptides could be a possible explanation for the absence of phosphorylated peptides after $10 \mathrm{~min}$ in the IP. Interestingly, glycated peptides did not result in differences of overall sequence coverage when comparing heat treatments but resulted in a higher number of peptides in some areas (Figure 6.3a and c). This could possibly affect immunoreactivity if present on an epitope or by binding of these peptides to AGE receptors, however it should be noted that quantities of glycated peptides were not measured and that it is not clear which effect the glycation of peptides has for epitope recognition. In summary, dry heating of MP decreases the number of peptides released upon simulated infant in vitro digestion and results in lower sequence coverage after $10 \mathrm{~min}$ in the IP. Glycated peptides had a minor role in differential sequence coverage. The discrepancies in sequence coverage of specific regions when comparing heat treatments can also be relevant for sIgE binding and T-cell epitope presentation. At the same time, progressing digestion results in less differences, suggesting that digestion kinetics are important determinants for differential release of immunoreactive digestion-derived peptides when comparing heat treatments.

\subsubsection{Hydrolysis resistant areas}

Most regions of $\kappa$-casein and ALA from which peptides were released after $10 \mathrm{~min}$ in the IP (Figure $6.3 \mathrm{~d}$ and $\mathrm{f}$ ) were also detected after $60 \mathrm{~min}$ in the IP (supplementary material: Figure 6-S2), however none of them were identified in areas with interest for possible immunological consequences. For $\alpha_{\mathrm{s} 2}$-casein, decreasing sequence coverage was only observed for NT-MP. This was related to the disappearance of the phosphorylated peptides (f16-34) and the peptide at f40-50, of which already only low numbers were detected after $10 \mathrm{~min}$ in the IP. However, no potential epitopes were identified after $60 \mathrm{~min}$ in the IP. For $\alpha_{\mathrm{s} 1}$-casein and $\beta$-casein, sequence coverage and number of peptides showed only minor decrease with prolonged digestion (Figure 6.2 and supplementary material: Figure 6-S1). For $\beta$-casein, the peptide pattern between samples showed only minor differences and therefore also a comparable persistence of peptides carrying an sIgE binding epitope (f96-110, f123-134, and f164-177) (supplementary material: Table 6-S1). For $\alpha_{s 1}$-casein, the region f202-213 was solely covered in heated samples by glycated peptides after $60 \mathrm{~min}$ in the IP, suggesting a higher digestion resistance of this area due to glycation. At the same time, f140-155 of $\alpha_{s 1}$-casein which has previously been reported to maintain high residual immunoreactivity after simulated in vitro digestion of spray dried milk powder [7], was only partly preserved until the end of the IP (supplementary material: Figure 6-S2a). A higher number of peptides in NT-MP-digests originating from this region could possibly result in a higher immunoreactivity of this sample. Next to this, a larger number of peptides in f119-134, which contained a potential T-cell epitope (Table 6.3) was still found at the end of intestinal digestion in all samples (supplementary 
material: Figure 6-S4a). In contrast to the two caseins, BLG showed large decreases of sequence coverage in all samples, whereas for which was related to the disappearance of f17-39 and f42-55. At the same time, the regions f57-73 and f139-154 of BLG were highly resistant to digestion until the end of intestinal digestion (supplementary material: Figure 6-S2e), independent from the heat treatment. This was in line with the findings by Egger at al. [42] who observed a high frequency of peptides within particularly these two areas of BLG until $120 \mathrm{~min}$ in the IP of a static in vitro model. Moreover, the findings for both BLG and $\alpha_{\mathrm{s} 1}$-casein were similar to previous findings by Picariello et al. [43], who described the sequence part f141-151 of BLG and f119-134 of $\alpha_{\mathrm{s} 1}$-casein as highly resistant to gastrointestinal digestion after simulated adult in vitro digestion. While there is no direct evidence for the presence of an immunoreactive structure within this region of BLG, f1 19-134 of $\alpha_{\mathrm{s} 1}$-casein partly covers the sequence of and sIgE binding epitope (Figure 6.3a) and was also identified as potential T-cell epitope (Table 6.3). Together with its high resistance until the end of intestinal digestion, this suggest a potential role of f1 19-134 in sIgE binding to the digest of MP, however independent from the heat treatment. To summarise these findings, caseins generally showed a higher resistance over large parts of their protein sequence until the end of gastrointestinal digestion, which was unaffected by the applied heat treatment. Therefore, no conclusions can be drawn from the resistance of specific areas within the proteins sequence regarding differential immunoreactivity of dry-heated MP compared to NT-MP.

\subsubsection{Effect of heat treatment on identification of sIgE binding epitopes}

Digestion-derived peptides were reported as potential sIgE binding epitopes if they covered at least $80 \%$ of the sequence of a linear sIgE binding epitope known from literature [33]. The three proteins showing the highest numbers of digestion-derived peptides, $\alpha_{s 1}$-casein, $\beta$-casein, and BLG (supplementary material: Figure 6-S1a) also led to the highest number of sIgE binding epitopes (Table 6.1) after $10 \mathrm{~min}$ in the IP. Most sIgE binding epitopes were found in the NT-MP digest, when compared to the heated samples (Table 6.1), which was in line with the higher number of peptides (Figure 6.1a) and the higher sequence coverage of NT-MP (Figure 6.2a). This suggests a higher availability of linear sIgE binding epitopes in NT-MP compared to dry-heated MP. The opposite trend was observed for sIgE binding epitopes carrying a glycation side (Table 6.2). However, this trend did not continue until $60 \mathrm{~min}$ in the IP (supplementary material: Table 6-S1). After $60 \mathrm{~min}$ in the IP, most sIgE binding epitopes were found in the digest of NT-MP, of which the majority was however present in all samples. This can be explained by the overall smaller differences between samples with progressing digestion, which is possibly related to differences in digestion kinetics especially in the beginning of the IP. The effect of heating and glycation on IgE binding has been subject to previous studies on isolated milk proteins in mixture [15-17,19]. As reviewed by Nowak-Wegrzyn et al. [18], milk proteins show reduced IgE binding upon extensive glycation via the MR. However, these observations are based on studies of undigested milk proteins and not of linear epitopes exclusively and thus can probably not be extrapolated for all MRPs and 
peptides. A study by Gasparini et al. [44] reported an approach to create the basis to study the effect of lactosylation on linear epitopes, however data comparing $\operatorname{SIgE}$ binding of lactosylated vs. non-modified peptides is not available at this time. With respect to the predicted T-cell epitopes, $\sim 50 \%$ were specifically found in the heated samples, however most of those peptides were glycated. To our knowledge, only data on T-cell epitopes from $\alpha_{\mathrm{s} 1}$-casein, BLG, and ALA are available in literature. In a previous study it was shown that a peptide f1 18-135 of $\alpha_{\mathrm{s} 1}$-casein, which is similar to the T-cell epitope identified in our study (f119-135, Table 6.3), is recognised by 1 out of 10 cow's milk allergic children. However, none of the major T-cell epitopes of $\alpha_{s 1}$-casein identified in previous studies have been observed in the digests in our study [45-47]. The T-cell epitopes identified in BLG partly overlapped with the peptide sequences identified

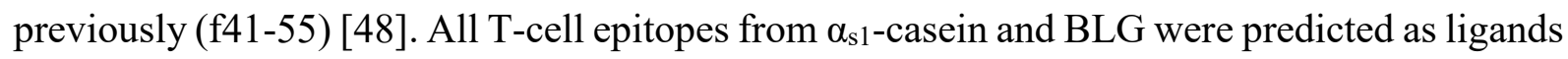
for multiple HLA alleles, indicating that their recognition could be less affected by individual differences in patients. While the majority of $\alpha_{\mathrm{s} 1}$-casein derived T-cell epitopes was phosphorylated, which in a previous study did not show consistent differences in epitope recognition [45], most of the $\alpha_{\mathrm{s} 2}$-casein derived T-cell epitopes were glycated (Table 6.3). To our knowledge there is no study directly showing the effect of glycation on T-cell epitope recognition. However, as glycation of food proteins has been shown to affect T-cell immunogenicity $[21,49]$, it could be hypothesised that glycation of peptides matching to a T-cell epitope could affect its immunogenicity. To summarise, dry heating of MP resulted in a lower number of peptides that match to known sIgE binding epitopes but a higher number of glycated sIgE binding epitopes. Moreover, T-cell epitopes were identified in the digest and equally distributed between samples, while glycated T-cell epitopes were solely found in heated samples. The consequences of glycation on sIgE epitope and T-cell epitope binding are, however, not clear.

\subsubsection{Identification of peptides on the basolateral side of the Caco-2 cell monolayer}

Transport across the epithelial layer was assessed using a Caco-2 cell monolayer model. Peptide length distribution found on the basolateral side (Figure 6.4) indicated a favoured transport of peptides up to 13 amino acids compared to the distribution in the digest (supplementary material-Figure 6-S3). Interestingly, also peptides with a length up to 24 amino acids were found on the basolateral side (Figure 6.4). The peptides in the larger size ranges (f17-19 and f20-22, and f23-25) were mainly non-glycated peptides derived from $\beta$-casein, which originated from hydrophobic patches within the sequence suggesting a passage via transcytosis [50]. Availability of larger peptides increases the possibility to be recognised by the immune system. Moreover, transport of peptides carrying sIgE binding epitope sequences (e.g. f159-177) via transcytosis enables the peptide to reach the lamina propria intact, indicating the importance of monitoring also transport pathways when studying the availability of immunoreactive digestion-derived peptides. Most digestion-derived peptides on the basolateral side were derived from $\alpha_{\mathrm{s} 1}$-casein, $\beta$-casein, and BLG, which is probably related to the higher number of peptides in the digest (supplementary material: Figure 6-S2a). Consequently, sIgE binding 


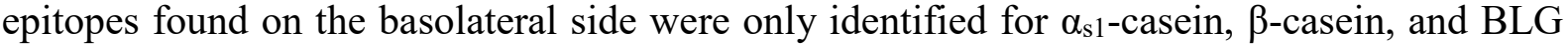
(Table 6.4). Moreover, sIgE binding epitopes were most abundant in NT-MP which was in line with the total number of digestion-derived peptides between samples (Table 6.1a) and the presence amongst proteins (supplementary material: Figure 6-S1a). However, only $19 \%$ of the sIgE binding epitopes (non-modified and glycated) and one T-cell epitope identified in the digests were also found on the basolateral side (Table 6.1, Table 6.2, and Table 6.4), while on average $49 \%$ of the number of peptides in the digest were found on the basolateral side, suggesting some sort of epitope-excluding effect of the epithelial layer. For T-cell epitopes it could be hypothesised that this was related to the size as the size ranges 8-10 as well as 11-13 amino acids were preferably transported, while T-cell epitopes normally have a length between 15-24 amino acids [34]. In contrast, most sIgE binding epitopes were identified within the smaller size ranges. Next to peptide size, the transport across the Caco- 2 cell monolayer can also be determined by charge and hydrophobicity [50]. However, further studies would be necessary to determine peptides properties to find the reasons for the observed restriction of epitope transport across the Caco-2 cell monolayer. Moreover, it should be noted that in vivo a larger number of microfold cells as well as specialised dendritic cells are present in the small intestine, that are able to directly sample antigens from the intestinal lumen [51]. It is thus hypothesised that the translocation of SIgE and T-cell epitopes in vivo could be directed towards specialised cells rather than transport via normal enterocytes.

In contrast to this, a relatively higher number of glycated peptides was observed on the basolateral side, e.g. in dry-heated samples, compared to the composition in the digest. Moreover, data indicated a preference for the transport of lactosyllysine and glucosyllysine-modified peptides amongst all samples, when comparing the composition of the digest (supplementary material: Figure 6-S4) and the composition of the basolateral side (Figure 6.5). As reviewed by Moradi et al. [52], N- and O-glycosylation with different mono- and polysaccharides of therapeutic peptides has been shown to increase their transport across various biological membranes including Caco-2 cells. For example, Varamini et al. [53] observed a 700-fold increased transport across the Caco- 2 cell monolayer after modification of the N-terminal amino group from endomorphin-1with lactose and suggested that this transport took place via a lactose-selective transporter. Such transporter-mediated translocation could be a possible explanation for the facilitated migration of glucosyllysine and lactosyllysine-modified digestion-derived peptides across the Caco-2 cell monolayer. However, it should be noted that the position and type of linkage (N- or O-linked) can strongly affect the structure, functionality and transporter mediated uptake of the peptides [52,54]. Therefore, an extrapolation of these findings to any peptide and any kind of modification is probably not possible. With respect to the potential immunological consequences, it is suggested that glycation if present on a linear sIgE binding epitope can affect the interaction between the peptide and the antibody [44]. Moreover, AGEs themselves have also been reported to modulate inflammatory pathways by binding to receptors for AGEs [14]. For the example of peptide-bound CML, it has been shown that it is a potent ligand for the receptor for AGEs and 
thus possibly affects inflammatory pathways [20]. This study showed that glycated peptides larger than 7 amino acids are transported independent of the type of modification (Figure 6.5). The findings of this study, suggested that diets with high AGE content can also result in higher uptake of AGE-modified peptides. As recently shown, the binding of AGE receptors depends on the concentration of food protein bound AGEs [22]. Therefore, quantitative data would be necessary to better judge the impact of the transport of AGE-modified peptides on the gastrointestinal immune system as well as the involved transport pathways. To summarise, results indicated that several potentially immunoreactive peptides are transported across a model epithelial barrier. In general, the presence of peptides on the basolateral side is more affected by the overall composition of the digest rather than the selective transport of specific peptides. However, observations for lactosylated and glucosyllysine-modified peptides indicated a facilitated transport of these peptides. Transport seemed to be favoured for smaller peptides (up to 13 amino acids) as well as peptides modified to lactosyllysine and glucosyllysine. However, data also showed that CML and pyrraline-modified peptides are transported comparable to the composition in the digest. At the same, time transport of sIgE binding epitopes and T-cell epitopes was limited, which is possibly related to some intrinsic properties of these peptides.

This study gave an overview of the composition and transport of peptides derived after simulated infant in vitro digestion of differentially dry-heated MP. However, it also had in some limitations, as only qualitative data were presented and allergenicity as well as immunogenicity was not measured directly. Moreover, other structures that could affect immunogenicity as well as allergenicity, such as aggregated protein that might also resist in vitro digestion, has not been considered $[55,56]$.

\subsection{Conclusions}

This study showed that different peptide profiles are generated during simulated infant in vitro digestion of milk that was dry-heated in the presence of lactose. HT dry heating had the largest effects on peptide generation, resulting in much lower numbers of peptides and a lower sequence coverage. Moreover, a much lower number of sIgE binding epitopes but a larger proportion of glycated sIgE binding epitopes and T-cell epitopes in heated samples indicated that immunogenicity and allergenicity of these samples could be affected. Transport studies showed that the transport of SIgE epitopes and T-cell epitopes across the Caco- 2 cell monolayer is limited, highlighting the importance to evaluate different transport pathways. Although, transport of lactosyllysine and glucosyllysine-modified peptides was favoured, also CML and pyrraline-modified peptides were transported depending on their presence in the digest. This resulted in relatively more glycated peptides on the basolateral side in heated samples, indicating that if the initial level of MR is high, this will also increase the transport of glycated peptides and can thereby possibly affect immunoreactivity via interaction with AGE receptors. 


\section{Supplementary material}

a

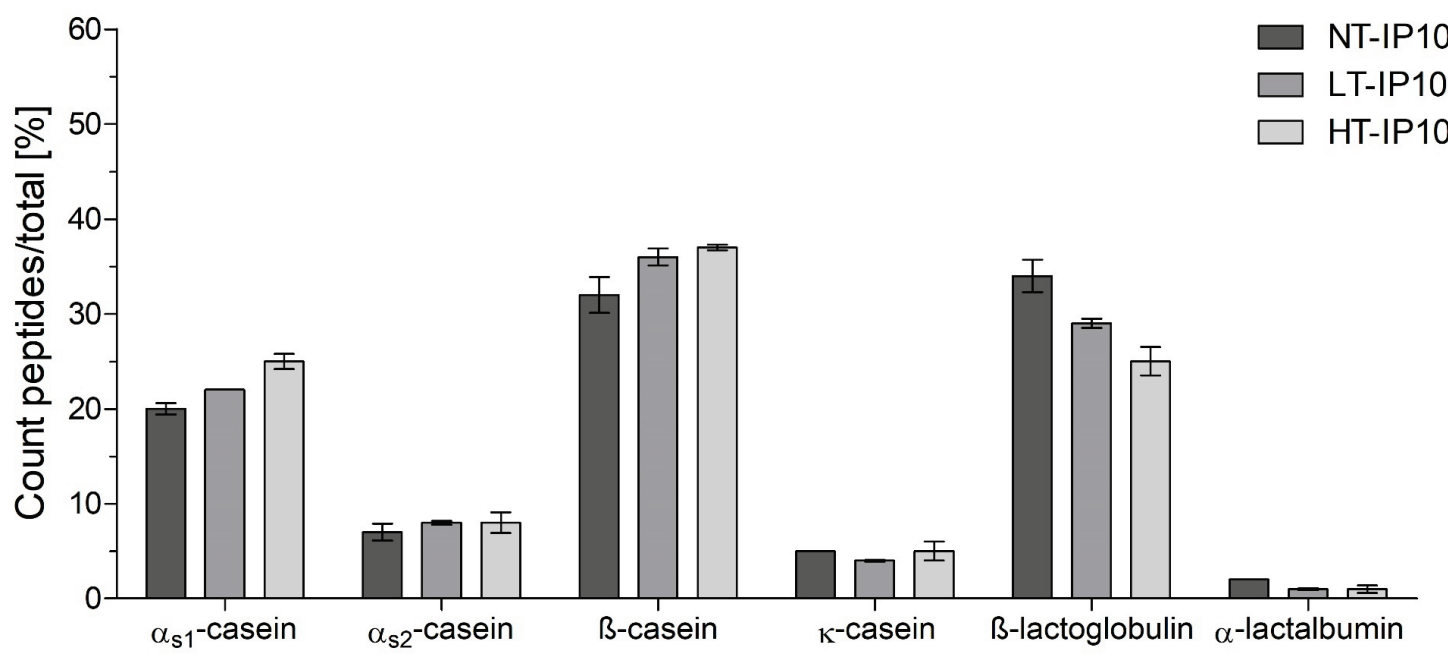

b

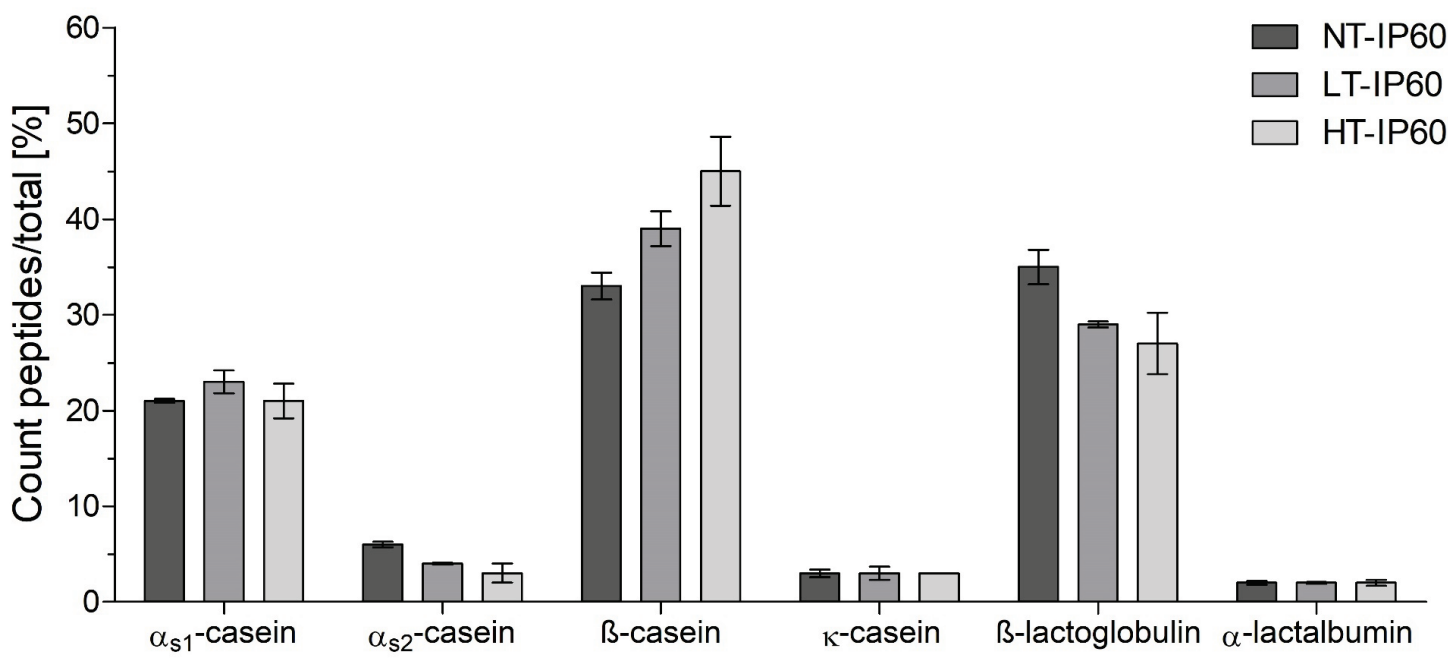

Figure 6-S1: Peptides derived from each of the five major milk proteins after infant in vitro digestion of cow's milk protein. Samples were non-treated (NT), heated at low temperature (LT), and heated at high temperature (HT), with data shown as percentage peptide count to total within the same sample after (a) $10 \mathrm{~min}$ in the intestinal phase (IP) and (b) after $60 \mathrm{~min}$ in the IP. Total number of peptides after $10 \mathrm{~min}$ in the IP was $436 \pm 4,369 \pm 26$, and $315 \pm 36$ for NT, LT, and HT, respectively. Total number of peptides after $60 \mathrm{~min}$ in the IP was $255 \pm 15$, $246 \pm 7$, and $207 \pm 1$ for NT, LT, and HT, respectively. Data are shown in mean \pm standard deviation from duplicate digestion experiments. 
a

\section{$\alpha_{s 1-c a s e i n}$}

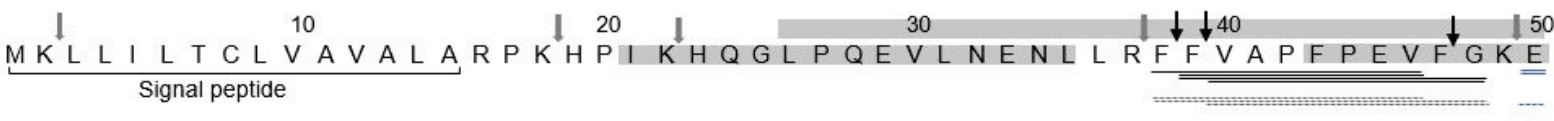

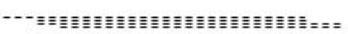

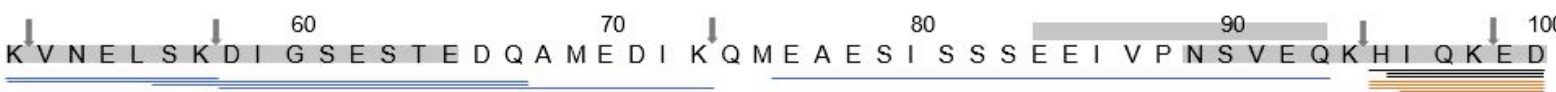

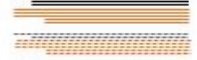

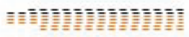

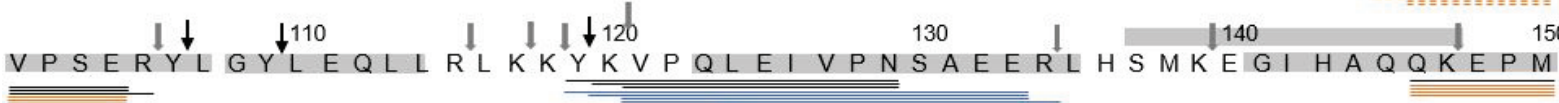

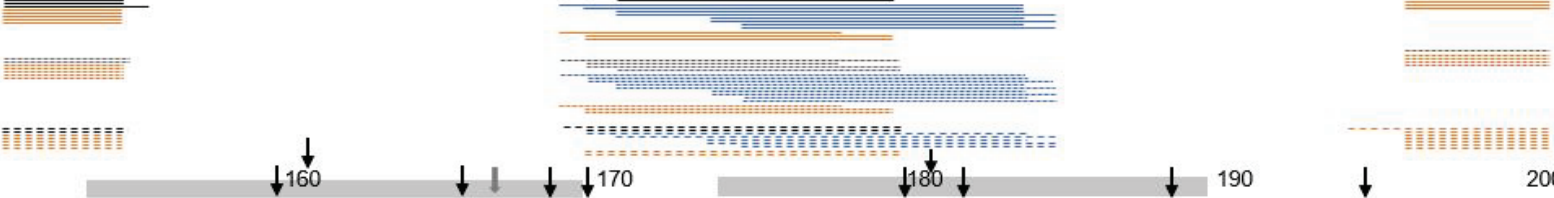
I GVNQELAYF Y PELFR Q \begin{tabular}{l}
$\downarrow 160$ \\
\hline \hline
\end{tabular}

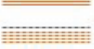

ininini:

210

I GSENSEKTT MPL W

-

b

\section{$\alpha_{\mathrm{s} 2-c a s e i n}$}

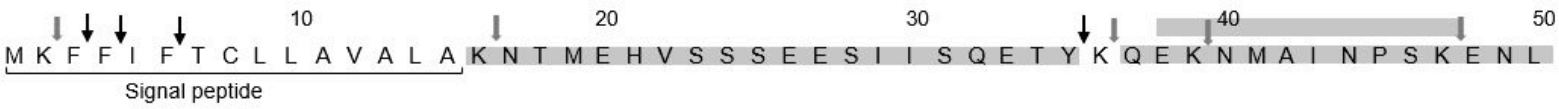

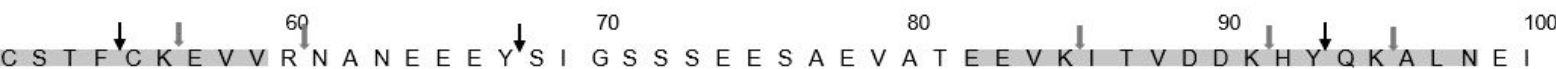

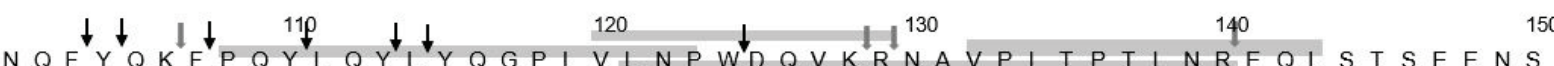
$\overline{\overline{=}}$

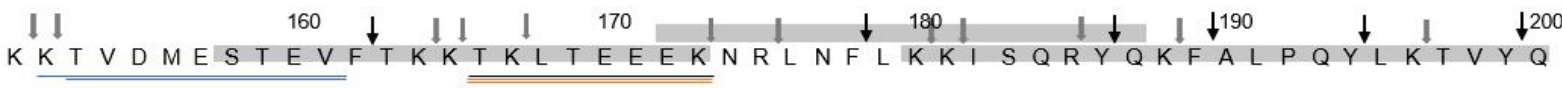

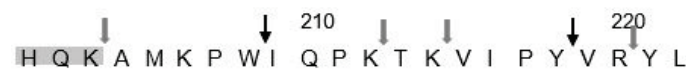


C (continuation Figure 6-S2)

\section{$\beta$-casein}

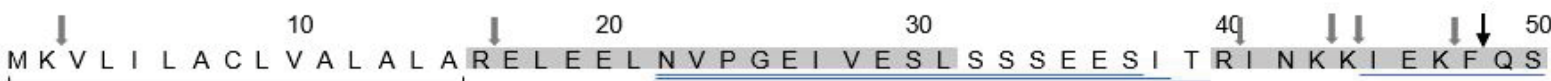
Signal peptide

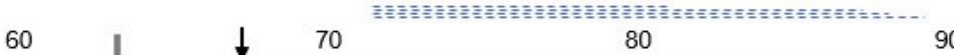

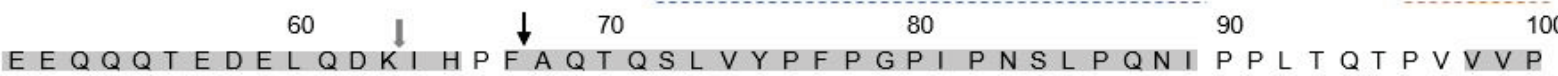

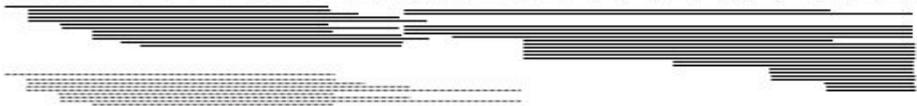

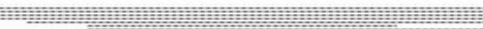

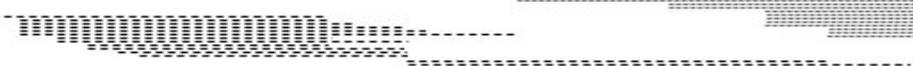

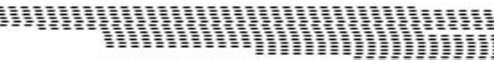

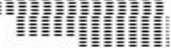

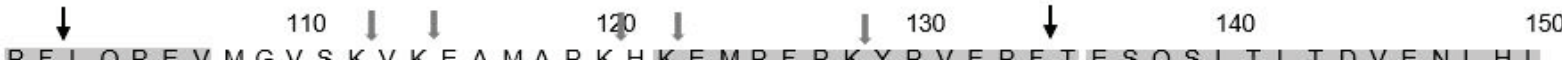

T

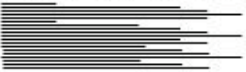

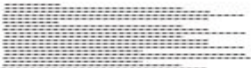

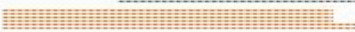

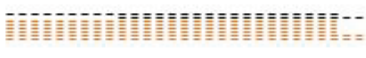

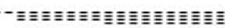

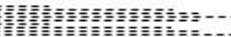
$P L P L L Q S W M H Q P H Q P L P P T V M F P P Q S V L S L S Q S K V L P V P Q K A V P Y P Q R D$

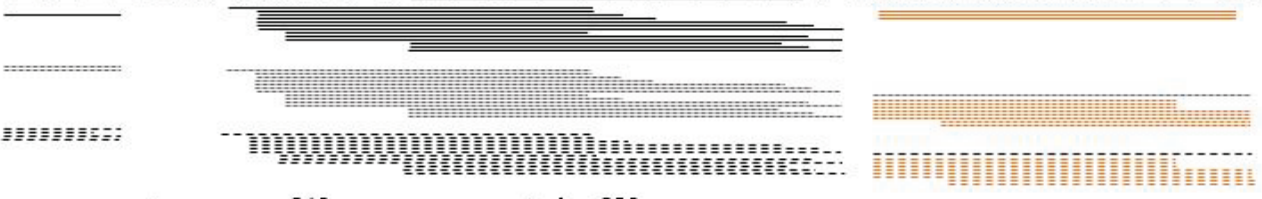

P I Q A F $\stackrel{2}{\downarrow}$ L Y Y Q P P V L G V R

- -

d

\section{K-casein}

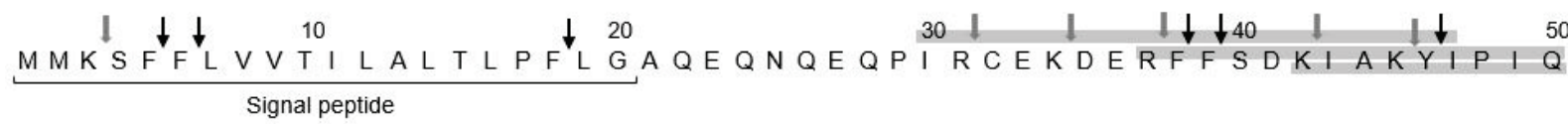

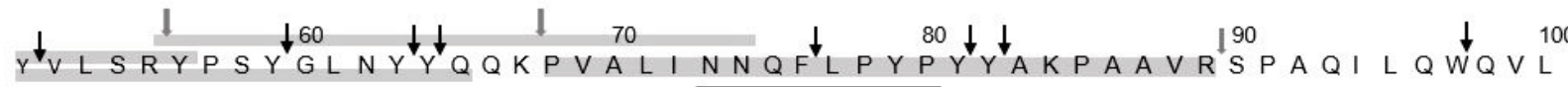

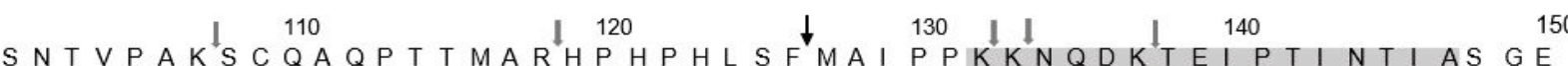

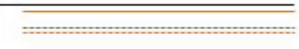

160

170

180

190

P T S T P T TEAVESTVATLEDSPEVI ESPPEI NTV Q T T STAV 
e (continuation Figure 6-S2)

\section{$\beta$-lactoglobulin}
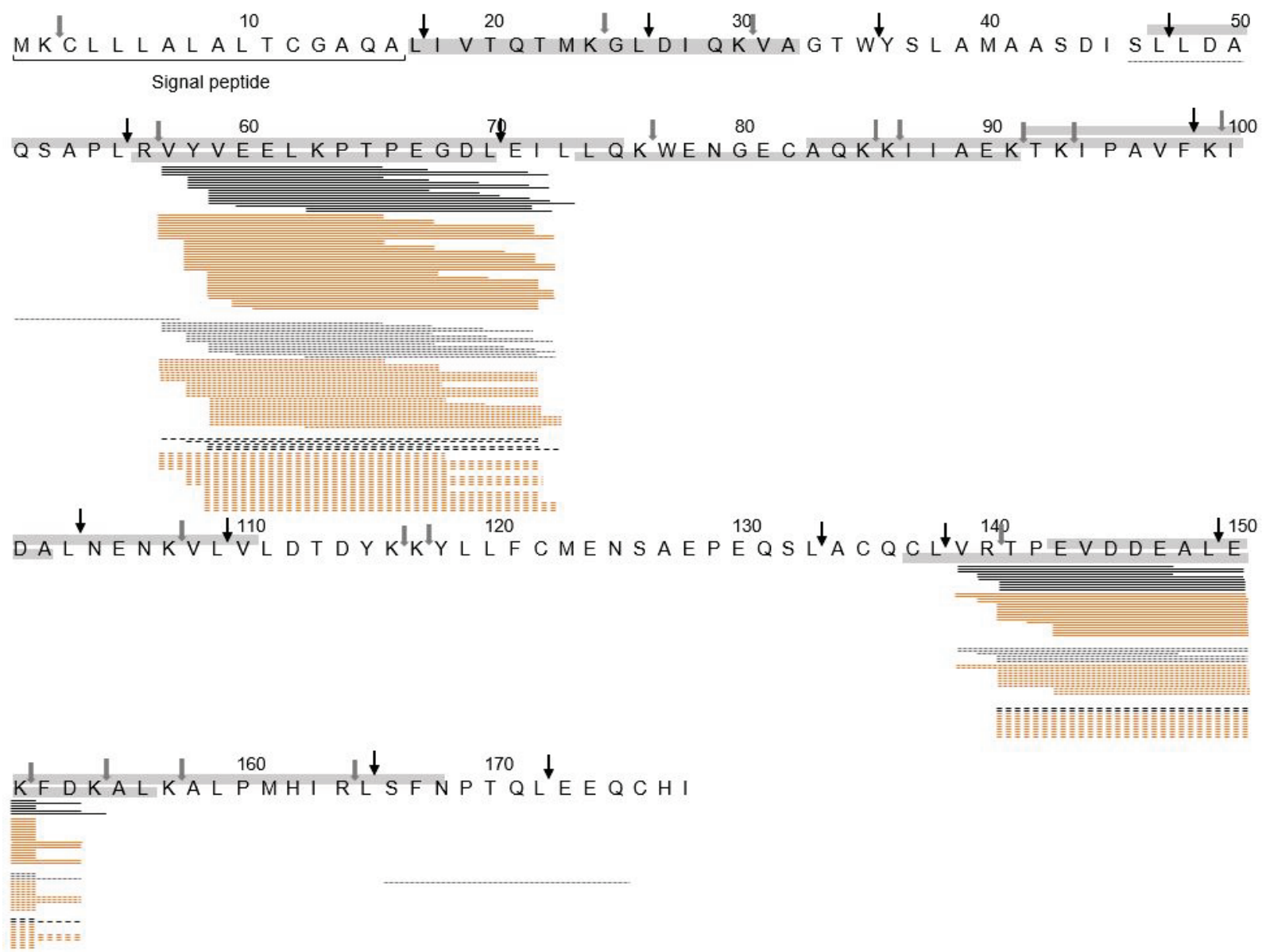

f

a-lactalbumin

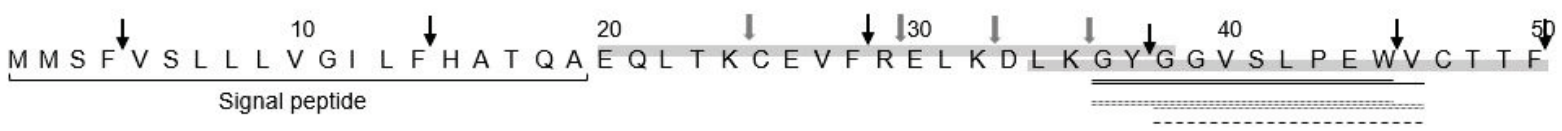

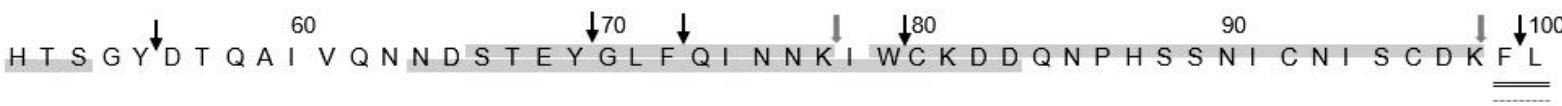

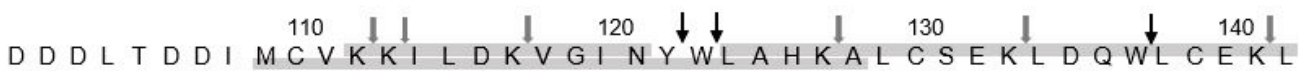

Figure 6-S2: Sequence alignment of digestion-derived peptides from the six major milk proteins (a-f) identified after $60 \mathrm{~min}$ in the intestinal phase of simulated infant in vitro digestion of non-treated cow's milk protein $(-)$, heated at low temperature (----), and heated at high temperature (---). Glycated peptides (orange), phosphorylated peptides (blue), trypsin cleavage sites ( $\downarrow$ ), chymotrypsin cleavage sites $(\downarrow)$. Grey highlights indicated $\operatorname{IgE}$ binding epitopes according to [33]. Trypsin and chymotrypsin cleavage sites were determined using Expasy Bioinformatics Resource Portal (https://web.expasy.org/peptide_cutter/ last visited 08.06.2020). 
Table 6-S1. sIgE binding epitopes ${ }^{1}$ identified in digestion-derived peptides derived from cow's milk protein after $60 \mathrm{~min}$ in the intestinal phase. Samples were non-treated (NT), heated at low temperature (LT), and heated at high temperature (HT) in the presence of lactose. Peptides derived from caseins (cn) and $\beta$-lactoglobulin (BLG). Amino acids (AAs) position indicates the position within the proteins including the signal peptide. Peptides carrying a post translational modifications (PTM) are marked with phosphorylation (Phos), where phosphorylated serine (S) and threonine $(\mathrm{T})$ as we as lysine residues $(\mathrm{K})$ modified to glucosyllysine (Gluc), lactosyllysine (Lac), pyrraline (Pyr), and $\mathrm{N}^{\varepsilon}$-carboxymethyllysine are highlighted in bold and underline. Localisation probabilities are given in brackets if multiple options were identified.

\begin{tabular}{|c|c|c|c|c|c|c|}
\hline Protein & Sample & Peptide sequence & $\begin{array}{l}\text { AAs } \\
\text { position }\end{array}$ & $\begin{array}{l}\text { sIgE } \\
\text { epitope } \\
\text { AAs } \\
\text { position }\end{array}$ & PTM & \\
\hline \multirow[t]{8}{*}{$\alpha_{\mathrm{s} 1-\mathrm{cn}}$} & LT & $\operatorname{VNEL} \underline{\mathbf{S}(\mathbf{1})} \operatorname{KDIGS(1)} \underline{\operatorname{SS}(\mathbf{0 . 8 7}) \mathbf{T}(\mathbf{0 . 1 3})} \mathrm{EDQ}$ & $52-67$ & $54-63$ & Phos & \\
\hline & NT,LT,HT & KVPQLEIVPN吕AEE & $120-133$ & $124-135$ & Phos & \\
\hline & LT & 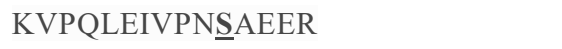 & $120-134$ & $124-135$ & Phos & \\
\hline & NT,LT,HT & VPQLEIVPNㅍAEER & $121-134$ & $124-135$ & Phos & \\
\hline & NT,LT,HT & 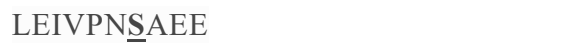 & $124-133$ & $124-135$ & Phos & \\
\hline & NT,LT,HT & 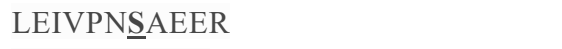 & $124-134$ & $124-135$ & Phos & \\
\hline & NT,LT,HT & 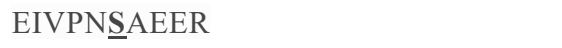 & $125-134$ & $124-135$ & Phos & \\
\hline & NT,LT,HT & QYTDAPSFSDIPNPI & $187-201$ & $186-200$ & $\mathrm{~N} / \mathrm{A}$ & \\
\hline \multirow[t]{14}{*}{$\beta$-cn } & LT & LVYPFPGPIPNSLPQ & $73-87$ & $70-85$ & N/A & \\
\hline & NT,LT,HT & PVVVPPFLQPE & $96-106$ & $98-107$ & N/A & \\
\hline & NT,LT,HT & PVVVPPFLQPEV & $96-107$ & $98-107$ & N/A & \\
\hline & LT,HT & PVVVPPFLQPEVMG & 96-109 & $98-107$ & N/A & \\
\hline & HT & PVVVPPFLQPEVMGV & $96-110$ & $98-107$ & N/A & \\
\hline & NT,LT,HT & VVPPFLQPE & 98-106 & $98-107$ & N/A & \\
\hline & NT,LT,HT & VVPPFLQPEV & $98-107$ & $98-107$ & N/A & $*$ \\
\hline & NT,LT,HT & EMPFPKYYPEP & $123-133$ & $122-135$ & Lac & \\
\hline & NT,LT,HT & ЕMPFPKYYPVEP & $123-133$ & $122-135$ & Gluc & \\
\hline & NT,LT,HT & 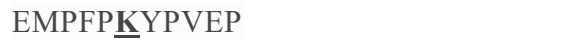 & $123-133$ & $122-135$ & CML & \\
\hline & NT,LT,HT & EMPFP్YЕP & $123-133$ & $122-135$ & Pyr & \\
\hline & LT,HT & 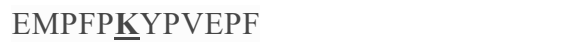 & $123-134$ & $122-135$ & Lac & \\
\hline & LT,HT & 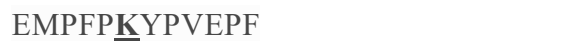 & $123-134$ & $122-135$ & Gluc & \\
\hline & NT,LT,HT & QPLPPTVMFPPQS & $164-176$ & $164-179$ & $\mathrm{~N} / \mathrm{A}$ & \\
\hline \multirow[t]{18}{*}{ BLG } & NT,LT,HT & VYVEELKPTPEGDLE & $57-71$ & $56-70$ & $\mathrm{~N} / \mathrm{A}$ & \\
\hline & NT,LT,HT & VYVEEL KPTPEGDLE & $57-71$ & $56-70$ & Lac & \\
\hline & NT,LT,HT & VYVEEL KPTPEGDLE & $57-71$ & $56-70$ & Gluc & \\
\hline & NT,LT,HT & VYVEEL KPPTPEGDLE & $57-71$ & $56-70$ & CML & \\
\hline & NT,LT,HT & VYVEELK KPTPEGDLE & $57-71$ & $56-70$ & Pyr & \\
\hline & NT & VYVEELKPTPEGDLEI & $57-72$ & $56-70$ & N/A & \\
\hline & NT & VYVEEL్PTPEGDLEI & $57-72$ & $56-70$ & Lac & \\
\hline & NT & VYVEEL K्PTPEGDLEI & $57-72$ & $56-70$ & Gluc & \\
\hline & NT & YVEEL్PTPEGDL & $58-70$ & $56-70$ & Lac & \\
\hline & NT,LT,HT & YVEELKPTPEGDLE & $58-71$ & $56-70$ & $\mathrm{~N} / \mathrm{A}$ & \\
\hline & NT,LT,HT & YVEEL K $P$ TPEGDLE & $58-71$ & $56-70$ & $\mathrm{Lac}$ & \\
\hline & NT,LT,HT & YVEEL K $P$ TPEGDLE & $58-71$ & $56-70$ & Gluc & \\
\hline & NT,LT,HT & YVEEL K & $58-71$ & $56-70$ & CML & \\
\hline & NT,LT,HT & YVEELK KPTPEGDLE & $58-71$ & $56-70$ & Pyr & \\
\hline & NT,LT & YVEELKPTPEGDLEI & $58-72$ & $56-70$ & N/A & \\
\hline & NT & YVEEL్PPEGDLEI & $58-72$ & $56-70$ & Lac & \\
\hline & NT & YVEEL్TPEGDLEI & $58-72$ & $56-70$ & Gluc & \\
\hline & NT & YVEELKPPTPEGDLEI & $58-72$ & $56-70$ & CML & \\
\hline
\end{tabular}

\footnotetext{
${ }^{1}$ Peptides were reported as sIgE binding epitopes if their sequence contained at least $80 \%$ of the sequence of an sIgE binding
} epitope. sIgE binding epitopes of the Peptides matching exactly the sIgE binding epitope sequence are indicated $(*)$. 
Table 6-S2: Potential T-cell epitopes identified after $60 \mathrm{~min}$ in the intestinal phase. Peptides were identified as potential T-cell epitopes using IEDB MHC Class II Binding Prediction software (http://tools.iedb.org/mhcii/). Digestion-derived peptides identified from cow's milk protein, non-treated (NT), dry-heated at low temperature (LT), and dry-heated at high temperature (HT) applied to simulated infant in vitro digestion, derived from casein (cn). Amino acids (AAs) position indicating the position within the proteins including the signal peptide. Unmodified peptides and peptides with post translational modifications (PTM), via phosphorylation (Phos), as well as modification to glucosyllysine (Gluc), lactosyllysine (Lac), $\mathrm{N}^{\varepsilon}$-carboxymethyllysin (CML), and pyrraline (Pyr) were reported if applicable.

\begin{tabular}{|c|c|c|c|c|c|c|}
\hline Protein & Sample & Sequence & HLA-allele & $\begin{array}{l}\text { AAs } \\
\text { position }\end{array}$ & PTM & $\begin{array}{l}\text { Perc. } \\
\text { rank }\end{array}$ \\
\hline \multirow[t]{14}{*}{$\alpha_{\mathrm{s} 1-\mathrm{cn}}$} & $\mathrm{NT}, \mathrm{LT}$ & EAESISSSEEIVPNSVEQ & HLA-DQA1*03:01/ & $76-93$ & Phos & 2.5 \\
\hline & & & DQB1*03:02; & & & \\
\hline & & & HLA-DQA1 *04:01/ & & & 5.3 \\
\hline & & & DQB1*04:02 & & & \\
\hline & $\mathrm{NT}, \mathrm{LT}$ & YKVPQLEIVPN포EE & HLA-DRB1*04:05; & $119-133$ & Phos & 1.9 \\
\hline & & & HLA-DQA1*04:01/ & & & 4.1 \\
\hline & & & DQB1*04:02; & & & \\
\hline & & & HLA-DQA1 *03:01/ & & & 5.8 \\
\hline & & & DQB1*03:02 & & & \\
\hline & $\mathrm{LT}$ & KVPQLEIVPNㅗAEER & HLA-DRB1*04:05; & $120-134$ & Phos & 1.9 \\
\hline & & & HLA-DQA1 *04:01/ & & & 5.6 \\
\hline & & & DQB1*04:02; & & & \\
\hline & & & HLA-DQA1 *03:01/ & & & 5.9 \\
\hline & & & DQB1*03:02 & & & \\
\hline \multirow[t]{4}{*}{$\alpha_{\mathrm{s} 2-\mathrm{cn}}$} & $\mathrm{NT}, \mathrm{LT}$ & SIGSSSEESAEVATEEV & HLA-DQA1 *04:01/ & $68-84$ & Phos & 0.14 \\
\hline & & & DQB1*04:02; & & & \\
\hline & & & HLA-DQA1 *03:01/ & & & 0.18 \\
\hline & & & DQB1*03:02 & & & \\
\hline \multirow[t]{3}{*}{$\beta-\mathrm{cn}$} & $\mathrm{NT}, \mathrm{HT}$ & NVPGEIVESLSSSEES & HLA-DQA1 *04:01/ & $22-37$ & Phos & 5.43 \\
\hline & & & DQB1*04:02 & & & \\
\hline & & NVPGEIVESLSSSEESI & HLA-DRB $1 * 04: 05$ & $22-38$ & Phos & 5.54 \\
\hline
\end{tabular}

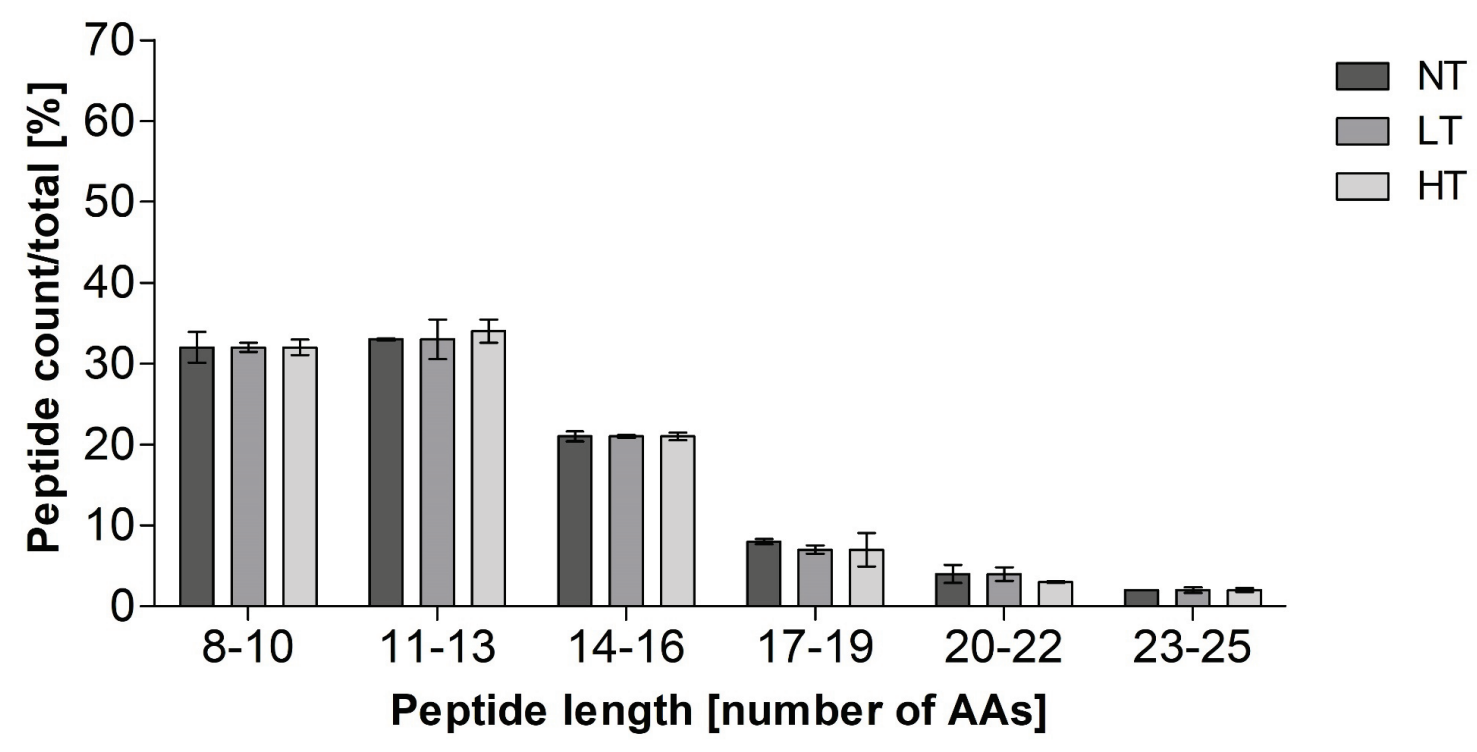

Figure 6-S3: Peptide length distribution identified in the in vitro digests of cow's milk protein after 10 min in the intestinal phase. Samples were non-treated (NT), heated at low temperature (LT) as well as at high temperature $(\mathrm{HT})$ in the presence of lactose and applied to simulated infant in vitro digestion. Data are, expressed as percentage to total number of peptides in the same sample (NT: $436 \pm 4$, LT: $369 \pm 26$, HT: $315 \pm 36$ ). 


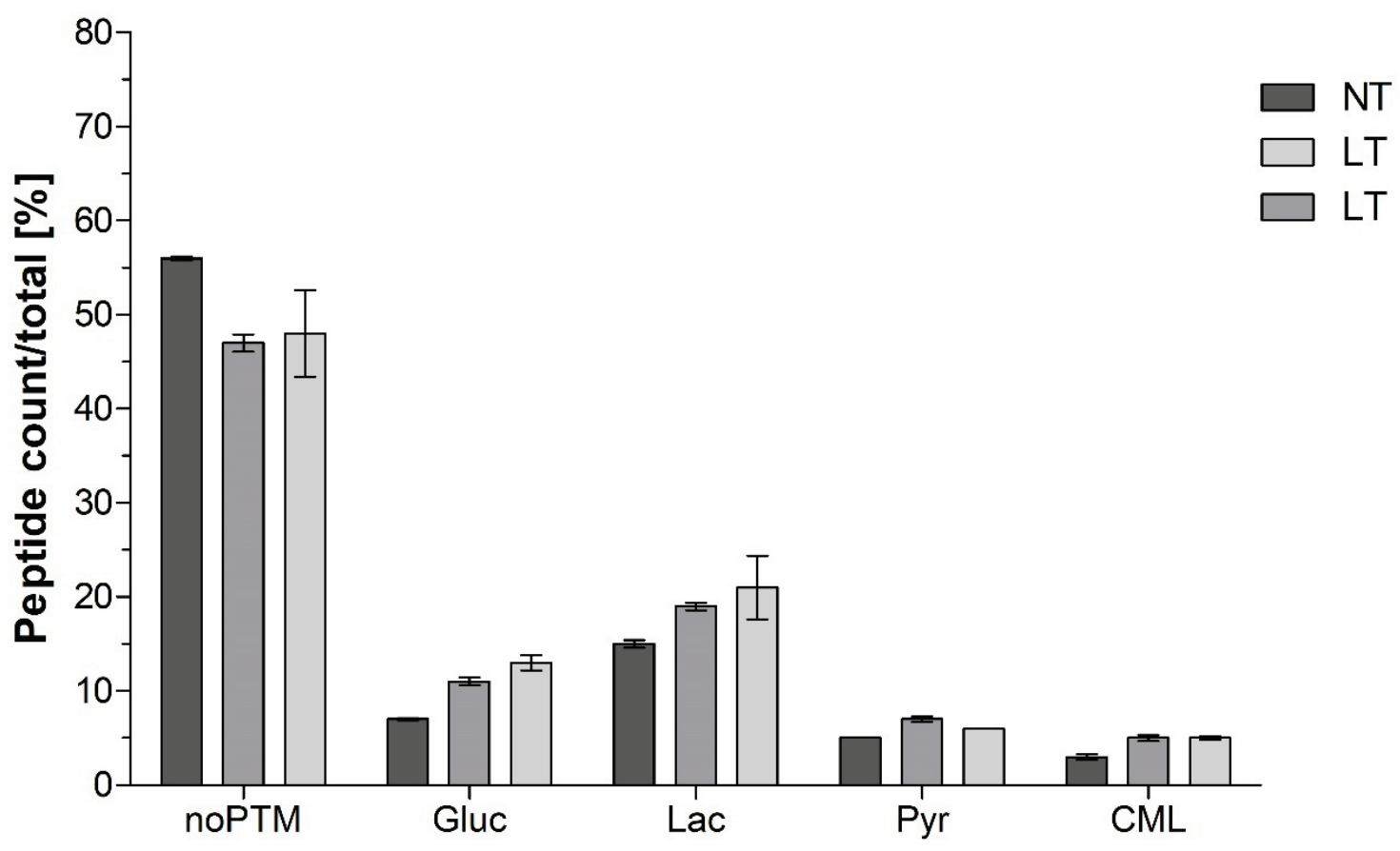

Figure 6-S4: Non-modified vs. glycated digestion-derived peptides identified after $10 \mathrm{~min}$ in the intestinal phase. Comparison of peptides without posttranslational modification (noPTM), as well as modified to glucosyllysine (Gluc), lactosyllysine (Lac), pyrraline (Pyr), and $\mathrm{N}^{\varepsilon}$-carboxymethyllysine (CML) that were identified in the in vitro digests of cow's milk protein, non-treated (NT), heated in the presence of lactose at low temperature (LT), and high temperature (HT), expressed as peptide count relative to the total number of peptides in the samples (NT: $436 \pm 4$, LT: $369 \pm 26$, HT: $315 \pm 36$ ). Error bars represent standard deviations of duplicate digestions.

a

Glucosyllysine-modified peptides

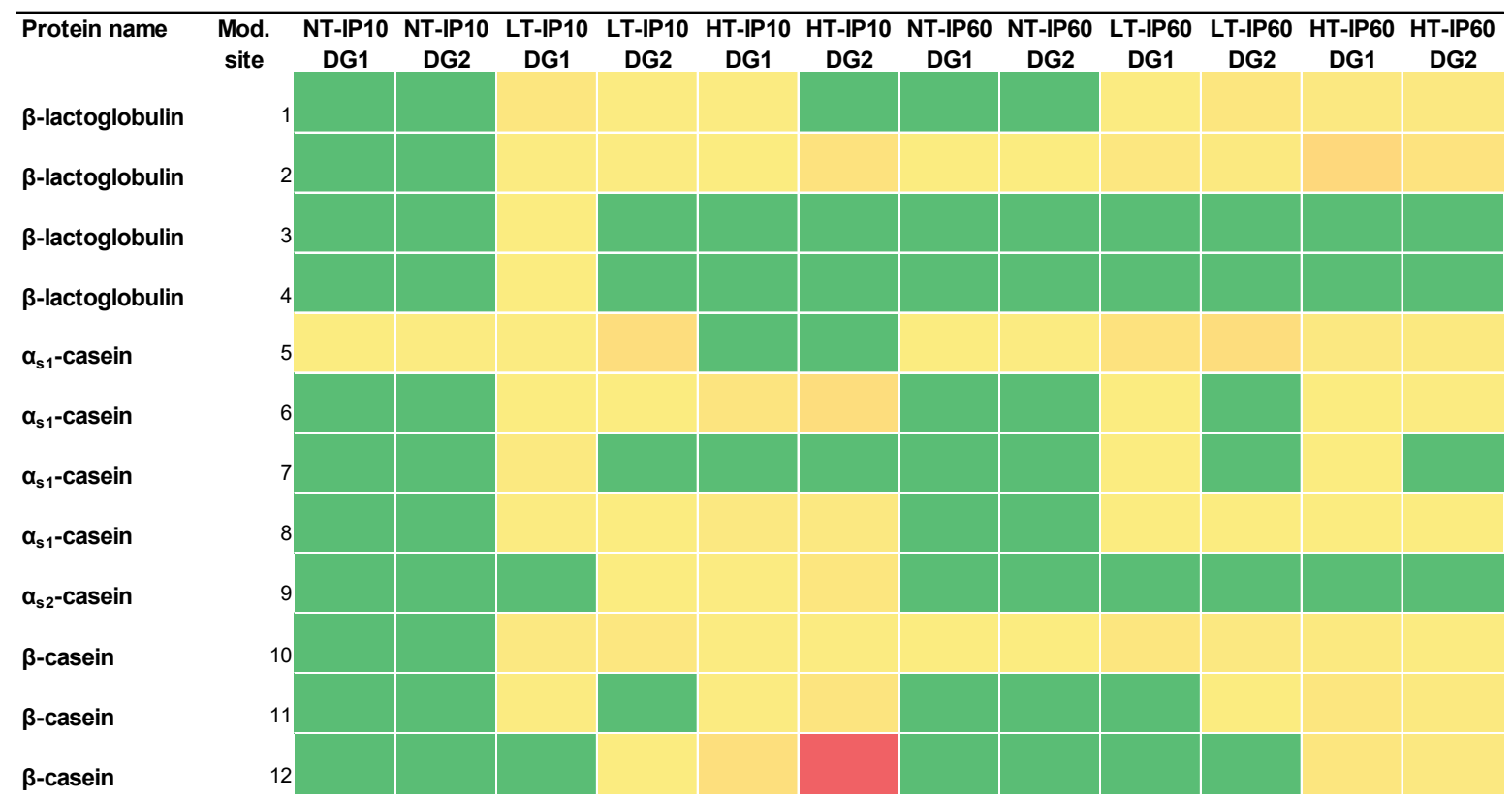


b (continuation Figure 6-S5)

Lactosyllysine-modified peptides

\begin{tabular}{|c|c|c|c|c|c|c|c|c|c|c|c|c|c|}
\hline Protein name & $\begin{array}{l}\text { Mod. } \\
\text { site }\end{array}$ & $\begin{array}{c}\text { NT-IP10 } \\
\text { DG1 }\end{array}$ & $\begin{array}{c}\text { NT-IP10 } \\
\text { DG2 }\end{array}$ & $\begin{array}{c}\text { LT-IP10 } \\
\text { DG1 }\end{array}$ & $\begin{array}{c}\text { LT-IP10 } \\
\text { DG2 }\end{array}$ & $\begin{array}{c}\text { HT-IP10 } \\
\text { DG1 }\end{array}$ & $\begin{array}{c}\text { HT-IP10 } \\
\text { DG2 }\end{array}$ & $\begin{array}{c}\text { NT-IP60 } \\
\text { DG1 }\end{array}$ & $\begin{array}{c}\text { NT-IP60 } \\
\text { DG2 }\end{array}$ & $\begin{array}{c}\text { LT-IP60 } \\
\text { DG1 }\end{array}$ & $\begin{array}{c}\text { LT-IP60 } \\
\text { DG2 }\end{array}$ & $\begin{array}{c}\text { HT-IP60 } \\
\text { DG1 }\end{array}$ & $\begin{array}{c}\text { HT-IP60 } \\
\text { DG2 }\end{array}$ \\
\hline$\beta$-lactoglobulin & & 1 & & & & & & & & & & & \\
\hline$\beta$-lactoglobulin & 2 & 2 & & & & & & & & & & & \\
\hline$\beta$-lactoglobulin & 3 & 3 & & & & & & & & & & & \\
\hline$\beta$-lactoglobulin & 4 & 4 & & & & & & & & & & & \\
\hline$\beta$-lactoglobulin & 5 & 5 & & & & & & & & & & & \\
\hline$\beta$-lactoglobulin & & & & & & & & & & & & & \\
\hline$\beta$-lactoglobulin & 7 & 7 & & & & & & & & & & & \\
\hline$\alpha_{\mathrm{s} 1}$-casein & $\varepsilon$ & & & & & & & & & & & & \\
\hline$\alpha_{s 1}$-casein & c & & & & & & & & & & & & \\
\hline$\alpha_{\mathrm{s} 1}$-casein & 10 & & & & & & & & & & & & \\
\hline$\alpha_{s 1}$-casein & 11 & & & & & & & & & & & & \\
\hline$\alpha_{\mathrm{s} 1}$-casein & 12 & & & & & & & & & & & & \\
\hline$\alpha_{s 1}$-casein & 13 & & & & & & & & & & & & \\
\hline$\alpha_{\mathrm{s} 1}$-casein & 14 & & & & & & & & & & & & \\
\hline$\alpha_{\mathrm{s} 2}$-casein & 15 & & & & & & & & & & & & \\
\hline$\alpha_{\mathrm{s} 2}$-casein & 16 & & & & & & & & & & & & \\
\hline$\alpha_{\mathrm{s} 2}$-casein & 17 & & & & & & & & & & & & \\
\hline$\beta$-casein & 18 & & & & & & & & & & & & \\
\hline$\beta$-casein & 10 & & & & & & & & & & & & \\
\hline$\beta$-casein & 20 & & & & & & & & & & & & \\
\hline$\beta$-casein & 21 & & & & & & & & & & & & \\
\hline$\beta$-casein & 22 & & & & & & & & & & & & \\
\hline$\beta$-casein & 23 & & & & & & & & & & & & \\
\hline $\mathrm{k}$-casein & 24 & & & & & & & & & & & & \\
\hline $\mathrm{k}$-casein & 25 & & & & & & & & & & & & \\
\hline $\mathrm{k}$-casein & 26 & & & & & & & & & & & & \\
\hline
\end{tabular}




\section{C (continuation Figure 6-S5)}

Carboxymethyllysine-modified peptides

\begin{tabular}{|c|c|c|c|c|c|c|c|c|c|c|c|c|c|}
\hline Protein name & $\begin{array}{c}\text { Mod. } \\
\text { site }\end{array}$ & $\begin{array}{c}\text { NT-IP10 } \\
\text { DG1 }\end{array}$ & $\begin{array}{c}\text { NT-IP10 } \\
\text { DG2 }\end{array}$ & $\begin{array}{l}\text { LT-IP10 } \\
\text { DG1 }\end{array}$ & $\begin{array}{c}\text { LT-IP10 } \\
\text { DG2 }\end{array}$ & $\begin{array}{c}\text { HT-IP10 } \\
\text { DG1 }\end{array}$ & $\begin{array}{c}\text { HT-IP10 } \\
\text { DG2 }\end{array}$ & $\begin{array}{c}\text { NT-IP60 } \\
\text { DG1 }\end{array}$ & $\begin{array}{c}\text { NT-IP60 } \\
\text { DG2 }\end{array}$ & $\begin{array}{c}\text { LT-IP60 } \\
\text { DG1 }\end{array}$ & $\begin{array}{c}\text { LT-IP60 } \\
\text { DG2 }\end{array}$ & $\begin{array}{c}\text { HT-IP60 } \\
\text { DG1 }\end{array}$ & $\begin{array}{c}\text { HT-IP60 } \\
\text { DG2 }\end{array}$ \\
\hline$\beta$-lactoglobulin & & 1 & & & & & & & & & & & \\
\hline$\beta$-lactoglobulin & & 2 & & & & & & & & & & & \\
\hline$\alpha_{\mathrm{s} 1}$-casein & & 3 & & & & & & & & & & & \\
\hline$\alpha_{\mathrm{s} 2}$-casein & & & & & & & & & & & & & \\
\hline$\beta$-casein & & & & & & & & & & & & & \\
\hline$\beta$-casein & & & & & & & & & & & & & \\
\hline$\beta$-casein & & & & & & & & & & & & & \\
\hline
\end{tabular}

d

Pyrraline-modified peptides

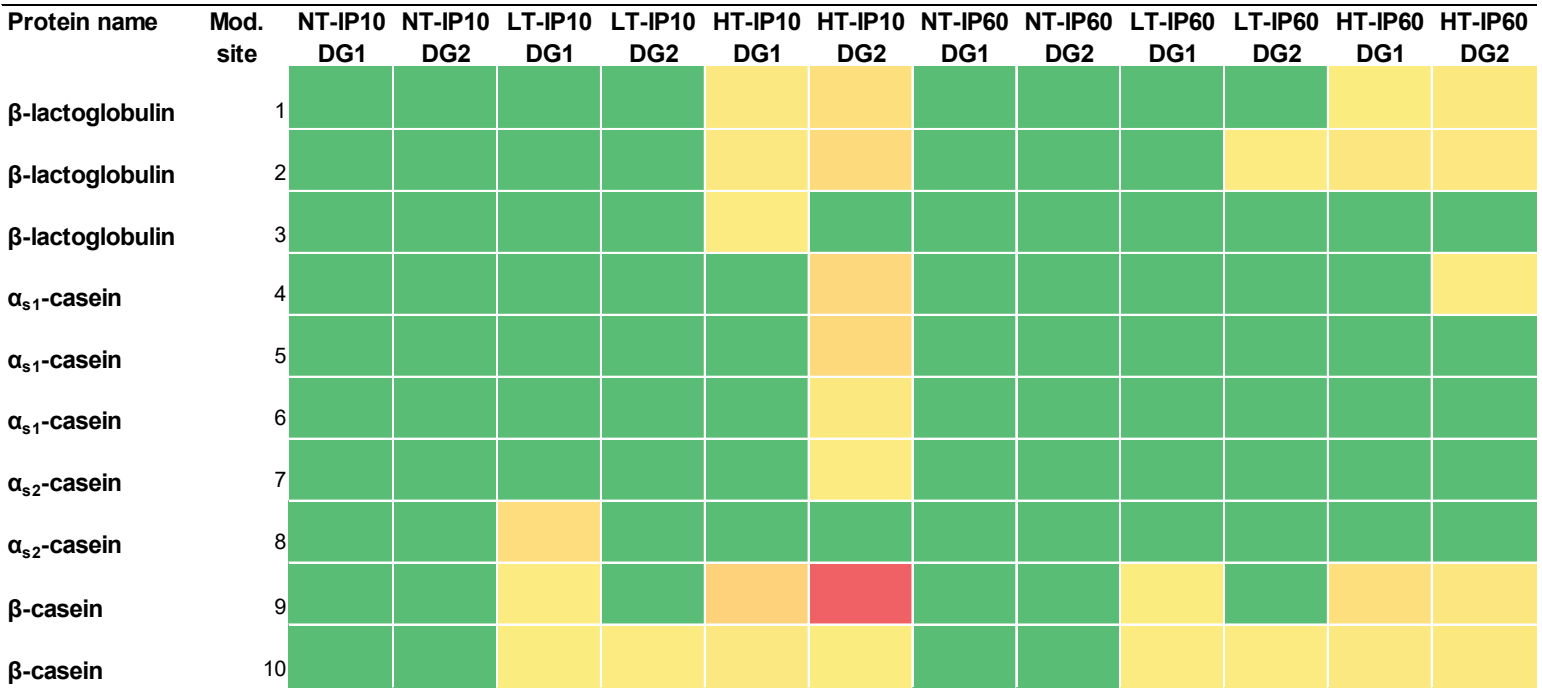

Figure 6-S5: Summed intensities of peptides associated with a specific modification, within the same amino acid sequence. Modification to glucosyllysine (Gluc), lactosyllysine (Lac), $\mathrm{N}^{\varepsilon}$-carboxymethyllysine (CML), and pyrraline (Pyr) found in peptides generated after simulated infant in vitro digestion of cow's milk protein, non-treated (NT), dry-heated at low temperature (LT), and dry-heated at high temperature (HT), sampled after $10 \mathrm{~min}$ in the intestinal phase (IP10) and after $60 \mathrm{~min}$ in the intestinal phase (IP60) are shown. Duplicate digestion experiments (DG1 and DG2) for the same sample are shown, where green indicates the lowest intensity (0.0 for Lac, Gluc, CML, and Pyr) and red indicates highest intensity (Gluc:1.3E+9, Lac: 7.5E+9, CML: 5.1E+7, Pyr: 2.7E+8). 


\section{References}

1. Kim, J.S.; Nowak-Wgrzyn, A.; Sicherer, S.H.; Noone, S.; Moshier, E.L.; Sampson, H.A. Dietary baked milk accelerates the resolution of cow's milk allergy in children. Journal of Allergy and Clinical Immunology 2011, 128, 125-131.e122, doi:10.1016/j.jaci.2011.04.036.

2. Van Boekel, M.A.J.S. Effect of heating on Maillard reactions in milk. Food Chemistry 1998, 62, 403-414, doi:10.1016/s0308-8146(98)00075-2.

3. Arena, S.; Renzone, G.; D'Ambrosio, C.; Salzano, A.M.; Scaloni, A. Dairy products and the Maillard reaction: A promising future for extensive food characterization by integrated proteomics studies. Food Chemistry 2017, 219, 477-489, doi:10.1016/j.foodchem.2016.09.165.

4. Birlouez-Aragon, I.; Pischetsrieder, M.; Leclère, J.; Morales, F.J.; Hasenkopf, K.; Kientsch-Engel, R.; Ducauze, C.J.; Rutledge, D. Assessment of protein glycation markers in infant formulas. Food Chemistry 2004, 87, 253-259, doi:10.1016/j.foodchem.2003.11.019.

5. Pischetsrieder, M.; Henle, T. Glycation products in infant formulas: Chemical, analytical and physiological aspects. Amino Acids 2012, 42, 1111-1118, doi:10.1007/s00726-010-0775-0.

6. Dupont, D.; Mandalari, G.; Mollé, D.; Jardin, J.; Rolet-Répécaud, O.; Duboz, G.; Léonil, J.; Mills, C.E.N.; Mackie, A.R. Food processing increases casein resistance to simulated infant digestion. Molecular Nutrition and Food Research 2010, 54, 1677-1689, doi:10.1002/mnfr.200900582.

7. Dupont, D.; Boutrou, R.; Menard, O.; Jardin, J.; Tanguy, G.; Schuck, P.; Haab, B.B.; Leonil, J. Heat treatment of milk during powder manufacture increases casein resistance to simulated infant digestion. Food Digestion 2010, 1, 28-39, doi:10.1007/s13228-010-0003-0.

8. Sánchez-Rivera, L.; Ménard, O.; Recio, I.; Dupont, D. Peptide mapping during dynamic gastric digestion of heated and unheated skimmed milk powder. Food Research International 2015, 77, 132-139, doi:10.1016/j.foodres.2015.08.001

9. Kopf-Bolanz, K.A.; Schwander, F.; Gijs, M.; Vergères, G.; Portmann, R.; Egger, L. Impact of milk processing on the generation of peptides during digestion. International Dairy Journal 2014, 35, 130-138, doi:10.1016/j.idairyj.2013.10.012.

10. Torcello-Gómez, A.; Dupont, D.; Jardin, J.; Briard-Bion, V.; Deglaire, A.; Risse, K.; Mechoulan, E.; Mackie, A. The pattern of peptides released from dairy and egg proteins is highly dependent on the simulated digestion scenario. Food \& Function 2020, 10.1039/D0FO00744G, doi:10.1039/D0FO00744G.

11. Wada, Y.; Phinney, B.S.; Weber, D.; Lönnerdal, B. In vivo digestomics of milk proteins in human milk and infant formula using a suckling rat pup model. Peptides 2017, 88, 18-31, doi:10.1016/j.peptides.2016.11.012.

12. Zenker, H.E.; Van Lieshout, G.A.A.; Van Gool, M.P.; Bragt, M.C.E.; Hettinga, K.A. Lysine blockage of milk proteins in infant formula impairs overall protein digestibility and peptide release. Food and Function 2020, 11, 358-369, doi:10.1039/c9fo02097g.

13. Zhao, D.; Li, L.; Le, T.T.; Larsen, L.B.; Xu, D.; Jiao, W.; Sheng, B.; Li, B.; Zhang, X. Digestibility of glycated milk proteins and the peptidomics of their in vitro digests. Journal of the Science of Food and Agriculture 2019, 99, 3069-3077, doi:10.1002/jsfa.9520.

14. Teodorowicz, M.; Van Neerven, J.; Savelkoul, H. Food processing: The influence of the maillard reaction on immunogenicity and allergenicity of food proteins. Nutrients 2017, 9, doi:10.3390/nu9080835.

15. Xu, Q.; Shi, J.; Yao, M.; Jiang, M.; Luo, Y. Effects of heat treatment on the antigenicity of four milk proteins in milk protein concentrates. Food and Agricultural Immunology 2016, 27, 401-413, doi:10.1080/09540105.2015.1117059.

16. Ehn, B.M.; Ekstrand, B.; Bengtsson, U.; Ahlstedt, S. Modification of IgE Binding during Heat Processing of the Cow's Milk Allergen $\beta$-Lactoglobulin. Journal of Agricultural and Food Chemistry 2004, 52, 13981403, doi:10.1021/jf0304371.

17. Taheri-Kafrani, A.; Gaudin, J.C.; Rabesona, H.; Nioi, C.; Agarwal, D.; Drouet, M.; Chobert, J.M.; Bordbar, A.K.; Haertle, T. Effects of heating and glycation of $\beta$-lactoglobulin on its recognition by ige of sera from cow milk allergy patients. Journal of Agricultural and Food Chemistry 2009, 57, 4974-4982, doi:10.1021/jf804038t.

18. Nowak-Wegrzyn, A.; Fiocchi, A. Rare, medium, or well done? The effect of heating and food matrix on food protein allergenicity. Current Opinion in Allergy and Clinical Immunology 2009, 9, 234-237, doi:10.1097/ACI.0b013e32832b88e7.

19. Corzo-Martínez, M.; Soria, A.C.; Belloque, J.; Villamiel, M.; Moreno, F.J. Effect of glycation on the gastrointestinal digestibility and immunoreactivity of bovine $\beta$-lactoglobulin. International Dairy Journal 2010, 20, 742-752, doi:10.1016/j.idairyj.2010.04.002.

20. Xue, J.; Rai, V.; Singer, D.; Chabierski, S.; Xie, J.; Reverdatto, S.; Burz, D.S.; Schmidt, A.M.; Hoffmann, R.; Shekhtman, A. Advanced glycation end product recognition by the receptor for AGEs. Structure 2011, 19, 722-732, doi:10.1016/j.str.2011.02.013. 
21. Heilmann, M.; Wellner, A.; Gadermaier, G.; Ilchmann, A.; Briza, P.; Krause, M.; Nagai, R.; Burgdorf, S.; Scheurer, S.; Vieths, S., et al. Ovalbumin modified with pyrraline, a maillard reaction product, shows enhanced T-cell immunogenicity. Journal of Biological Chemistry 2014, 289, 7919-7928, doi:10.1074/jbc.M113.523621.

22. Zenker, H.E.; Teodorowicz, M.; Ewaz, A.; van Neerven, R.J.J.; Savelkoul, H.F.J.; De Jong, N.W.; Wichers, H.J.; Hettinga, K.A. Binding of CML-Modified as Well as Heat-Glycated $\beta$-lactoglobulin to Receptors for AGEs is Determined by Charge and Hydrophobicity. International Journal of Molecular Sciences 2020, 21, doi:doi.org/10.3390/ijms21124567

23. Foerster, A.; Henle, T. Glycation in food and metabolic transit of dietary AGEs (advanced glycation endproducts): Studies on the urinary excretion of pyrraline. Biochem. Soc. Trans. 2003, 31, 1383-1385, doi: $10.1042 /$ bst0311383.

24. Roncero-Ramos, I.; Delgado-Andrade, C.; Tessier, F.J.; Niquet-Léridon, C.; Strauch, C.; Monnier, V.M.; Navarro, M.P. Metabolic transit of Ne-carboxymethyl-lysine after consumption of AGEs from bread crust. Food and Function 2013, 4, 1032-1039, doi:10.1039/c3fo30351a.

25. Hellwig, M.; Geissler, S.; Matthes, R.; Peto, A.; Silow, C.; Brandsch, M.; Henle, T. Transport of Free and Peptide-Bound Glycated Amino Acids: Synthesis, Transepithelial Flux at Caco-2 Cell Monolayers, and Interaction with Apical Membrane Transport Proteins. ChemBioChem 2011, 12, 1270-1279, doi:10.1002/cbic.201000759.

26. Zhao, D.; Li, L.; Le, T.T.; Larsen, L.B.; Su, G.; Liang, Y.; Li, B. Digestibility of Glyoxal-Glycated $\beta$ Casein and $\beta$-Lactoglobulin and Distribution of Peptide-Bound Advanced Glycation End Products in Gastrointestinal Digests. Journal of Agricultural and Food Chemistry 2017, 65, 5778-5788, doi:10.1021/acs.jafc.7b01951.

27. Zenker, H.E.; Raupbach, J.; Boeren, S.; Wichers, H.J.; Hettinga, K.A. The effect of low vs. high temperature dry heating on solubility and digestibility of cow's milk protein. Food Hydrocolloids $\mathbf{2 0 2 0}$, 109, 106098, doi:10.1016/j.foodhyd.2020.106098.

28. Ménard, O.; Bourlieu, C.; De Oliveira, S.C.; Dellarosa, N.; Laghi, L.; Carrière, F.; Capozzi, F.; Dupont, D.; Deglaire, A. A first step towards a consensus static in vitro model for simulating full-term infant digestion. Food Chemistry 2018, 240, 338-345, doi:10.1016/j.foodchem.2017.07.145.

29. Dingess, K.A.; De Waard, M.; Boeren, S.; Vervoort, J.; Lambers, T.T.; Van Goudoever, J.B.; Hettinga, K. Human milk peptides differentiate between the preterm and term infant and across varying lactational stages. Food and Function 2017, 8, 3769-3782, doi:10.1039/c7fo00539c.

30. Liu, M.Q.; Zeng, W.F.; Fang, P.; Cao, W.Q.; Liu, C.; Yan, G.Q.; Zhang, Y.; Peng, C.; Wu, J.Q.; Zhang, X.J., et al. PGlyco 2.0 enables precision N-glycoproteomics with comprehensive quality control and onestep mass spectrometry for intact glycopeptide identification. Nat. Commun. 2017, 8, doi:10.1038/s41467017-00535-2

31. Cox, J.; Mann, M. MaxQuant enables high peptide identification rates, individualized p.p.b.-range mass accuracies and proteome-wide protein quantification. Nature Biotechnology 2008, 26, 1367-1372, doi:10.1038/nbt.1511.

32. Boggs, I.; Hine, B.; Smolenski, G.; Hettinga, K.; Zhang, L.; Wheeler, T.T. Changes in the repertoire of bovine milk proteins during mammary involution. EuPA Open Proteomics 2015, 9, 65-75, doi:10.1016/j.euprot.2015.09.001.

33. Matsuo, H.; Yokooji, T.; Taogoshi, T. Common food allergens and their IgE-binding epitopes. Allergology International 2015, 64, 332-343, doi:10.1016/j.alit.2015.06.009.

34. Knol, E.F.; de Jong, N.W.; Ulfman, L.H.; Tiemessen, M.M. Management of cow's milk allergy from an immunological perspective: What are the options? Nutrients 2019, 11, doi:10.3390/nu11112734.

35. Milkovska-Stamenova, S.; Hoffmann, R. Identification and quantification of bovine protein lactosylation sites in different milk products. Journal of Proteomics 2016, 134, 112-126, doi:10.1016/j.jprot.2015.07.021.

36. Donato, L.; Guyomarc'h, F. Formation and properties of the whey protein/א-casein complexes in heated skim milk - A review. Dairy Science and Technology 2009, 89, 3-29, doi:10.1051/dst:2008033.

37. Alexander, L.J.; Hayes, G.; Pearse, M.J.; Stewart, A.F.; Willis, I.M.; Mackinlay, A.G. Complete sequence of the bovine $\beta$-lactoglobulin cDNA. Nucleic Acids Res. 1989, 17, 6739, doi:10.1093/nar/17.16.6739.

38. Vetri, V.; Militello, V. Thermal induced conformational changes involved in the aggregation pathways of beta-lactoglobulin. Biophys. Chem. 2005, 113, 83-91, doi:10.1016/j.bpc.2004.07.042.

39. Van Boekel, M.A.J.S. Heat-induced deamidation, dephosphorylation and breakdown of caseinate. International Dairy Journal 1999, 9, 237-241, doi:10.1016/S0958-6946(99)00068-0.

40. Wada, Y.; Lönnerdal, B. Effects of Industrial Heating Processes of Milk-Based Enteral Formulas on SiteSpecific Protein Modifications and Their Relationship to in Vitro and in Vivo Protein Digestibility. Journal of Agricultural and Food Chemistry 2015, 63, 6787-6798, doi:10.1021/acs.jafc.5b02189. 
41. Bernard, H.; Meisel, H.; Creminon, C.; Wal, J.M. Post-translational phosphorylation affects the IgE binding capacity of caseins. FEBS Lett. 2000, 467, 239-244, doi:10.1016/S0014-5793(00)01164-9.

42. Egger, L.; Ménard, O.; Baumann, C.; Duerr, D.; Schlegel, P.; Stoll, P.; Vergères, G.; Dupont, D.; Portmann, R. Digestion of milk proteins: Comparing static and dynamic in vitro digestion systems with in vivo data. Food Research International 2019, 118, 32-39, doi:10.1016/j.foodres.2017.12.049.

43. Picariello, G.; Ferranti, P.; Fierro, O.; Mamone, G.; Caira, S.; Di Luccia, A.; Monica, S.; Addeo, F. Peptides surviving the simulated gastrointestinal digestion of milk proteins: Biological and toxicological implications. Journal of Chromatography B: Analytical Technologies in the Biomedical and Life Sciences 2010, 878, 295-308, doi:10.1016/j.jchromb.2009.11.033.

44. Gasparini, A.; Buhler, S.; Faccini, A.; Sforza, S.; Tedeschi, T. Thermally-induced lactosylation of whey proteins: Identification and synthesis of lactosylated $\beta$-lactoglobulin epitope. Molecules 2020, 25 , doi:10.3390/molecules25061294.

45. Ruiter, B.; Trégoat, V.; M'Rabet, L.; Garssen, J.; Bruijnzeel-Koomen, C.A.F.M.; Knol, E.F.; Van Hoffen, E. Characterization of T cell epitopes in $\alpha$ s1-casein in cow's milk allergic, atopic and non-atopic children. Clinical and Experimental Allergy 2006, 36, 303-310, doi:10.1111/j.1365-2222.2006.02436.x.

46. Elsayed, S.; Eriksen, J.; Øysæd, L.K.; Idsøe, R.; Hill, D.J. T cell recognition pattern of bovine milk $\alpha \mathrm{S} 1$ casein and its peptides. Mol. Immunol. 2004, 41, 1225-1234, doi:10.1016/j.molimm.2004.05.010.

47. Nakajima-Adachi, H.; Hachimura, S.; Ise, W.; Honma, K.; Nishiwaki, S.; Hirota, M.; Shimojo, N.; Katsuki, T.; Ametani, A.; Kohno, Y., et al. Determinant analysis of IgE and IgG4 antibodies and T cells specific for bovine alpha(s)1-casein from the same patients allergic to cow's milk: existence of alpha(s)1-caseinspecific B cells and T cells characteristic in cow's-milk allergy. The Journal of allergy and clinical immunology 1998, 101, 660-671, doi:10.1016/s0091-6749(98)70175-7.

48. Gouw, J.W.; Jo, J.; Meulenbroek, L.A.P.M.; Heijjer, T.S.; Kremer, E.; Sandalova, E.; Knulst, A.C.; Jeurink, P.V.; Garssen, J.; Rijnierse, A., et al. Identification of peptides with tolerogenic potential in a hydrolysed whey-based infant formula. Clinical and Experimental Allergy 2018, 48, 1345-1353, doi:10.1111/cea.13223.

49. Ilchmann, A.; Burgdorf, S.; Scheurer, S.; Waibler, Z.; Nagai, R.; Wellner, A.; Yamamoto, Y.; Yamamoto, H.; Henle, T.; Kurts, C., et al. Glycation of a food allergen by the Maillard reaction enhances its T-cell immunogenicity: Role of macrophage scavenger receptor class A type I and II. Journal of Allergy and Clinical Immunology 2010, 125, 175-183.e111, doi:10.1016/j.jaci.2009.08.013.

50. Xu, Q.; Hong, H.; Wu, J.; Yan, X. Bioavailability of bioactive peptides derived from food proteins across the intestinal epithelial membrane: A review. Trends in Food Science and Technology 2019, 86, 399-411, doi:10.1016/j.tifs.2019.02.050.

51. Reitsma, M.; Westerhout, J.; Wichers, H.J.; Wortelboer, H.M.; Verhoeckx, K.C.M. Protein transport across the small intestine in food allergy. Molecular Nutrition and Food Research 2014, 58, 194-205, doi:10.1002/mnfr.201300204.

52. Moradi, S.V.; Hussein, W.M.; Varamini, P.; Simerska, P.; Toth, I. Glycosylation, an effective synthetic strategy to improve the bioavailability of therapeutic peptides. Chem. Sci. 2016, 7, 2492-2500, doi:10.1039/c5sc04392a.

53. Varamini, P.; Mansfeld, F.M.; Blanchfield, J.T.; Wyse, B.D.; Smith, M.T.; Toth, I. Synthesis and biological evaluation of an orally active glycosylated endomorphin-1. J. Med. Chem. 2012, 55, 5859-5867, doi:10.1021/jm300418d.

54. Polt, R.; Porreca, F.; Szabò, L.Z.; Bilsky, E.J.; Davis, P.; Abbruscato, T.J.; Davis, T.P.; Horvath, R.; Yamamura, H.I.; Hruby, V.J. Glycopeptide enkephalin analogues produce analgesia in mice: Evidence for penetration of the blood-brain barrier. Proc. Natl. Acad. Sci. U. S. A. 1994, 91, 7114-7118, doi:10.1073/pnas.91.15.7114.

55. Zenker, H.E.; Ewaz, A.; Deng, Y.; Savelkoul, H.F.J.; Van Neerven, R.J.J.; De Jong, N.; Wichers, H.J.; Hettinga, K.A.; Teodorowicz, M. Differential effects of dry vs. Wet heating of $\beta$-lactoglobulin on formation of sRAGE binding ligands and sIgE epitope recognition. Nutrients 2019, 11, doi:10.3390/nu11061432.

56. Pinto, M.S.; Léonil, J.; Henry, G.; Cauty, C.; Carvalho, A.F.; Bouhallab, S. Heating and glycation of $\beta$ lactoglobulin and $\beta$-casein: Aggregation and in vitro digestion. Food Research International 2014, 55, 7076, doi:10.1016/j.foodres.2013.10.030. 



\section{Chapter 7}

General discussion 


\subsection{Project summary}

This thesis was part of a NWO-TTW project entitled: "Immunogenic Properties of Heated and Glycated Cow's Milk Protein - Effect on Initiation and Resolution of Cow's Milk Allergy" (short title "iAGE") that was divided in 4 work packages. The outcomes of work package 1 are described in this thesis, while an outline of the results from work package 2, work package 3, and work package 4 is presented below:

- Work package 2: immunological in vitro methods were developed to investigate the effect of heated milk protein (MP) on immunogenicity, including all immunoassays used in chapter 5 . Chapter 5 and chapter 3 describe the published outcomes of this work package.

- Work package 3: a product of heated and glycated cow's milk protein was developed by FrieslandCampina and included in the clinical trial.

- Work package 4: cow's milk allergic children were recruited in several children's hospitals all over the Netherlands and were challenged with the product developed in work package 3 if they showed an initial tolerance to baked milk. After repeated challenge with the product for a period between $8-23$ months, $73 \%$ of the children that were recruited at this time (26) tolerated the product without adverse effects. Eight children successfully introduced cow's milk in their diet.

\subsection{Background}

Thermal processing of cow's milk protein (MP) has previously been shown to result in both increased and decreased immunoreactivity of the protein. The consumption of dry-heated milk ("baked milk") accelerated the resolution of cow's milk allergy symptoms [1], whereas industrial heat treatments, as for instance applied in ultra high temperature (UHT) treated milk, appears to lead to pro-inflammatory immune responses [2]. The heating conditions of "baked milk" strongly differ from industrial heating processes in terms of heating load, water activity $\left(\mathrm{a}_{\mathrm{w}}\right)$, and reactant mobility. It is therefore considered that the structural modifications differ between the dry vs. wet heating and that the Maillard reaction (MR) is considerably higher in dry-heated MP due to the promoting effect of low $a_{w}$ on the MR [3]. All major MPs are considered to be potential allergens, however heat induced denaturation/aggregation may alter their immunogenicity and allergenicity. Next to this, advanced glycation end products (AGEs) resulting from the MR have been described as pro-inflammatory if formed endogenously but have also been described as potentially immunomodulatory if derived from exogenous sources [4,5]. The promoting role of dry heating on the formation of AGEs highlights the importance to investigate their potential role in modulating the immunological response towards dry-heated MP. However, it is not clear whether this is a distinctive effect of AGEs themselves or the accompanying protein aggregation. Moreover, aggregation as well as lysine blockage via the MR affects the digestibility of the MP [6,7]. If coming from exogenous sources, for instance after oral ingestion, protein digestion and thus the availability of 
immunoreactive structures in the gastrointestinal tract is an important determinant for potential immunological consequences. In the past, a higher resistance of a protein towards digestive enzymes has been linked to its allergenic potential. However, this opinion has been reconsidered as analytical approaches are lacking to establish a direct link between these two factors [8]. Nevertheless, that carry an immunoreactive structure, can give an indication of the immunomodulatory potential of the differentially treated cow's MP. The aim of this thesis was to investigate the structural changes that occur upon heating of MP and to combine these with digestion experiments as well as immuno-assays. This provides better insights in the role of heat- and glycation-induced changes on digestibility and immunoreactivity.

\subsection{Structural modifications of cow's MP upon wet vs. dry heating}

Chapter 2 showed that casein and whey protein (WP) in mixture loses solubility upon heat treatment under dry conditions at both low temperature (LT) and high temperature (HT), indicating severe structural changes of the protein. The main component of the insoluble fraction was casein, which has previously been suggested to be a result of loss of electrostatic repulsion [9] as well as inter- and intramolecular interactions e.g. the MR [10-12]. As shown in chapter 2, not only the MR but also other inter- and intramolecular interactions promote the loss of solubility (Figure 2.3). Nevertheless, HT heating resulted in relatively more (MR-induced) covalent crosslinking as well as aggregation compared to LT heating, pointing out the role of (MR-induced) covalent crosslinking in loss of solubility and protein aggregation in this model system (Figure 2.2 and Figure 2.5). However, a limitation of the study in chapter 2 was that the large loss of solubility upon dry heating of casein and WP in mixture did not allow a more extensive investigation of the 3D-changes of the proteins. Therefore chapter 3 used isolated $\beta$-lactoglobulin (BLG) to monitor structural changes and the possible immunological consequences induced by differential heating conditions. Chapter 3 showed that under dry heating conditions aggregation is promoted by the presence of lactose (Figure 3.1), which was also observed by Cardoso et al. [13]. In contrast, aggregation of BLG heated in solution was independent from the presence of lactose. Chapter 3-5 showed that both dry and wet heating of isolated BLG also results in increased hydrophobicity and formation of $\beta$-sheet structures. Both, aggregation and increased hydrophobicity of heated and glycated BLG has previously been shown to increase uptake by THP1-macrophages and thus possibly modulate immunological responses [14]. Moreover, Roth-Walter et al. [2] showed that pasteurisation-induced aggregation of BLG enhanced the uptake via Peyer's patches in mice and promotes the Th2 pathway. Nevertheless, it should be noted that upon wet heating in the presence of casein micelles and $\alpha$-lactalbumin, BLG interacts with these proteins [15]. The findings of chapter 2 , however, indicated that the formation of the $\kappa$-casein/BLG complex on the casein micelle, does not occur upon dry heating of MP (Figure 2.3 and Figure 2.5) and that dry heating of MP in mixture rather promotes changes of the protein structure via other inter- and intramolecular interactions, possibly due to the decreased reactant's mobility. This 
suggested that changes of protein-protein interactions when comparing dry vs. wet heating could also result in the formation of different immunoreactive structures.

Next to the changes of the 3D-structure of the protein, the level of $\mathrm{N}^{\varepsilon}$-carboxymethyllysine (CML) as well as the abundance of other glycation structures was higher in dry-heated BLG compared to wet heated samples and increased depending on the heating temperature (Table 3.3). This was expected as low $a_{w}$-levels and high temperatures promote the MR [3]. High levels of AGEs could affect the immunogenicity of MP as several cell surface receptors on antigen presenting cells (APCs) have been described as receptors for AGEs indicating a potential role of the MR in inflammation [16]. In summary, the findings on structural modifications of BLG upon dry heating showed increased hydrophobicity and aggregation while the level of MR differed depending on the heating conditions. Moreover, dry heating of the mixture of protein resulted in different intermolecular interactions compared to heating in solution (chapter 2). The observed structural changes e.g. formation of AGEs and aggregation can possibly affect protein immunogenicity and allergenicity. However, the two determinants need to be disentangled to better understand their role in sensitisation or resolution of allergic symptoms to cow's milk.

\subsection{The effect of aggregation vs. MR on allergenicity and immunoreactivity}

One of the hypotheses underlying this thesis was that heat-induced modifications of the protein structure, and amongst those especially the formation of AGEs, is responsible for the acceleration of cow's milk allergy resolution. Chapter 3 showed that both aggregation and the presence of AGEs can affect immunogenicity and allergenicity of MP. Moreover, it was demonstrated that allergenicity was affected by both aggregation and glycation. Previous studies showed, that aggregation decreases Immunoglobulin E (IgE) binding of WPs after heating at $>80^{\circ} \mathrm{C}$ in solution [17]. In contrast, IgE binding to casein remained unchanged when heated in solution at $90{ }^{\circ} \mathrm{C}$ for $60 \mathrm{~min}$, which is possibly related to their higher heat stability and higher abundance of linear epitopes rather than conformational epitopes $[18,19]$. Next to aggregation, high levels of MR can have a masking effect on both, linear and conformational epitopes. However, literature looking at the effect of either aggregation or glycation in relation to changes in allergenicity is limited, as the reaction conditions for AGE formation during the MR also facilitate protein aggregation, and even MR itself promotes aggregation [13]. Chapter 3, aimed to disentangle the effect of aggregation and glycation of IgE binding to BLG, however high individual differences (Figure 3.7) did not allow a distinction between the two factors or a conclusion regarding the general direction given by either one of these determinants.

Next to this, chapter 3 and 5 also showed that when BLG was heated in solution, protein aggregation appeared to be the crucial determinant for binding of BLG to AGE receptors. However, both chapters also showed that glycation still has an additional promoting effect on AGE receptor binding (Figure 3.5 and Figure 5.2), which could also be related to slightly higher exposure of hydrophobic structures and $\beta$-sheet structures as shown in chapter 4 and chapter 5 
(Figure 4.2 and Figure 5.1). A previous study by Pinto et al. [6] reported different morphology of wet heating induced aggregates of BLG depending on the presence of sugars, which possibly explains these observations. Similarly, dry heating of BLG at both LT $\left(60^{\circ} \mathrm{C}\right)$ and HT $\left(130^{\circ} \mathrm{C}\right)$ heating resulted in increased binding to AGE receptors, however in this case binding only occurred to a minimal extent in the absence of lactose. Similarly, also aggregation occurred to a much higher extend when lactose was present during dry heating. Deng et al. [14] previously showed that aggregation is an important determinant for the receptor mediated uptake of heated and glycated BLG by THP1-macrophages. However, also the presence of AGEs has been described in relation to inflammatory health implications and it has been reported that AGEs are ligands for AGE receptors expressed on antigen presenting cells such as the receptor for advanced glycation end products (RAGE), galectin-3 (Gal-3), and scavenger receptor class A type I and II $[4,20]$. In chapter 3, the presence of CML was observed on only some of the protein structures in the western blot that were recognised by the soluble form of RAGE (sRAGE) (Figure 3.6) but could not directly be proven in all structures that showed binding to sRAGE (Figure 3.3). Therefore chapter 4, aimed to understand the role of protein-bound CML in binding to AGE receptors. It was shown that such protein-bound CML is indeed a ligand for the three receptors for AGEs: sRAGE, Gal-3, and CD36 (Figure 4.5). Next to this, chapter 4 showed that the negative charge induced to the lysine residue via modification to CML is an important determinant for the binding to all tested receptors, which was evaluated by changing the concentration of sodium chloride in the ELISA assay (Figure 4.6). The presence of CML on peptides can also result in binding to sRAGE indicating that even after digestion, high initial levels of CML can still modulate the immunological response [21]. At the same time, AGE ligands formed due to aggregation and hydrophobicity may (partly or completely) lose their ability to bind to AGE receptors after gastrointestinal digestion, as conformational epitopes are easier destroyed upon digestion.

\subsection{Effect of heating and glycation on protein digestion and immunological consequences}

During gastrointestinal digestion, proteins are hydrolysed into peptides and amino acids. Heat treatment of MP can affect their digestibility depending on the structural modifications that occurred during heating [22]. While denaturation increases the accessibility for digestive enzymes, aggregation and side modifications of specific amino acids can reduce enzymatic hydrolysis [23]. In chapter 2, the effects of LT heating and HT heating of MP on infant in vitro digestion were investigated. The results showed that dry heating at HT impaired overall digestibility (Figure 2.7), especially due to decreased tryptic hydrolysis (supplementary material: Figure 2-S2). This indicated that MR is an important determinant for digestibility of HT heated MP (HT-MP) as trypsin specifically cleaves after lysine residues [24].

Moreover, chapter 2 showed that aggregated proteins are released from the insoluble material upon gastric digestion and eventually enter the small intestine, thus possibly becoming available 
to the immune system (Figure 2.8). Already after $10 \mathrm{~min}$ in the intestinal phase (IP) these aggregates are hydrolysed to smaller structures, that however persist until $60 \mathrm{~min}$ in the IP (Figure 2.10). Although there is no direct link between resistance of a protein to digestion and its potential to act as an antigen, it is hypothesised that the longer survival of immunoreactive structures during digestion could affect the immunological response. This was also addressed in chapter 5 where the binding of heated and glycated BLG before and after simulated infant in vitro digestion was compared. Chapter 5 showed, that binding to the AGE receptor of BLG hydrolysates is decreased compared to undigested wet heated and in-solution glycated BLG (Figure 5.2). However, the hydrolysate of glycated BLG still showed binding to sRAGE and Gal-3 after gastrointestinal digestion (Figure 5.6), which is possibly related to a higher resistance to hydrolysis of glycation-induced BLG aggregates compared to heat-induced BLG aggregates [6]. Similar observations were also made by Liu et al. [25] who still observed binding of HT dry-heated BLG to sRAGE after simulated infant in vitro digestion. However, immunoreactivity and aggregation behaviour may change when MPs are present in mixture. For example, a study of Bogahawaththa et. al. [26] showed that the production of interleukin (IL)-10, IL17A, and interferon- $\gamma$ in human PBMCs is significantly decreased after exposure to unheated MP as a mixture compared to isolated proteins. Moreover, the presence of casein can decrease aggregation of BLG and results in the formation of the $\kappa$-casein/ BLG complex on the micelle surface when heated in solution $[15,27]$. The findings of chapter 2 did not indicate the same protein-protein interactions upon dry heating as observed during wet heating. Moreover, BLG aggregation upon dry heating in the mixture with casein was limited compared to the extent of aggregation for HT dry-heated isolated BLG (Figure 2.3 and Figure 3.1). This indicated that if WP is heated together with casein aggregates of different morphology and composition are formed. These aggregates might show differential digestibility if applied to in vitro digestion and survival in the IP, which can result in a dissimilar immunological response compared to aggregates formed upon heating of isolated protein.

This was also indicated by the results from the ELISA binding assays performed to assess the binding of sRAGE, CD36, and Gal-3 to digested non-treated MP (NT-MP), LT heated MP (LT-MP), and HT-MP (Figure 7.1), which showed that binding of all three receptors was high directly after the GP and was strongly decreased after the IP. All receptors showed higher binding to HT-MP in the GP compared to NT-MP and LT-MP, which is possibly related to the aggregates observed after $60 \mathrm{~min}$ in the GP on sodium dodecyl sulphate gel electrophoresis (SDS-PAGE) (Figure 2.8) and scanning electron microscopy images (Figure 2.10). In the IP, binding was lower to HT-MP compared to NT-MP for CD36 and sRAGE suggesting that with further hydrolysis of these aggregates their immunoreactive potential decreases. 
a

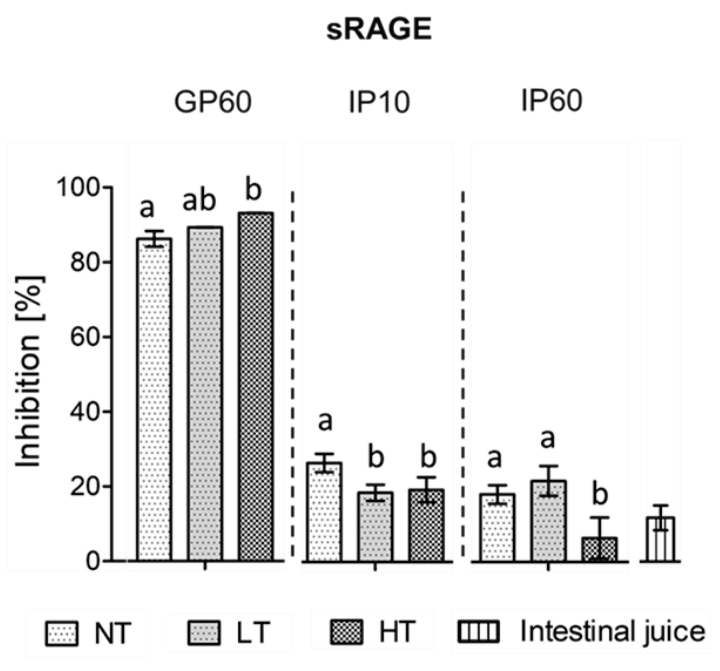

b

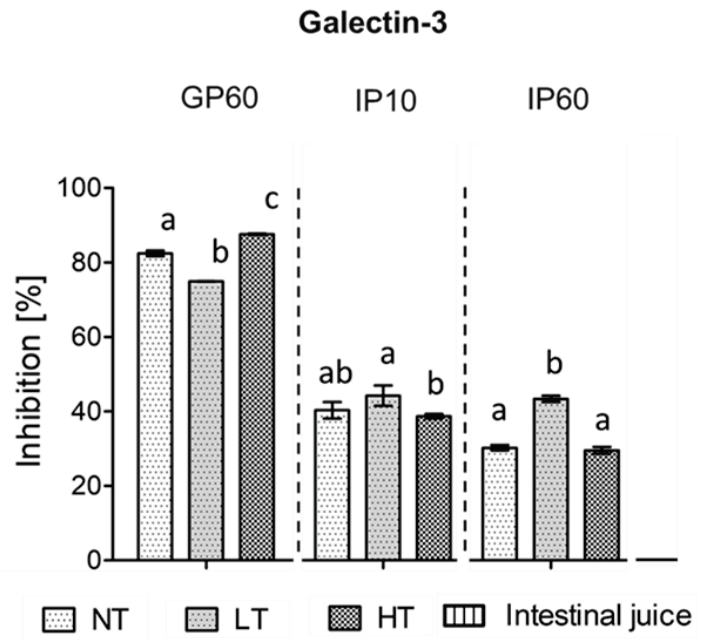

C

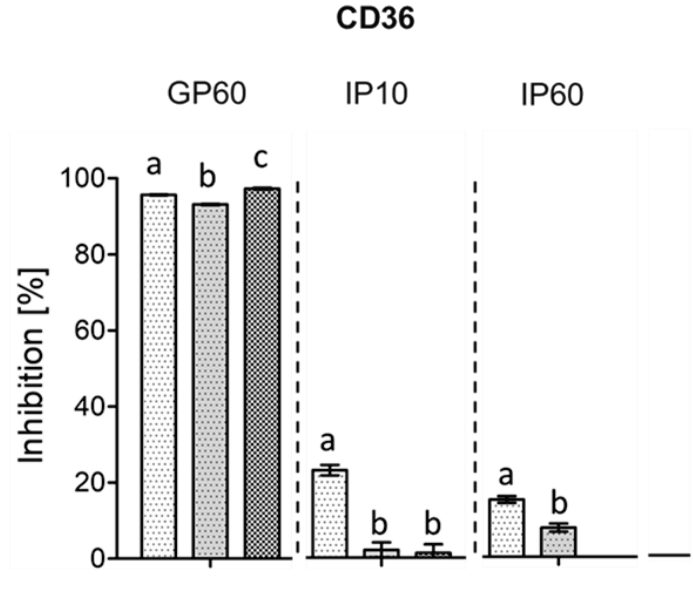

Figure 7.1: Binding of (a) sRAGE, (b) galectin-3, and (c) CD36 to simulated infant in vitro digests of cow's milk protein, non-treated (NT), heated at low temperature (LT), and heated at high temperature (HT) after $60 \mathrm{~min}$ in the gastric phase (GP60), $10 \mathrm{~min}$ in the intestinal phase (IP10), and $60 \mathrm{~min}$ in the intestinal phase (IP60) at $100 \mu \mathrm{g}$ protein $/ \mathrm{mL}$. Statistically significant differences of technical replicates between samples of different heat treatments at the same sampling point of digestion are indicated by different letters within the sample sets with $\mathrm{p}<0.05$ ( $\mathrm{n}=2$ for GP60 and $\mathrm{n}=3$ for IP10 and IP60). Statistically significant differences were tested using one-way ANOVA (SPSS) with Tukey post hoc test.

Interestingly, the relative higher proportion of larger particles observed in the IP for HT-MP did not affect binding to the receptors for AGEs. A recent study showed for the example of macrophage uptake, that not only aggregation but also hydrophobicity played a role in the response of the innate immune system to heated MPs [14]. However, sample-dependent differences in hydrophobicity (Figure 7.2) could explain the higher binding when comparing GP with IP but did not explain differences between heat-treatments. 
GP60

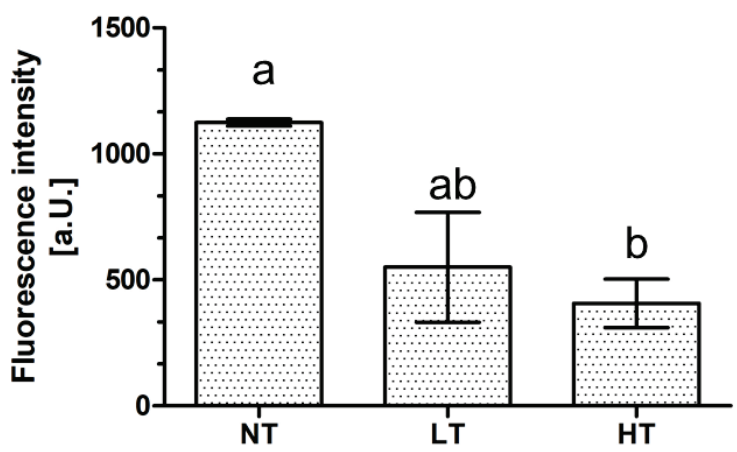

b

IP10

C

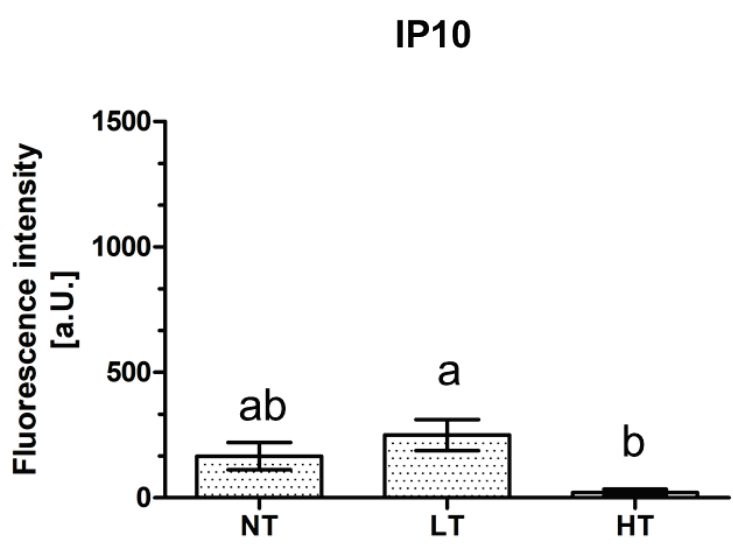

IP60

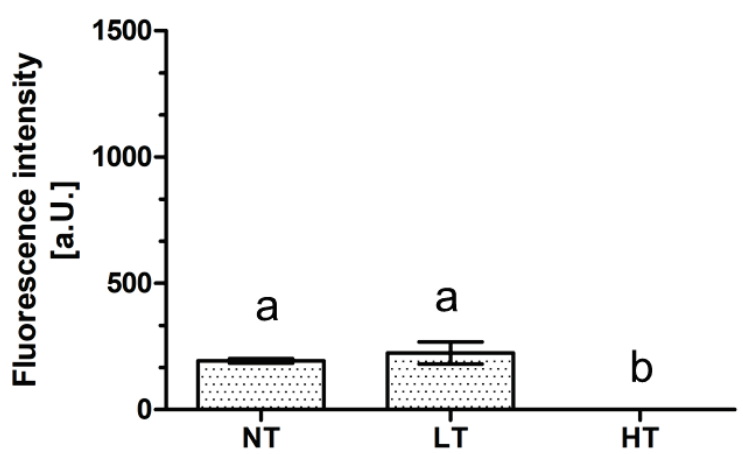

Figure 7.2: ANS-assay on cow's milk protein non-treated (NT), heated at low temperature (LT), and heated at high temperature (HT), applied to an infant in vitro digestion and sampled after $60 \mathrm{~min}$ in the gastric phase (a), $10 \mathrm{~min}$ in the intestinal phase (b) and $60 \mathrm{~min}$ in the intestinal phase (c). Error bars represent standard deviation of technical duplicates. Statistically significant differences were tested using one-way ANOVA (SPSS) with Tukey post hoc test and were considered as significantly different at $\mathrm{p}<0.05$, where two variables have different letters if they are significantly different.

Moreover, the higher residual immunoreactivity as shown for glycation-induced aggregates of wet heated BLG after gastrointestinal digestion was not observed for aggregates formed after dry heating in a mixture of casein and WPs. With respect to the different $\mathrm{a}_{\mathrm{w}}$-level of these two systems, it has been shown that WPs, dry-heated at $130^{\circ} \mathrm{C}$, preserve residual binding of sRAGE after gastrointestinal in vitro digestion [25]. It is thus hypothesised, that residual binding to AGE receptors after in vitro digestion is not only related to differential aggregation behaviour comparing dry vs. wet heating but also to the presence of other proteins during heating and in vitro digestion. These findings as well as the findings of chapter 5 indicate, that recognition of heated and glycated MP by APCs is strongly affected by the enzymatic hydrolysis in the gastrointestinal tract and that the resistance of initially present immunoreactive structures to digestion could be a crucial determinant for the immunoreactivity in vivo. However, it remains unknown which factors resulted in the differential binding of these specific receptors to heated and unheated casein and WP in mixture after in vitro digestion. As neither hydrophobicity nor 
relative proportion of aggregates after intestinal digestion could be related to the differences in AGE receptor binding between samples, it is hypothesised that peptides might as well play a role.

\subsection{Peptide patterns and their potential relevance in predicting immunological effects}

The two major MP fractions show different susceptibility to gastric and intestinal digestion, which is related to their natural structure. WPs are relatively resistant to gastric digestion but rapidly hydrolysed upon intestinal digestion, while caseins are hydrolysed to larger peptides upon gastric digestion and show a slower hydrolysis in the IP compared to WPs [28,29]. As reviewed by Bogahawaththa et al. [26], it was suggested that caseins contain relatively more linear IgE epitopes than conformational epitopes. Linear epitopes would still be recognised on the peptide level, while conformational IgE binding epitopes are easier destroyed upon digestion. It is thus hypothesised that a longer persistence of peptides in the gastrointestinal tract can also affect the immunological response if these peptides carry immunoreactive structures. Extensive glycation can decrease IgE binding due to a masking effect on linear as well as conformational epitopes and can also affect the recognition of peptides by AGE receptors [21,26]. Therefore, a higher level of glycated digestion-derived peptides may also alter the immunological response towards digested MP.

In chapter 4, it was demonstrated that HT-MP showed the highest percentage of glycated peptides after $10 \mathrm{~min}$ in the IP (Figure 6.1). Moreover, it was confirmed that these glycated peptides were able to pass through a Caco-2 cell monolayer (Figure 6.5), thus suggesting that they are accessible for immune cells in the lamina propria. Xue et al. [21] demonstrated that the modification of the synthetic peptides FKDLGEE and DEFKADE with CML and $\mathrm{N}^{\varepsilon}$-carboxyethyllysine increases their binding to sRAGE compared to the non-modified form. This shows that for these specific modifications and peptide sequences, the MR can be a crucial determinant of the cellular response even on the peptide level. Moreover, it highlights the importance to gain more insights into the peptide patterns and post translational modifications of the peptides formed upon digestion of differentially heated MP. It should be noted that the concentrations of these peptides are often too low to show a significant change in receptor binding. However, the role of other MR products has not been investigated and it could be hypothesised that an increasing total concentration of peptides carrying any MR products with similar properties, such as a negative charge (chapter 4), could also show physiologically relevant binding to AGE receptors. Although receptor binding to the in vitro digest was tested (Figure 7.1), it does not allow any conclusion to underline this hypothesis, as quantification of the glycated peptides was not possible and interfering substrates, such as protein aggregates and substrates of the intestinal juice, are present in the digests.

Changes of peptide patterns upon digestion of differentially heated cow's milk and dairy products has been the subject of a number of studies [7,30-35]. The prediction of the immunological consequences in relation to digestion-derived peptides is however still 
challenging. Nevertheless, the screening of linear IgE binding and T-cell binding epitopes in the in vitro digest, in combination with their availability to the immune system in the gastrointestinal tract, can indicate the potential of a specific heat treatment to modulate immunoreactivity. Chapter 6 , demonstrated that after $10 \mathrm{~min}$ in the IP more IgE binding epitopes are found in NT-MP compared to dry-heated samples. This has previously been demonstrated by Picariello et al. [36] who observed that the peptides derived from BLG (f127-135), which showed remarkable resistance upon in vitro digestion and trans-epithelial translocation, were also recognised by IgE of allergic patients. Next to this, chapter 6 also demonstrated that the majority of specific $\operatorname{IgE}$ ( $\operatorname{sgE}$ ) binding epitopes and T-cell epitopes found in dry-heated samples were glycated. It was suggested by Gasparini et al. [37] that lactosylation could have an effect on binding to linear sIgE epitopes, however studies that directly show an effect of glycation on either sIgE or T-cell epitope binding are limited. Moreover, the transport of epitopes across the Caco-2 cell monolayer was limited, which suggested that other transport pathways, such as direct sampling via dendritic cells or translocation via microfold cells (M-cells) could play a pivotal role in availability of immunoreactive digestion-derived peptides.

\subsection{Transport of peptides across the Caco-2 cell monolayer}

The passage of the intestinal epithelial barrier is important to make the antigen available for APCs in the lamina propria. Moreover, the form in which an antigen is presented to the immune system, after heat induced modifications and enzymatic hydrolysis upon digestion, is crucial for the immunological response. In chapter 6 , it was demonstrated that peptides of a length up to 24 amino acids, including glycated peptides, were able to pass through a Caco-2 cell monolayer. Although it is not clear whether the transport of glycated peptides occurs in immunological relevant dosages, the proof that they are able to pass the epithelial layer gives first insights and points out the relevance of further studies. It also has to be noted that next to epithelial cells, direct sampling as well as the uptake via M-cells and the Peyer's Patches (Figure 1.2) has a pivotal role in the subsequent immunological reaction cascade. Roth-Walter et al. [2] showed that UHT-treated BLG is preferably taken up via Peyer's Patches, thus pointing out the importance of studying different uptake routes. Moreover, Deng et al. [22] demonstrated that heated and glycated BLG can pass through the Caco- 2 cell monolayer, pointing out that also the digestion persistent aggregates could be accessible for the immune system in the lamina propria. Next to this, allergic sensitisation can also result in increased permeability in the intestine ("leaky gut") which might increase the uptake of specific peptides and larger particles that can possibly affect the immunological response to the digested protein. Further studies, with both intact proteins but also their digestion-derived peptides, including also studies on different transport mechanisms, would improve the knowledge on the effects of heat treatment on immunoreactivity of cow's MP. 


\subsection{Immunological consequences of dietary derived AGE ligand interaction with AGE receptors}

Chapter 5 showed that due to a higher resistance of glycated aggregates of BLG to simulated infant in vitro digestion, they maintain their binding ability to sRAGE and Gal-3 (Figure 5.6). Both sRAGE and Gal-3 play a role in inflammation. With respect to AGEs as ligands, this has mostly been described in relation with high serum levels of AGEs, however so far little was known on whether binding occurs to diet-derived AGEs and how APCs process the antigen after recognition. Chapter 5 showed that Gal-3 mediates internalisation of glycated BLG, whereas RAGE only showed binding but no involvement in the internalisation of glycated BLG (Figure 5.4). This indicated a differential role of the two receptors in allergic sensitisation to glycated MPs. However, it remains to be further investigated whether the binding to these receptors will result in a pro- or an anti-inflammatory response. Previous studies showed that receptor mediated recognition and uptake by APCs is a key point for cytokine expression in subsequent $\mathrm{T}$-cell cocultures resulting in the increased expression of either pro- or anti-inflammatory cytokines [38-42]. Perusko et al. [38] suggested that the intercellular fate of BLG affects cytokine expression, where faster degradation results in lower expression of pro-inflammatory cytokines. However, as shown in chapter 3 and 5, differential treatment of BLG results in different ligands for AGE receptors and thus possibly modulates the uptake via ACPs and the immunological response. Moreover, the sensitisation pathway may affect the cellular response after re-exposure to the antigen or its thermally modulated form. The exposure to "baked milk" normally occurs in the already sensitised patient, highlighting the importance of further investigations of the immunomodulatory properties of heat induced structural modifications to pre-exposed APCs. As the immune system of infants still develops, infant formulas generally experience intensive heat treatment to ensure a safe consumption. This treatment as well as the high content of lactose results in relatively higher levels of MR products compared to most other dairy products [43]. This suggests that sensitisation may already occur against glycated MPs. However, the heating conditions strongly differ from the ones applied in "baked milk" products. Therefore, the structure of the heat-modulated proteins may not be comparable to the one in commercially available infant formula and results in a differential immune response. One of the hypothesise of the iAGE-project was that children that are able to consume baked milk are sensitised to conformational epitopes which are destroyed upon dry heating of the MP, either via protein aggregation or by the masking effect of the MR. A role of 3D-modification as well as the MR was shown in this thesis (chapter 3-5). However, data also suggested that the role of 3D-modifications decreases when the MP is applied to simulated infant in vitro digestion. It was thus hypothesised that digestion-derived peptides carrying a immunoreactive structure could play a role in tolerance to "baked milk" and that MR-induced modifications on the peptide level could also be a determinant in the resolution of cow's milk allergy symptoms upon "baked milk" consumption (chapter 6). 


\subsection{Overall conclusions}

In summary, the research presented in this thesis showed that heat-induced changes of the protein structure affect digestibility and immunoreactivity of cow's MPs. The applied heat treatment (dry vs. wet and LT vs. HT) is a crucial determinant for the generation of structural modification of MP that can affect their digestibility, immunoreactivity, and allergenicity. In addition, it was demonstrated that the presence of specific AGEs can modulate binding to the receptors of AGEs by adding an additional negative charge to the modified amino acids. This also indicates that any other amino acid side chain modification that has comparable properties could possibly result in similar effects. However, it was also shown that next to the presence of AGEs, hydrophobicity and aggregation play a pivotal role in modulating the immunological response towards MPs. The persistence of these immunoreactive structures upon enzymatic hydrolysis as shown on the example of aggregated BLG can still induce an immunological response after in vitro digestion. This highlights the importance of combining digestion experiments with immuno-assays to better judge the physiological relevance of heat-induced structural changes. Next to the persistence of immunoreactive aggregates upon digestion also the release of potentially immunoreactive peptides could modulate the immunological response. It was shown that glycated peptides were able to cross the Caco- 2 cell monolayer and thus are possibly accessible for the immune system. The quantities in which these peptides arrive at the basolateral side might be crucial for the immunological response to these peptides. Overall, the findings of this thesis indicate that the immunological response can be manipulated depending on the chosen heating conditions. 


\subsection{Future perspectives}

This thesis demonstrated that CML-modified BLG is a potent ligand for the receptors for AGEs and that peptides carrying a CML modification are able to pass the epithelial barrier. However, further studies would be needed that include quantitative data of the glycated peptides that are transported across this barrier. This could, for example, be achieved using isotopic labelling which can display statistical significant differences already at small differences, while label free approaches less repeatable and thus not suitable for comparison of samples with only little differences [44]. The most accurate option would be the use of a synthetic peptide as MR-induced modifications of peptides can largely affect the ionisation of the peptide and thus the signal intensity. This is however difficult to obtain for each peptide and including every possible modification.

Next to the limitations of a quantitative analysis of glycated peptides, it is also still a debate whether or not the site modifications of a peptide by MR would affect the functionality of an sIgE-binding or T-cell epitope. Therefore, testing of specific peptides in modified vs. non-modified form in immunological assays would strongly improve the understanding of the role of the MR on the peptide level. Gaining more insights in the quantities of these peptides and the threshold at which they possibly induce an immunological response is an important factor to determine at which level the MR is able to stimulate immunological responses after in vitro digestion.

Chapter 5 showed that heated and glycated BLG is take up by APCs, however, further studies on DC-T-cell interaction would be needed to understand whether the receptor mediated recognition and internalisation of glycated aggregates of BLG would result in a pro- or anti-inflammatory immunological response. Moreover, an extension of this research to the effect of dry heating on isolated BLG that, as shown in chapter 3, results in the formation of different sRAGE ligands compared to wet heated BLG, would help to understand the role of dry heating in general.

Finally, immunological assays should be extended to WPs and caseins in a mixture, to stepwise develop the model system towards the situation in "baked milk" as both MP fractions can induce immunological responses and influence the aggregation behaviour and digestion kinetics of each other. Knowing the underlying immunological mechanisms and the structural modifications on both MP fractions will help to develop dry-heated MP products (i.e. "baked milk"). 


\section{References}

1. Kim, J.S.; Nowak-Wgrzyn, A.; Sicherer, S.H.; Noone, S.; Moshier, E.L.; Sampson, H.A. Dietary baked milk accelerates the resolution of cow's milk allergy in children. Journal of Allergy and Clinical Immunology 2011, 128, 125-131.e122, doi:10.1016/j.jaci.2011.04.036.

2. Roth-Walter, F.; Berin, M.C.; Arnaboldi, P.; Escalante, C.R.; Dahan, S.; Rauch, J.; Jensen-Jarolim, E.; Mayer, L. Pasteurization of milk proteins promotes allergic sensitization by enhancing uptake through Peyer's patches. Allergy: European Journal of Allergy and Clinical Immunology 2008, 63, 882-890, doi:10.1111/j.1398-9995.2008.01673.x.

3. Van Boekel, M.A.J.S. Effect of heating on Maillard reactions in milk. Food Chemistry 1998, 62, 403-414, doi:10.1016/s0308-8146(98)00075-2.

4. Uribarri, J.; del Castillo, M.D.; de la Maza, M.P.; Filip, R.; Gugliucci, A.; Luevano-Contreras, C.; MacíasCervantes, M.H.; Markowicz Bastos, D.H.; Medrano, A.; Menini, T., et al. Dietary advanced glycation end products and their role in health and disease. Advances in Nutrition 2015, 6, 461-473, doi:10.3945/an.115.008433.

5. Uribarri, J.; Cai, W.; Sandu, O.; Peppa, M.; Goldberg, T.; Vlassara, H. Diet-derived advanced glycation end products are major contributors to the body's AGE pool and induce inflammation in healthy subjects. In Annals of the New York Academy of Sciences, New York Academy of Sciences: 2005; Vol. 1043, pp 461466.

6. Pinto, M.S.; Léonil, J.; Henry, G.; Cauty, C.; Carvalho, A.F.; Bouhallab, S. Heating and glycation of $\beta$ lactoglobulin and $\beta$-casein: Aggregation and in vitro digestion. Food Research International 2014, 55, 70 76, doi:10.1016/j.foodres.2013.10.030.

7. Zenker, H.E.; Van Lieshout, G.A.A.; Van Gool, M.P.; Bragt, M.C.E.; Hettinga, K.A. Lysine blockage of milk proteins in infant formula impairs overall protein digestibility and peptide release. Food and Function 2020, 11, 358-369, doi:10.1039/c9fo02097g.

8. Verhoeckx, K.; Bøgh, K.L.; Dupont, D.; Egger, L.; Gadermaier, G.; Larré, C.; Mackie, A.; Menard, O.; Adel-Patient, K.; Picariello, G., et al. The relevance of a digestibility evaluation in the allergenicity risk assessment of novel proteins. Opinion of a joint initiative of COST action ImpARAS and COST action INFOGEST. Food and Chemical Toxicology 2019, 129, 405-423, doi:10.1016/j.fct.2019.04.052.

9. Gazi, I.; Huppertz, T. Influence of protein content and storage conditions on the solubility of caseins and whey proteins in milk protein concentrates. International Dairy Journal 2015, 46, 22-30, doi:10.1016/j.idairyj.2014.09.009.

10. Fan, F.; Liu, M.; Shi, P.; Xu, X.; Lu, W.; Wang, Z.; Du, M. Protein cross-linking and the Maillard reaction decrease the solubility of milk protein concentrates. Food Science and Nutrition 2018, 6, 1196-1203, doi:10.1002/fsn3.657.

11. Le, T.T.; Bhandari, B.; Holland, J.W.; Deeth, H.C. Maillard reaction and protein cross-linking in relation to the solubility of milk powders. Journal of Agricultural and Food Chemistry 2011, 59, 12473-12479, doi:10.1021/jf203460z.

12. Le, T.T.; Holland, J.W.; Bhandari, B.; Alewood, P.F.; Deeth, H.C. Direct evidence for the role of Maillard reaction products in protein cross-linking in milk powder during storage. International Dairy Journal 2013, 31, 83-91, doi:10.1016/j.idairyj.2013.02.013.

13. Cardoso, H.B.; Wierenga, P.A.; Gruppen, H.; Schols, H.A. Maillard induced aggregation of individual milk proteins and interactions involved. Food Chemistry 2019, 276, 652-661, doi:10.1016/j.foodchem.2018.10.061.

14. Deng, Y.; Govers, C.; Bastiaan-Net, S.; van der Hulst, N.; Hettinga, K.; Wichers, H.J. Hydrophobicity and aggregation, but not glycation, are key determinants for uptake of thermally processed $\beta$-lactoglobulin by THP-1 macrophages. Food Research International 2019, 120, 102-113, doi:10.1016/j.foodres.2019.01.038.

15. Donato, L.; Guyomarc'h, F. Formation and properties of the whey protein/ $\kappa$-casein complexes in heated skim milk - A review. Dairy Science and Technology 2009, 89, 3-29, doi:10.1051/dst:2008033.

16. Teodorowicz, M.; Van Neerven, J.; Savelkoul, H. Food processing: The influence of the maillard reaction on immunogenicity and allergenicity of food proteins. Nutrients 2017, 9, doi:10.3390/nu9080835.

17. Bu, G.; Luo, Y.; Zheng, Z.; Zheng, H. Effect of heat treatment on the antigenicity of bovine $\alpha$-lactalbumin and $\beta$-lactoglobulin in whey protein isolate. Food and Agricultural Immunology 2009, 20, 195-206, doi:10.1080/09540100903026116.

18. Bloom, K.A.; Huang, F.R.; Bencharitiwong, R.; Bardina, L.; Ross, A.; Sampson, H.A.; Nowak-Wegrzyn, A. Effect of heat treatment on milk and egg proteins allergenicity. Pediatric Allergy and Immunology 2014, 25, 740-746, doi:10.1111/pai.12283.

19. Clare Mills, E.N.; Sancho, A.I.; Rigby, N.M.; Jenkins, J.A.; Mackie, A.R. Impact of food processing on the structural and allergenic properties of food allergens. Molecular Nutrition and Food Research 2009, 53, 963-969, doi:10.1002/mnfr.200800236. 
20. Teodorowicz, M.; Hendriks, W.H.; Wichers, H.J.; Savelkoul, H.F.J. Immunomodulation by processed animal feed: The role of maillard reaction products and advanced glycation end-products (AGEs). Frontiers in Immunology 2018, 9, doi:10.3389/fimmu.2018.02088.

21. Xue, J.; Rai, V.; Singer, D.; Chabierski, S.; Xie, J.; Reverdatto, S.; Burz, D.S.; Schmidt, A.M.; Hoffmann, R.; Shekhtman, A. Advanced glycation end product recognition by the receptor for AGEs. Structure 2011, 19, 722-732, doi:10.1016/j.str.2011.02.013.

22. Deng, Y.; Govers, C.; Tomassen, M.; Hettinga, K.; Wichers, H.J. Heat treatment of $\beta$-lactoglobulin affects its digestion and translocation in the upper digestive tract. Food Chemistry 2020, 330, doi:10.1016/j.foodchem.2020.127184.

23. van Lieshout, G.A.A.; Lambers, T.T.; Bragt, M.C.E.; Hettinga, K.A. How processing may affect milk protein digestion and overall physiological outcomes: A systematic review. Critical reviews in food science and nutrition 2019, 10.1080/10408398.2019.1646703, doi:10.1080/10408398.2019.1646703.

24. Olsen, J.V.; Ong, S.E.; Mann, M. Trypsin cleaves exclusively C-terminal to arginine and lysine residues. Molecular and Cellular Proteomics 2004, 3, 608-614, doi:10.1074/mcp.T400003-MCP200.

25. Liu, F.; Teodorowicz, M.; Wichers, H.J.; Van Boekel, M.A.J.S.; Hettinga, K.A. Generation of Soluble Advanced Glycation End Products Receptor (sRAGE)-Binding Ligands during Extensive Heat Treatment of Whey Protein/Lactose Mixtures Is Dependent on Glycation and Aggregation. Journal of Agricultural and Food Chemistry 2016, 64, 6477-6486, doi:10.1021/acs.jafc.6b02674.

26. Bogahawaththa, D.; Chandrapala, J.; Vasiljevic, T. Modulation of milk immunogenicity by thermal processing. International Dairy Journal 2017, 69, 23-32, doi:10.1016/j.idairyj.2017.01.010.

27. Yong, Y.H.; Foegeding, E.A. Effects of caseins on thermal stability of bovine $\beta$-lactoglobulin. Journal of Agricultural and Food Chemistry 2008, 56, 10352-10358, doi:10.1021/jf801658u.

28. Sanchón, J.; Fernández-Tomé, S.; Miralles, B.; Hernández-Ledesma, B.; Tomé, D.; Gaudichon, C.; Recio, I. Protein degradation and peptide release from milk proteins in human jejunum. Comparison with in vitro gastrointestinal simulation. Food Chemistry 2018, 239, 486-494, doi:10.1016/j.foodchem.2017.06.134.

29. Boutrou, R.; Gaudichon, C.; Dupont, D.; Jardin, J.; Airinei, G.; Marsset-Baglieri, A.; Benamouzig, R.; Tomé, D.; Leonil, J. Sequential release of milk protein-derived bioactive peptides in the jejunum in healthy humans. Am. J. Clin. Nutr. 2013, 97, 1314-1323, doi:10.3945/ajcn.112.055202.

30. Dupont, D.; Mandalari, G.; Molle, D.; Jardin, J.; Léonil, J.; Faulks, R.M.; Wickham, M.S.J.; Mills, E.N.C.; Mackie, A.R. Comparative resistance of food proteins to adult and infant in vitro digestion models. Molecular Nutrition and Food Research 2010, 54, 767-780, doi:10.1002/mnfr.200900142.

31. Dupont, D.; Mandalari, G.; Mollé, D.; Jardin, J.; Rolet-Répécaud, O.; Duboz, G.; Léonil, J.; Mills, C.E.N.; Mackie, A.R. Food processing increases casein resistance to simulated infant digestion. Molecular Nutrition and Food Research 2010, 54, 1677-1689, doi:10.1002/mnfr.200900582.

32. Dupont, D.; Boutrou, R.; Menard, O.; Jardin, J.; Tanguy, G.; Schuck, P.; Haab, B.B.; Leonil, J. Heat treatment of milk during powder manufacture increases casein resistance to simulated infant digestion. Food Digestion 2010, 1, 28-39, doi:10.1007/s13228-010-0003-0.

33. Sánchez-Rivera, L.; Ménard, O.; Recio, I.; Dupont, D. Peptide mapping during dynamic gastric digestion of heated and unheated skimmed milk powder. Food Research International 2015, 77, 132-139, doi:10.1016/j.foodres.2015.08.001.

34. Kopf-Bolanz, K.A.; Schwander, F.; Gijs, M.; Vergères, G.; Portmann, R.; Egger, L. Impact of milk processing on the generation of peptides during digestion. International Dairy Journal 2014, 35, 130-138, doi:10.1016/j.idairyj.2013.10.012.

35. Torcello-Gómez, A.; Dupont, D.; Jardin, J.; Briard-Bion, V.; Deglaire, A.; Risse, K.; Mechoulan, E.; Mackie, A. The pattern of peptides released from dairy and egg proteins is highly dependent on the simulated digestion scenario. Food \& Function 2020, 10.1039/D0FO00744G, doi:10.1039/D0FO00744G.

36. Picariello, G.; Ferranti, P.; Fierro, O.; Mamone, G.; Caira, S.; Di Luccia, A.; Monica, S.; Addeo, F. Peptides surviving the simulated gastrointestinal digestion of milk proteins: Biological and toxicological implications. Journal of Chromatography B: Analytical Technologies in the Biomedical and Life Sciences 2010, 878, 295-308, doi:10.1016/j.jchromb.2009.11.033.

37. Gasparini, A.; Buhler, S.; Faccini, A.; Sforza, S.; Tedeschi, T. Thermally-induced lactosylation of whey proteins: Identification and synthesis of lactosylated $\beta$-lactoglobulin epitope. Molecules 2020, 25, doi:10.3390/molecules25061294.

38. Perusko, M.; van Roest, M.; Stanic-Vucinic, D.; Simons, P.J.; Pieters, R.H.H.; Cirkovic Velickovic, T.; Smit, J.J. Glycation of the Major Milk Allergen $\beta$-Lactoglobulin Changes Its Allergenicity by Alterations in Cellular Uptake and Degradation. Molecular Nutrition and Food Research 2018, 62, doi:10.1002/mnfr.201800341.

39. Van Der Lugt, T.; Weseler, A.R.; Gebbink, W.A.; Vrolijk, M.F.; Opperhuizen, A.; Bast, A. Dietary advanced glycation endproducts induce an inflammatory response in human macrophages in vitro. Nutrients 2018, 10, doi:10.3390/nu10121868. 
40. Ilchmann, A.; Burgdorf, S.; Scheurer, S.; Waibler, Z.; Nagai, R.; Wellner, A.; Yamamoto, Y.; Yamamoto, H.; Henle, T.; Kurts, C., et al. Glycation of a food allergen by the Maillard reaction enhances its T-cell immunogenicity: Role of macrophage scavenger receptor class A type I and II. Journal of Allergy and Clinical Immunology 2010, 125, 175-183.e111, doi:10.1016/j.jaci.2009.08.013.

41. Heilmann, M.; Wellner, A.; Gadermaier, G.; Ilchmann, A.; Briza, P.; Krause, M.; Nagai, R.; Burgdorf, S.; Scheurer, S.; Vieths, S., et al. Ovalbumin modified with pyrraline, a maillard reaction product, shows enhanced T-cell immunogenicity. Journal of Biological Chemistry 2014, 289, 7919-7928, doi:10.1074/jbc.M113.523621.

42. Hilmenyuk, T.; Bellinghausen, I.; Heydenreich, B.; Ilchmann, A.; Toda, M.; Grabbe, S.; Saloga, J. Effects of glycation of the model food allergen ovalbumin on antigen uptake and presentation by human dendritic cells. Immunology 2010, 129, 437-445, doi:10.1111/j.1365-2567.2009.03199.x.

43. Pischetsrieder, M.; Henle, T. Glycation products in infant formulas: Chemical, analytical and physiological aspects. Amino Acids 2012, 42, 1111-1118, doi:10.1007/s00726-010-0775-0. 


\section{Summary}

The consumption of baked milk products has been described in relation to an accelerated resolution of cow's milk allergic symptoms in cow's milk allergic children that can tolerate baked milk. This thesis was part of a larger project, consisting of 4 work packages. This project aimed to understand the underlying mechanism of this accelerated resolution, by combining a physicochemical characterisation of the heat-induced protein modifications (work package 1) with immunoreactivity characterisation (work package 2 ). The obtained knowledge should then be used to support the production of a baked milk product (work package 3 ) which was used in a clinical trial (work package 4) to assess the tolerance-inducing ability and clinical reactions towards this product. This thesis focused on the physicochemical changes that occur upon heating of cow's milk protein (MP) and connect this to their possible effects on immunoreactivity. The underlying hypothesis of this work was that $3 \mathrm{D}$-modifications of the protein structure that occur upon dry heating as well as the Maillard reaction (MR), in particular the formation of advanced glycation end products (AGEs), affect the immunoreactivity of the protein. These heat-induced modifications also affect digestibility. Furthermore, the form in which an antigen encounters the immune system in the gastrointestinal tract is crucial for its recognition by the immune system. Therefore, the assessment of digestibility was also part of the investigations.

In chapter 2, a mixture of casein and whey protein was dry-heated in the presence of the reducing milk sugar lactose at high temperature and low temperature to assess the impact of aggregation and MR vs. minimal aggregation and MR on protein digestibility. Both heat treatments resulted in loss of solubility. Therefore, investigations on the inter- and intramolecular interactions that lead to insolubility were performed to determine their role in both the decrease of protein solubility as well as digestibility. Results indicated that mainly caseins end up in the insoluble fraction. Different inter- and intramolecular interactions were responsible for the loss of solubility after both heat treatments. Among all changes occurring, after high temperature heating, both MR-induced crosslinking and other mechanisms of crosslinking were suggested to play a crucial role in decreasing both solubility and digestibility of MP. This also resulted in the release of larger particles from the insoluble material upon gastric digestion and a slower degradation in the intestinal phase. This, as well as the high levels of AGEs, was proposed to affect immunoreactivity of MP.

To disentangle the role of aggregation and the MR on immunoreactivity, chapter 3 used a simplified model system containing only isolated $\beta$-lactoglobulin (BLG). Differential heat treatments comparing low vs. high temperature, dry vs. wet heating, as well as presence and absence of lactose were applied. By using a combination of western blot and ELISA assays, the binding of immunoglobulin $\mathrm{E}$ ( $\mathrm{IgE}$ ) as well as the soluble form of the receptor for AGEs (sRAGE) towards the different protein structures (high and low molecular weight) that are visible on the SDS-PAGE was determined. Results showed that protein aggregation plays an 
important role in the formation of IgE-binding epitopes and sRAGE binding ligands. While high individual differences between patients did not allow a clear distinction between the effect of aggregation and glycation on IgE binding, it was observed that sRAGE binding strongly increased in the presence of lactose. The promoting effect of glycation on protein aggregation as well as the formation of glycation structures were found as possible explanations for this. In contradiction to literature, sRAGE binding was not observed to all structures visible on the SDS-PAGE, that contained $\mathrm{N}^{\varepsilon}$-carboxymethyllysine (CML). Moreover, it is unclear whether these ligands would encounter the immune system in the gastrointestinal tract in the same form after in vitro digestion.

In chapter 4, BLG was chemically modified to create CML-BLG, to gain more insights in the role of CML in binding to three different AGE receptors: sRAGE, galectin-3 (Gal-3), and CD36. By using this approach, other 3D-modifications of the protein were minimised and allowed a better assessment of the specific role of CML. This was additionally compared to low temperature glycated BLG. Results showed that protein-bound CML was indeed a ligand for AGE receptors which was related to the negative charge of CML. At the same time, binding to low temperature glycated BLG seemed to be related to its increasing hydrophobicity, however results also suggested a possible role of other MR products which may have affected the charge state of the protein and thus its binding to AGE receptors.

The immunological mechanisms following the binding of heated and glycated BLG to AGE receptors was studied in chapter 5. BLG wet heated in the presence and absence of two reducing sugars (glucose and lactose) was incubated with THP-1-derived macrophages and monocyte-derived dendritic cells, respectively. The receptor binding was assessed using ELISA and the role of different AGE receptors in internalisation as well as cytokine production was measured. Results showed that especially aggregation led to the formation of AGE-binding ligands and internalisation via CD36, Gal-3 and scavenger receptor class A type I by both cell types. After in vitro digestion of heated and glycated BLG, binding to sRAGE and Gal-3 was higher to the digest of glycated BLG compared to other samples. This suggested that even after digestion, glycated milk protein could still trigger immunological responses that could possibly lead to T-cell activation. Moreover it was suggested that immnological responses that are induced by binding to AGE receptors occur via different pathways, with sRAGE functioning in signalling pathways and Gal-3 as a putative receptor responsible for antigen uptake.

Next to aggregates that survive in vitro digestion, also digestion-derived peptides can carry immunoreactive structures. In chapter 6, peptides generated after simulated infant in vitro digestion of dry-heated MP were monitored. sIgE binding epitopes were identified based on literature, while potential T-cell epitopes were predicted using a software tool. Similar numbers of epitopes were found in all samples, however in heated samples more of these peptides were glycated. This suggested that epitope recognition could be altered in heated samples. Overall, relatively more glycated peptides were generated in heated samples and Caco-2 cell experiments indicated a preferred transport of especially lactosyllysine and 
glucosyllysine- modified peptides, but also CML-modified peptides in high temperature heated MP. This suggests that relatively more AGE receptor ligands are available in heated samples. On the other hand, only a low number of peptides carrying an epitope structure were transported, suggesting that the availability of T-cell and $\operatorname{sgE}$ binding epitopes following transport via normal enterocytes might be limited.

This thesis showed that several heat-induced structural modifications e.g. increased hydrophobicity, protein aggregation, and presence of AGEs, can affect immunoreactivity of MP. Moreover, it suggested that especially those immunoreactive structures that are able to survive gastrointestinal digestion could also modulate the immunological responses in vivo. 



\section{List of abbreviations}

\begin{tabular}{|c|c|}
\hline $\operatorname{Abs}_{\operatorname{Max}}$ & Absorbance obtained from receptor without competition agent \\
\hline Abs & Absorbance obtained blank sample \\
\hline AbsSample & Absorbance obtained the mixture of the receptor and the sample \\
\hline $\mathrm{ACN}$ & Acetonitrile \\
\hline AGEs & Advanced glycation end products \\
\hline ALA & $\alpha$-lactalbumin \\
\hline ANS & 8-anilino-1-naphthalenesulfonic acid \\
\hline APCs & Antigen presenting cells \\
\hline$a_{w}$ & Water activity \\
\hline BLG & $\beta$-lactoglobulin \\
\hline BSA & Bovine serum albumin \\
\hline CBA & Cytometric bead array \\
\hline $\mathrm{CD}$ & Circular dichroism \\
\hline $\mathrm{CE}$ & Collision energy \\
\hline CEL & $\mathrm{N}^{\varepsilon}$-carboxyethyllysine \\
\hline $\mathrm{CM}$ & Cow's milk \\
\hline CMA & Cow's milk allergy \\
\hline CML & $\mathrm{N}^{\varepsilon}$-carboxymethyllysine \\
\hline $\mathrm{CV}$ & Cone voltage \\
\hline DCs & Dendritic cells \\
\hline DDT & Dithiothreitol \\
\hline $\mathrm{DH}$ & Degree of hydrolysis \\
\hline DMEM & Dulbecco's modified eagles medium \\
\hline ECL & Enhanced chemiluminescence \\
\hline FBS & Fetal bovine serum \\
\hline FITC & Fluorescein isothiocyanate \\
\hline Gal-3 & Galectin-3 \\
\hline GP & Gastric phase \\
\hline HT & High temperature \\
\hline HT-MP & High temperature heated milk protein \\
\hline $\operatorname{IgE}$ & Immunoglobulin E \\
\hline $\mathrm{IgG}$ & Immunoglobulin $\mathrm{G}$ \\
\hline $\operatorname{IgM}$ & Immunoglobulin $\mathrm{M}$ \\
\hline IL & Interleukin \\
\hline IP & Intestinal phase \\
\hline LFQ & Label free quantification \\
\hline LPS & Lipopolysaccharide \\
\hline LT & Low temperature \\
\hline LT-MP & Low temperature heated milk protein \\
\hline M-cells & Microfold cells \\
\hline MG-DH1 & Methylglyoxal-dihydroxyimidazoline \\
\hline
\end{tabular}




\begin{tabular}{|c|c|}
\hline $\mathrm{MGO}$ & Methylglyoxal \\
\hline MoDCs & Monocyte-derived dendritic cells \\
\hline MP & Milk protein \\
\hline MHC-II & Major histocompatibility complex class II \\
\hline MR & Maillard reaction \\
\hline MRPs & Maillard reaction products \\
\hline MW & Molecular weight \\
\hline $\mathrm{NaCl}$ & Sodium chloride \\
\hline nePTMs & Non-enzymatic post translational modification \\
\hline $\mathrm{NH}_{2}$ (acid) & $\begin{array}{l}\text { Total concentration of free amino groups in the sample after acid } \\
\text { hydrolysis }\end{array}$ \\
\hline $\mathrm{NH}_{2}$ (final) & Concentration of free amino groups in the digested sample \\
\hline $\mathrm{NH}_{2}$ (initial) & Concentration of free amino groups in the sample before digestion \\
\hline $\mathrm{N}_{\text {measured }}$ & The nitrogen concentration in the soluble fraction \\
\hline $\mathrm{N}_{\text {theoretical }}$ & $\begin{array}{l}\text { The maximum possible concentration of nitrogen that can go into } \\
\text { solution }\end{array}$ \\
\hline $\mathrm{N}_{\text {transfer }}$ & Nitrogen transferred into in solution \\
\hline NT & Non-treated \\
\hline NT-MP & Non-treated milk protein \\
\hline OPA & o-phthaldialdehyde \\
\hline Ovalbumin & Ovalbumin \\
\hline oxLDL & Oxidised low density lipoprotein \\
\hline PBS & Phosphate buffer saline \\
\hline PMA & Phorbol 12-myristate 13-acetate \\
\hline PMCS & Peripheral blood mononuclear cells \\
\hline PTMs & Post translational modifications \\
\hline RAGE & Receptor for advanced glycation end products \\
\hline RPMI 1640 & Roswell park memorial institute 1640 medium \\
\hline SDS-PAGE & Sodium dodecyl sulfate gel electrophoresis \\
\hline SE & Glycated soy extract \\
\hline SEM & Scanning electron microscopy \\
\hline sIgE & Specific immunoglobulin E \\
\hline sMRM & scheduled multiple reaction monitoring mode \\
\hline SMUF & Simulated milk ultra-filtrate \\
\hline SR-AI & Scavenger receptor class A type I \\
\hline sRAGE & Soluble receptor for advanced glycation end products \\
\hline TEER & Transepithelial electrical resistance \\
\hline TBS & Tris buffer saline \\
\hline TBST & Tris buffer saline with tween \\
\hline Th & T-helper \\
\hline ThT & Thioflavin-T \\
\hline TL & Tube lens offset \\
\hline TMB & 3,3',5,5'-tetramethylbenzidine \\
\hline TNF- $\alpha$ & Tumor necrosis factor $\alpha$ \\
\hline
\end{tabular}


$\mathrm{T}_{\text {reg }}$

q

Q

UHT

WP
Regulatory T-cells

Transitions used for quantification

Transitions used for confirmation

Ultra high temperature

Whey protein 



\section{Acknowledgments}

Under the title of a $\mathrm{PhD}$ thesis there is only one name written, but there are many more people who made it possible. When I started my $\mathrm{PhD}$ I expected to learn a lot about science but I never imagined that I will get to know so many outstanding people who probably teached me more than any book could do. At the end of my PhD journey I am taking some wonderful memories with me and I am grateful to all the people who have been part of this adventure during the past 4 years.

I would like to thank my supervisors Kasper, Harry, Gosia, and Nicolette. Kasper and Harry you have been my mentors right from the beginning and I really appreciated that you gave me so much freedom to develop my own ideas and choose the directions that I would like to take in my research, while at the same time you helped me find solutions when things did not go according to plan. Thank you Kasper for the inspirational and sophisticated discussions as well as your commitment during my $\mathrm{PhD}$ project. Thank you Harry, for keeping me on track when needed and for your quick feedback on my manuscripts which has not only been very helpful but also, due to a good portion of humour, has often been quite enjoyable to read. I learned a lot from working with both of you and I am deeply grateful for all the support that you gave me during the past years.

Thanks a lot to Gosia for all your positive energy and your help with the immunological assays. I truly value your commitment and support during the past years.

My gratitude also goes to Nicolette. You and Kasper made this whole project possible and I am grateful that I could be a part of it. Thank you for all your help with my manuscripts and especially during the last stretches of my $\mathrm{PhD}$.

Thank you Vincenzo for all your support and valuable advice during the past years. You always had an open ear when I asked for your help and I am still amazed how easily you inspire and motivate people.

Thank you Huub and Joost for all your help and valuable feedback during our meetings and the writing of my manuscripts. It always stimulated me to look at some aspects from a different perspective and I am truly grateful that I had the opportunity to learn from you in the past years.

Working in FQD has been an extraordinary experience for me. I still remember the first FQD student colloquia that I attended and I was really amazed about the multidisciplinarity of the group and support that people offer. This first impression never changed during the past years and I am grateful that I had the opportunity to meet you all. 
I especially like to thank our secretaries Kim, Corine, and Lysanne. Thank you so much for always doing your very best to help us with all the administrative issues. You really make our life easier.

I would like to thank the technicians of FQD, Charlotte, Eric, Frans, Mike, and Xandra for all your help during the past 4 years. Many thanks also to Christos, who has helped me with some measurements during the Corona times, although the circumstances were not really ideal.

Moreover, I would like to thank my colleagues from FQD, Alim, Ana, Andrijana, Arianne, Burce, Dario, Domenico, Evita, Femke, Ita, James, Jared, Jonna, Jules, Ling, Lucía, Mary Luz, Mostafa, Naomi, Pieter, Renske, Ruben, Sara, Sine, Vale, and Vito. Thank you for the workrelated help and even more for the coffee break chats, your company during the Friday evening drinks, the karaoke evenings, and other not work-related activities which helped a lot to adjust my work-life balance every now and then.

Thanks a lot to Etske for your help with the casein isolation. Although I did not follow up on this I am very grateful for having the opportunity to learn from you.

Many thanks to Burçe and Sine. I really enjoyed sharing the "flex" office with you. Thank you for your professional advices and your help during the past years. I am very grateful for your friendship and all the "off-work" time that we spent together.

Many thanks to my dear paranymphs Lucía and Evita. I am very happy to have you by my side during my defence and am deeply grateful for your friendship during the past years.

I would like to thank Sjef for his exceptional help with the peptidomics and proteomics experiments. I really appreciated all the efforts you did and that I had the possibility to learn from you.

I would like to thank all BSc and MSc students who were partially involved in my project. Gooike, Peichun, Huanghong, Madelon, Nine, and Rosanne thank you for all your efforts and the valuable contributions to this project. My special thanks also goes to Arifa for all her help with the ELISA and the cell culture experiments in CBI.

Furthermore, I would like to thank the people from FBR, Coen, Shanna, Monic, Renata, Anouk, Dianne, and Els who have always been very helpful and supportive when I was working in the labs of FBR.

My gratitude also goes to Paola who has hosted me in her research group at the Università degli Studi di Napoli Federico II, as well as to Dario for teaching me so much about the method for MRPs. The work with you helped me a lot and I am grateful for the time that I could spend in Naples and the warm welcome you gave me.

Mein Dank gilt vor allem meiner Familie. Meinen Geschwistern, Sam, Mirjam und Micha, meinen Großeltern, und Karola. Ganz besonders aber danke ich meinem Vater für seine 
bedingungslose Unterstützung, sein unerschütterliches Vertrauen, dass ich meinem Weg machen werde und für den selbstverständlichen Rückhalt, unabhängig davon ob ich den Weg bis zum Ende gehe oder nicht.

Zu guter Letzt danke ich meinem Partner Peter. Danke, dass du diesen Weg mit mir gegangen bist. Die letzten Wochen waren alleine durch Corona schon eine Herausforderung und umso dankbarer bin ich, dass du an meiner Seite warst. 

About the author 



\section{Curriculum vitae}

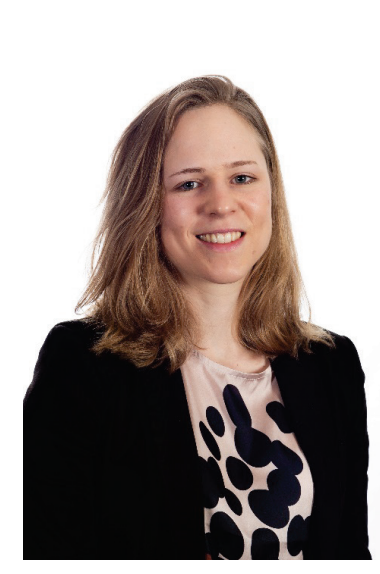

Hannah Elisabeth Zenker was born on the $28^{\text {th }}$ of November 1992 in Augsburg, Germany.

In 2011, she started her studies of food chemistry at the Friedrich-Alexander University Erlangen-Nuremberg.

For her scientific dissertation from October 2015 to March 2016 she spent 6 months at Abertay University in Dundee, Scotland under the supervision of Alberto Fiore. In this project she focused on the mitigation of Maillard reaction products in cookies by the phenolic compounds, fibre, and protein derived from rapeseed press-cake. She finished the first part of the state exam for a state examined food chemist in April 2016. In October 2016, she started her PhD project in the Food Quality and Design Group at Wageningen University and Research in Wageningen, the Netherlands. The results of her research are presented in this thesis. 


\section{List of publications}

This Thesis:

- Hannah E. Zenker, Jana Raupbach, Sjef Boeren, Harry J. Wichers, Kasper A. Hettinga (2020). The effect of low vs. high temperature dry heating on solubility and digestibility of cow's milk protein. Food Hydrocolloids. (in press)

- Hannah E. Zenker, Arifa Ewaz, Ying Deng, Huub F. J. Savelkoul, R. J. Joost van Neerven, Nicolette W. De Jong, Harry J. Wichers, Kasper A. Hettinga, Malgorzata Teodorowicz. (2019). Differential effects of dry vs. wet heating of $\beta$-lactoglobulin on formation of sRAGE binding ligands and sIgE epitope recognition. Nutrients, 11(6):1432.

- Hannah E. Zenker, Malgorzata Teodorowicz, Arifa Ewaz, R. J. Joost van Neerven, Huub F. J. Savelkoul, Nicolette W. De Jong, Harry J. Wichers, Kasper A. Hettinga (2020). Binding of CML-modified as well as heat-glycated $\beta$-lactoglobulin to receptors for AGEs is determined by charge and hydrophobicity. International Journal of Molecular Sciences, 21, 4567.

- Hannah E. Zenker, Harry J. Wichers, Monic M. M. Tomassen, Sjef Boeren, Nicolette W. De Jong, Kasper A. Hettinga (2020). Peptide release after simulated infant in vitro digestion of dry heated cow's milk protein and transport of potentially immunoreactive peptides across the caco-2 cell monolayer. Nutrients, 12, 2483.

Others:

Hannah E. Zenker, Glenn A. A. van Lieshout, Martine P. van Gool, Marjolijn C. E. Bragt, Kasper A. Hettinga (2020) Lysine blockage of milk proteins in infant formula impairs overall protein digestibility and peptide release. Food and Function, 11, 358369. 


\section{Overview of complete training activities}

\section{Discipline specific activities}

\section{Courses}

Advance Food analysis (VLAG, Wageningen-Netherlands 2017)

Advanced proteomics (VLAG, Wageningen-Netherlands, 2017)

Advanced Immunology (IIU, Utrecht-Netherlands, 2018)

Reaction Kinetics (VLAG, Wageningen-Netherlands, 2018)

Dairy Biochemistry Masterclass (Aarhus University \& VLAG, Aarhus-Denmark \& Wageningen-Netherlands, 2019)

\section{Conferences and meetings}

Young AGErs symposium (University of Berlin, Berlin-Germany, 2017)

Young AGErs symposium (Wageningen University, Wageningen-Netherlands, 2018)

Young AGErs symposium (Maastricht University, Maastricht-Netherlands, 2019)

International conference of food digestion (Infogest, Granada-Spain, 2019)

German food chemistry days (TU Dresden, Dresden-Germany, 2019)

International symposium of molecular allergology (EAACI, Amsterdam-Netherlands, 2019)

\section{General courses}

Applied statistics (VLAG, Wageningen-Netherlands, 2017)

Introduction to R (WGS, Wageningen-Netherlands, 2017)

Brain Training (WGS, Wageningen-Netherlands, 2017)

Competence assessment (WGS, Wageningen-Netherlands, 2017)

Scientific publishing (WGS, Wageningen-Netherlands, 2018)

Scientific writing (Wageningen in'to language, Wageningen-Netherlands, 2018)

Reviewing a scientific paper (WUR library, Wageningen-Netherlands, 2018)

Research data management (WUR library, Wageningen-Netherlands, 2018)

Debate training and practice tournament (WGS, Wageningen-Netherlands, 2018)

Scientific artwork vector and images (WGS, Wageningen-Netherlands, 2018)

Searching and organising literature for PhD candidate (WGS, Wageningen-Netherlands, 2018) 


\section{Optional activities}

Preparation of research proposal (Wageningen-Netherlands, 2016)

$\mathrm{PhD}$ study tour to Australia (Australia, 2018)

Preparing PhD study tour to Australia (Australia, 2018)

Organising young AGErs symposium (Wageningen-Netherlands, 2018)

Member of the VLAG PhD council (Wageningen-Netherlands 2016-2019)

Meetings and colloquia (Wageningen, 2016-2020) 
The research described in this thesis was financially supported by the grant from the Netherlands Organisation for Scientific Research, Domain Applied and Engineering Sciences (AES).

The Financial support from Wageningen University and Research for printing this thesis is gratefully acknowledged.

Cover design by Hannah E. Zenker and Martin Küchle (www.kuechle-design.de)

Printed by Digiforce || ProefschriftMaken 

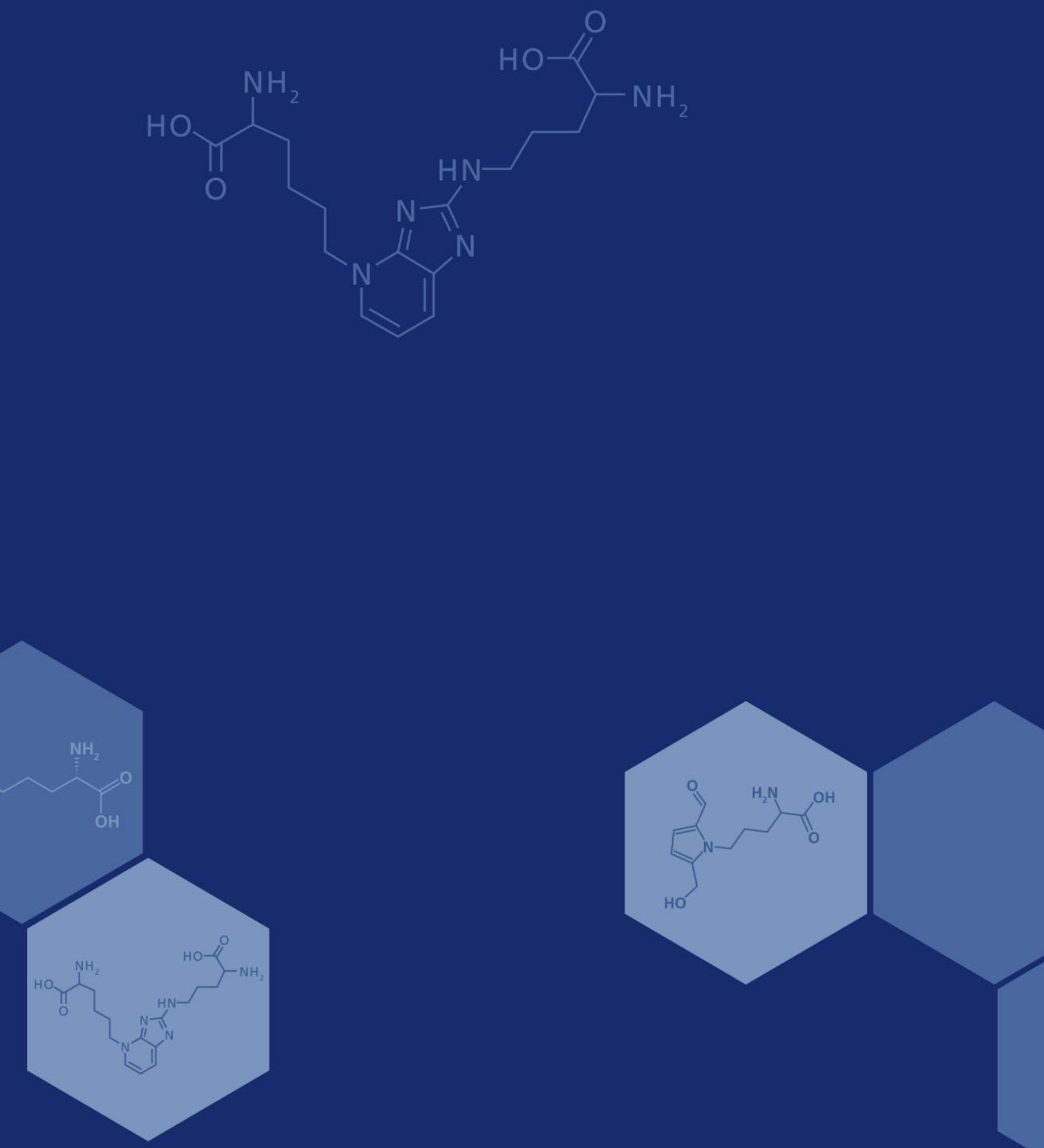